Portland State University

PDXScholar

$1-1-1987$

\title{
Electricity Demand Forecasting in a Changing Regional Context: The Application of the Multiple Perspective Concept to the Prediction Process
}

James Christopher Sapp

Portland State University

Follow this and additional works at: https://pdxscholar.library.pdx.edu/open_access_etds Let us know how access to this document benefits you.

\section{Recommended Citation}

Sapp, James Christopher, "Electricity Demand Forecasting in a Changing Regional Context: The Application of the Multiple Perspective Concept to the Prediction Process" (1987). Dissertations and Theses. Paper 574.

https://doi.org/10.15760/etd.574

This Dissertation is brought to you for free and open access. It has been accepted for inclusion in Dissertations and Theses by an authorized administrator of PDXScholar. Please contact us if we can make this document more accessible: pdxscholar@pdx.edu. 
ELECTRICITY DEMAND FORECASTING IN A CHANGING REGIONAL CONTEXT: THE APPLICATION OF THE MULTIPLE PERSPECTIVE CONCEPT TO THE PREDICTION PROCESS

by

JAMES CHRISTOPHER SAPP

A dissertation submitted in partial fulfillment of the requirements for the degree of

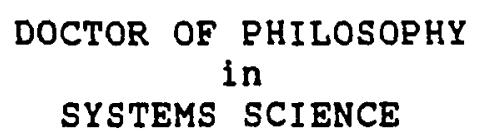

Portland state University

1987 
TO THE OFFICE OF GRADUATE STUDIES AND RESEARCH:

The members of the Committee approve the dissertation

of James Christopher Sapp presented June 12, 1987.

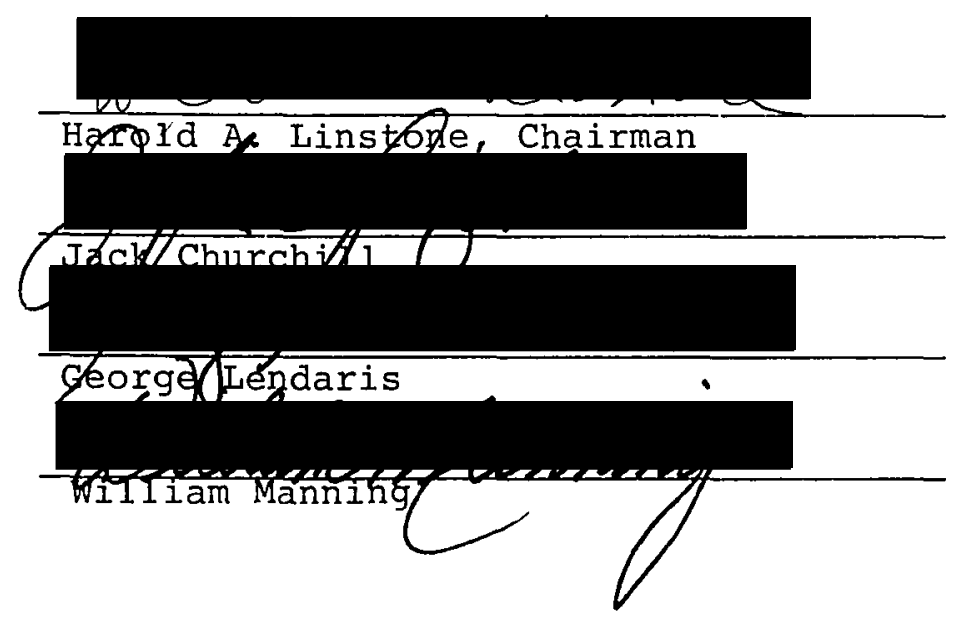

APPROVED :

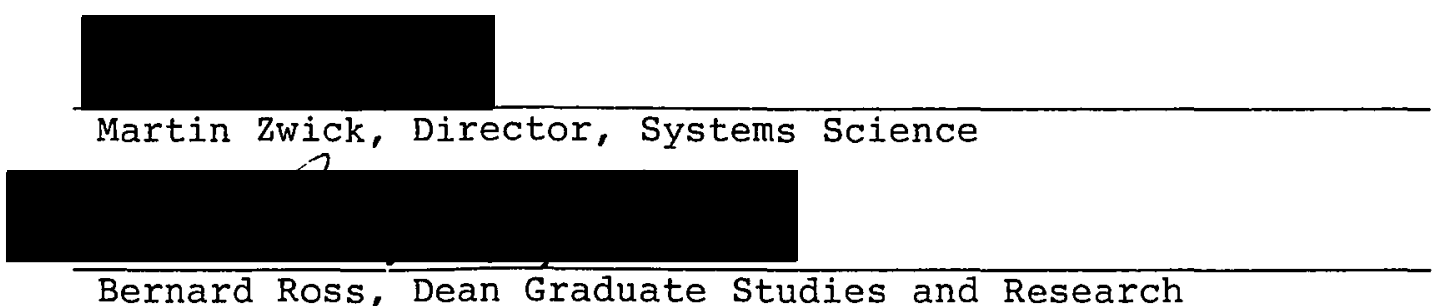


AN ABSTRACT OF THE DISSERTATION OF James Christopher Sapp for the Doctor of Philosophy in Systems Science presented June $12,1987$.

Title: Electricity Demand Forecasting in a Changing Regional Context: The Application of the Multiple Perspective Concept to the Prediction Process

APPROVED BY MEMBERS OF THE DISSERTATION COMMITTEE:
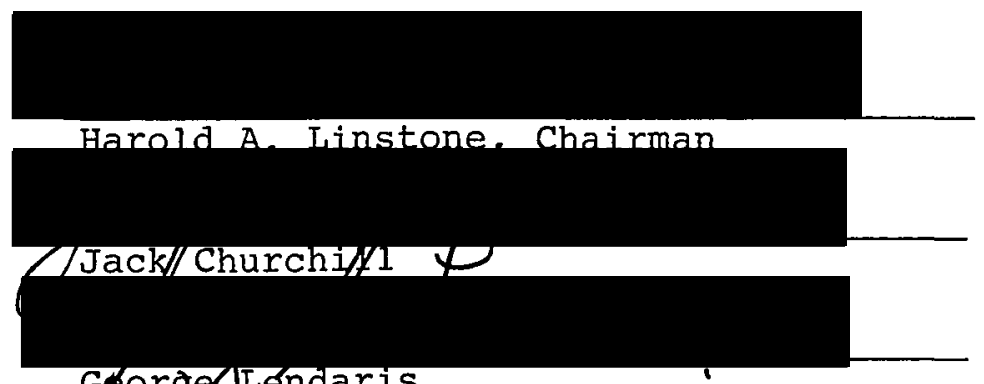

William Manning

Since 1937, the Bonneville Power Administration (BPA)

has marketed hydroelectric power to utility and industrial

customers in the Pacific Northwest. In 1982, the agency

found itself in a new role, one which required it to acquire whatever power resources were needed to meet the demands of the region's utilities. In particular, its Administrator had to confront the problem of how to deal with the 
escalating costs of the troubled Washington Public Power Supply System's nuclear plant projects. In response, BPA undertook the preparation of its first independent regional power forecast. The process by which this forecast was produced was intricate and multidimensional, involving a variety of parties having stakes in the outcome of the WPPSS decision. Application of the Multiple Perspective Concept to this process illuminates its technical, organizational, and personal dimensions and, in doing so, uncovers both strengths and weaknesses in the forecast.

Examination of the forecast from the technical perspective revealed an elaborate set of interlinked models. Baseline, high, and low forecasts were developed based upon different sets of economic projections and different assumptions about conservation and resource acquisition. The organizational perspective revealed $\mathrm{BPA}$ to be in a transitional stage. Its more traditional engineering functions waned in relative importance, as new functions grounded more heavily in economics (ratemaking, forecasting, conservation, resource acquisition, and financial management) swelled. Interorganizationally, environmentalists, ratepayer groups, and the region's utilities all had strong but contrasting interests in the outcome of any decision regarding the fate of the WPPSS plants.

The personal perspective revealed that each of the Administrators heading BPA since the early 1970 s defined 
the agency's approach to the resource planning problem differently. In the early 1970s, where major regional power deficits seemed imminent, Donald Hodel, then Administrator, approached this problem as one having an engineering solution: build capacity ahead of need. When his successor, Sterling Munro, was confronted by slowing load growth and increasing regional concern over rate disparities and environmental protection, he focused upon a predominantly political solution: the passage of Regional Power Act legislation. Finally, Peter Johnson, Administrator at the time of the 1982 forecast, facing the economic strains placed upon the Northwest by WPPSS, reframed the problem as one having a business solution.

Taken together, the Multiple Perspectives yielded the following conclusions about BPAs 1982 forecast. - BPA's range forecast constituted a major improvement over the point forecasts preceeding it. It did, however, leave important classes of uncertainty unexplored and the region vulnerable to certain events or outcomes.

- BPA's models were better suited to address certain issues importani at the time of the 1982 forecast than their predecessors (e.g. rate provisions of the Regional Power Act, conservation potential, etc.). The model of the national economy, however, remained a black box, potentially significant feedbacks (e.g. electricity prices on economic variables) were not represented, and the sheer size and 
elaborateness of the modeling system placed practical limits on its use.

- The technical review process surrounding the forecast ultimately resulted in a new consensus within the power planning community on load futures (i.e. low growth). This review process centered on choices between existing models and, to the degree it required a fluency in econometrics and engineering concepts, undoubtedly excluded potential valuable insights.

- A stronger method of dealing with forecast uncertainty is needed, one which utilizes a disaster-avoidance strategy and plans for high impact/low probability events (such as oil shocks, Depressions, nuclear accidents, etc.). This method need not involve the use of large models, but should seek to incprorate qualitative insights from persons normally outside the technical sphere. 


\section{ACKNOWLEDGEMENTS}

Guidance and encouragement is essential to a research project as ambitious as this dissertation. I would like to thank my committee members, Jack Churchill, George Lendaris, William Manning, and especially the committee chairman, Harold Iinstone, for their assistance, cooperation, and patience in this effort.

I would also like to express thanks to the Bonneville Power Administration, both for their openness and support in this project. Particularly helpful, at various stages of my work, were John McConnaughey, Terry Esvelt, Don Hoffard, Chuck Schneider, Roger Moore, and members of the Uncertainty Work Group.

Special thanks go to $\mathrm{Kimm}$ olin for producing this document under a series of tight deadines.

Finally, I thank my mother and my trusty beagle, Casey, for moral support throughout the project. 
TABLE OF CONTENTS

PAGE

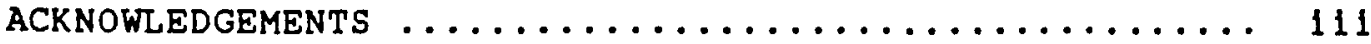

LIST OF TABLES $\ldots \ldots \ldots \ldots \ldots \ldots \ldots \ldots \ldots \ldots \ldots \ldots \ldots \ldots \ldots \ldots \ldots$

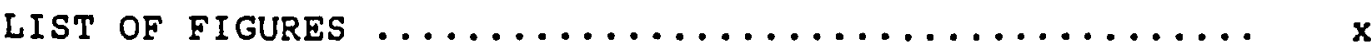

LIST OF ABBREVIATIONS $\ldots \ldots \ldots \ldots \ldots \ldots \ldots \ldots \ldots \ldots \ldots \ldots \ldots \ldots$

CHAPTER

I INTRODUCTION $\ldots \ldots \ldots \ldots \ldots \ldots \ldots \ldots \ldots \ldots \ldots \ldots$

Overview: Loads, Forecasts, and Power

Planning .................. 1

Background: The Historical Context for

Columbia River Resource Planning ..... 6

The New Deal and Growth of the Northwest

The Hydrothermal Power Plan, WPPSS

\& the Reglonal Power Act

Power Forecasts and Their Role in

Shaping the Northwest's Future ...... 15

The Multiple Perspective Concept: Three Views of the Forecast ............ 20

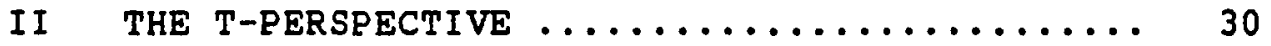

Forecasts, Decisions, and Plans:

The Technical Context for Model Usage 30

An Overview of BPA Forecasting system .... 38

Energy Demand and Energy Supply: The Models Used in BPA's Forecast ....... 44

Economic/Demographic Projections:

Inputs to Energy Forecasting Models 
Demand Models: End-Use and Econometric Tools

The Supply Pricing Model

Projections of Regional Energy Consumption: Outputs and Adjustments

The Reglonal Demand Forecast: Evaluation

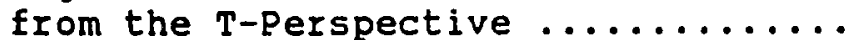

Inputs, Outputs, Data Flows: The Forecasting system Revisited

Forecasts Core Assumptions: White and Black Boxes

Forecast Evaluation: Risk and Reliability

Ends and Means: The Forecast in the Context of Planning Objectives

Organizations and Their Products: An

Introduction to the 0 -Perspective ....

The Intraorganizational Dynamics of BPA:

A Look Inward

Overview: The Climate within the Organization

Power Reguirements: Projecting Loads and the Regional Economy

Rates: Lessening Disparities Under the Terms of the Regional Act

Conservation: A New Organizational Prlority in the $1980 \mathrm{~s}$

Power Resources: New options for Electricity Supply

signiflcant "Non-Participants": Financial Management and the Policy Committee

The Interorganizational Power Planning Arena: A Look Outward ............. 
Overview: The Texture of Changing Roles and Responsibilities

The PNUCC: A Waning of Traditional Authority in Forecasting

The Regional Council: A New Look at Resource Planning

ODOE: The Council's Precursor in oregon?

NRDC: Alternative Futures for Alternative Energy

DSI's: New Contracts, New Conditions

The Northwest Natural Gas Distributors: The other Guys

The "Expert" Groups: Consultants and Research Organizations

The Media: Selectively Reflecting the Issues

The Energy Forecasting Arena Through the O-Perspective: Summary and

Conclusions ................. 236

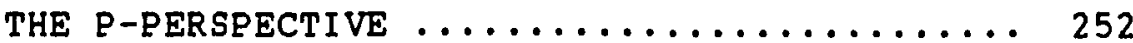

When Individuals Do Make a Difference The P-Perspective in Overview ....... 252

Managing the Organization: A View From the Top ................... 256

Managing the Forecast: A View From the Middle ................... 271

The P-Perspective -- Concluding Remarks .. 291

v CROSS-CUING THE PERSPECTIVES ........... 294

Introduction: Cross-Cuing - The Decision

Process in $3-D \ldots \ldots \ldots \ldots \ldots \ldots \ldots \ldots . \ldots 294$

Cross Cuing: The "Map" .............. 298

Describing the Timelines - $T$, 0 , and $P$ in Parallel 
Events and Impacts - A Discussion of the Elements and Cross Cues in the Map

A Digraph Interpretation of the Forecast Process ................. 403

VI

CONCLUSIONS $\ldots \ldots \ldots \ldots \ldots \ldots \ldots \ldots \ldots \ldots \ldots$

Tying the Threads Together: An Overview of the Chapter ................ 414

Conclusions About the Forecast: What Multiple Perspectives Says ........ 415

Conclusions from the T-Perspective Conclusions from the 0 -Perspective Conclusions from the P-Perspective Conclusions from $T$ - and 0 -Perspective Cross-Cues

Conclusions from $\mathrm{T}$ - and P-Perspective Cross-Cues

Conclusions from $\mathrm{O}$ - and $\mathrm{P}$-Perspective Cross-Cues

Conclusions From T, $O$, and P: The Big Picture

Conclusions about Multiple Perspectives:

that the BPA Forecast Says ........ 488

Overall Methodological Considerations Specific Methodological Conclusions

Concluding Thoughts $\ldots \ldots \ldots \ldots \ldots \ldots \ldots$

Postscript $1987 \ldots \ldots \ldots \ldots \ldots \ldots \ldots \ldots \ldots$

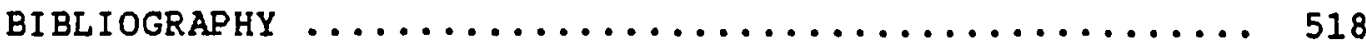




\section{LIST OF TABLES}

TABLE

PAGE

I Multiple Perspectives .............. 25

I I Basic Industry Employment Estimation ..... 61

II Key Energy Forecast Assumptions. Explicit Modeling Choices by sector ......... 77

IV Summary of Residential Model Inputs ...... 82

V Summary of Commercial Model Inputs ....... 101

VI Inputs to the NEPP Industrial Model ...... 119

VI I Inputs to the Supply Pricing Model ....... 127

VIII Summary of Forecast Results by sector

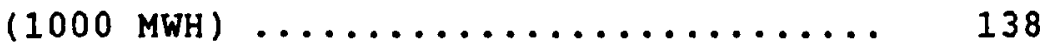

IX Summary of Forecast Core Assumptions ...... 159

$x \quad$ A Summary of Organizational Actors in the Forecasting Process ............. 237

XI Administrators' Perspectives on Resource Development $\ldots \ldots \ldots \ldots \ldots \ldots \ldots \ldots \ldots \ldots$

XII A Sumnary of Comments Presented at BPA's Technical Workshops .............. 352

XIII Technical Choices Made by BPA For Its 1982 Forecast ..................... 379

XIV A Summary of Technical Changes Between Draft and Final Forecasts ............. 386

XV Comments on BPA's Forecast and Responses ... 397 
XVI Selected Core Assumptions Underlying BPA's 1982 Forecast $\ldots \ldots \ldots \ldots \ldots \ldots \ldots \ldots \ldots$

XVII A Summary of Key Conclusions from Multiple

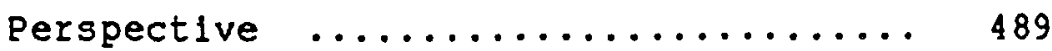




\section{LIST OF FIGURES}

1. Relationship of Rates, Resources, and

Regional Growth ...............

2. The BPA System of Forecasting Models.

An Overview of Inputs, Models, and

Outputs..................... 41

3. Schematic of Models Used for Economic/

Demographic Inputs. A Diagram of

Data Flows Between Models ........... 47

4. Dynamics Assumed by Economic Base Model. A

Digraph of Relationships Between Basic

and Non-Basic Industries ........... 52

5. The BPA Population Model. A Flowchart of

Calculations.................. 63

6. The BPA Housing Model. The Derivation of

Households, Average Unit Size and New

Construction.................. 67

7. Flow Chart of Regional Income Model ........ 70

8. Schematic: ORNL Residential Energy Use

Model $\ldots \ldots \ldots \ldots \ldots \ldots \ldots \ldots \ldots \ldots \ldots \ldots$

9. Calculation of Average Energy Use in the ORNL Residential Model 
10. Calculation of Thermal Integrity in the ORNL Residential Model ........... 86

11. Calculation of Heating Fuel saturations in the ORNL Residential Model ..........

12. Calculation of Appliance Usage Intensity in the ORNL Residential Model ........ 90

13. Final Energy Use Calculation for the ORNL Residential Model ............... 93

14. An Overview of the structure of the ORNL Model of Commercial Sector Energy Use.... 98

15. Calculation of Floorspace Additions in the ORNL Commerclal Model ............ 103

16. Calculation of Energy Use Per Square Foot in the ORNL Commercial Model ........ 106

17. Calculation of Floorspace Saturations by Fuel and End-Use in the ORNL Commerclal Model. 110

18. Calculation of Equipment Utilization in the ORNL Commerclal Model ............. 112

19. Computation of Final Energy Use In the ORNL Commercial Model .................. 114

20. An Overview of the structure of the NEPP Industrial Energy Use Model ......... 120 
21. An Overview of the structure of the BPA Supply Pricing Model ............ 128

22. Adjacency Matrix for Models in the Forecasting system................ 142

23. Reachability Matrix for Models in the Forecasting system ................. 144

24. Input-output Diagram of BPA Forecasting system. A Detailed Representation of Data Flows in the Modeling system ........ 147

25. Organizational Charts of BPA 1971 - 1982 (selected detail). A Look at the Growth of Power Requirements (A), Rates (B), Conservation (C), Power Resources (D), and Financial Management (E) $\ldots \ldots \ldots \ldots 194$

26. Map of Cross Cues Between the Three Perspectives. Critical Events, Decisions, and Processes Depicted on Tlmelines ....... 299

27. A Digraph Representation of Multiple Perspectives Surrounding BPA's 1982 Forecast $\ldots \ldots \ldots \ldots \ldots \ldots \ldots \ldots \ldots \ldots \ldots \ldots$ 


\section{LIST OF ABBREVIATIONS}

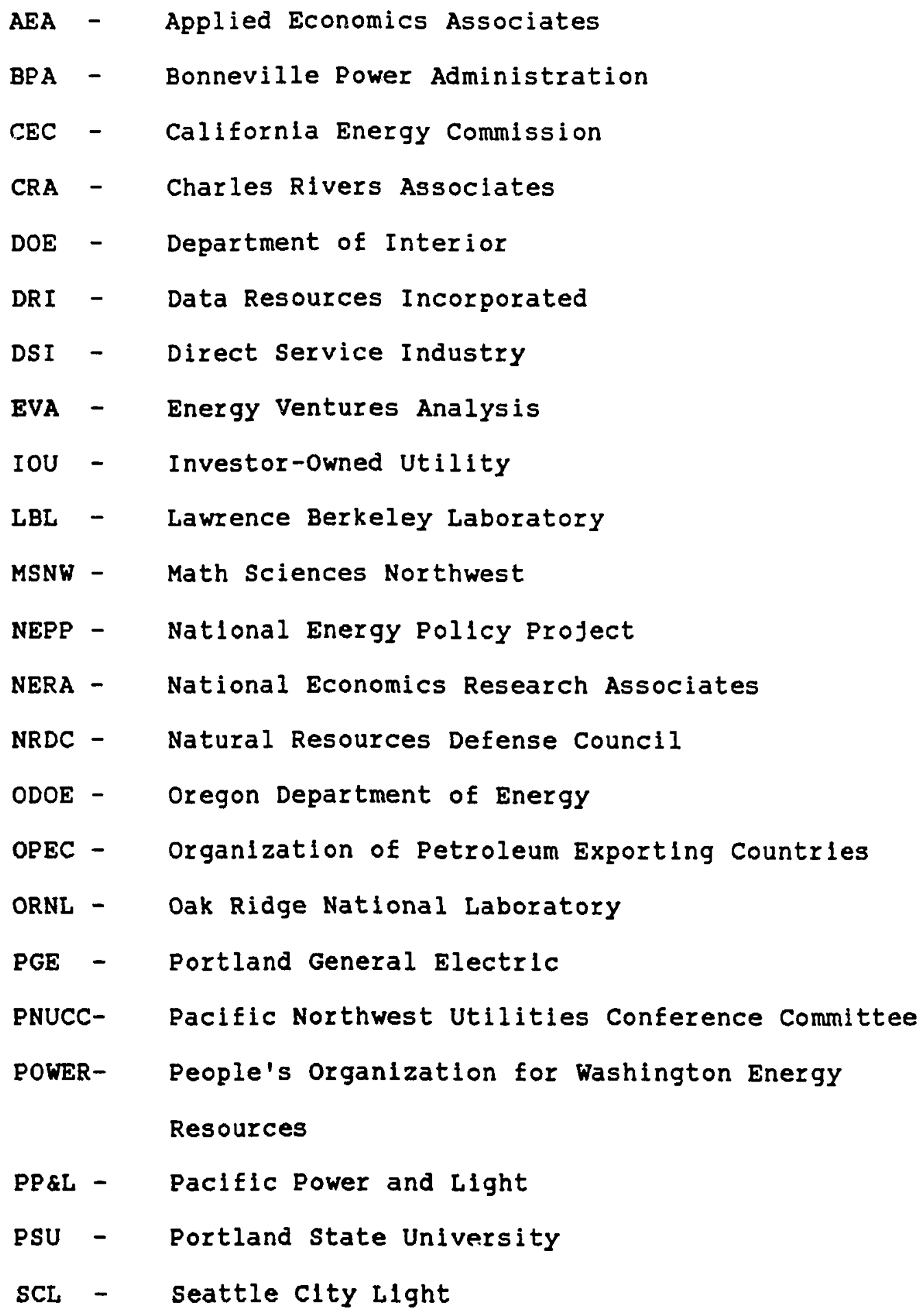


xiv

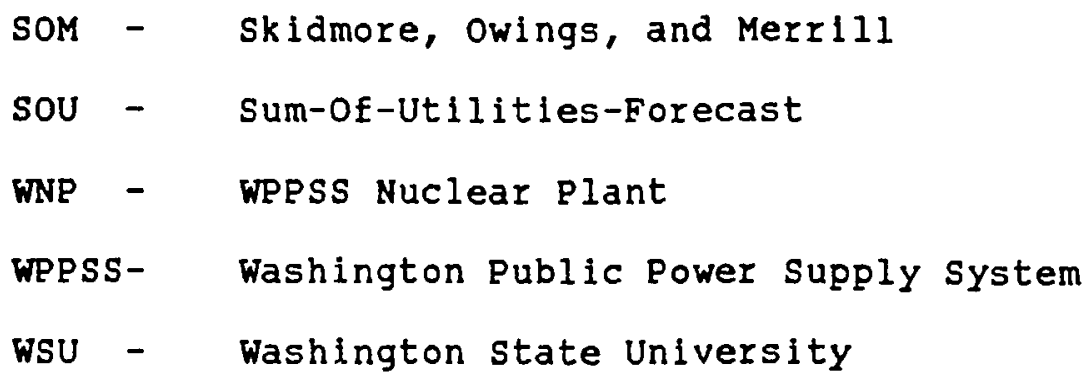


CHAPTER I

INTRODUCTION

OVERVIEW: LOADS, FORECASTS, AND POWER PLANNING

The passage of the Regional Pover Act in 1980 reflected a shared recognition of the need for more extensive and careful planning of the region's energy resources. Not surprisingly, in parallel with this increased concern for resource planning there has emerged a concern for the development of reliable long-term electricity demand forecasts. For most of the Bonneville Power Administration's existence, an overabundance of power and the ready availability of new hydroelectric sites made demand forecasting relatively simple: elementary trend extrapolations sufficed. When electricity is cheap and readily avallable, the incentives for conservation and efficlent resource allocation are few. Under such conditions, no major changes in resource mix or development strategy are to be expected. When new resources are expensive and potentially damaging to the environment, forecasting becomes more difficult technically and more sensitive politically because demand profections may be used to Justlfy declsions differentlally affecting the population.

In the current situation not only has the complexity of demand forecasting grown, but a need to understand the 
practical implications of such forecasts more clearly has become paramount. New generations of econometric and end-use models used for forecasting allow a wider array of social, economic, and political factors which influence demand to be dealt with. At the same time, however, they introduce complexity (and often ambiguity) and sometimes conceal judgmental manipulations buried in the elaborate structures of the models. Such introduction of fudgment, along with the inevitable imposition of practical and organizational constraints on methodology, render forecasting a dynamic activity, and one that cannot be understood or evaluated by technical criteria alone.

Under the terms of the Pacific Northwest Electric Power Planning and Conservation Act, the primary responsibility for long-term reglonal forecasts and resource acguisition plans lies with the Regional Council's staff. BPA, however, is required to make resource acquisition and financing decislons which depend, at least in part, on a long-term projection of electricity demand growth. In the past, BPA has been a participant in the sum-of-Utilities forecast of the Paciflc Northwest Utilities Conference Committee (PNUCC). In the perlod inmediately preceding the publication of the council's official regional forecast and regional plan in 1983, BPA's decisions were based entirely upon its own first independent long-range demand forecast, developed using a methodology and a set of models which 
closely resemble those ultimately adopted by the council. More specifically, this independent forecast required the development of primary economic and demographic inputs, the iterative use of an electricity supply pricing model with demand forecasting models (for residential, commercial, and Industrial sectors), and ongoing public involvement during the forecast development period.

Given the regional importance of the BPA forecast and the complexity of the associated technical and non-technical factors, a thorough analysis of the forecasting process as well as the methodology is warranted. The aim of this dissertation is to perform such an analysis of the BRA forecast. The main methodological tool to be employed is the Multiple Perspective Concept developed by Linstone et al (1981), described in detail below.

The objectives of the research described in this dissertation are threefold. The first is to understand more clearly and completely how forecasts of energy and, more speciflcally, electricity loads affect regional decisionmaking processes in the areas of economic and power planning. Within the forecasting and futures research communities there is fairly widespread acceptance of the idea that the chief task of forecasters is not to predict exactly what will occur in the future, but rather to provide planners and decision makers with information which will help them better antlcipate future possiblilties (or future 
consequences of present decisions). In recognition of the possible effects of forecasts as self-fulfilling or self-denying prophecies, point forecasts specifying a single future are increasingly being replaced by range and contingency forecasts which explore the consequences of different sets of potential events and circumstances. Even in such a broadened (and to some extent self-critical) forecasting context, however, it is essential to explore what Ascher (1978) refers to as "core assumptions", usually unstated assumptions about background or context factors which influence the behavior of the varlables or trends under investigation. The first objective, then, is to use the Multiple Perspective Concept to gain a better understanding of the elements and assumptions which give shape to the numerical values embodled in the final forecast.

The second and complementary objective is to gain a better understanding of the process of forecasting. Forecasts are used as data upon which decisions are made. The information needs of decision makers serve to define both the research questions asked and the models selected to answer them. Moreover, the varleties of problems which forecasts address can be seen to undergo development over time as members of the forecasting and decision-making "communities" interact. Interactions among the numerous elements of the forecasting process are complex and mult 1dimensional. The Multiple Perspective Concept, with its 
explicit recognition of distinct technical, organizational, and personal dimensions of problem solving or decisionmaking situations provides a useful tool in explicating the dynamic, interactive characteristics of demand forecasting. The third and final objective is to develop and demonstrate further the usefulness and applicability of the Multiple Perspective Concept (the MP Concept) as a tool for researching complex aspects of decision making. The power forecasting context chosen for the research described in this dissertation, characterized as it is by the use of new models in a poitically sensitive situation engendering a modicum of organizational restructuring, is ideally suited to analysis using the Multiple Perspective methodology. Application of this conceptual and methodological framework to the forecasting situation descibed should result in the fulfillment of the first two objectives. In addition, however, a generalization of findings on the use of the MP Concept and the interrelation between the perspectives is an important additional goal of the research.

Before beginning an examination and analysis of BPA's first independent long-term forecast, however, it is necessary to take a closer look at both the context in which the forecast was performed and the tool to be used for the Investigation. The remainder of this chapter thus focuses upon the history of power planning in the paclfic Northwest and the characteristics of the Multiple Perspective Concept. 
BACKGROUND: THE HISTORICAL CONTEXT FOR COLUMBIA RIVER RESOURCE PLANNING

Current regional power plannlng efforts, and the forecasts used to support them, may be fully understood only by placing them in an historical context. The resources of the Columbia River, along with its numerous tributaries, have been central to the sustained development of the Pacific Northwest, and have in many ways formed the core of the region's economy. A brief examination of the history of the development of the Columbia River system is thus necessary to llluminate the numerous issues which surround the use of its waters, particularly as they relate to power resource use and planning.

The New Deal and the Growth of the Northwest

The modern-day development of the Columbla River had its roots in the Depression years of the 1930s. Appalled by the poverty of the then relatively underdeveloped Northwest, President Franklin Roosevelt author'zed the construction of the first of a serles of dams along the Columbla in March, 1933. Authorized under the National Industrial Recovery Act, the Bonneville and Grand Coulee Dams typifled the multiple-purpose Public Works Administration profects of the era. In addition to creating a wealth of jobs at a time they were desperately needed the projects allowed funds from the Federal Treasury to be funnelled into undertakings 
designed to stimulate economic growth; undertakings of a scale well above what small governmental bodies or private interests could afford to implement. Specifically, positioning massive dams at key locations along the Columbia served to control floods, enhance navigation (and, hence, commercial transport), expand recreational opportunities, and promote irrigation through the control of streamflows. Perhaps most significantly, the dams permitted the region to tap the awesome hydroelectric potential of the columbia River system. With the facilities subsidized by Federal funds and constructed by the Army Corps of Engineers, the hydropower generated at the damsites promised to be both cheap and abundant -- perfectly suited for Roosevelt's objective of the rural electrification of the Northwest. On August 20, 1937 Roosevelt signed the Bonneville Project Act, creating the Bonneville Power Administration within the Department of the Interlor. This act established BPA as a power marketing agency, empowering it to bulld and operate transmission facilities necessary to encourage the widest possible use of electric energy, giving preference and priority of its use to public bodies and cooperatives (Springer, 1976).

Over the next thirty years, the addition of twenty more Federal dams along the river essentlally transformed it from a freeflowing stream (within which many varleties anadromous Elsh flourlshed) Into a serles of manmade lakes. As long as 
the Federal government was willing to invest U.S. Treasury dollars in these large scale projects (built at relatively low cost) electric power was both cheap and abundant. Not only was BPA able to market power from the Federal based hydrosystem to the public bodies and cooperatives of the region which comprised its "preference customers" but it also had plenty of power to sell to other groups, most notably Investor Owned Utilities (IOUs) and Direct Service Industries (DSIs). The latter group was composed of large, electricity-intensive industries, such as aluminum, which settled in the reglon during World War II. These Industrles remained after the War, signing long-term contracts with BRA guaranteeing them a reliable electricity supply. DSIs were "serviced directly" in that they maintained their own transformers and bought power directly from BPA rather than from the public or private utilities within the region. Inexpensive electricity aiso brought industrial and commercial customers to the region who did not buy directly from BPA, but benefitted substantlally from the Federal hydrosystem. Underlying this trend of regional growth was a set of dynamic processes which was essentlally self-amplifying. For a long perlod of time the network of dams was somewhat "overbulit" -- that is, the system was capable of generating more power than was needed. Under conditions of surplus, it is to everyone's advantage to seek new customers and raise demand levels. This is because when the construction, 
operating, and maintenance costs associated with the power system are spread over a larger base the costs per kilowatt are lower. Low rates also promote the use of electricity where alternative fuels might be substituted if they were price-competitive (e.g. electric resistance space heating in homes instead of gas heat).

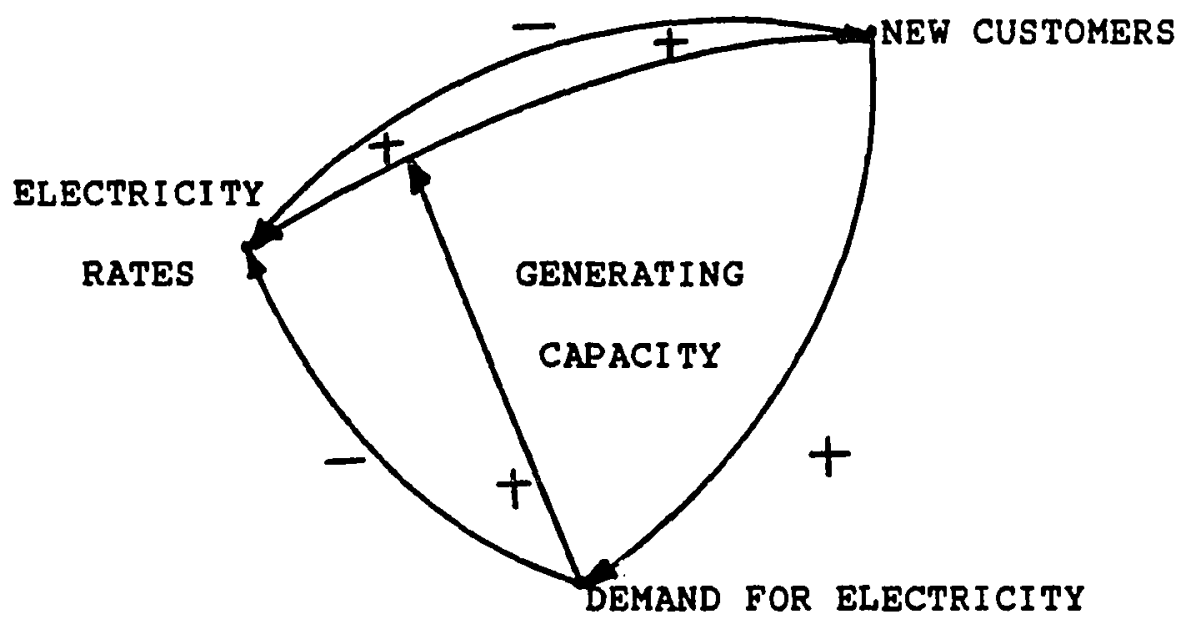

Elqure 1. Relationship of rates, resources, and regional growth

Figure 1 represents this dynamic in the form of what is called a digraph. A ' +' above an arrow Indicates that the element at the head (point) of the arrow is influenced to change its size or value in the same direction as that of the element at the arrow's tail (i.e. If the tail element increases or decreases so also will the head element). Conversely, a '-' Indicates that the two elements change in opposite directions; an Increase in the value of the tall 
element will produce a decrease in the head element while a decrease will engender an increase. What the digraph in this generalized form omits, however, is the strength of the links and the exact sequencing of the reciprocal impacts (i.e. the time lags). During the Northwest's growth period hydroelectric generating capacity was added in large chunks on a regular basis as the Corps of Engineers continued to exploit the sites along the Columbia River system promising the highest yield. The influx of new customers into the region was steady enough that wholesale electricity rates were among the lowest in the country and rate increases were minor. In the late sixties and early seventles, however, a number of developments took place which were destined to change this situation.

The Hydrethermal Power Plan. IPPSS, and the Regional Power Act

The signing of the Columbla River Treaty in 1964 and the subsequent construction of the intertie connecting the Northwest with the Paciflc southwest in many ways heralded the end of an era of the growth of cheap hydropower in the region. The treaty allowed the joint U.S.-Canadian construction of a final serles of dams near and above the canadian border. In the short-term, these projects resulted In a sizable power surplus. Canada's share of this surplus was especially large in proportion to the population of British columbia. As a consequence, one of the conditions 
of the Treaty specified that the U.S. (i.e. BPA) would promise to purchase a share of Canada's surplus. The intertie permitted BPA to sell avallable surplus power to California.

Despite the bountiful supply of hydropower avallable to seemingly any customer desiring 1t, it became apparent that virtually all the potential sites for high-head, Federally-sponsored hydro projects had been exhausted. Profections of continued high demand growth suggested to the power planners of this era that alternative sources of generation would be needed to prevent anticipated power deficits. BPA's response to this perceived need was the development and institution of the Hydro-Thermal Power Plan in 1968. As a power marketing agency, BPA did not possess the authority to build any generation. Under the Hydro-Thermal Power Plan, however, BPA entered Into a "net billing" arrangement with its preference customers. Under net biling BPA acquires the power generated by thermal plants constructed by the public utilities which comprise its preference customers and integrates this power into its transmission grid. BPA assumes the preference customer's share of the costs of the new thermal plants, and averages these costs with those of the less expensive hydropower. Reglonal power rates then reflect this melded cost of thermal and hydroelectrlc energy. 
Perhaps the most significant of the thermal resource development projects undertaken were the five nuclear plants constructed primarily by the Washington Public Power Supply system (WPPSS), a consortium of 16 public utility districts, with secondary participation by major investor-owned utilities in the region. While BPA assumed a role in the financing of only the first three of the five plants, all were planned and sited in anticipation of the major power shortages then predicted to occur in the mid-1980s which provided the impetus for the Hydro-Thermal Power Plan.

Progressively, increasing regional demand for electricity and ambitious new thermal plant construction altered the dynamic illustrated by Figure 1, modifying primarliy the strength and timing of the reciprocal impacts depicted. New generating capacity was being added in the form of coal and nuclear plants sponsored by various public and private utilities instead of the usual form of largescale, relatively regularly scheduled Federal hydro projects. Whereas the Corps of Engineers' expertise was largely a known quantity, that of the contractors involved In the construction of the varlous thermal projects was not, and, in retrospect, proved highly variable in quality from project to project. Cost overruns, sometimes Immense (as in the case of the wPPS nuclear plants), plagued and delayed construction and, to the extent that these costs were Incorporated into rate structures, caused a serles of 
"Jumps" in the price of electricity. Moreover, because a surplus of hydropower was no longer avallable, the regions's IOU's could no longer depend upon BPA for their power supply. They now were forced to take a back seat to the region's preference customers. As a result, private utilities had to rely more heavily upon expensive thermal power than their public utility counterparts, creating significant rate disparities in the region. Along with a growing concern for the potentially hazardous enviromental impacts of thermal plants (particularly nuclear), these rate disparities triggered a number of political responses. A variety of groups actively championed conservation as an environmentally sound and cost-effective alternative to increased thermal generating capacity, some of them intervening in facility siting procedures. Additionally, several pleces of legislation were prepared, targetted at the differential reglonal electricity rates. DRPA (Domestic and Rural Power Authority) would have transformed all of the residential and small farm customers in the state of oregon, largely served by IOUs with noticeably higher rates, into a large public utility district, thereby entitling them to preference customer status. The Pacific Northwest Electric Power Planning and Conservation Bill (known familiarly as the Regional Bill) was proposed in the 1970 s and finally enacted in 1980. Reflecting the prior 1tles of an impending energy "crisis" as percelved during the 
1970s, the Act established a Regional Power Planning Council comprised of eight memiers, two persons appointed by each of the governors of the four states in the region (Washington, Oregon, Idaho, and Western Montana). The Council is responsible for developing a twenty-year demand forecast and resource acquisition plan giving conservation and renewable resources priority over any new non-renewable energy sources. The Act also considerably augmented BPA's responsibllities in the region, requiring it to acquire all the resources necessary to supply wholesale power to any utilities applying for 1 t. Under the power allocation strategy defined by the Act, BPA's existing preference customers enjoy electric rates which cannot exceed what they would have been without the passage of the Act. Investor owned utilities are permitted to "exchange" power for their resldential and small farm customers, priced at the utility's average wholezale cost, for electricity at the lower Federal rate, thereby considerably reducing regional rate disparities. The DSIs, in effect, provide rate rellef for the IOU's domestic and rural customers through rate increases they bear in exchange for long-term firm power contracts that would otherwise not be avallable. Subject to these requirements, Bonneville must project demand and purchase whatever power is needed to prevent shortages, employlng the same priority ranking for resource acquisition as does the councll. 
POWER FORECASTS AND THEIR ROLE IN SHAPING THE NORTHEEST'S FUTURE

It was thus in a set of circumstances very different from what had served for over thlrty years as the regional status oue that BPA assumed 1 ts new and augmented roles and responsibilities. Severe cost overruns on new thermal faclilties, Increasing rate disparlties, and a growing advocacy of conservation and environmental protection had undermined the dynamics of steady regional growth. In the wake of the passage of the Regional Act, resource and rate planning became matters of increasing concern: BPA could not afford to compound the consequences of mistakes and misjudgments which it inherited from the 1970s. BPA's first independent long-term forecast, prepared in 1982 (a full year before that of the Regional Councill was thus destined to prove central to a number of financlally critical and politically sensitive decislons concerning the Power system.

A major factor compounding the sensitive nature of BPA's forecast was the role earller forecasts has played in shaping some of the region's emerging problems. Beginning in 1954, the Pacific Northwest Utilities Conference Committee (PNUCC), a consortium of all of the region's utilities, prepared 11-year (and, after 1968, 20-year) forecasts of loads and resource requirements for the West Group Area (a geographlc domaln, largely congruent with the 
Northwest Region, except for the omissions of portions of eastern Oregon and Idaho). PNUCC's forecast for the West Group Area, known as the Sum-Of-Utilities (sou) forecast, was produced, as the name suggests, by simply adding together the forecasts submitted by the DSIs, IOUs, and public utilities in the region. Bonneville was a regular participant in the sou forecast, producing demand profections for a number of the public utilities that lacked their own load forecasting capabilities. The ostensible strength of this approach is that it allows each utility to take a hard look at its own service territorles; territories about which it is presumably best informed. In practice, however, a wide variation in forecasting expertise and sophistication exists among the member utilities of PNUCC, and key assumptions about economic and population growth and the elasticity of demand with respect to price which each of the utilities made in preparing their own forecasts were often Inconsistent. Between 1968 and 1978 the projected twenty-year average annual rates of growth (AARGs) expressed In the sOU forecasts were consplcuously high, though falling from 5.38 to 3.88 very gradually over thls perlod (Marshall, 1978:23). However they may have differed in their judgment of speslfics, virtually all of the member utilities assumed that the regional economic boom of the 1960 s and 1970 s would continue unabated through the periods described in the forecasts and that power would remain sufficiently inex- 
pensive that ratepayers would maintain existing consumption levels, even in the face of inevitable rate increases. In addition to the efficacy of these assumptions in inflating long-term forecasts, several other incentives have been cited as sources of overforecasting during this period (Ernst and Ernst, 1976): the legal requirement of utilities to supply anyone requesting power, the perceived moral obligation to prevent power shortfalls, and (so long as the regulated return on investment exceeds the cost of capita1) the tendency to add capital equipment in order to increase overall revenues. Though, in hindsight, the erroneous underpinnings of these forecasts appear self-evident, at the time a 58 AARG of regional electricity demand was generally accepted as realistic, and utility planners championed the increased construction of thermal plants in response to their belief in the reliability of these estimates. Notably, elghty-eight of the region's utilities responded by joining the construction consortium for the ill-fated wPPSS nuclear projects 4 and 5 , endeavoring to avoid a power shortfall anticipated to occur in mid-1983.

The lower growth power consumption patterns of the late 1970 s suggested that the demand projections contained in the SOU forecasts might prove unrealistically high. Economic recession, slowed reglonal growth, and concern about the effects of often escalating thermal plant construction costs on future rates led to speculation about the 
consequent impact of these factors on the size of loads. A number of alternative regional forecasts were developed in response to the perceived severity of this uncertainty. In 1977, PNUCC began using an econometrlc model (described in more detail in Chapter II) developed by National Economic Research Associates (NERA) as a cross-check for its sOU forecast. This model's demand projections, however, baslcally tracked those of the sou forecast and, as such, did not provide a noticeably different alternative to the utility industry's "conventional wisdom" (twenty-year growth rates ranging from 4.11 to 5.46 percent, with a mean of 4.558 in the first year of the model's use). Substantially different growth rates, however, had been produced several years earller by the Washington state University (wSU) Environmental Research Center. In 1975, the wSU research group prepared a set of three thirty-year (1971-2000) demand projections for electricity, natural gas, oil, and coal for each of the states in the Paciflc Northwest (PNW). The end-use model employed by wSU profected demand for four consuming sectors (residential, commercial, industrial, and extractive) based upon various sets of assumptions regarding population and fuel prices. The WSU forecasts were markedly lower than elther PNUCC's SOU or econometric forecasts, displaying 30-year AARGs ranging from 1.43 to 2.38 percent (Marshall 1978:31). Early in 1977, the Natural Resources Defense Councll (NRDC) in Palo Alto, California prepared an 
end-use analysis of power demand in the Northwest. Building upon other studies (partlcularly a 1976 report prepared for BPA by the consulting firm of skidmore, Owings, and Merrill) rather than employing an econometrlc or end-use model, NRDC's forecast focused upon potential conservation savings in the region. Assuming that virtually all of the waste of electricity could be eliminated by conservation (without regard to the nature or effectiveness of the incentives needed to bring about these demand reductions) and that no thermal plants would be built other than those approved or under construction in 1977, NRDC projected a modest 2.41 percent annual growth from 1975 to 1985, followed by a slight decline in loads ( 0.95 percent) between 1985 and 1995. Lastly, in 1978, the Northwest Energy Policy Project (NEPP) released a twelve volume report evaluating regional energy issues and policy options. Included in the report was a series of forecasts (low, medium, and hlgh) of possible energy futures for the Northwest. Prepared using an econometric model (to be described in detall in the next chapter) the average annual growth rates for electricity through the year 2000 were $1.43,2.93$ and 4.38 for the low, medium, and high scenarios respectively. When, by the early 1980s, loads fell far short of almost all predictions, rate hikes became increasingly frequent, and skyrocketing construction costs forced wPPSS projects 4 and 5 into mothballs, any offlclal forecast which 
would be used to direct power and conservation resource planning decisions tended to be viewed with mistrust, or at least great caution, both by the general ratepaying public and the numerous special interests in the region. It was in this context that BPA produced its first independent longterm forecast, the subject of this dissertation.

THE MULTIPLE PERSPECTIVE CONCEPT: THREE VIEWS OF THE EORECAST

Given the recognized impacts of forecasts on past resource planning and the signiflcance of the decisions facing $B P A$ and the region in the early 1980s, it is not surprising that BPA's first independent long-term forecast was an object of conslderable concern and attention. In order for this forecast to be useful as a gulde to the power planning decisions facing the BPA Administrator and the region, it was necessary that the models and methodology used in its development display greater sophistication and comprehensiveness in dealing with resource, rate, and conservation policy alternatives than their predecessors. Moreover, in order for this forecast to be accepted by the numerous parties to be affected by consequent power planning, It was helpful, if not necessary, to open up the processes of input development, model testing, and forecast preparation to public involvement. 
In no sense, then, can the forecast and its development be understood simply as a technical exercise uninfluenced by historical precedent, institutional priorities, or political considerations. The process of its development was mult1faceted: as such, thorough comprehension of the forecast and Its ramifications require consideration of a wealth of technical and non-technical factors. An investigatory tool ideally sulted to the tasks of examining and analyzing such factors is the Multiple Perspective Concept, a recent outgrowth of research in the areas of technology assessment and systems analysis.

The systems approach to research and problem solving rests upon the premise that problems are complex and interrelated and that their solution is predicated on, in some way, comprehending them as a whole rather than as isolated, independent fragments. This basic premise, however, has undergone fundamental reinterpretation as systems research had matured. As Nehnevajsa and Menkes in Linstone et al (1981) have noted (in the context of technology assessment) a number of basic stages of development may be identified. stage I extended the basic calculi and optimizing techniques of narrowly-defined systems analysis (or operations researeh) to encompass a range of concerns other than economic feasibility. "The whole" of most problems was acknowledged to be larger than prevlously characterized by cost-benefit evaluation. stage II aimed 
for "comprehensiveness" in impact identification and

evaluation. "Wholeness" was sought in schemes attempting to address all of a problem's key quantitative and qualitative dimensions. stage II emerged from a recognition of the futility involved ia the overly ambitious goal of comprehensiveness. Instead, it ldentifled the generation of an array of good-risk contingency plans and policy options as a more useful and practical way to address "whole" problems of concern to decision makers.

The Multiple Perspective Concept rests upon the premises of the third stage (and shows promise of moving research into stage IV as it transcends some of the limits of traditionally-defined "rationality"). It seeks to provide a number of useful inslghts developed from different perspectives applied to a single decision process or problem area. Based upon the insights of political analyst Graham Allison (from his 1971 work, Essence of Decision: Explaining the Cuban Mlssile Cr1s/s) and developed by Linstone et al (1981) the concept recognizes three distinct, though complementary, perspectives for viewing a decision area: a technical perspective (T), an organizational perspective $(0)$, and a personal perspective (P).

The T-perspective is the one commonly assoclated with research and structured inquiry. For a great many investigators, it is the enly strategy of inquiry ever employed or considered. The T-perspective is premised on notions of 
cause-and-effect, objectivity, and prediction by completely rational means. Problem solving aims at optimization and employs formal analysis, quantification, and modeling towards this end. The T-perspective is also frequently reductionist in character and biased against the Individual or unique phenomenon.

By contrast, the o-perspective typifles in the "Inquiry" conducted as part of the dally round of organizational life. Managers, bureaucrats, and staff personnel in organizations do not deal with the world in the abstract or from a detached point of view. Real practical necessities and organizational needs shape the ways they look at things and the ways they go about doing things. The o-perspective is both objective and subjective; it "sees" the world according to a $\mathrm{mix}$ of standard operating procedures and uncertainties, aiming at satisfactory rather than optimal solutions to problems. Both investigation and implementation tend to be incremental and reflect the parochial prlorities and planning rituals of the participants.

Finally, the P-perspective is the most unique and idiosyncratic, reflecting the subjective visions and "partial rationalities" of particular individuals. Although individuals often view the world in ways which fuse false certainty, simplification, and needs for esteem with their rationales for action, it is often the unlque viewpoint 
which illuminates or explains otherwise incomprehensible events. Perhaps more importantly, individuals act in terms of their perceptions and in ways shaped by their personal histories. While the individual may indeed disappear into the crowd, he or she may also be the prime mover in major events, bringing specific abilities to bear upon circumstances in ways that engender unique results.

The goal of the Multiple Perspective Concept is to illuminate decision areas through the simultaneous application of the three perspectives. As noted above, the perspectives are distinct but complementary: they not only tend to concentrate attention on different objects but also proceed from very different paradigms of thought. They thus together form a more complete plcture of the world though they can not be derived from a more comprehensive framework by means of a single logic. Table I (reproduced from Linstone et al, 1981) summarizes and contrasts the salient features of each of the three perspectives.

Some precedent exists for the critical evaluation of applications of systems analysis and forecasting which is performed using complex models. Both Berlinski (1976) and Andersen (1977) have leveled criticisms against the use of systems dynamics models (Andersen doing so using a framework which 1s, in many ways, a direct "ancestor" of the Multiple Perspective Concept). The specific application of the MP Concept to the forecast product (and associated procedures) 
TABLE I

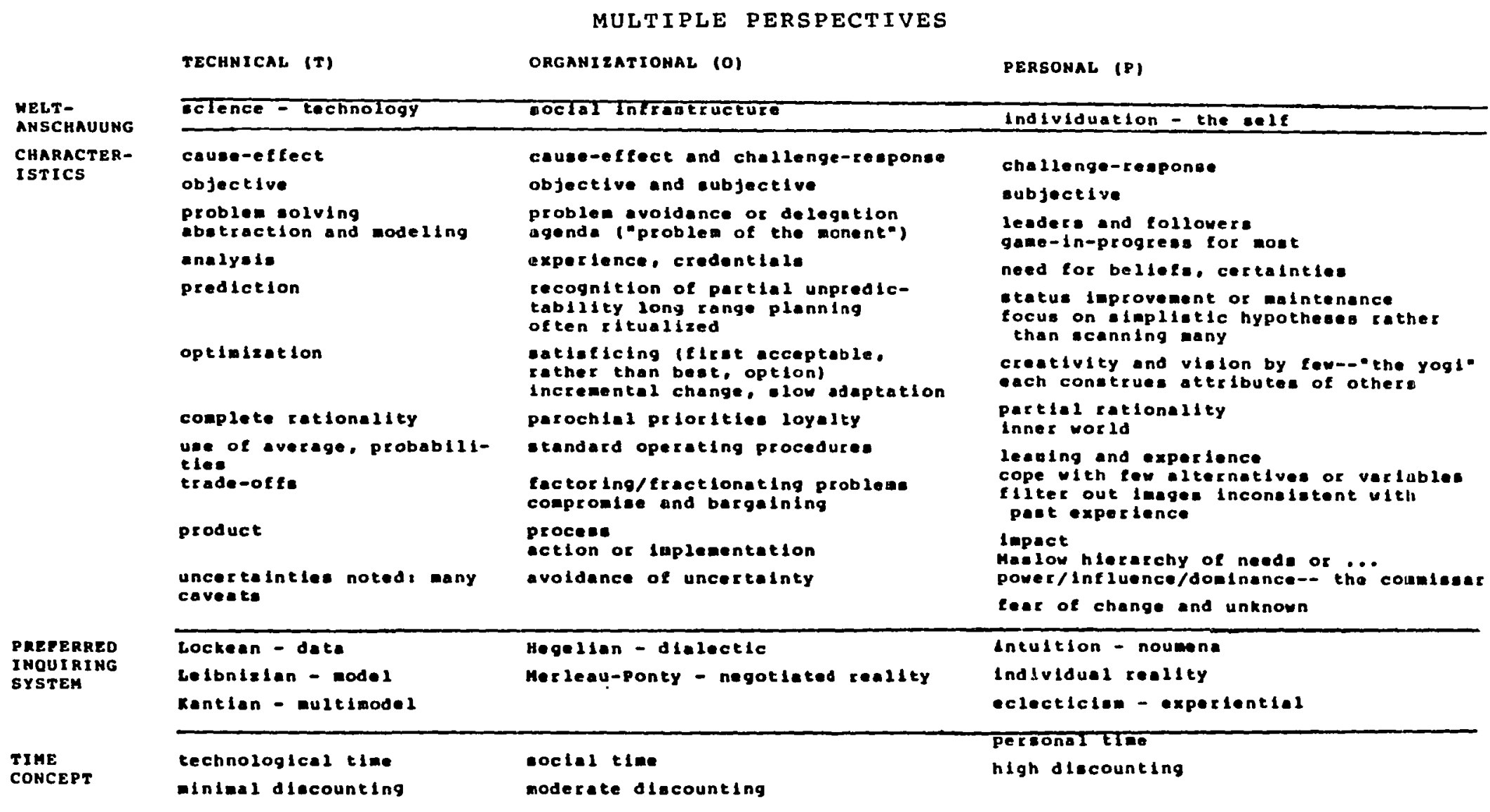


developed by BPA for their first independent regional load forecast forms the basis for this dissertation and proceeds in series of steps reflected in the sequence of chapters. Chapter II focuses upon the forecast from the dominant viewpoint of science and technology, the T-perspective. Each of the models used in the reglonal forecasting effort-the NEPP and PNUCC econometric models, the Oak Ridge National Laboratory Residential and Commercial End-Use Models, and the BPA electricity supply pricing model are discussed and diagrammed, as is the system by which their outputs were interlinked. The methods by which primary model inputs were developed are discussed. Finally, the models and methodology are critically evaluated. This entails generic comparisons of the strength and weaknesses of econometric and end-use models, an identification of limiting core assumptions assoclated with the modeling enterprise, and a discussion of the results (1.e. the forecast product) and their rellabllity.

In Chapter III, the 0-perspective is applied to the forecasting process, viewing it as a response of BPA's Power Requirements staff to the challenge placed upon it by internal organizational needs (e.g. tailoring modeling to the various, and sometimes conflicting needs of ratemakers and planners elsewhere in the organization) and outside agencles (e.g. PNUCC, private utilities, the Reglonal Counc11). To understand the organizational underpinnings of 
both challenges and responses affecting the forecasting process, it is necessary to describe the principal actors in the power planning arena, the standard operating procedures by which they operate, and the changes or developments in their institutional enviroments. Descriptions of intraorganizational developments center on an enumeration of BPA's new responsibilities under the Regional Act, the growth and development of several Divisions during BRA's recent internal restructuring, the application of standard and add hoc operating procedures in the forecasting effort, and the dynamic, interactive character of organizational needs as they constrain or steer the technical process of forecasting. Interorganizationally, BPA's changing relationship with the council, established reglonal forecasting bodies, and the Involved public is documented and analyzed to see how its influence is felt on the forecast. The goal of this analysis is to see what forces (or actors) in a changing organizational situation in the region (and in BPA) helped glve shape to an Important plece of technlcal output (1.e. the BPA forecast) upon whlch signiflcance decisions were at least partially based.

In Chapter IV, the P-perspective is used to Illuminate yet another dimension of the forecasting process. Key actors and outstanding decisions affecting the course of the demand forecasting effort are identified and their significance assessed. Included here are both the actions of the 
staff and "non-technical" decision makers (e.g. the Power Administrator) which modified or gave direction to the events shaping the forecast product. Analysis is directed toward identifying personal and situational characteristics which predispose principal actors towards their behavior. Chapter $V$ cross-cues the inslghts obtained through the application of each of the three perspectives (1.e. displays their interdependencles), producing a composite or integrated picture of BPA's forecasting effort. It is in this chapter that the "explanatory" powers of the Multiple Perspective Concept are demonstrated. Whereas the previous three chapters explored the forecasting process through the "selective lenses" of each of the perspectives individually this chapter builds a composite picture lllustrating the interpretation of elements identified and isolated in the earlier chapters. Included in this chapter is an investigation of the 1ssue of "validation" of the insights gained through the use of Multiple Perspectives. Following guldeIInes proposed by Linstone (1984:321-327) a digraph representation of the dynamics of interaction between the perspectives is presented. Such a representation not only displays a picture of overall findings clearly and unambiguously, permitting critical evaluation and, potentially, reinterpretation, but also yields new insights through analysis of cyclical and Indirect impacts between the perspectives. 


\begin{abstract}
Finally, Chapter VI summarizes and concludes the research. It focuses both upon conclusions about the BPA 20-year forecasts derived through the application of the Multiple Perspective Concept, and upon general conclusions on the use of the MP Concept in research on decision areas. This includes a set of propositions about the appropriate domains and methods of application of each of the perspectives and general comments on the types of problems a researcher may expect to have to deal with using the MP Concept in an organizational context.
\end{abstract}


CHAPTER II

THE T-PERSPECTIVE

FORECASTS, DECISIONS, AND PLANS: THE TECHNICAL CONTEXT FOR MODEL USAGE

Most generally, the intent of forecasts, whatever the domain of their application, is to assist decision makers in dealing with the uncertainty associated with the future. In situations where forecasting is performed, the forecasts provide the decision maker with selected "vistas" of the future "state of the world", based on various assumptions or speculations. Forecasting is thus perhaps best understood as fundamentally interlinked with the activities of planning and decision making. Planning may be though of as "the process of preparing a set of decisions for action in the future, directed at achieving goals by optimum means". Decision making, in turn, consists of the act of selecting one from several courses of action (Martino, 1978:332-337). In all but the most trivial situations, the decision maker is confronted with some aspect (or aspects) of the environment over which he has little or no control but which nonetheless critically impacts the mission or task he is responsible for carrying out (e.g. consumer demand for goods, services, or energy). Informed decision making, whether a part of short- or long-range planning, requires 
an assessment of the likely state of the environment, and it is this role which forecasting attempts to fill.

Forecasts, however, may differ widely in terms of the amount of information they yield, the number of issues they address, and the variety of questions they are able to answer. Forecast sophistication is a function of the techniques or models used, the resources available, and, perhaps most importantly, the scope of the associated planning effort. In situations where the environment is relatively unchanging or where key decision makers see the future as unfolding in a relatively straightforward fashion, forecasts tend to be vlewed as reasonably precise statements of what is going to happen. By contrast, where the environment is viewed as complex and turbulent and the future as fraught with uncertainty, planning is almed at devising reasonable courses of action in the face of a variety of contingent events. The forecasts associated with such planning tend to be more complex, addressing a wider spectrum of environmental variables and providing potentially valuable information about the contingencles envisioned.

Both the overall methodological strategy and the specific technique (or techniques) employed in a forecast are, in large part, functions of the percelved needs of decision makers and the planning philosophy espoused, though quite obviously, decision makers, planners, and forecasting 
technicians may incorrectly assess the situation and proceed In an inapproprlate fashion. The simplest, and in many ways the most risky, methodological strategy is to produce a point forecast, which alms at an accurate description of a single "most likely" future state of key elements in the environment. Unless the environment is extremely stable (and extremely simple in its behavioral characteristics) such a forecast is apt to provide a poor base for planning. Range forecasts remove some of the risk normally associated with point forecasts by defining the upper and lower bounds to a region within which the values of outcome of future events or trends are thought likely to fill. The conditions which define the boundarles of the range usually do not differ qualitatively from those of a single point forecast; rather it is the magnitude of influence of certain crucial variables which is subjected to variation. Planning based upon range forecasts is thought less rlsky because it is geared to a accommodate the varlety of possible future states falling within the posited boundaries. Unfortunately, where the character of the environment is subject to more rapid change, range forecasts are insufficient to address the full spectrum of qualitatively different futures that may be considered reasonably likely. A scenario or, more correctly, contingency analysis, seeks to explore the signiflcance of different constellations of possible occurrences to planning and decision-making efforts. Such 
analysis is predicated upon a recognized need for highly flexible planning options, and, as such, associated forecasting techniques and models tend to be more complex, since they must address a wider variety of events, trends, or policy consequences.

The specific forecasting tool (or tools) selected is also primarily a function of planning and decision-making needs (though, clearly, the sheer avallability or workability of a technique or model in a given situation is additionally of central importance). Most generally, these techniques may be grouped into two major categories: exploratory and normative.

Exploratory forecasting techniques start from the present situation and profect the future of some variable (or variables) or concern by making various assumptions about continuation of past or present patterns of growth and actlvity (Martino, 1978:287). Although these techniques may vary rather widely in terms of their complexity and sophistication, they all are suited to planning in environments where basic relationships among elements do not vary appreciably over time (even though the particular values or states the elements may assume). Trend extrapolation and correlation are perhaps the simplest of exploratory techniques. Both plot the change in a dependent variable agalnst a single independent variable whose behavior is more stable or at least better known (in the case of trend 
extrapolation the independent variable is time). Any causal mechanisms which might link the variables remain unknown, in effect burying possible complex linkages between the variables considered and othe factors in the "black box" of the trend or correlation relationship. Growth curves constitute marginally more sophisticated techniques for plotting trends agalnst time, requiring prior knowledge of the upper limits of the value of the dependent varlable -- something which is neither always known or even always applicable. Econometric models consist of linked, simultaneously-solved regression equations (derived Erom hlstorlcal relationships between each dependent variable and one or more independent variables) whose terms are based upon economic theory. Such models display noteworthy differences in size (ranging from several to several thousand equations) and accuracy. Generally, econometric models explicitly address a somewhat wlder range of environmental factors than most exploratory techniques and are particularly approprlate where price, income, or productivity are significant "drivers" of the trends under consideration. Finally, simulation models, first developed in an engineering context, may be used to Illuminate the unfolding of a wider variety of processes over time. A simulation attempts to "imitate" the dynamic characteristics of the real world system it models by performing a serles of numerical calculations which follow the changes of the states of that system over time (Gordon, 
1978:9-10). In contrast to other exploratory forecasting technigues, simulations are "white boxes" which endeavor to explicate the structure of causal connections between system elements, though, admittedly, what is embodied in a simulation model's structure is what its developers believe to be the structure of the real world (whlch may or may not be 1 ts true structure). The mathematical equations connecting variables reflect observed (or adjudged) relationships thought to endure over time. As such, they share a weakness of other exploratory techniques: they cannot address structural changes in real world relationships which might occur in the future. The strength of simulation models is the "intermediate output" which they produce in arriving at their final calculation; namely, the description of interactions between system elements which may be useful for derisionmaking.

Normative forecasting methods seek to Identify what type of future conditions are most desirable with the objective of bringing them about (thus, the name "normative"). This is accomplished through techniques which permit the forecaster to lay out the full array of alternatives so that critical comparisons can be made. Where the system or process being analyzed can be described in terms of causation, hierarchy, or levels of complexity relevance trees (which permit cost-benefit comparisons between different systems required to fulfill a number of 
missions) may be used. By contrast, where a system may be broken down into nonhierarchical elements which can be altered independently, morphologies (which enumerate a row of different alternatives for each of the problem parameters forming the columns of the matrix) are appropriate. Final$1 y$, in the cases where all the alternative routes or sequences by which a task or mission may be accomplished can be mapped, misslon flow diagrams may be employed (Martino, 1978:287-317). Normative methods are best used where decision makers and planners have a great deal of control over the courses of behavior which key elements will follow. Where the full spectrum of alternatives cannot be readily specified, or where decision-making power is insufficient to affect critical environmental parameters, normative methods are of limited use.

While this classificatory distinction between exploratory and normative forecasting methods is a useful one, two qualifications need to be made. The Elrst is that there are commonly used techniques which may fall into either category (or both categorles) depending upon how they are used. Most notable are informed judgment ("genius forecasting") and Delphi, an anonymous, iterative technique for evoking and structuring expert opinion on various forecasting issues and topics. Whether these techniques are to be regarded as exploratory or normative is dependent upon whether they are used for, respectively, predictive or policymaking purposes. 
A second, and perhaps more important, qualification is that the distinction between exploratory and normative techniques is not as sharply drawn as first may appear to be the case. Even though decision makers may not be able to control the major "environmental" factors which their forecasts address, they are quite often able to influence them (albeit indirectly and incompletely) through their decisions, frequently without suspecting they are doing so. self-fulfiling prophecy refers to a condition where an image of the future helps bring about events which might otherwise not have occurred. For example, the widespread belief in an imminent stock market crash can result in a pattern of reckless selling and trading which in fact serves to drive the market down. Conversely, gelf-denying prophecy refers to a cond1tion where a probably correct Image of the future (based on current trends) results in actions by decision makers which bring about a very different set of outcomes. Forecasts of severe resource depletion, for example, may bring about increased exploration for and conservation of materlals, thereby averting a foreseen crisis. Thus, where planning and decision making can affect the environment which an "exploratory" forecast addresses, that forecast can have very real normative, pollcymaking consequences. The BPA 20-year regional demand forecast subjected to analysis in this dissertation was geared to planning resource acquisitions and ratemaking in lieu of the Regional 
Council's April 1983 forecast and resource plan. The forecast used three sets of economic and demographic projections and policy assumptions to produce a range of demand growth trajectories (baseline, low, and high) within which actual electricity consumption is anticipated to fall. The method of forecasting was to employ an interacting set of demand and electricity pricing models in an exploratory mode (though, as will be seen in the Chapter $v$ a number of parties in the region questioned its possible "normative" consequences). The "system" of interacting models used in the BPA forecast is described in the section that follows.

AN OVERVIEW OF THE BPA FORECASTING SYSTEM

The BPA forecasting effort was carried out over a number of months in three stages designed to allow the interested public and opportunity to criticize, comment, and make suggestions on the execution of the forecast.

- Stage One: In December of 1981, a preliminary set of regional economic and demographic projections were prepared. The public was invited to examine the credibility of the projected values of such variables as regional employment, population, income, and fuel prices as well as the method of their derivation. At roughly the same time, the technical merits of four demand models being considered for use in BPA's first independent long-range forecast of electricity consumption were revlewed by the staff. The Northwest 
Energy Policy Project (NEPP) All-Sector Model of electricity use, the Pacific Northwest Utilities Conference Committee (PNUCC) Econometric Model, and the Oak Ridge National Laboratory (ORNL) Energy Use Models for the residential and commercial sectors were used to simulate four possible energy growth scenarios for the region exemplifying different levels of conservation program implementation. The results were published and made avallable to the public. - Stage Two: In April of 1982, BPA released a draft forecast of electricity consumption in the Pacific Northwest along with a revised set of economic/demographlc projections. For the forecast, a somewhat more sophisticated approach was taken than was the case for the earlier model review. Separate economic and demographic inputs were prepared for public and private electric utility service districts. The ORNL Residential and Commercial sector Demand Models and the industrial portion of the NEPP Econometric Model were used in tandem with an electricity supply pricing model to determine private and public utility loads. - Stage Three: In July of 1982, the Elnal version of the 20-year demand forecast was released. Only slight model changes were implemented between draft and final forecasts. The sundry changes in model Input assumptions prompted by public comment and the substitution of the results of the Brookhaven Pulp and Paper Process Model for the NEPP model's highly counterintultive results for that Industry resulted 
in a minor decrease in the projected average annual rate of growth over the 20-year perlod from 1.7 to 1.6 percent.

The major development characterizing stages Two and Three of the forecasting process was the development of a price-responsive system of interlinked models. Fuel price, as the 1970s have effectively taught, is a prime determinant of energy consumption. People will not only use larger amounts of energy for particular tasks when the source of that energy is abundant and cheap but will also employ the energy for a larger variety of end-uses. As the price of a fuel rises, consumers characteristically curtail their use of that fuel or switch to a cheaper competing source of energy. Conversely, energy demand is a central Eactor in determining energy price, particularly in the case of electricity. As the demand upon established power-generating resources approaches their capacity, new facilities must be bulit or developed to accommodate antlclpated Increases in consumption. New resources are more costly to construct, and the power they generate is, correspondingly, sold at a higher price. This higher price for new energy will, in turn, tend to dampen demand.

The system of models developed by BPA designed to deal with this interrelationship between electricity supply and demand is depicted in simplified form in Figure 2 below. 


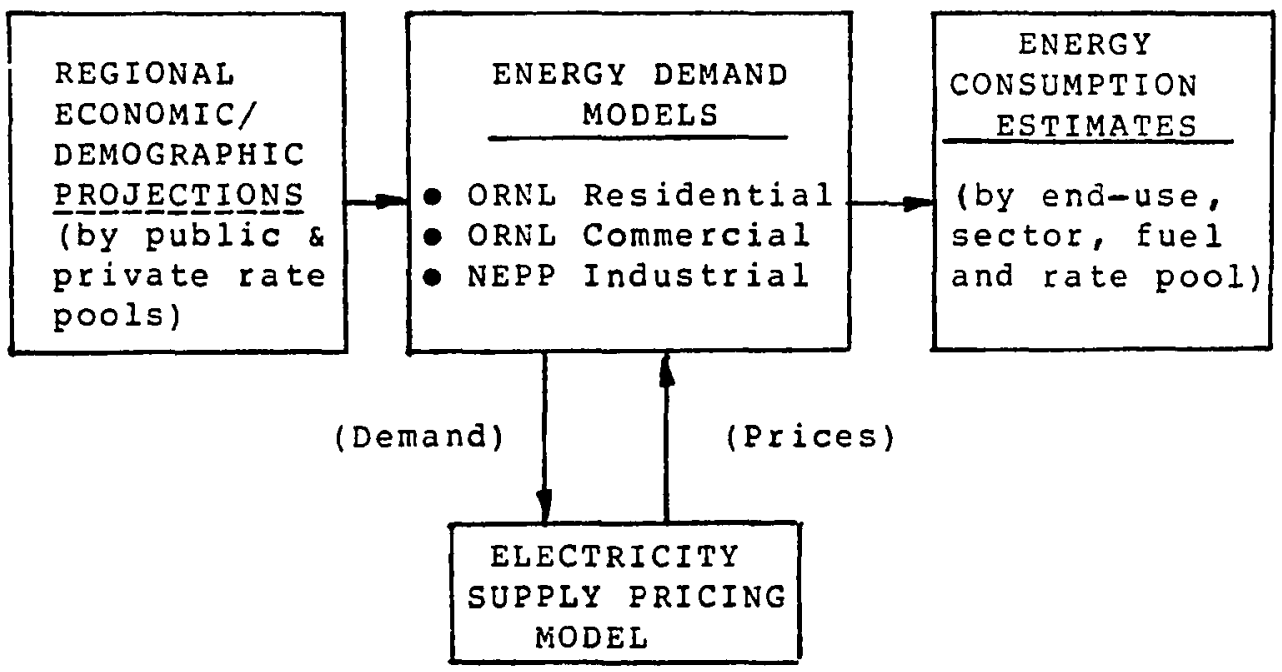

Elqure 2. The BPA system of forecasting models. An overvlew of inputs, models and outputs.

The first component is the one in which the economicl demearaphic inputs needed to operate the demand models are prepared. While some of the inputs used by the demand models are not reglon-specific (e.g. parameters for engineering or econometric relationshlps used in the model) the values for a number of the basic driving varlables le.g. non-electric fuel prices, employment, population, Income) are and must be derlved in-house by BPA staff. Regional inputs (broken down by public and private electric utility service districts) are developed from national economic models (1.e. the Data Resources Inc., or DRI, model) varlous Industries' own profections of employment and 
productivity, and several BPA In-house models le.g. population).

The economic/demographic projections serve as inputs to the second system component which is comprised of three energy demand models: the ORNL Residentlal Model, the ORNL Commerclal Model, and the industrial and street lighting portions of the NEPP model. Both of the ORNL models are hybrid economic/engineering models which are particularly well suited to policy analysis applications. The NEPP model is an all-sectors, all-fuels econometric model, though only portions of its total capabilities were used for the BPA forecast.

The third component of the forecasting system is an electricity supoly pricing model developed in-house at BPA. Orginally known as the Integrated Supply Demand Model, the current pricing model substitutes the ORNL and NEPP models for its demand module. The prlcing model takes as its input the sector-specific demands calculated in the second component of the forecasting system and develops a set of prices based upon the least-cost $\mathrm{mix}$ of new resources needed to meet the projected loads. The stream of prices so derived in turn becomes input for the demand models which are rerun to develop a secondary estimation of future consumption. These calculated demands are again entered into the pricing model, and the iterative process continues unt 11 an equllibrlum of both price and demand is reached. 
The fourth and final component is where the output of the forecasting process is adjusted and tallied: energy consumption estimates broken down by fuel type (though in fact the officlal forecast document focused upon electricity), rate pool, (i.e. public vs. private), sector, and end use (e.g space heating, lighting, etc.). Several calculations were performed external to the models, and these ultimately affected consumption estimated totals. Projected irrigation loads (developed us Ing a BPA Irrigation model) were added into the residential load. Irrigation loads were calculated only once and did not change from iteration to iteration with the pricing model. Similarly, loads for federal agencles and direct service industries (DSIs) were complled from long-term contract demands (whlch were not subject to price changes during contract 11 fetimes) and added to commerclal and industrlal loads respectively. ORNL Commercial Model and NEPE street lighting submodel loads were pooled during the iterative process to approximate commercial demand. Finally, for the pulp and paper industry, the output of the Brookhaven Pulp and Paper Process Model (run at Brookhaven Laboratory) was substituted for that of the NEPP model.

As noted above, the actual structure of the models forming the BPA forecasting system embodies a complexity not displayed in this cursory overview. The next sections examine the models and procedures in greater detall. 
ENERGY DEMAND AND ENERGY SUPRLY: THE MODELS USED IN BRA'S FORECAST

A problem with the foregoing discussion of major types of forecasting is that focusing upon a relatively few general features whlch distinguish a technique obscures whatever internal complexity may be present in a given application. Though simple in princlple, each of the models used by BRA employed a significant number of assumptions which were represented with varying degrees of explicitness. To understand the forecast fully, it is necessary to delineate the entire methodology employed in arriving at the economic and denographic projections used as model inputs through the iterative, concatenated use of sector demand and electricity pricing models to the final calculation of 20-year demand growth.

This major subchapter detalls both the overall methodology and the internal structures of each of the models employed in the BPA forecast. Flrst, the basic components of the system of models are presented in broad stroke in an overview section whlch focuses upon how the system as a whole operates, what role each of the models lor components) plays, and how these models are interlinked. Next, each individual component is examined in detail, its Internal operating structure (and the concomitant technical assumptlons) lald bare for examination. Finally, the larger forecasting system is reconstructed, but at a higher degree 
of detail and resolution than in the overview section. The resulting "master" input-output diagram should allow each model calculation to be referenced to each of its antecedent calculations, transformations, and assumptions.

\section{Economic/Demegraphic Profections: Inputs to Energy Fore-}

\section{casting Models}

In order to forecast the energy future of the Pacific Northwest it is necessary to develop a set of projections of economic/demographic conditions characteristic of the region to serve as inputs to the demand models for the various sectors. For BPA's 1982 long-term forecast, projections of a number of key variables reflecting changing economic and demographic conditions were prepared. Three distinct streams of values for such factors as employment, population, income, housing, and fuel prices were developed to represent conditions which would concelvably characterize baseline (1.e. "best guess"), high, and low energy consumption (this was done for both public and private utility service districts). These profections are developed by the Economic studies section of Power Requirements using a number of different models and techniques.

While the profections of economic or demographic varlables are done separately, each using a distinct procedure and embodying a unique array of assumptions, the derivations are interdependent to the extent that the 
calculated values of one varlable (e.g. employment) are used as Inputs to the models used to compute the values of other variables (e.g. population). This interdependence renders the entire set of projections more internally consistent than would be the case if each variable were profected in 1solation from each other but, at the same time, makes the consequences of many assumptions "hereditary", or embedded In final values other varlables assume. Figure 3 provides an overview of the relationship of the models employed in the development of the set of economic/demographic projections.

Outputs of the Data Resources Inc. (DRI) model of the national econemy are used for a number of purposes: as inputs to the models used to project the future values of economic and demographic variables, as direct inputs to the demand models, and as standards for determining high and low ranges. The economic base model refers to a technique (not an actual computer modell for deriving non-basic industry employment from projections of employment in basic (i.e. exporting) industries (which are calculated in a variety of ways depending upon the particular industry). Employment projections are used as inputs to the BPA population model (which develops Euture values for both population and households) and the BPA Income model, which also uses the output of the population model in the calculation of total personal and per caplta income. The BPA housing model takes 
(1)

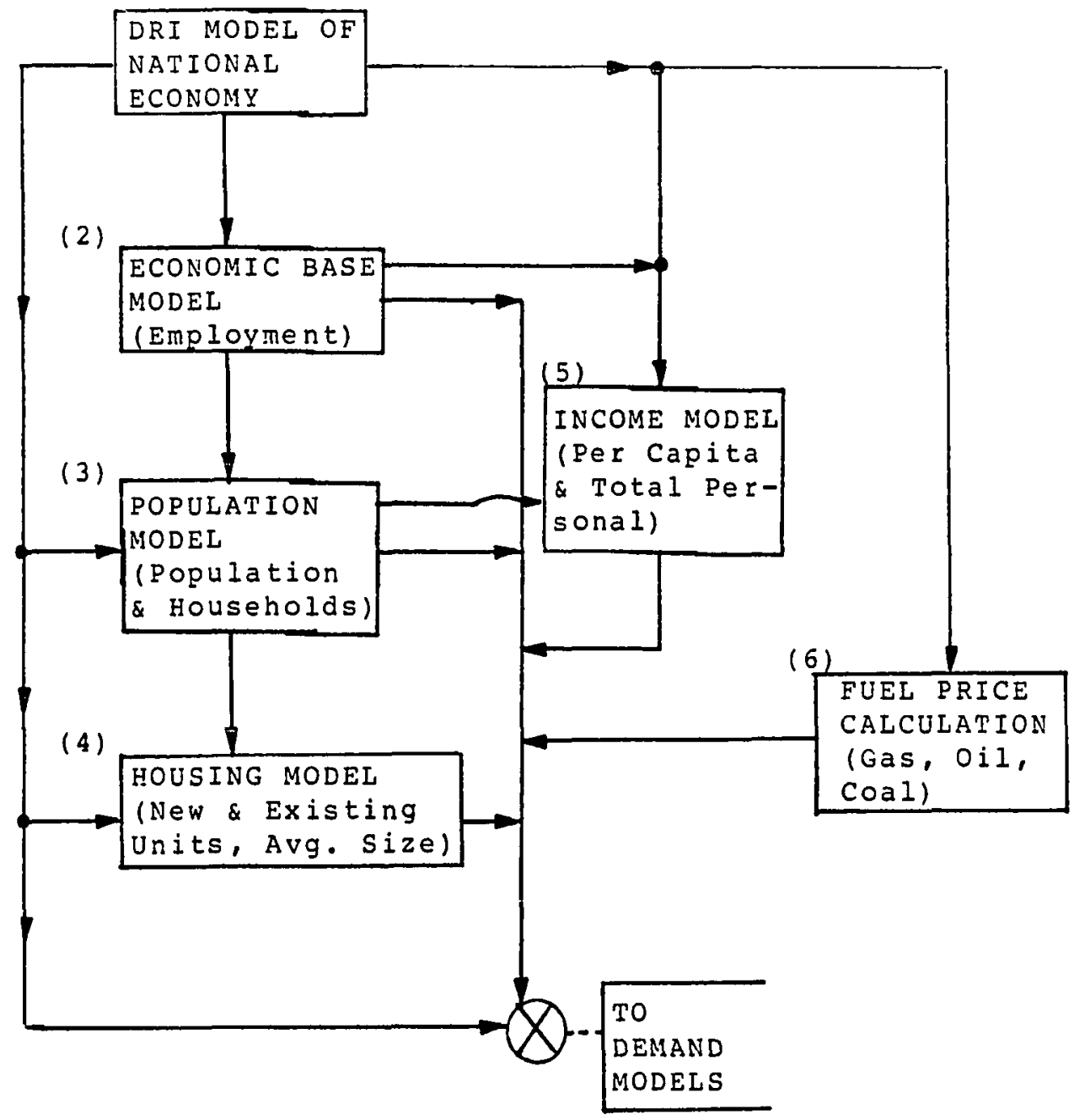

Elqure 3. Schematic of Models used for economic/ demographic inputs. A diagram of data flows between models. 
the number of households as determined by the population model as an input to develop estimates of total housing stock, new construction, and average unit size for homes for the-forecast period. Finally, fuel orlce projections for energy sources competitive with electricity (1.e. natural gas, oil, and coall are prepared independently of the other BPA models, though DRI projections are involved.

Having taken an overview of the relationships existing between the techniques employed to develop Individual economic or demographic projections, it is now appropriate to examine each of these techniques separately and in greater detail.

The DRI Model of the National Economy, Data Resources Incorporated is one of a number of firms which prepares and operates models of the U.S. economy which may be accessed or operated by subscribers to their computer service. Three distinct projections of national economic trends from 1980 to 2006 were utilized by BPA: TRENDLONG2006B (a baseline profection), OPTIMLONG2006B (an optimistic, "high case"), and PESSIMLONg2006B (a pessimistic, "low case"). While this model is essentially a "black box" to its users, a number of basic assumptions may be identified.

TRENDLONG2006B represents, or embodies, the following assumptions.

- no major economic mishaps (such as oll price shock or untoward policy shifts) 
- average annual rate of population growth .98 by 1985 , .88 by 1990 , and .68 by 2000

- potential output grows by average annual rate or 2.88 in 1980 and 2.38 in 1990

- growth of labor force slows to 1.08 per year in the 1980 s and .88 from 1990 to 2000

- labor force particlpation race increases to 66.88 of population by 1990 and 67.58 by 2006

- employment growth continues at an average annual rate of 1.78 between 1980 and 1990, declining to .98 between 1990 and 2006

- annual inflation rate drops from 7.98 in 1982 to 6.48 In 2006

- both energy prices and energy consumption increase slowly ( 1.98 per year in $1980 \mathrm{~s}, 1.48$ afterward)

- housing starts recover from current slump and average 1.87 million unfts from 1981 to 1990 and 1.69 million from 1991 to 2000 .

Optimistic and pessimistic trends also assume a relatively smooth path of economic growth without any major mishaps. They differ from the mean, or baseline, growth trajectory in a manner which is more quantitative then qualitative. 
In ORTIMLONG2006B

- average annual rates of growth (AARGs) of potential output are 3.58 for the $1980 \mathrm{~s}$ and 2.68 from 1990 on to the end of the forecast perlod

- inflation settles down to 58 per year in 1986 and averages that value until 2006

- employment in 2006 is increased by 4.78 over the base case

- labor force particlpation increases to 71.48 in 2006 FOI PESSIMLONG2006B

- The AARG for potential output is 2.38 through 1990 and 1.88 form 1990 to 2006

- the rate of inflation rises to 108 in 1986 and remains at that level through 2006

- year 2006 employment is down 4.78 from TRENDLONG2006B

- labor force participation is 1 imited to 64.48 in 2006

Outputs of the DRI model are used in three aistinct ways.

First, some of the outputs of the model are used in the sector demand models without any alteration or modiflcation. Included here are DRI projections of the AARG of Industrial productivity, interest rates, gross nation product (GNP), consumer price index (CPI), and implicit price deflators (based upon GNP and personal comsumption expenditures, or PCE) . 
Second, a number of the DRI national model outputs are used as inputs to the other economic/demographic models deplcted in Figure 3.

Specifically

- The housing model uses state level projections of housing starts.

- The model used for projecting employment in the timber industry uses the GNP forecast.

- The regional income model uses U.S. contributions per employee, U.S. per capita property income, and U.S. per capita transfer payments, and

- Fuel price calculations employ DRI estimates of prices for crude and retall petroleum, natural gas, and coal.

Finally, the ranges of the three DRI trend Iines were used to establish proportional ranges in the high and low case values of many of the BPA's regional projections. The Economic Base Model. The name given to the overall methodology for projecting reglonal employment is 'economic base model'. 'Model' here refers to a way of determining employment from non-basic industries from a series of calculations which project employment for each of ten basic (i.e. exporting) industries individually. The economic assumptions behind the economic are represented in the digraph in Figure 4. (NOTE: An arrow from one element in the algraph to another Indicates that the element at the arrow's tall influences the element at the arrow's head. If 


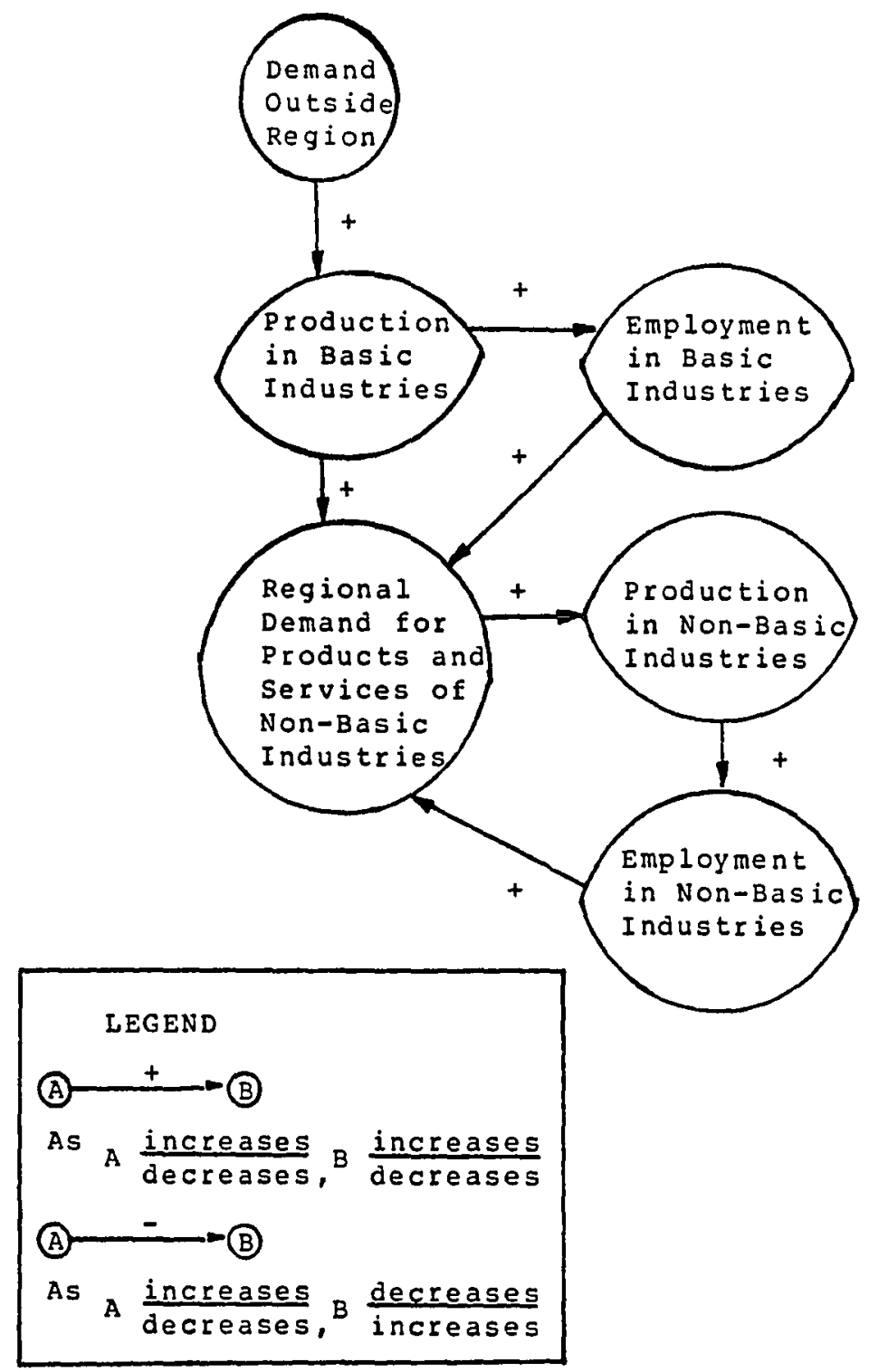

Figure 4. Dynamics assumed by economic base model. A digraph of relationships between basic and non-basic industries. (Detall of Figure 3, Box 2) 
the arrow is 'signed' with a '+' the change in the affected element is in the same direction as that of the element impacting it; whereas a '-' indicates a change in the opposite airection.)

Basic industries are those which export their output to consumers outside of the region. As such, they are essentially "driven" by external demand which spurs increased productivity which, in turn, requires increased employment. Industries classified as "basic" include agriculture, food processing, lumber and wood products, pulp and paper, chemlcals, primary metals, electronics, transportation equipment, mining, and Federal government. Growth in basic industry correspondingly stimulates the growth of non-basic industry in the region. Demand for the products and services of non-basic industries encourages increased production and employment. The actual calculation of non-basic industry employment is carrled out by applying an employment multiplier to total projected basic industry employment. The multiplier, consisting of the ratio of total to basic industry employment, was derived by calculating this ratio for each year from 1950 to 1979, by state, and then extrapolating to the end of the forecast period. Applying the multiplier to projected basic employment yields total employment. Subtracting basic from total employment produces the total non-basic industry employment for forecast years, which is then disaggregated into distinct sector 
categories based upon historlcal trends and national profections of individual industry growth.

Thus, the values which the projections of non-basic industry employment assume are dependent upon the size of basic employment in the region. Figure 4 would seem to indicate that reglonal employment is completely demand-driven and subject to continued growth as long as unfilled demand for exports exists. In reality, however, basic industry growth is limited by a variety of resource, price, and policy constraints which are, to a large degree, industryspecific. For this reason, employment in each of ten basic industries is projected using a distinct methodology, as well as its own distinct data sources, which reflect the unique circumstances affecting its growth and development.

Projecting employment in agriculture involves embracing somewhat greater uncertainty than is the case with other basic industries. A reasonable share of farm employment is comprised of migrant and part-time family labor, a fact which makes precise estimation difficult and virtually requires some use of judgment. BPA estlmates were prepared from data originating at two sources. One was the reports of state level agencies which document historical employment (and disaggregate it to county level). The other was Bureau of Economic Analysis (BEA) projections of state and county level employment in agrlculture. Essentlally, BPA Judgmentally modified the trend described by BEA so that 
projections were more consistent with the historical employment statistics from the state agency reports. High and low ranges were placed around the baseline employment projections using the ranges, though not the actual values, developed in a 1979 study by the Northwest Agricultual Development Project (NADP). As a check for the credibilty of the BPA projections they were cross-compared with those developed by the Census of Agriculture and the U.S. Department of Agriculture's Crop Reporting Board.

For the food processing industry, historical employment data at the county level obtained from state employment departments were subjected to a trend analysis. Trends were modified slightly where information from county level sources indicated specific industry expansion plans. High and low ranges were developed around the baseline trend for food processing employment based upon DRI national employment ranges for the industry.

A computerized model first developed for the U.S. Forest service was used to develop the baseline employment figures for the lumber and rood products industry. The Timber Assessment Market Model (TAMM) determines levels of future prices and production by simulating interactions in the markets for stumpage, lumber, and plywood as constrained by the biological growth of the timber resource base. Using U.S. Census forecast of national population and DRI middle range GNP frojections, the model produces a forecast of 
industry output. These TAMM forecasts are disaggregated to the state lovel and multiplled by a ratio of worker-years per unit of industry output, ylelding total industry employment. High and low projections were based upon past relationships between employment and new housing starts and DRI high and low projections of natlonal housing starts. Employment in the pulp and paper Industry was forecasted in two different ways. For primary product sectors (pulp, paper, and paperboard) employment estimates were made by analyzing current U.S. Forest Service forecasts of regional pulp production and earlier forecasts of regional pulp production levels (both of which suggested virtually stable employment levels for the duration of the forecast period). In the converted paper product sectors employment-to-population ratios were calculated and multiplied by preliminary population projections. Because growth in the pulp and paper industry is tightly constrained, high and low ranges could not deviate greatly from the baseline. They were derived by varying the start-up times and production levels of new plants.

The chemicals (and allied products) industry baseline employment was also projected to grow at a moderate rate. Industries in this category may be subdivided into three maln groups: chlorine-caustic, agricultural chemicals, and nuclear fuels processing and englneering (1.e. Hanford). For each group, historical data was obtained from state 
agency reports. Projections, however, were developed differently for each group. Chlorine-caustic employment growth is calculated by correlating it with changes in the pulp and paper Industry (where such chemical products are used routinely). For the agricultural chemical industry, employment growth was consldered proportional to DRI projections of national industry employment. Finally, for nuclear fuels (a very constralned area of growth) industry estimates of potential growth were Judgmentally adjusted. High and low ranges were developed by applying different estimates of the Pacific Northwest's share of national employment to DRI national industry employment forecast. For the high case, the historic growth of the region's share was extrapolated to the end of the forecast perlod, and the resulting values applied to DRI's optimistic trend. For the low case, a constant share equal to the 1980 value was applied to the DRI pessimistic economic projection.

Employment in primary metals was projected in two different ways, depending upon the metal under consideration. Primary aluminum smelters obtain almost all their electricity from BPA. Since sales are not expected to increase significantly over the next 20 years, aluminum production growth was assumed to occur only because of modernization of existing plants and the addition of the planned Alumax plant. From reports on plants modernized since 1979 and knowledge of planned efflclency improvements 
in other plants, projections were made of anticipated primary aluminum output increases and the additional labor force required (adjusting for increased productivity). High and low ranges were established by varying demand and electricity prices relative to the base case. The high case assumed greater demand and increased production (and employment) due to further price-induced modernization. By contrast, the low case assumed lower demand, less modernization, and the termination of plans to construct Alumax. For "non-aluminum" primary metals regional growth (based on historlcal values and antlcipated developments in specific facilities) was indexed to national trends for the industry developed by DRI. High and low ranges were likewise indexed to DRI optimistic and pessimistic trends.

For the electronlas Industry in the PNW employment profections were based upon both the public statements of Individual companies and the reports of both state departments of economic development and local agencles. From these profections, each state's share of DRI's national employment estimates was determined. For the high case, these same shares were applied to the DRI optimistic projection. For the low case, the states' shares were Judgmentally reduced (to represent a slowing in the relative growth of the regional electronics industry) and applied to the DRI pessimistic national industry employment projection. 
The transportation equlpment industry is comprised of three main subgroups: aerospace (chlefly Boeing), ship and boat building, and miscellaneous other (motor vehicles, railroad eqiupment, and travel trailersi. For each of these subgroups, specific industry estimates of anticlpated employment were obtained and judgmentally adjusted to be consistent with other forecasted economic trends. High and low ranges for transportation equipment were developed by determining the share of each state (except Washington) of DRI's estimates for the base case and applying these shares to the appropriate employment estimates in the optimistic and pessimistic trends. Because of historically wide swings in the industry in the state of Washington, its average absolute change in yearly employment for the last 20 years was determined and that amount added to (high case) or subtracted from (low case) baseline values to approximate its range.

The mining industry is extremely resource-dependent and its employment only determined by demand to a limited degree. Mine-specific estimates of employment were developed from historical values and scaled up or down to reflect different levels of production for high and low cases. Finally Federal qovernment employment, limited by each Adminlstration's hiring cellings, was obtalned from in-house estimates, with high and low cases representing, respectIvely, relaxed and tightened hiring restrictions. 
Table II summarizes the primary industry employment derivations.

The BPA Population/Household Model. The BPA population model employs what is known as a cohort-component method for projecting population change. Cohorts are persons born within a distinct period of time (in the case of the BPA model, every five years). The components of population change are fertility, mortality, and migration. The model, in effect, operates by "aging" the members of each cohort in the existing population at five year increments, making adjustments for births, deaths, age and sex composition changes, varying labor force participation rates, and inand out-migration. The model produces state level population estimates whlch are split into public and private service territories by disaggregating 1980 county level census data using percentages of residential customers served by public and private utilities. These percentages were modified slightly where employment profections indicated a change of proportion of total employment in public or private service areas.

A more detalled representation of the operational structure of the population model is depicted in Figure 5 . The model is based in the year 1970 and accordingly begins its operation using 2970 population values (although it was operated to match the 1980 age composition of each state). Age- and sex-specific fert 111 ty and surylyal rates (taken 
TABLE II

BASIC INDUSTRY EMPLOYMENT ESTIMATION

\begin{tabular}{|c|c|c|}
\hline Industry & Employment Derivation & Hich/Low Adiustment \\
\hline Agriculture & $\begin{array}{l}\text { - judgmental adjustment of } \\
\text { BPA projections based } \\
\text { on state level agency } \\
\text { reports }\end{array}$ & $\begin{array}{l}\text { - NADP high/low } \\
\text { ranges applied to } \\
\text { BPA-calculated } \\
\text { baseline }\end{array}$ \\
\hline Food Processing & $\begin{array}{l}\text { - trend analysis of state } \\
\text { employment departments } \\
\text { (modified for specific } \\
\text { industry expansion } \\
\text { plans) }\end{array}$ & $\begin{array}{l}\text { state's shares of } \\
\text { national employ- } \\
\text { ment applied to } \\
\text { DRI optimistic } \\
\text { pessimistic trends }\end{array}$ \\
\hline $\begin{array}{l}\text { Lumber \& Wood } \\
\text { Products }\end{array}$ & $\begin{array}{l}\text { - TAMM forecasts of re- } \\
\text { gional production } \\
\text { disaggregated to state } \\
\text { level a mutiplied by } \\
\text { employment/output ratio }\end{array}$ & $\begin{array}{l}\text { DRI projections } \\
\text { of optimistic and } \\
\text { pessimistic case } \\
\text { housing starts } \\
\text { applied to BPA } \\
\text { baseline }\end{array}$ \\
\hline Pulp and paper & $\begin{array}{l}\text { - primary product: USFS } \\
\text { projections earlier } \\
\text { BPA forecasts converted } \\
\text { paper products: em- } \\
\text { ployment/population } \\
\text { ratios multiplied by } \\
\text { preliminary population } \\
\text { projections }\end{array}$ & $\begin{array}{l}\text { - start-up times } \\
\text { and production } \\
\text { levels of known } \\
\text { plants scaled up } \\
\text { or down }\end{array}$ \\
\hline Chemicals & $\begin{array}{l}\text { - chlorine-caustic: } \\
\text { correlated with pulp } \\
\text { and paper growth } \\
\text { agricultural: growth } \\
\text { proportional to } \\
\text { national DRI baseline } \\
\text { nuclear fuels: judg- } \\
\text { mental adjustment of } \\
\text { industry estimates }\end{array}$ & $\begin{array}{l}\text { - each state's share } \\
\text { of national em- } \\
\text { ployment extra- } \\
\text { polated to } 2000, \\
\text { shares applied to } \\
\text { DRI's optimistic } \\
\text { trend for high } \\
\text { case, constant } \\
\text { share (l980 level) }\end{array}$ \\
\hline & & $\begin{array}{l}\text { assumed for low } \\
\text { case derivation } \\
\text { from DRI pessi- } \\
\text { mistic trend }\end{array}$ \\
\hline
\end{tabular}


TABLE II (Cont'd)

\begin{tabular}{|c|c|c|}
\hline Industry & Employment Derivation & High/Low Adjustment \\
\hline Primary Metals & $\begin{array}{l}\text { - aluminum: industry } \\
\text { estimates of produc- } \\
\text { tion (including } \\
\text { modernization) cor- } \\
\text { related with employ- } \\
\text { ment, Alumax added } \\
\text { non-aluminum: regional } \\
\text { historical estimates } \\
\text { indexed to pRI baseline }\end{array}$ & $\begin{array}{l}\text { - aluminum: high case } \\
\text { adjusts demand \& } \\
\text { amount of modern- } \\
\text { ization upward, low } \\
\text { case assumes lower } \\
\text { demand, less modern- } \\
\text { ization. no Alumax } \\
\text { non-aluminum: state } \\
\text { shares of national } \\
\text { employment applied } \\
\text { to DRI optimistic } \\
\text { and pessimistic } \\
\text { trends }\end{array}$ \\
\hline Electronics & $\begin{array}{l}\text { - public statements of } \\
\text { individual companies } \\
\text { expansion plans and } \\
\text { projections of state } \\
\text { depts. of economic } \\
\text { development }\end{array}$ & $\begin{array}{l}\text { - state shares applied } \\
\text { to DRI optimistic } \\
\text { trend for high case, } \\
\text { reduced shares } \\
\text { applied to DRI } \\
\text { pessimistic trend } \\
\text { for low.case }\end{array}$ \\
\hline $\begin{array}{l}\text { Transportation } \\
\text { Equipment }\end{array}$ & $\begin{array}{l}\text { - judgmental adjustment } \\
\text { of aerospace industry } \\
\text { estimates of growth } \\
\text { and expansion; non- } \\
\text { aerospace shares taken } \\
\text { from historic data } \\
\text { and DRI baseline } \\
\text { national trend }\end{array}$ & $\begin{array}{l}\text { - states' shares ap- } \\
\text { plied to DRI opti- } \\
\text { mistic pessimistic } \\
\text { trend except for wA } \\
\text { where avg. absolute } \\
\text { yearly employment } \\
\text { change added to or } \\
\text { subtracted from } \\
\text { baseline }\end{array}$ \\
\hline Mining & $\begin{array}{l}\text { - mine-specific employ- } \\
\text { ment estimates }\end{array}$ & $\begin{array}{l}\text { - baseline estimates } \\
\text { scaled up/down to } \\
\text { reflect different } \\
\text { levels of mine pro- } \\
\text { duction }\end{array}$ \\
\hline Eederal government & $\begin{array}{l}\text { in-house estimates } \\
\text { lgiven current hiring } \\
\text { cellings existing }\end{array}$ & $\begin{array}{l}\text { - in-house estimates } \\
\text { (relaxed or tightened } \\
\text { hiring ceilings) }\end{array}$ \\
\hline
\end{tabular}




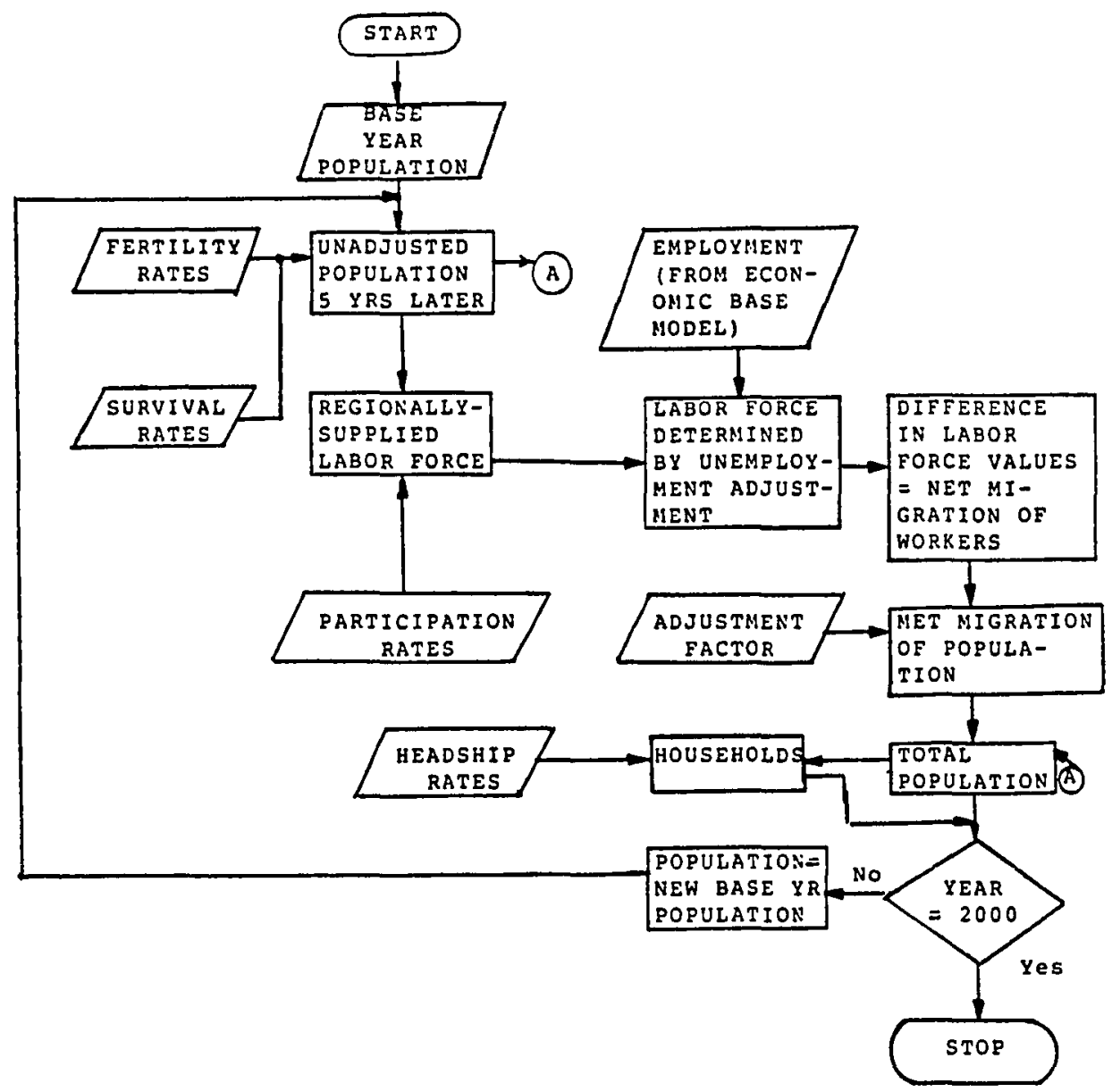

Eiqure 5. The BPA population model. A flowchart of calculations. (Detall of Figure 3, Box 3) 
from state Depts. of Vital statistics for the historical period and from national profections of the U.S. Bureau of Census from 1980 to 2000 ) are then applied to the base year values to produce a preliminary 1975 population value. To this preliminary value, labor force particlpation rates (also age-and sex-speciflc) taken from the U.S. Bureau of Labor statistics are applied, ylelding the portion of the 1975 labor force fllled by "survivors" of the 1970 population who are of working age.

This labor force value, however, does not reflect the net migration of workers occurring from 1970 to 1975 (just as the preliminary 1975 population figures do not reflect total net migration). A calculation of the total 1975 employment is developed using the economic base model described in the previous section (though, prior to 1980, the employment values are actuals, not estimates). An unemployment adfustment, accounting for frictional unemployment, is then performed to convert total 1975 employment into the total 1975 labor force. Th1s "employment-derived" labor force value was developed by applying participation rates to preliminary 1975 population. The difference between these two values constitutes the net migration of workers. Since many migrating workers characteristically bring (or take) their families with them, the net migration of workers is multiplied by an adjustment factor to yield the net miaration of population. This resulting value is then added to 
(or subtracted from) the preliminary 1975 population value, producing a final figure reflecting mortality, fertility, and migration.

From the final 1975 population value, the number of households is calculated by applying headship rates (i.e. proportion of persons heading a household) to each age-sex group and summing the forecasts for each of the groups. Headship rates are taken from national projections developed by the U.S. Bureau of Census.

Once the flnal population and household values are calculated for 1975 the population is once again "aged" 5 years to 1980 and the set of calculations begun again. This process is repeated until the forecast horizon $(2000)$ is reached.

The high and low ranges for population were developed by varying some of the key model input values, based upon changes in fundamental assumptions. For the high case, high employment, higher levels of labor force participation, lower fertility (since more childbearing-age women shift to the work force), and high headship rates were assumed. By contrast, the low case assumed lower employment and labor force participation, highter fertility, lower headship rates and higher unemployment adjustment.

The Housing Model. The housing model used at BPA utilizes the output of the population model to project the total housing stock, new housing construction, and average 
house size for four housing types: single-family attached, single-family detached, multifamily, and mobile home. Projections are done on a state level and aggregated to regional totals. Since housing profections are driven by outputs of the population model, the public-private split for housing is simply accomplished by using public and private population values.

The internal structure of the housing model is depicted in Figure 6. A breakdown of households by age class is produced by multiplying age-specific population estimates by headship rates. (These values are taken from the population model discussed in previous section). 0ccupancy rates for the four types of housing are determined from three factors. The first is a set of base year (1980) eccupancy rates, developed from residential survey data developed for PNUCC and BPA by Elrick and Lavidge. (For 1980, no further calculation is perfomed: the values are used as taken from the survey data). The second is a penetration rate which estimates the preference choices among the housing types for new construction. This penetration rate is derived from DRI state level projections of housing starts. The third and Einal factor is a distribution rate which allows the additional construction to be allocated among the various age groups in the population. These distribution rates are calculated from residential survey data. For each year in the forecast perlod after 1981, the occupancy rate is cal- 


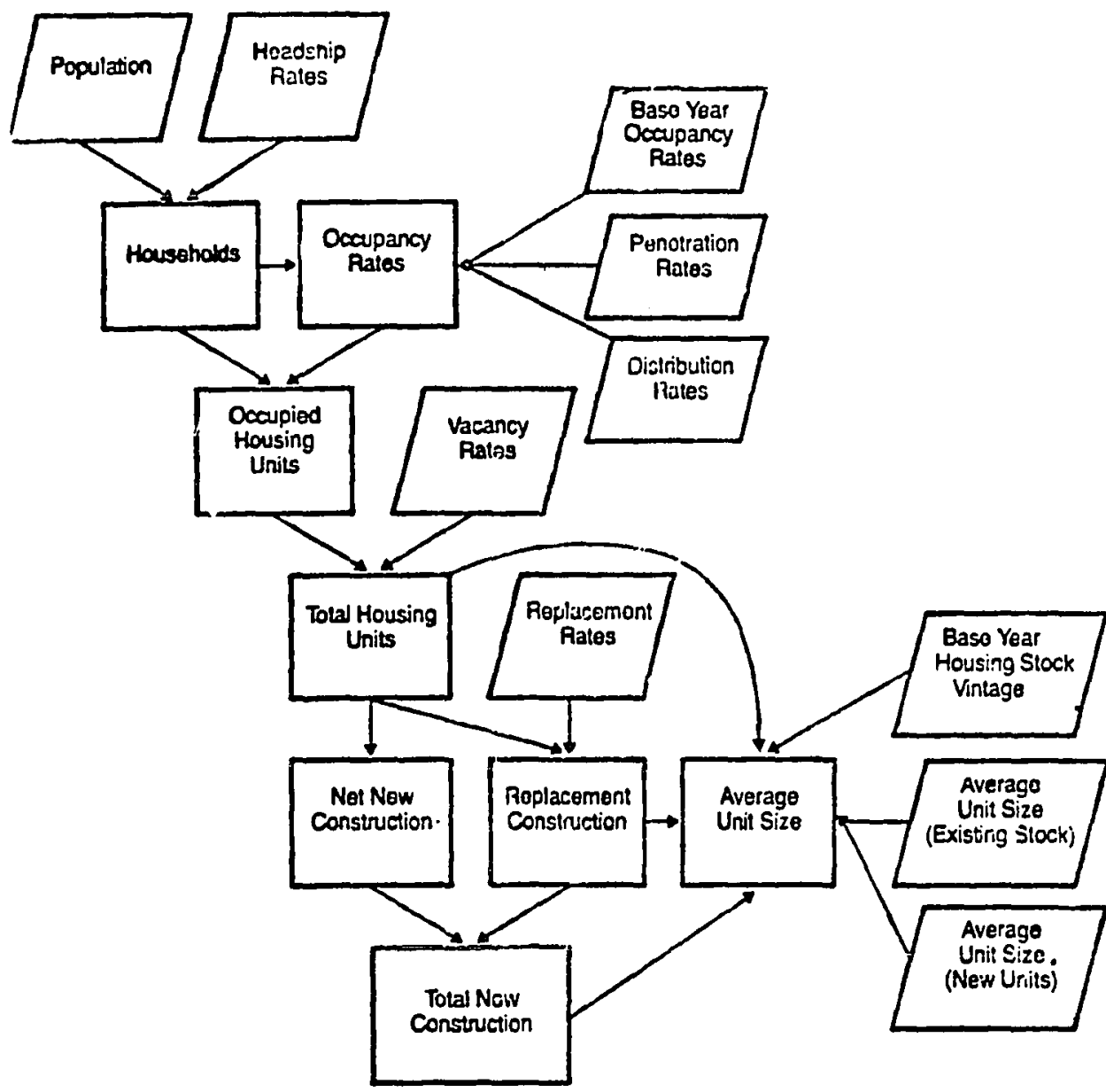

Reprinted from (B:A, 1982b:43)

Fiqure 6 . The BPA housing model. The derivation of touseholds, average unit size and new construction. (zetail of

Figure 3, Box 4) 
culated by adjusting the previous year's occupancy rate to account for the penetration rates of new construction (distributed among the various age groups).

Multiplying the number of households by occupancy rates gives the breakdown of occupled housing units. Total housing stock is next derived by adjusting occupled housing stock for vacancies. This is accomplished by dividing occupled housing by one minus the vacancy rate (taken from Annual Housing Suryeys).

Having calculated the total stock for a given year, the housing model next determines new construction. This is done in several steps. New net construction represents the construction of new homes to accommodate the needs of a growing population. It is simply the difference between a given year's total housing stock of a given type and that of the same category for the previous year. Next, replacement construction (new homes to replace those which were demolished) is calculated by multiplying the previous year's total stock by a replacement rate (assumes an average $11 \mathrm{fe}$ of 56 years for a conventional home, 24 years for a mobile home). Finally, total new construction is derived by summIng net new and replacement construction.

The final output of the housing model, average unit slae, is estimated using a simple vintage model which disaggregates the total stock of houses into groups constructed In the same year. From the residential survey data are ob- 
tained the average unit size of the existing stock (by vintage) constructed prior to the base year, the average unit size for new homes (assumed to remain equal to the average size of the most recent vintage covered by the survey), and the breakdown of the base year housing stock by vintage, For each forecast year units which must be replaced are removed from the oldest available vintage. After this has been done, average unit size is calculated by taking a weighted average of all the vintages.

High and low ranges for housing were developed simply by substituting high and low values for population and headship rates for those used in the baseline run.

The Income Model. An econometric model was recently developed by BPA staff to project both personal and per capita Income by state. The model first projects the varlous components of income and performs successive aggregations to arrive at total personal income. As such, the intermediate outputs (1.e. the income values of the various components) of the model are also of significance (some of them are, in fact, used in the demand models). Figure 7 provides a detailed representation of the internal structure of the income model. Using an econometric equation, the incomes for various sectors of the economy are calculated as a function of employment (by category) and U.S. average earnings (also by employment category). The employment estimates are those developed by 


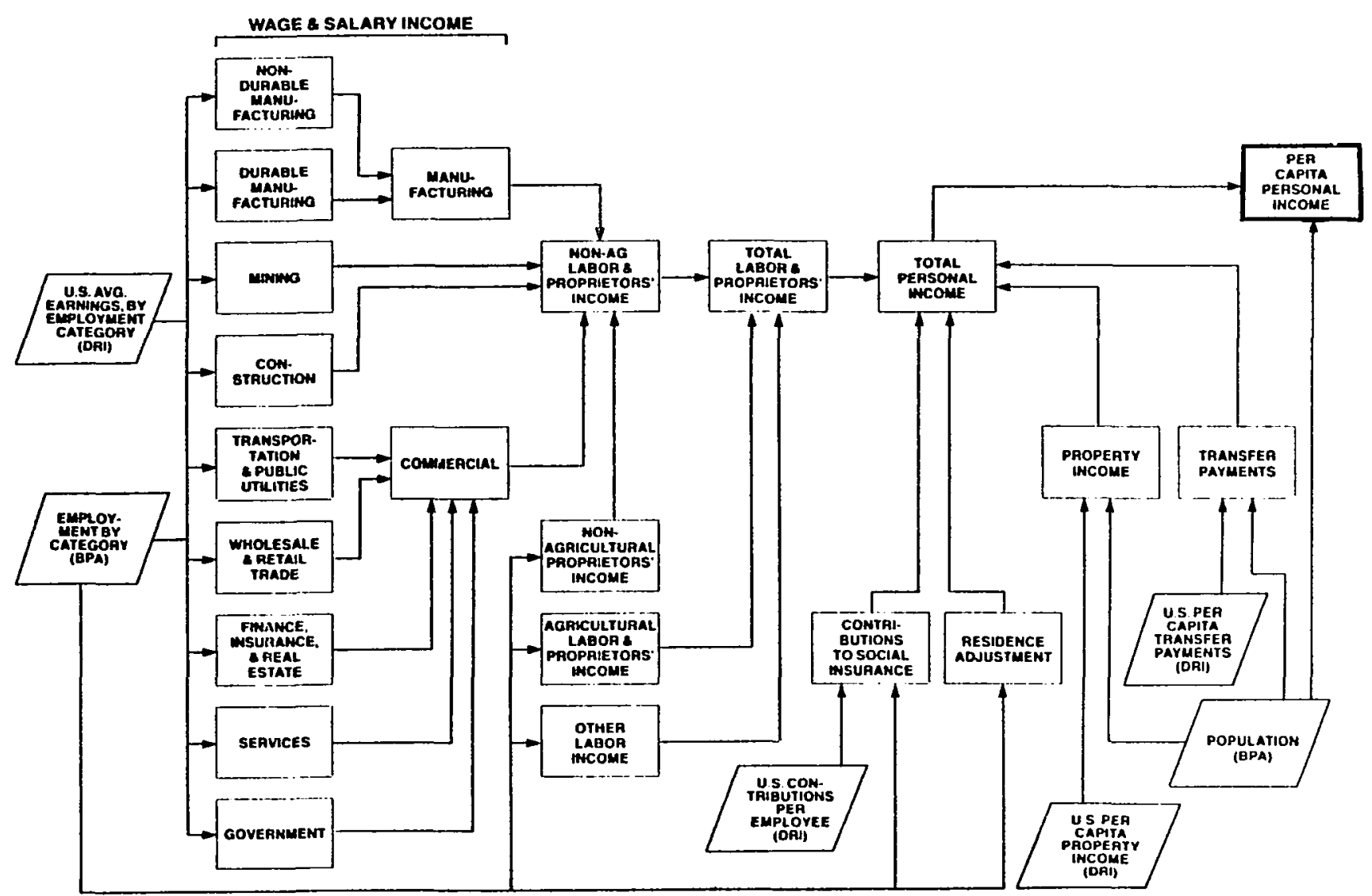

Reprinted from (BPA, $1982 b: 132$ )

Figure 7. Flow chart of regional income model. (Detail of Figure 3 , Box 5) 
BPA, while the average earnings for each category are obtained from DRI. The categories thus calculated are non-durable and durable manufacturing, mining, construction, transportation, wholesale/retail trade, F.I.R.E. (finance, insurance and real estate), services, and government. Nonagricultural proprietors' income, agricultural labor and proprietors' income, and other labor income for the region are developed as shares of national totals (DRI). Nondurable and durable manufacturing incomes are summed to obtain total manufacturing income. Transportation, wholesale and retall trade, F.I.R.E., servlces and government incomes are aggregated to produce commercial income. Next, non-agricultural labor and proprietors' income is derived by summing incomes from the manufacturing, commercial, mining, construction, and non-agricultural proprletors' categorles. The further addition of agricultural labor and proprietors' income and other labor income to this sum ylelds total labor and proprletors' income.

Tetal personal Income is subsequently obtained from this last total by a series of calculations. Property Lncome (a function of BPA population estimates and DRI values for U.S. per capita income) and transfer payments (the product of BPA population estimates and DRI U.S. per caplta transfer payment projections) are added to total labor and proprietors' income. From this figure is subracted contributions to soclal insurance (the product of BPA 
employment and DRI estimates of U.S. contributions per employee). The resulting value is then given a "resldence adjustment" measuring the net difference between income inflows and outflows which result from such factors as commuting employees or absentee landlords and proprletors. This residence adjustment, based upon BPA employment values, completes the calculation of total personal income.

Finally, per capita personal income is derived simply by dividing total personal income by BPA population estimates.

High and low range income were developed by substituting high and Iow BPA population and employments for baseline values and optimistic and pessimistic DRI trends for its base case TRENDLONG2006B.

Public/private splits are similarly determined by the values of the BPA-derived inputs to the income model. The varlables estimated by DRI are all national averages and, as such, apply equaliy to public and private utility service districts.

Euel prices. A critical variable driving all of the demand models is the price of fuels competitive with electricity. The prices of oil, natural gas, and coal in the region are calculated by BPA, though no computerized model is employed. Oll prices are reglonal, but coal and natural gas prices vary somewhat from state to state. No differences in non-electric fuels are observed to exist between 
public and private electric utility service areas: hence, no public/private split needs be made.

Petroleum prices are calculated in four basic steps. First, the relative shares (or the percentages of the total amount supplied to the region) originating at various sources are determined. The shares of crude origination from Canadian, Alaskan, Domestic, and Imported sources vary across the forecast perlod. The values assigned to the shares for these sources are determined for the historical period (1978) from U.S DOE's Energy Data Report, and for the period from 1979 to 2000 from DRI crude petroleum projections. Second, the prices for crude orlginating at each source are determined from DOE's Monthly Eneray Review (1978-1980) and from DRI projections (1981-2000). In the third step, the average reglonal prices of crude ofl are determined by multiplying each source's shares by its particular associated crude price value and summing. Finally, the crude prices are adjusted for markups of refiners and retallers using price data obtained from the Bureau of Labor statistics and markup data from DOE. The resulting values describe the prices of residential, commercial, and industrial distillate fuels and industrial resldual oll.

Natural gas and coal price profections follow the same serles of steps. For natural gas, the relative shares of Canadian, Alaskan, and Domestic sources are calculated for 
the forecast period, pipeline prices are determined from DRI projections, an average pipeline price is computed, and this average price adjusted for markups for interstate transmission pipelines and distributing utilities (based on DOE cost and revenue data). Retail prices of residential, commerclal, and industrlal natural gas were determined for each state as well as the whole region. For coal, the shares (for each state in the PNW) are produced for coal sources in Colorado, Wyoming, and Utah and contract prices computed using DRI projections. An average contract price for each state is calculated and subsequently transformed into delivered price (reflecting transportation costs also based on DRI projections). Delivered coal prices are prepared for both the region and each of the states. High and low ranges are the result of substituting alternative DRI projections for the baseline trend in the calculations described above. No modification of procedures is necessary.

Demand Models: End-Use and Econometric Tools

The economic/demographic projections described above were used in one or more of the sector-specific demand models employed in the BPA forecast. These models were run in confunction with a supply pricing model (described below) electriclty demand feeding into the pricing model, electricity prices input to the demand models, until equilibrium (or convergence) was reached. For each 1teration, all of 
the models were run with a separate set of inputs corresponding to the economic and demographic characteristics of public and private utllity service areas. As noted above, the wholesale rates charged to investor-owned utilities differ substantially from those of public utilities (the Regioral Power Bill notwithstanding): thus, two distinct demand streams were produced so that the supply pricing model could determine the appropriate corresponding rates. (Note: Irrigation, DSI, and federal agency loads were calculated exogenously and not subjected to a public/private disaggregation. Their values did not vary from iteration to iteration, though they were added to the demand outputs before they were entered into the pricing model. As a result, they will be discussed below where final consumption values are presented).

In addition to a baseline run (BPA's "best guess" at the future of regional electricity demand) high and low demand projections were developed (also employing the public/private split and iterative operation with the pricing model). These alternative growth trajectories represent the highest and lowest levels of electricity consumption to be expected given the set of economic, demographice and policy constraints assumed to be effective. In addition to using high case economic and demographic inputs, the high demand trajectory assumed less robust regional conservation. Contrariwise, the low case alterna- 
tive embodied low economic and demographic projections and assumed slightly greater levels of conservation savings than the baseline. Table III provides a fuller enumeration of the assumptions embodied in the inputs to the individual demand models. How these assumptions affect each of the models' operations is described in the detailed discussions of the ORNL Residential Model, the ORNL Commercial Model, and NEPP Industrial Model presented below.

The ORNL Residential Model, One of the three principal models of energy demand employed by BPA staff in producing the 1982 forecast was the Oak Ridge National Laboratory Model of residential sector energy consumption. The ORNL model was one of several developed for the USDOE shortly after 1ts formation in 1977. The ORNL Residential Model embodies a hybrid structure, which reflects characteristics of both engineering and econometric models. The model architects, most notably Eric Hirst, designed the basic features of the model to address the effects of both the relatively continuous demographic and economic trends stimulating demand growth and the discontinuous energy policy interventions anticipated by the newly elected Carter Administration. The basic structure of the model is illustrated below in Figure 8 . 
TABLE III

KEY ENERGY FORECAST ASSUMPTIONS

EXPLICIT MODELING CHOICES BY SECTOR

Low Case

Base Case

High Case

Residential

Secter

\begin{tabular}{|c|c|c|c|}
\hline $\begin{array}{l}\text { Economic and } \\
\text { Demographic } \\
\text { Projections }\end{array}$ & low projections & base projections & $\begin{array}{l}\text { high projec- } \\
\text { tions }\end{array}$ \\
\hline Fuel Prices & low projections & base projections & $\begin{array}{l}\text { high projec- } \\
\text { tions }\end{array}$ \\
\hline Conservation & $\begin{array}{l}\text { BPA budgeted } \\
\text { programs }\end{array}$ & $\begin{array}{l}\text { BPA budgeted } \\
\text { programs }\end{array}$ & $\begin{array}{l}\text { slower pene- } \\
\text { tration of } \\
\text { BPA budgeted } \\
\text { programs }\end{array}$ \\
\hline $\begin{array}{l}\text { Customer Discount } \\
\text { Rate }\end{array}$ & base value & base value & higher value \\
\hline $\begin{array}{l}\text { Appliance } \\
\text { Lifetimes }\end{array}$ & base lifetimes & base lifetimes & $\begin{array}{l}\text { longer life- } \\
\text { times }\end{array}$ \\
\hline Housing size & $\begin{array}{l}108 \text { smaller } 1990 \\
158 \text { smaller } 2000\end{array}$ & $\begin{array}{l}\text { constant } \\
\text { constant }\end{array}$ & $\begin{array}{l}108 \text { higher } 1990 \\
108 \text { higher } 2000\end{array}$ \\
\hline $\begin{array}{l}\text { "Other" Elec- } \\
\text { tricity Use }\end{array}$ & $\begin{array}{l}\text { calculated by } \\
\text { model }\end{array}$ & $\begin{array}{l}\text { calculated exter- } \\
\text { nally to increase } \\
\text { by losper house- } \\
\text { hold }\end{array}$ & $\begin{array}{l}\text { calculated ex- } \\
\text { ternally to } \\
\text { increase by } \\
188 \text { per house- } \\
\text { hold }\end{array}$ \\
\hline
\end{tabular}

commercial seator

\begin{tabular}{|c|c|c|c|c|}
\hline $\begin{array}{l}\text { Economic and } \\
\text { Demographic } \\
\text { Projections }\end{array}$ & low & projections & base projections & $\begin{array}{l}\text { high projec- } \\
\text { tions }\end{array}$ \\
\hline Fuel Prices & low & projections & base projections & $\begin{array}{l}\text { high projec- } \\
\text { tions }\end{array}$ \\
\hline $\begin{array}{l}\text { Fuel Choice } \\
\text { Assumption }\end{array}$ & $\begin{array}{l}\text { some } \\
2000\end{array}$ & oil used by & $\begin{array}{l}\text { little oil used } \\
\text { by } 2000\end{array}$ & $\begin{array}{l}\text { little oil } \\
\text { used by } 2000\end{array}$ \\
\hline
\end{tabular}


TABLE III (CONt'd)

\begin{tabular}{|c|c|c|c|}
\hline & Low case & Base case & High case \\
\hline Conservation & $\begin{array}{l}\text { BPA budgeted } \\
\text { programs }\end{array}$ & $\begin{array}{l}\text { BPA budgeted } \\
\text { programs }\end{array}$ & $\begin{array}{l}\text { s lower penetra- } \\
\text { tion of BPA } \\
\text { budgeted pro- } \\
\text { grams }\end{array}$ \\
\hline $\begin{array}{l}\text { Floor space per } \\
\text { Employee }\end{array}$ & 108 lower & constant & 10: higher \\
\hline $\begin{array}{l}\text { Building Owner } \\
\text { Discount Rate }\end{array}$ & lower & base & higher \\
\hline $\begin{array}{l}\text { Equipment Life- } \\
\text { times }\end{array}$ & base lifetimes & base lifetimes & $\begin{array}{l}\text { longer life- } \\
\text { times }\end{array}$ \\
\hline \multicolumn{4}{|l|}{ Industrial sector } \\
\hline $\begin{array}{l}\text { Economic and } \\
\text { Demographic } \\
\text { Projections }\end{array}$ & low projections & base projections & $\begin{array}{l}\text { high projec- } \\
\text { tions }\end{array}$ \\
\hline Fuel Prices & low projections & base projections & $\begin{array}{l}\text { high projec- } \\
\text { tions }\end{array}$ \\
\hline Aluminum Plants & $\begin{array}{l}\text { Alumax not built; } \\
20 \text { of existing } \\
\text { capacity closed }\end{array}$ & Alumax built & Alumax built \\
\hline $\begin{array}{l}\text { Labor Product- } \\
\text { ivity }\end{array}$ & lower projection & base projection & $\begin{array}{l}\text { higher pro- } \\
\text { jection }\end{array}$ \\
\hline
\end{tabular}



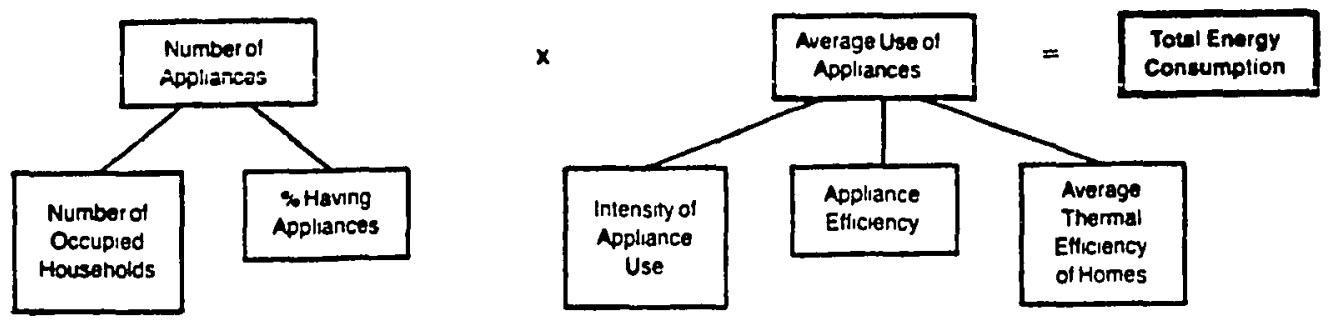

Reprinted from BPA, $1982 \mathrm{a}: 68$

Elqure 8. Schematic: ORNL residential energy use model

The fundamental equation represented in the model

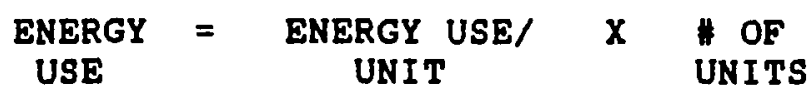

The basic unit in the case of the residential sector is the appliances. The model determines the number of appliances of a given type by multiplying the number of occupied households (calculated using the BPA housing model discussed earlier) by the percentage having appllances (or the saturation rate). The average use per appliance is computed by multiplying the estimated apoliance efficiency for average use) relative to the base year of 1979 , times a usage intensity factor describing the level at whlch an appliance is operated. Finally, for the heating and air conditioning end uses, a thermal integrity index, describing the shell characteristics of the homes modeled (i.e. how efficiently the homes hold heat), also enters into the calculation of average appliance use.

The ORNL Resldential Model is based in 1979, and projected changes in such factors as appliances efficlency 
or saturations are calculated as indices of base year values given as inputs. The model distingulshes between new (1.e. constructed during the forecast year) and existing (1.e. constructed before the forecast year) homes. New equipment efflciencies, appliance saturations, usage intensitles, and thermal integritles are computed for new homes while, for existing homes, the values for these varlables are weighted averages of previous years' values. Conservation policy options are tested through the components modeling appliance efficiency and thermal integrlty by substituting exogenously determined index values for those calculated as a response to fuel price changes. This capability constitutes one of the two major strengths of the ORNL model relative to others used to determine residential energy use. The other strength of the model is the detailed breakdown of its output. The ORNL Resldential Model projects energy use for each of 72 distinct housing type/appliance/fuel type categories over the entire forecast period, recognizing three housing types (single-family, multiple-family, and mobile home), eight appliances or end-uses (space heating, air conditioning, water heating, refrigeration, freezing, cooking, lighting, and 'other'), and three fuels (electricity, natural gas, and oill. Forecast totals are produced by aggregating across the varlous energy use categories. 
To understand the capabilities and limitations of this model fully, it is necessary to look at each of the components identifled above individually and in greater detall. Such an examination follows Table IV below which summarizes the varlables used as inputs to the model (economic/ demographic profections prepared by Economic studies are denoted by an asterisk).

The average use component calculates the efficiency of the average appliance servicing the eight end uses recognized by the model for each of the three housing types. Figure 9 charts the logic flows of the component's operation.

1979 is the base year for all average use calculations. The values for this year were developed from the residential survey performed by Elrick and Lavidge for BPA and PNUCC and are glven as inputs. After 1979, the average use values for newly constructed homes ( $i . \pm$. "new" in the forecast year) are estimated as a proportion of the 1979 base year value.

The index values (1.e. the proportion of the base year values) for new construction after 1979 are derived using efficiency/cost tradeoff curves lalso referred to as technology curves). These curves embody the concept of lifecycle cost minimization which predicts that homeowners will offset the higher operating costs of appliances resulting from increased fuel prices by investing more initial capital for more efficient equipment. The inputs to these equipment 
TABLE IV

SUMMARY OF RESIDENTIAL MODEL INPUTS

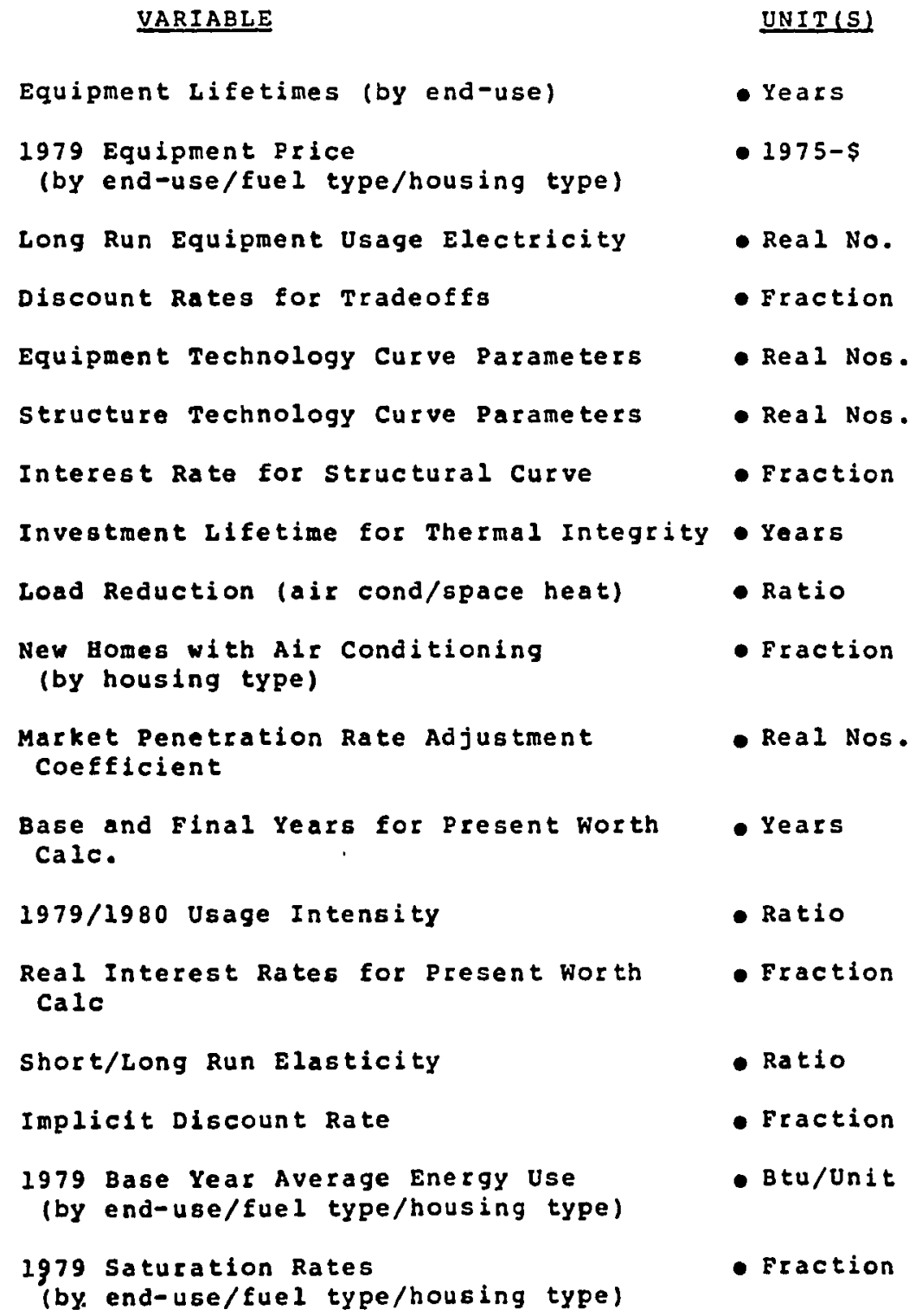


TABLE IV (Cont'd)

YARIABLE

1979 Penetration Rates

(by end-use/fuel type/housing type)

Housing Stocks (1979-2000) (housing type)

* New Construction (1979-2000)

(by house type)

*Avg. House Size (1979-2000)

(by housing type)

-Indexed Fuel Prices (1979-2000) (by fuel type)

- Indexed Per Capita Income (1979-2000)

Number of Units Retrofit (1979-2000) (by housing type)

Retrofit Thermal Integrity

Conservation Measures (1979-2000)

(by housing type)

- new home construction

- water heater wraps

- shower flow restrictors

- faucet flow restrictors

- low flow shower heat

- heat pumps

Reduction Factors for Measures
UNIT(S)

- Fraction

- Milizon Units

- Million Units

- Praction of 1979

- Fraction of 1979

- Fraction of 1979

- Millfons of Units

- Real Nos.

- No. of Units Affected

- Fractions 


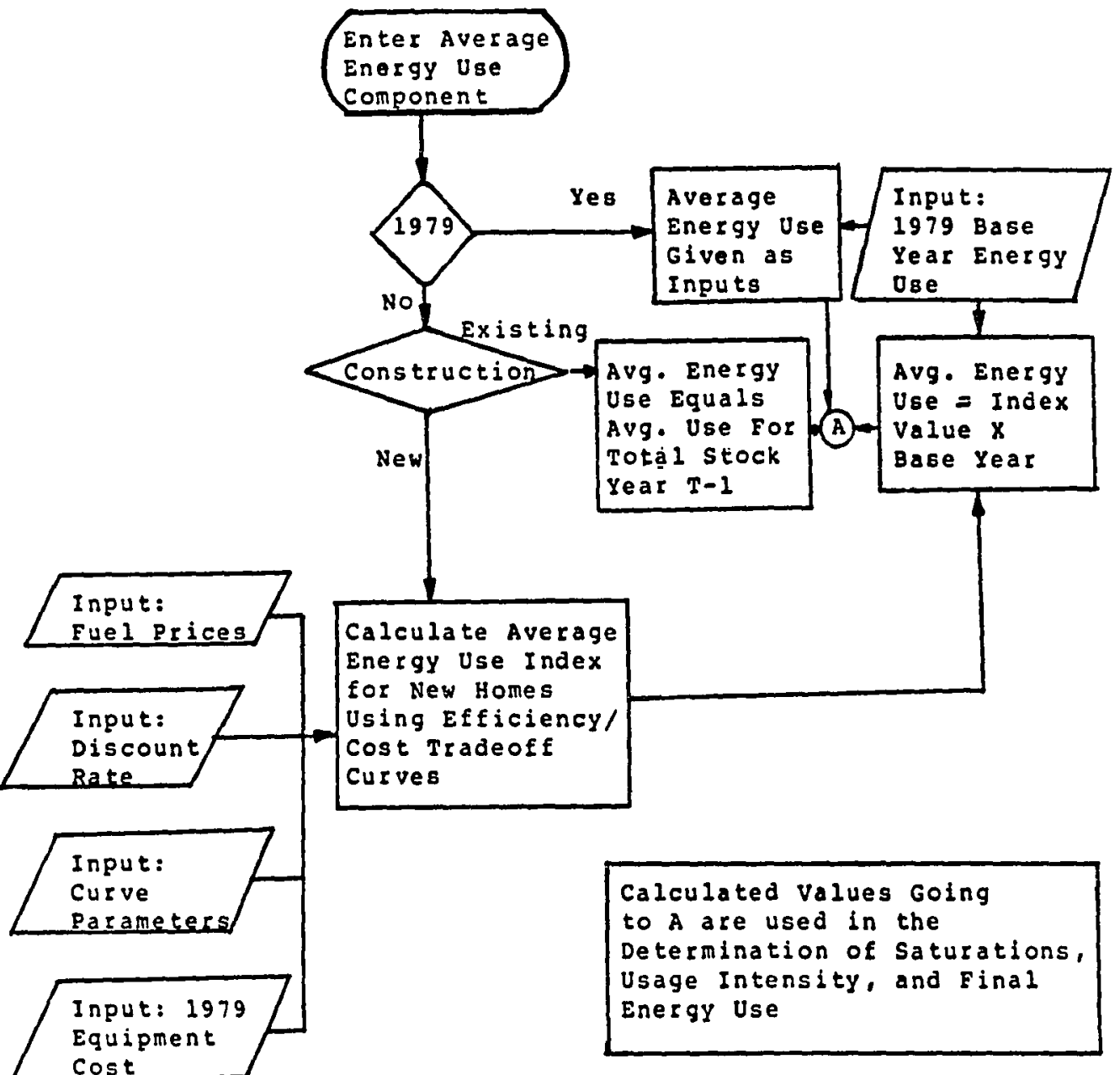

Eigure 2. Calculation of average energy use in the ORNL residential model. 
efficiency/cost tradeoff curves are Euel prices, 1979 equipment costs, a discount rate (representing the homeowners perceived payback period for capital investment), and the Rarameters for the curves. The resulting index value is multiplied by the 1979 base year value to yield the average use for a given type of appliance in a given type of new home.

For existing homes, the average use is assumed to equal the average use value calculated for the total stock of homes for the year prior to the forecast year (e.g. for existing homes in 1987 the average use equals that of the total 1986 stock). The derivation of this value is detalled below in the section describing the final energy use calculation.

The thermal integrity component, describing the efficiency with which homes maintain their interlor temperatures, functions according to a logic virtually identical to that of the average use component. This logic is mapped in Figure 10. Thermal integrity calculations, as the name suggests, apply only to those modeled end-uses speciflcally concerned with regulation the internal temperature of dwellings: hence the calculations are not apolicable to end-uses other than space heating and air conditioning. As is the case with all components in the residentlal model, the thermal integrity component is referenced to the base year 1979. Thermal integrity base year values are given as In- 


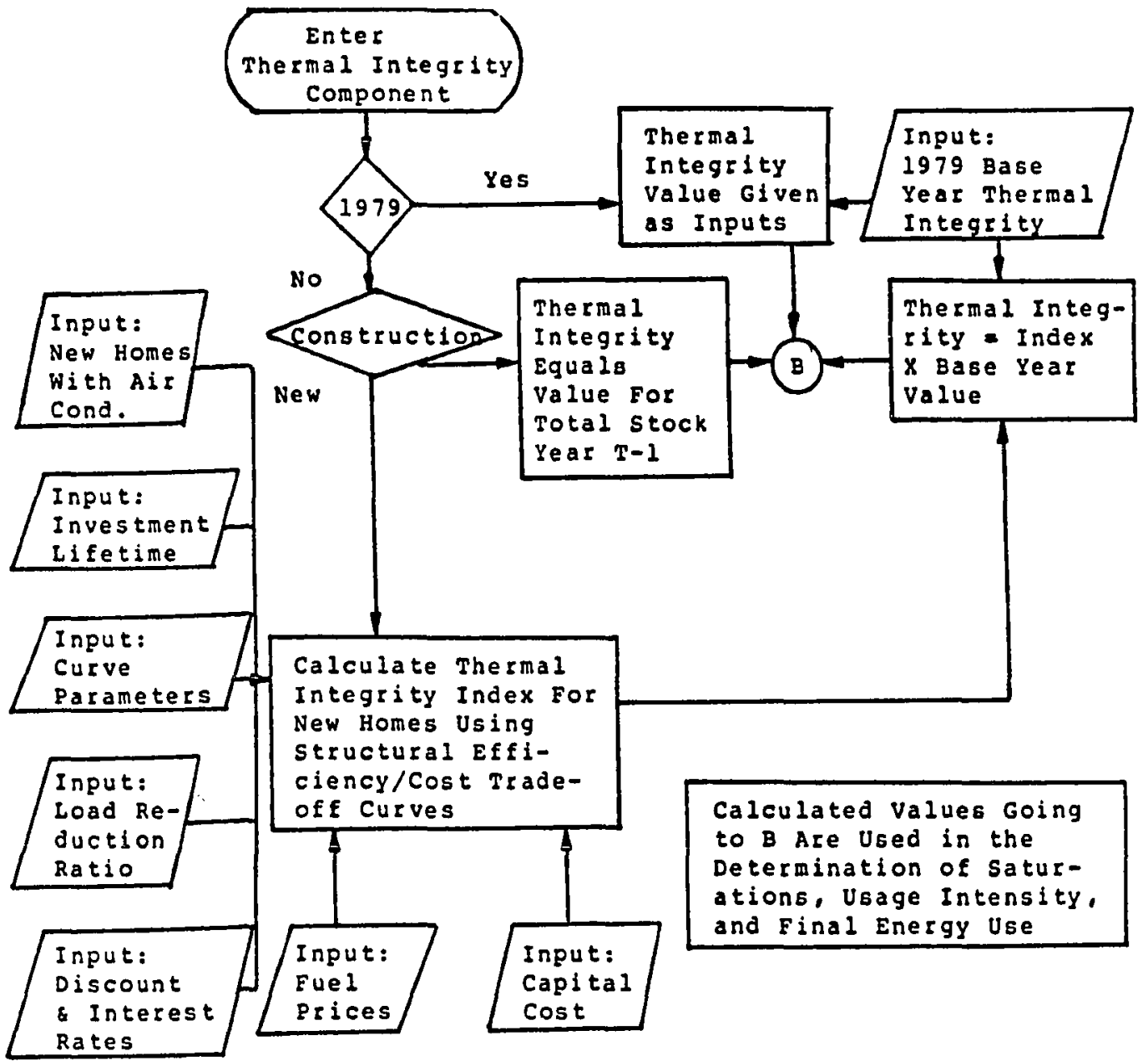

Eigure 10. Calculation of thermal integrity in the ORNL residential model. 
puts to the model and calculated as an index value for new homes in subsequent years (1.e. 1979=1.0 for index calculations).

For years after 1979 the thermal integrity index for new construction is calculated using structural efficiency/ cost tradeoff curves, which are conceptualiy identical to the curves used in the average use calculations except that they apply to shell characteristics rather than appliance efficiency. (For existing construction after 1979 the previous year's thermal integrity index for the total stock of homes is maintained. Its calculation is described below in the section of the final energy use calculation). A number of variables enter into the life-cycle cost calculation of thermal integrity: the anticipated investment lifetime for the thermal integrity measure, fuel prices, the initial capital cost of the measure, discount and interest rates, the fraction of new homes with alr conditioning, the load reduction ratio for homes with alr conditioning (i.e. air conditioning loads divided by space heating loads), and the curve parameters. Thermal integrity is determined, for new homes, by multiplying the resulting index by the base year value.

The saturation component calculates the proportion of homes having a certaln type of appliance using a specific fuel. This proportion is referred to as a 'saturation' when describing the total stock of homes and as a 'penetration' 
when applied to the vintage comprised of new homes. The logic of the calculation is represented in Figure 11.

In 1979, the base year of the ORNL Residential Model, both the saturation for the total stock of homes and the penetration of appliances in the 1979 vintage are given as inputs. After 1979, saturations and penetrations are calculated by the model. For existing homes, the saturation is equal to the saturation for the previous year's total stock of homes. For new homes, the fuel and appliance choice is calculated using a series of inputs. These specified by the user (i.e. In the input deck for the model) include fuel prices, per capita income, 1979 equipment prices, discount rates for tradeoffs between appliances choices, and a market penetration rate coefficlent (adjusting the calculation for market imperfections). Two other inputs to the calculation are produced internaliy by the model. The first is the index value calculated in the average use component for new homes. The second is a similar index calculated by the thermal integrity component. The latter is applied only if the end-use under consideration is elther space heating or air conditioning.

The usage intensity component, depicted in Figure 12, models behavioral responses of homeowners in response to changing fuel costs. While over the long run, owners respond by replacing old appliances with newer, more energyefficlent equipment, their short-term response is to curtail 


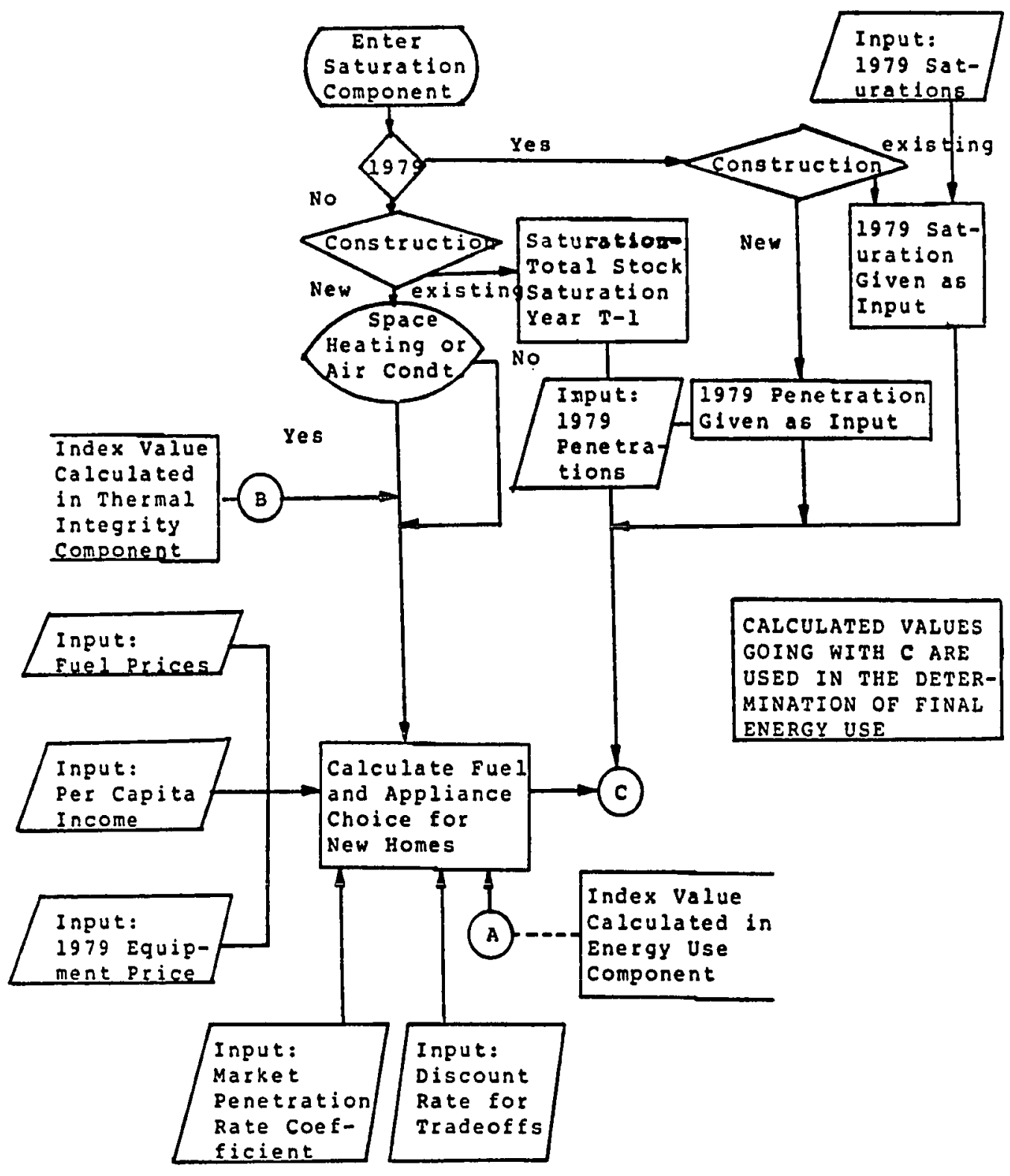

Elqure 11. Calculation of heating fuel saturations in the ORNL residential model. 


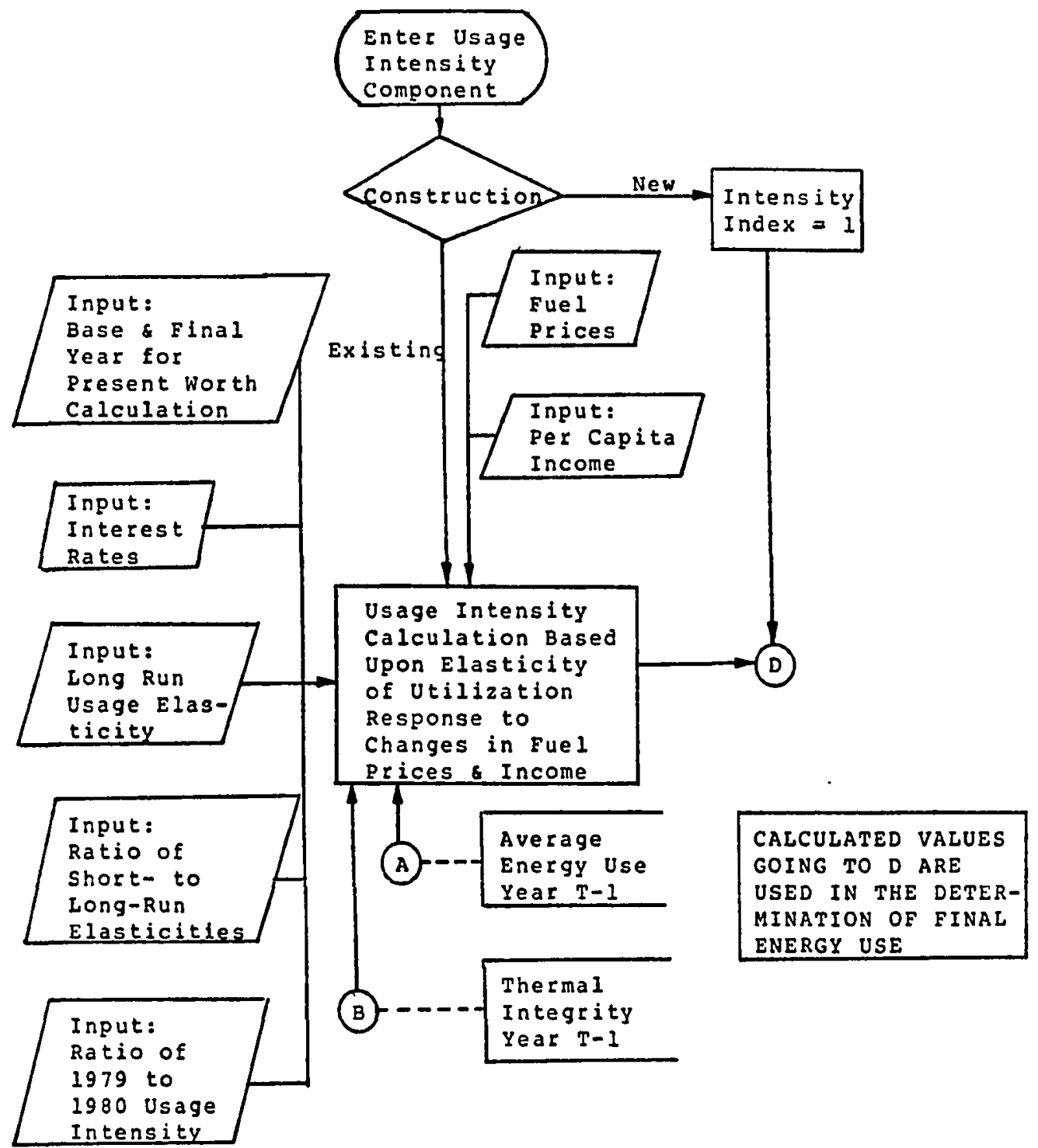

Eiqure 12. Calculation of appliance usage intensity in the ORNL residential model. 
consumption (i.e. reduce the intensity of appliance usage) to offset increased energy costs.

For newly constructed homes the usage intensity index equals 1, denoting that new appliances are receiving full expected use. This is not surprising since the average use algorithm specifles that new equipment cholces reflect and optimal life-cycle cost response to fuel prices in the year of selection: hence the equipment may be cost-effectively operated at expected levels during that year. For existing construction, however, full usage intensity is scaled downward (or, potentially, upward, should Euel prices decrease) to account for changes in fuel prices taking place between the year the appliance was installed and the forecast year. The calculation of the usage intensity index is based upon the elasticity of the homeowner's appliance utilization response to changes in fuel prices and income. User-specified inputs to this calculation include, in addition to fuel prices and per caplta income, interest rates, a long-run usage elasticity, the ratio of short-to leng-run elasticities, the ratio of 1979 to 1980 usage intensities, and the base and final years for the present worth calculation. Additional inputs to the calculation which are developed within the model, rather than specified by the user are the average eneray use index for the prevlous year's total stock of homes (by type) from the previous year and, similarly, if the appliance under consideration is used for 
space heating or air conditioning, the average thermal integrity index for the previous year's total stock (also by housing type). The usage intensity index is used to scale energy use values in the final energy use calculation.

The final energy use calculation, represented graphically in Figure 13, deplets how the "products" of each of the components are combined to produce the final model outputs (which are disaggregated by housing type, fuel type, and end-use). This calculation (mirroring that of Figure 8 but with increased detaill is carried out both for newly constructed housing units and for the total stock of homes. Conservation policy testing is carried out at this point by modification of values entering into the calculation.

For new homes, the calculation of energy use is a stralghtforward multiplication. The number of new homes (i.e. new construction) is multiplied by the percentage of new homes having appliances (derived in the saturation component) yielding the number of apoliances in new construction. The average use of appliances in new construction is calculated as a product of average use, usage intensity, and (if the end-use in question is space heating or air conditioning) thermal integrity. The resulting values for energy use per appliance and number of appliances are multiplied together to yleld energy use for new construction in the forecast year. 


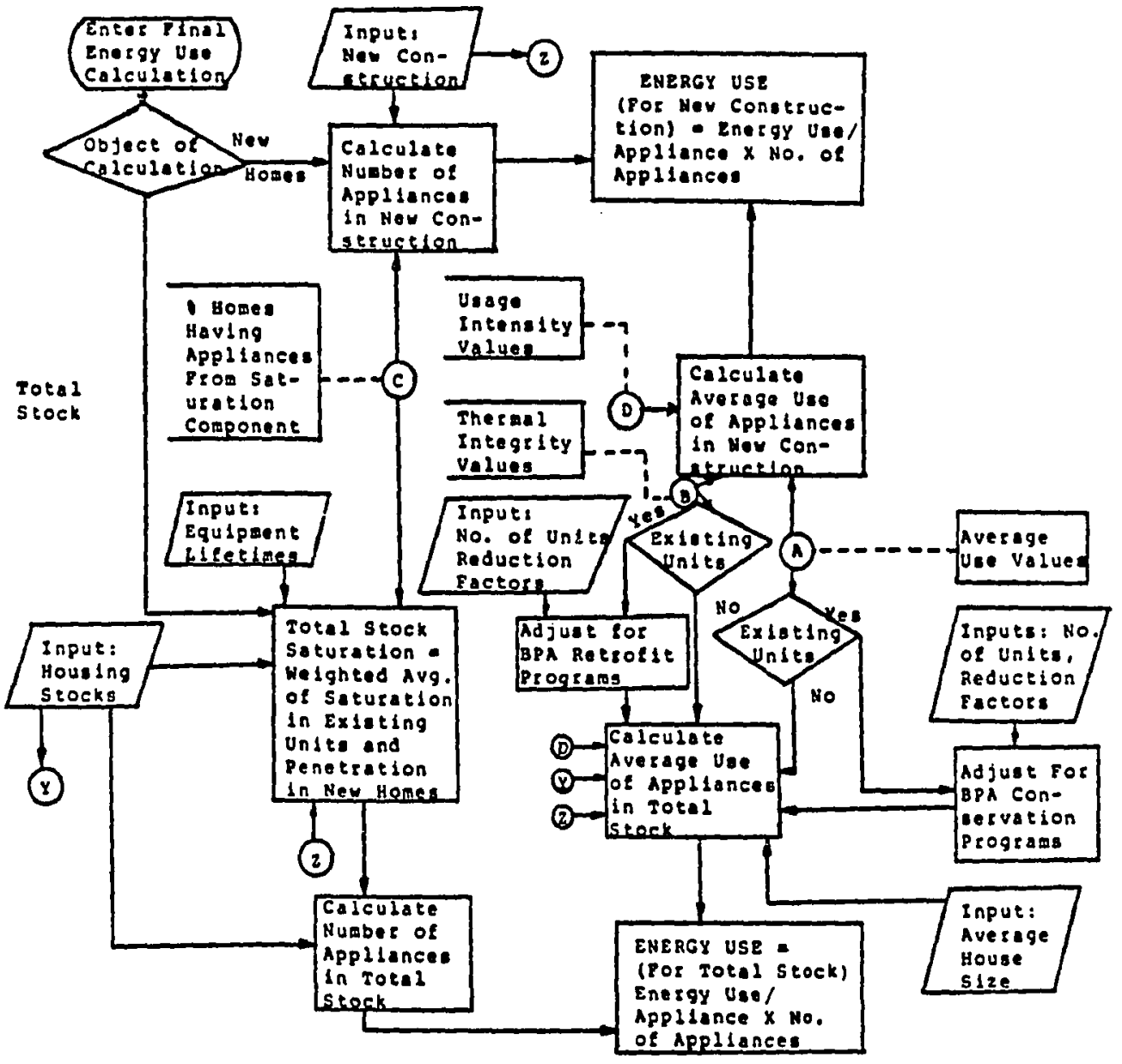

Eiqure 13. Final energy use calculation for the ORNL residential model. 
For the total stock of homes, the final energy use calculation is somewhat more complicated. Summarily, it Involves taking a welghted average of energy use in new and existing units, adjusting for demolition of older homes and replacement of obsolete appliances, and applying conservation measures to existing units. A saturation of the total stock of homes is calculated as the weighted average of the previous year's appliance saturation for the total stock and penetration rates for appliance in new homes (these saturations are weighted by the total housing stock and new construction). Adjustments are made to the weighting of existing units to account for demolitions of older homes and the replacement of portion of older appliance based upon user-specified equipment lifetlmes. The replacement appliance mix reflects that of new units, rather than the previous year's total stock. Multiplying the total stock saturation by the total housing stock for the forecast year ylelds the total number of appliances in the residential stock. The average use of apoliances in the total stock of homes is calculated as the product of the weighted averages of the outputs of usage intensity average use, and (where appropriate) thermal integrity components. If BPA conservation programs are assumed to be in effect adjustments are made to thermal integrity (for retrofits) or average use values, scaling then down by externally determined reduction factors in proportion to the number of undts affected. For 
space heating and air conditioning end-uses the average use calculation is further scaled by an index value for the average house size for the total stock (relative to the average 1979 house). Final energy use for the total stock is determined by multiplying number of appliances by energy use per appliance.

The ORNL model produces sector energy consumption totals from the "bottom-up" first, projecting demand for each of the 96 end-use/fuel type/housing type combinations and arriving at final totals by means of aggregation. Public and private forecasts are developed simply by running the appropriate input sets through the model. Baseline, high, and low forecasts are distinguished not only by the sets of inputs employed but by differing sets of operating assumptions. The size of new homes, treated as constant in the base case, is assumed to be, in the low case, 108 smaller by 1990 and $15 \%$ smaller by 2000, and, in the high case, 108 higher by 1990 . Appliance lifetimes were lengthened, in comparison to low and base cases, for the high case: from 23 to 29 years for space heating, from 13 to 16 years for air conditioning and water heating, from 19 to 24 years for refrigeration, from 21 to 26 years for freezing, from 18 to 23 years for cooking, and from 10 to 13 years for 'other' (1ighting was assumed to have a 1 year lifetime irrespective of which case was under consideration). Because of the introduction of new appliances such as VCRs and 
home computers into the residential sector, the 'other' end use for electricity was manually adjusted upward by $10 \%$ per household for the base case and 188 per household for the high case (internally calculated values were unmodified for the low case). Finally, for the high case the consumer discount rate was raised, relative to low and base cases, and BPA budgeted programs were assumed to have a slower penetration.

To illustrate how the ORNL Residential Model operates, the following description of its operation in the year 1990 is provided.

The average use component determines the efficiency of appliances in the newly constructed 1990 vintage of homes in response to changes in fuel prices. Existing homes are assumed to display the average use value of the total stock of homes for 1989 .

Similarly, the thermal integrity component determines the structural efflciency of 1990 homes, whlle applying the 1989 total stock value to existing homes. Thermal integrity calculations are applicable only to two of elght end-uses, space heating and air conditioning.

The saturation component calculates the penetration of new appliances for the 1990 vintage of homes. The 1989 saturation for the total stock of homes is applied to exlsting homes. 
The ysage intensity component derives a "scaling factor" for the average use value for existing homes, representing the home owner's behavioral response to changes in income and fuel prices. For new homes, the "scaling factor" is equal to 1.0 (i.e. no behavioral adjustment is made).

Einal energy use calculations are made for both new homes and the total 1990 stock. New 1990 construction is multiplied by the saturation, a average use, usage intensity, and, where appropriate, thermal integrity values for new homes to yield a energy use value. This is carried out for each end-use/fuel type/housing type combination. For total 1990 stock, the total number of housing units is multiplied by weighted averages of the values of new and existing 1990 homes for appllance saturation, average use, usage intensity, and, for two end-uses, thermal integrity. Adjustments occur to account for houses torn down in 1990, appliances replaced (in proportion to their expected lifetimes), and projected end-use specific BPA conservation programs. These are also projected for each end-use/fuel type/housing type combination. Final consumption values for each fuel, both for new homes and the total residential stock, are determined by aggregating categorical values. The ORNL Commerclal Model. The ORNL Commercial Model was developed at Oak Ridge National Laboratory in 1977 for the U.S. Department of Energy, princlpally by Dr. Jerry 
Jackson. Ilke the ORNL Residentlal Model (which, of the two, was completed first) the commerclal model was designed to address a speciflc variety of policy consideration. Not surprisingly, its basic hybrid engineering/econometric structure, depicted in Figure 14, closely resembles that of the residential model.

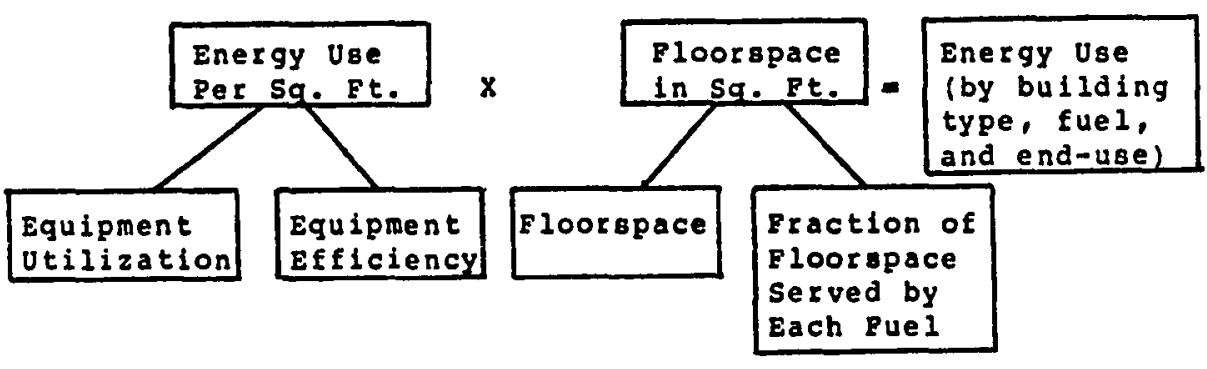

Eiqure 14. An overview of the structure of the ORNL model of commercial sector energy use.

In the commercial sector, this basic unit is a square foot of floorspace. The model projects the floorspace for ten types of commercial buildings over the forecast period (by means of either an econometric or stock-flow approach). It then segments or partitions this floorspace by the saturations of four basic fuels (1.e. the fraction of floorspace served by each fuel). Next it determines the basic efficiency of equipment for each of five different end-uges (1.e. Its operating energy use per square foot) for each new or refitted vintage. Finally, it determines the level of ut 11ization of the equipment the short-term, be- 
havioral conservation response to changes in fuel prices. Most basically, the commercial model differs from the residential model in three ways. First, the commercial model is based in 1970 rather than 1979. While this sometimes makes it more difficult to obtain needed data inputs, it facilitates model calibration, since it must "track" ten years of history before reaching the forecast period. Second, the model recognizes a different array of building, fuel, and end-use type. Commercial floorspace is broken down into ten building types (retail-wholesale, office, auto repair, warehouse, school, health care, public, religious, hotel, and miscellaneous), four fuel types (electricity, natural gas, oil, and other), and five end-uses (heating, cooling, water heating, lighting, and other). Flnally, rather than simply distinguishing new from existing buildings, the commercial model treats each vintage (1.e. all the floorspace constructed in a given year) separately. Since the Eirst vintage modeled is 1924 construction, by the year 2000 (the forecast horizon) a total of seventy-seven distinct vintages are being dealt with separately.

The ORNL Commerclal Model, I Ike the residential model, operates from the bottom up. For each forecast year it calculates the energy use for every bullaing type/fuel type/end-use comblnation (a total of 200) for each vintage and aggregates these calculations to arrive at a final energy use total. 
While the basic model structure, outlined above, is relatively simple the actual calculations are somewhat more complex. To clarify the commercial model's operation further, each component will be descrlbed individually in greater detail, and a description of the calculations carrled out for an example forecast year, 1990, provided. A summary list of model inputs is presented in Table $V$ (an asterisk denotes those inputs developed by the Economic studies section as economic/demographic projections.)

Although the ORNL Commercial Model is based in 1970 , the floorspace component begins projection square footage in commercial bulldings after 1980 . This is because, sometime after receiving the model from ORNL, BPA was able to obtain ten aditional years of historic data on regional floorspace.

Figure 15 depicts the fashion in which the floorspace total for each vintage constructed between 1924 and 2000 are calculated. For vintage constructed prior to 1981, the "calculation" consists of merely reading the historical values for 1924 total standing stock (1.e. all commercial construction built up to 1924) and the annual floorspace additions from 1925 to 1980 from the input tape. These Eloorspace values were estimated at ORNL based on F.W. Dodge construction data. For vintages constructed after 1980, one of two floorspace projection submodels may be employed. 
TABLE V

SUMMARY OF COMMERCIAL MODEL INPUTS

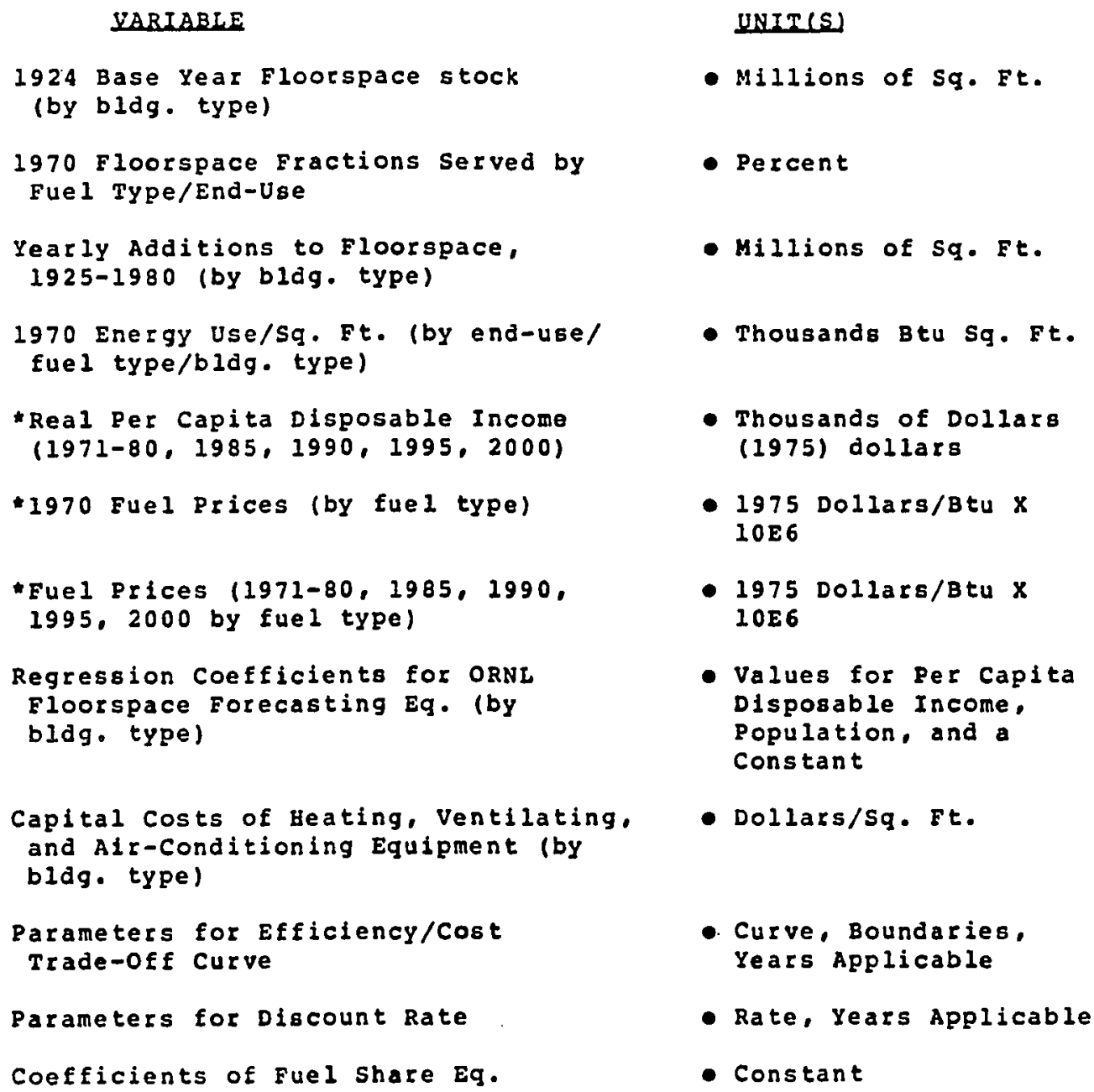




\section{YABIABLE}

Policy Options Building standards

Tax Credits

Grants Program

(Schools Hospltals)

Retrofit Program

\section{$\operatorname{unTT(S)}$}

- Applicable Years

- Applicable Years, Credit Percentage

- Applicable Years. Expenditure/Sq. Et. Reducing Effective Equipment Costs

- Applicable Years, Percent Reduction in Energy Use/Sg. Ft.

e* aditional inputs for Battelle Floorspace component * *

- Retail-wholesale Employment

- Einancial. Insurance and Real Estate - Government Employment

- Total Personal Income (PI)

- Total Labor and Proprietor'B Income

- Total Population

- Population Less than 5

- Population Less than 18

- Population Greater than 65

- Interest Rates

- National GNP Deflector

Costs of Construction
- No. of Employees

- No. of Employees

- No. of Employees

- Nominal $\$$

- Nominals

- No. of Persons

- No. of Persons

- No. of Persons

- No. of Persons

- Rate

- Deflator

- Nominal 


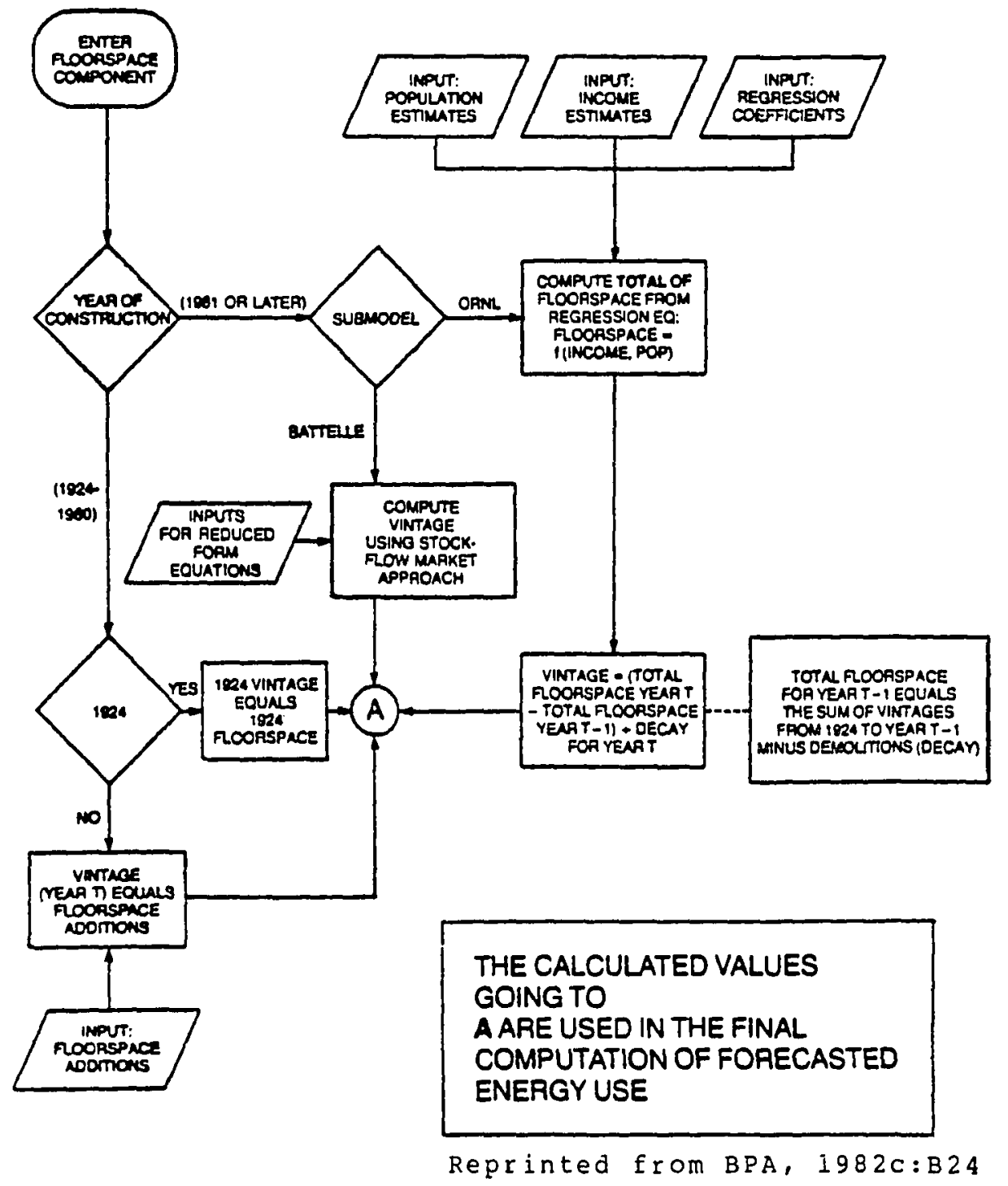

Eiqure 15. Calculation of floorspace additions in the ORNL commercial model. 
The original ORNL submodel calculated Eloorspace econometrically. The basic regression equation computed the total floorspace stock for a given year as a function of population and real per capita disposable income. The new construction for that year (i.e. the new vintage) was derived by taking the difference between the total floorspace for the year under consideration and the previous year's floorspace total. This econometric submodel was used for the December 1981 (Stage One) technical revlew of the model but not for elther the draft or final forecasts.

For BPA's offlclal forecast, a new floorspace projection submodel, developed by Battelle's Pacific Northwest Laboratories, was inserted into the ORNL model. The Battelle submodel calculates annual additions (not total stock) by means of a somewhat more sophisticated stock-flow approach. Thls approach assumes that new construction is a function of asset demand, land requirements, and construction services. The Battelle submodel was assessed to be preferable to the ORNL submodel for the final forecast for two basic reasons: its theoretical underpinnings were more sound from an economic perspective and the distribution of floorspace among building categorles was intuitively more correct (i.e. unlike the ORNL submodel, there was no large, unexplained growth of categories such as 'Auto Repair'). One further modification of the floorspace calculation was performed by BPA stafe which did not alter the manner in 
which floorspace was calculated but did affect the resulting values. The data obtalned from a survey of non-residential bulldings carried our for BPA by Westat Inc. confirmed a widely held suspicion that the F.w. Dodge data used by both ORNL and Battelle in estimating their respective submodels systematically undercounted annual additions by about 50 to 60 percent.

To remedy this problem an exogenous calculation was performed to estimate 1980 and 2000 Eloorspace. From the non-residential building survey a ratio of floorspace per employee was developed for 'Trade', 'Service', and 'Office' employment categories. Multiplying these ratios by corresponding employment estimates for 1980 and 2000 yielded target floorspace totals. The computer program for the commerclal model was then modifled to accept a set of interactive, user-specified floorspace mutipliers to scale the yearly floorspace additions so as to hit target totals. since the F.W. Dodge undercounting was assumed systematic, the same multiplier was applied for all bullding types. In effect, for the final forecast, the quantity of floorspace was determined exogenously while the distribution among building categories was a product of the historical data and the operation of Battelle submodel.

. The second component of the ORNL model (deplcted in Figure 16) determines the efficiency of the equipment used to service commerclal floorspace (1.e. energy use per square 


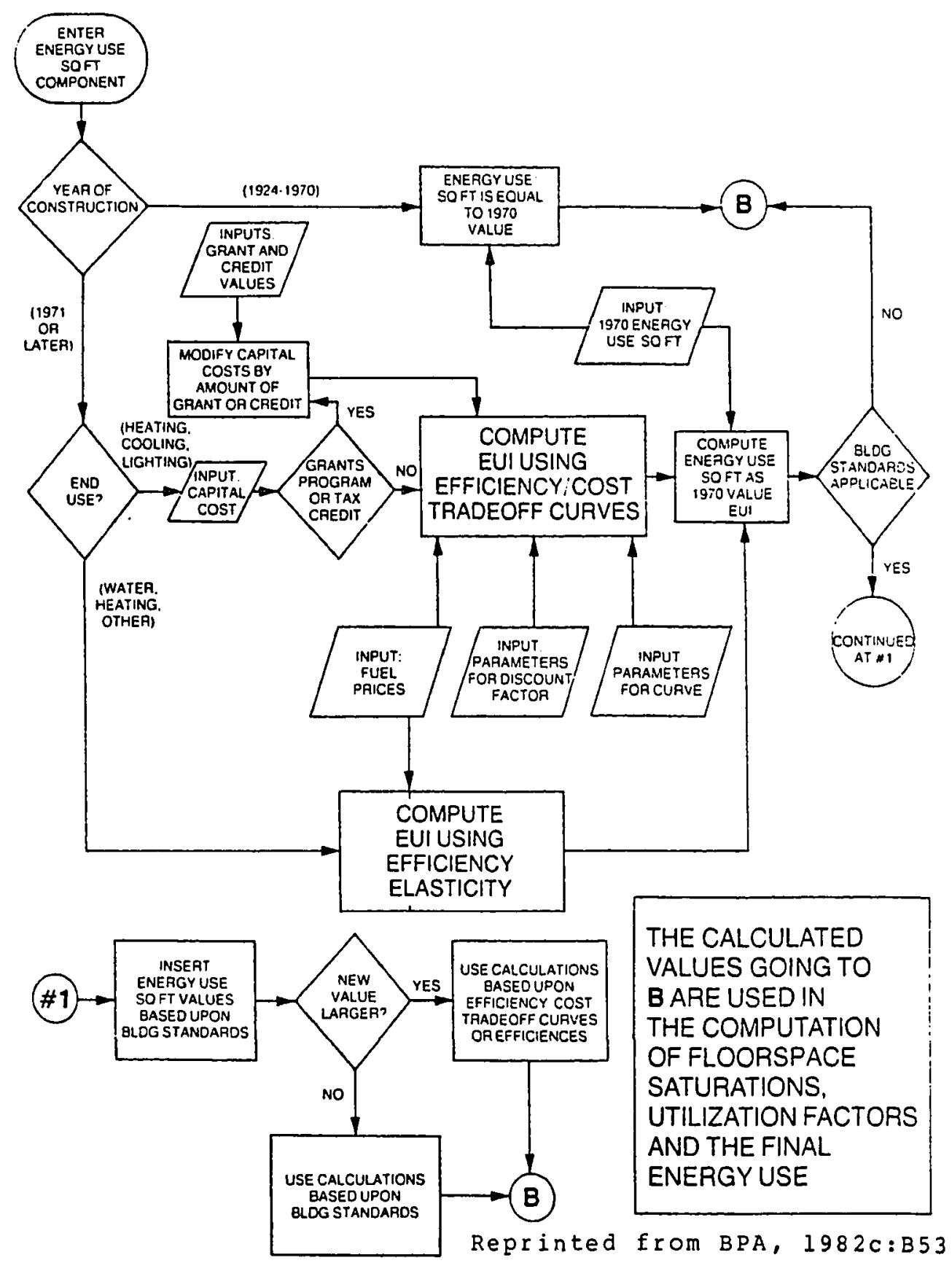

Eiqure 16. Calculation of energy use per square foot in the ORNL commercial model. 
foot). This calculation is performed for ach building type/fuel type/end-use combination for each vintage (though only for the years when that vintage is constructed or refitted with equipment).

For all vintages constructed prior to 1970, the energy use per square foot is set equal to a historlcal base year yalue representing the average efflciency for the total standing stock (1.e. vintages constructed 1924-1970). For forecast years 1971 through 2000 the energy use per square foot is obtained by multiplying the base year value times an energy utilization index (EUI), representing the proportion of the base year value used in a given forecast year.

The EUI is calculated by one of two means depending upon the end-use under consideration. For water heating and "other" end-uses an efficlency elasticity (developed econometrlcallyl is employed which describes changes in equipment efficlency resulting from changes in fuel price. For heating, cooling and lighting a series of efficlency/= cost tradeoff curves (one for each end-use) developed from engineering analysis conducted at ORNL are used. These curves, in effect, plot a relationship between the capital cost of equipment and Its efficiency. The theoretical assumption behind the curves is that owners will seek to minimize the life-cycle costs associated with the equiphent fitted to their bulldings. In other words, as fuel prices increase owners will offset anticipated increases in opera- 
ting costs by purchasing more expensive, but more efficient, equipment. In addition to the price of fuel, the owner's discount rate for the anticlpated payback period for the capital investment, tax credits, and subsidies in the form of grants for institutional buildings are factors which affect a equipment selection.

It is by means of the equipment efficiency calculation that the ORNL model explicitly addresses conservation through grants and tax credits (both of which function as subsidies which increase the initial capital costs which owners axe willing to bear), discount rates (a change in discount rates can be used to model the alterations in perception prompted by such information as audit programs would generate), and building standards. The modeling of building standards is accomplished by inserting an array of EUIs within the computer program which correspond to the fraction by which base year energy use per square foot values would need to be multiplied to obtain efficiencies matching ASHRAE 90-75 building codes. The model calculates EUIs based upon the fuel prices given as inputs and compares then to the building standard EUIs. If price-induced values are low (i.e. efficiency is greater) they are used. If the bullding standards are lower a welghted average of priceinduced and building standard EUIs is used, simulating an expected incomplete compliance with building codes. 
The ASHRAE 90-75 codes were effective in 1979 and were the only ones modeled for the forecast. A second, more strlngent set of codes are avallable to supplant the ones already in effect. Similarly, an alternative set of efficiency/cost tradeoff curves were avallable for use which represented the efficiency to be expected from equipment technology more closely approachlng its maxium performance predicted by engineering analysis. These curves were not used because highly counterintultive results during test runs suggested problems in their estimation.

The floorspace saturation component determines the fuel cholce for the stock of commercial floorspace. Its operation is depleted by the flowchart Figure 17. For the entire standing stock of bulldings constructed between 1924 and 1970 a single set of saturations or floorspace fractions (disaggregated by bullding type/fuel type/end-use) are used. For vintages constructed after 1971, the penetration of each of the fuels into new vintages is calculated in one of two ways.

For all non-heating end-uses the "calculation" is a trivial one. The penetrations are determined fudgmentally or by means of survey information. One hundred percent of each new vintage's Eloorspace is assumed to be served by electricity for lighting and "other" (1.e. electromechanical devices) end-uses. In the case of reta1l/wholesale buildIngs, 1008 of the floorspace is also assumed serviced by 


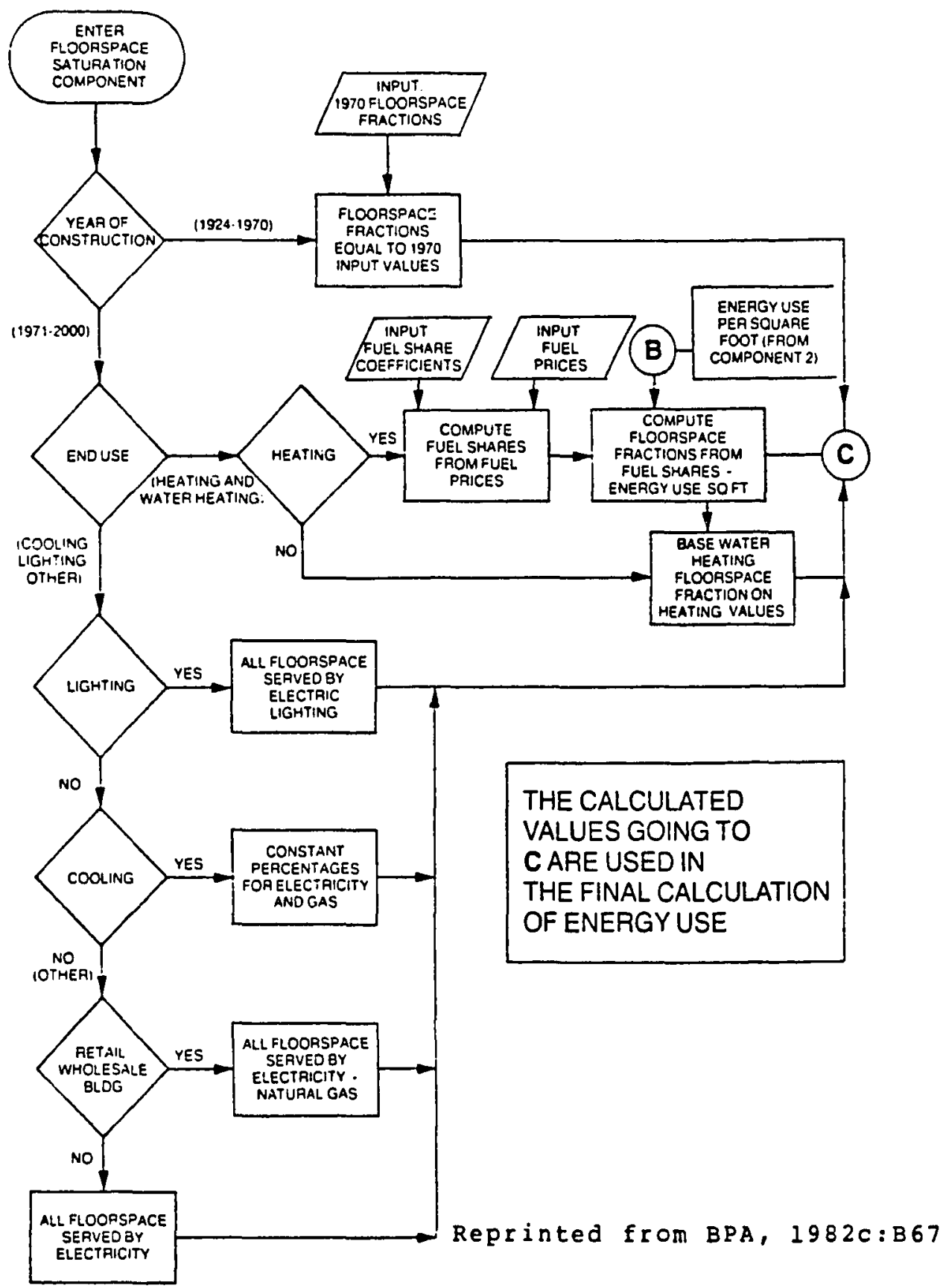

Flaure 17. Calculation of floorspace saturations by fuel and end-use in the ORNL commerclal model. 
natural gas (for a very small amount or cooking). For cooling, 50.38 of new floorspace is fitted with electric equipment; 3.88 with gas equipment. For water heating, 688 is electric, 278 is gas, and 58 is oll.

For heating, an actual calculation is carried out in two steps. First, fuel shares (1.e. the proportion of each fuel used in the commerclal sector as a whole) are calculated based upon the fuel prices in a given year and predetermined price elasticities. In the second step the fuel shares are converted into floorspace fractions using the energy use per square foot values calculated by the component previously described. Ratios are derlved for each fuel by dividing its fuel share by the energy use per square foot for heating using fuel. Each of these ratios is divided by the sum of the ratios to determine the floorspace fractions for each fuel.

The fourth and final component of the ORNL commercial model simulates the behavioral response of bullding owners and occupants to change in fuel prices land, concomitantly, equipment operating costs). Since it is unreasonable to replace equipment every time fuel prices increase, most building occupants respond by decreasing the intensity of its use. The equipment utilization component, represented graphically in Figure 18, produces what is, in effect, a scaling factor applied to the energy use per square foot. This value is a proportion of the full utilization assumed 


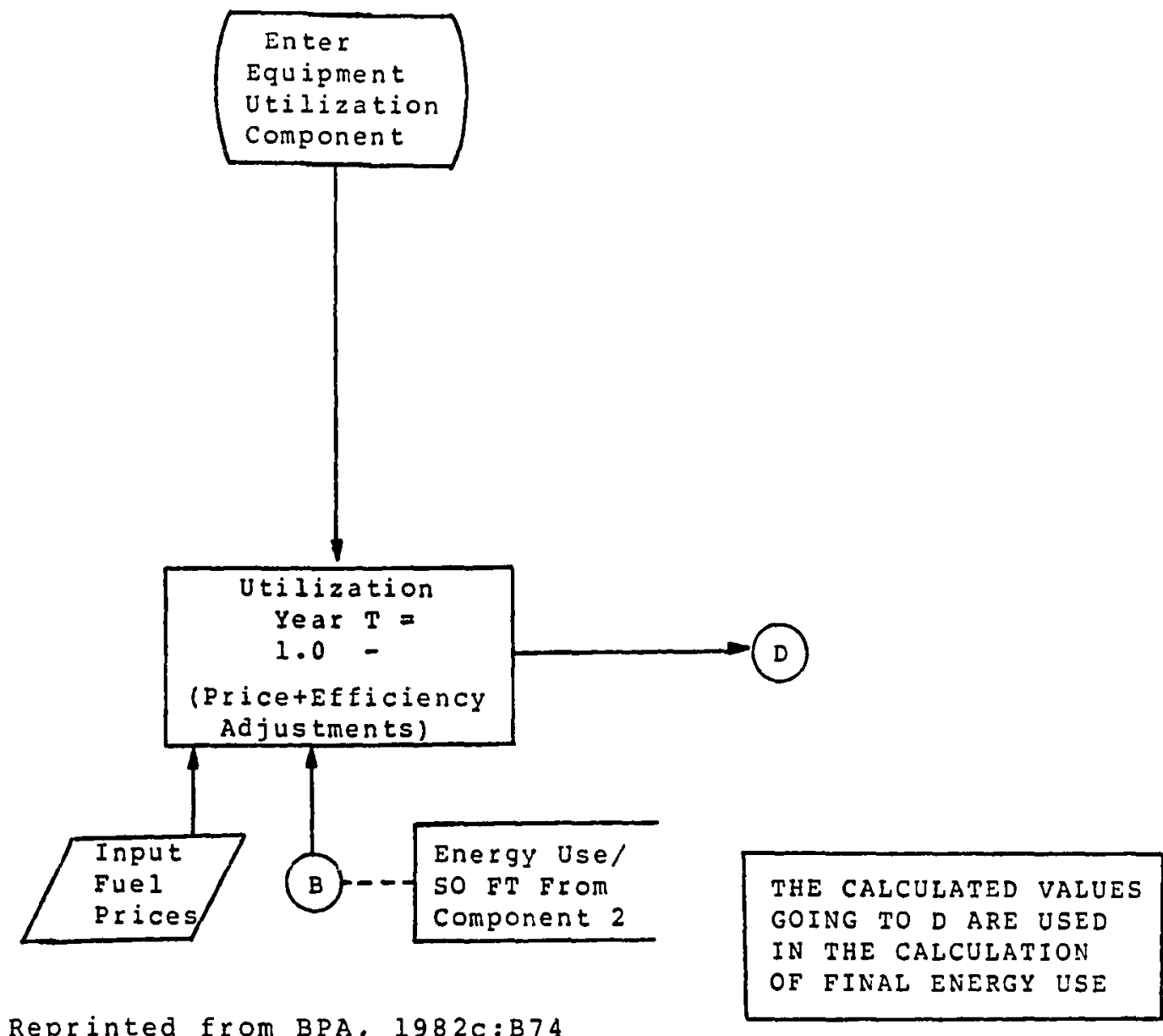

Elqure 18. Calculation of equipment utilization in the ORNL commercial model. 
for the year equipment is installed (1.e. In the year of its Installation, the equipment utilization factor is 1.0 ).

The calculation of the equipment utilization value for a given year from fuel prices and energy use per square foot value for that year. From this product is subtracted a similar product of the previous year's fuel price and equipment efficiency. This resulting term is divided by the latter product, ylelding a value representing the change in price and efflclency relative to the previous year. This value is multiplied by a utilization elasticity and the resulting quantity subtracted from 1.

Figure 19 depicts the calculation of final energy use, wherein the outputs of the four components described above are used to produce a demand total for a given forecast year. The multiplication of values here described takes place on a vintage by vintage basis for each bullaing type/fuel type/end-use combination. The final demand total is reached by summing all of the resulting values.

While this calculation is basically stralghtforward, a few features not previously discussed should be highlighted. First, to all vintages (except the one constructed during the forecast year) is applied a decay function, simulating inevitable demolitions of some of the standing commercial floorspace. Second, every 18 years of forecast time, a vintage's heating equipment is replaced (1.e. for each forecast year, the heating equipment efficiencies for every 


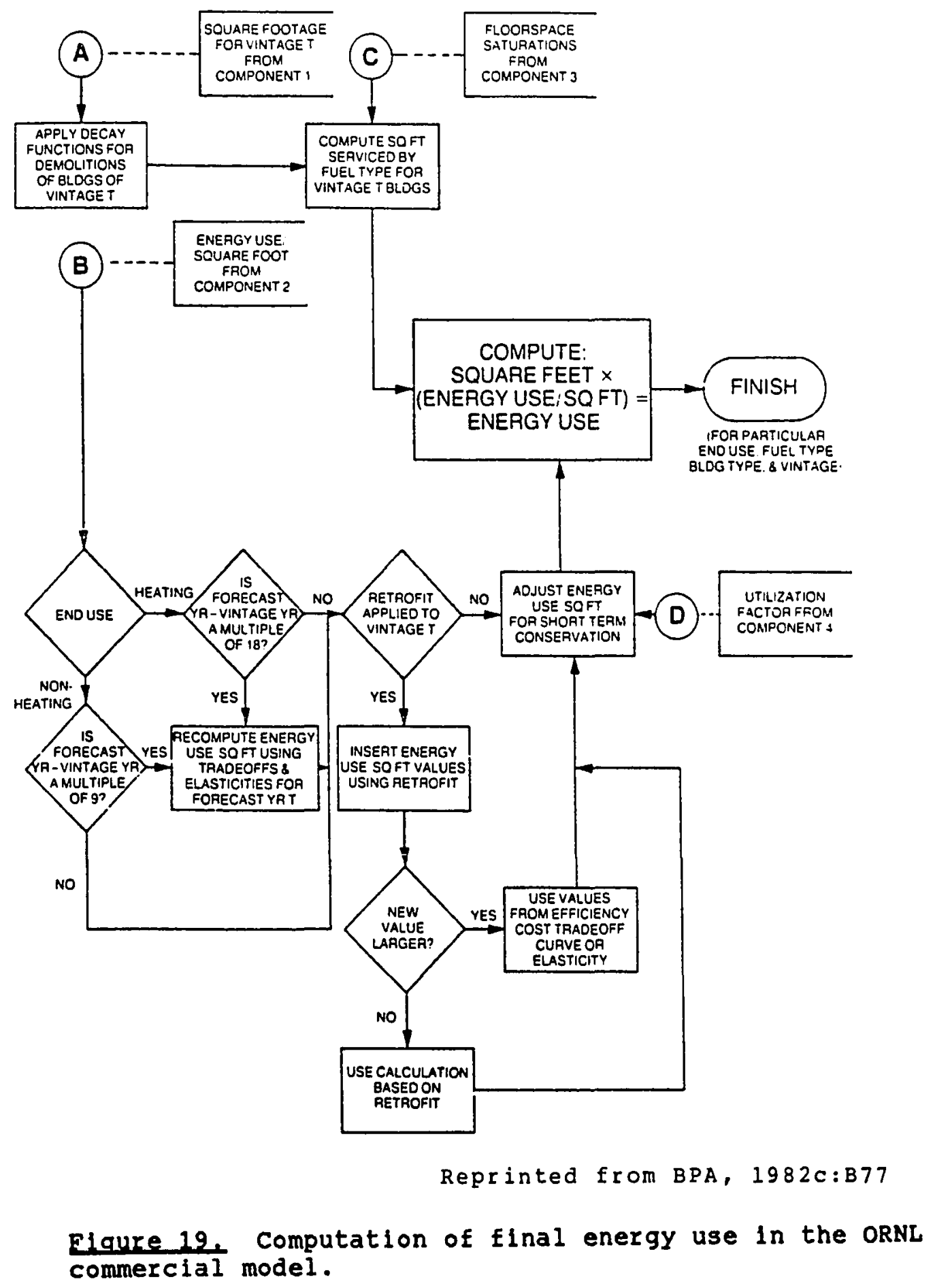


18th vintage are recalculated). For non-heating end-uses this equipment replacement takes place every 9 years. Finally, the model simulates retrofits in a Eashion virtually identical to the use of bullaing standards, except that retrofits apply to existing rather than new vintages. An array of precalculated retrofit EUIs are stored in the input data set. The user specifles the first and last years of the retrofit program and the proportion of standing vintages to be affected. The program compares the price-determined EUIs for the vintages selected with the retrofit EUIs and uses the lower of the two values for a revised demand calculation. This feature was added to the model by BPA staff but not used for the 1982 forecast.

The operation of the ORNL model is perhaps best illustrated by the use of an example of how it performs in producing a set of forecast energy use values for the year 1990.

The floorspace component calculates the square footage in the new 1990 vintage. Previously computed square footage values for 1924-1989 vintages are decayed to account for demolitions. Total 1990 standing stock is derived by summing the resulting values for $1924-1990$ vintages.

The energy use per square foot component determines equipment efficlencles (for all end-uses) for the 1990 vintage. The heating efflciencles for 1936, 1954, and 1972 vintages are recalculated. For non-heating end-uses, 
efflclencles are recalculated for 1927, 1936, 1945, 1954 , 1963, 1972, and 1981 vintages (i.e.9 - rather than 18-year equipment replacement assumption).

Eloorspace saturations for all fuel types are calculated for heating for all vintages fitted or refitted with equipment. Other vintages retain the heating saturations they had prior to 1990. For all other end-uses, "wired in" penetrations are applied to fitted or refitted vintages.

An equipment utildration factor for the year 1990 is computed for each vintage still standing.

Final energy use is calculated by aggregating the energy use totals for each of the 200 bullding type/fuel type/end-use combinations for all of the 67 vintages present in 1990 .

Baseline, high, and low demand values were produced by using corresponding sets of economic/demographic projections as inputs. Additionaliy, minor modiflcations were made to conservation policy assumptions to differentiate the three demand trajectorles.

- All three cases assumed bullding standards in effect in 1979 and grants programs for schools and hospltals from 1978 to 1987 . The bullding standards were rendered more stringent for the low case by modifying the factor used to calculate the welghted average of price and building standard EUIs so that the standards would have added influence (i.e. simulating more complete compliance). 
- The equlpment replacement 11 fetimes for the high case were lengthened to 22 years for heating, and 11 years for other end-uses. Owners were assumed to maintain equipment of lesser efficlency for longer perlods of time.

- The discount rate used to approximate the anticipated payback period for costs resulting from equlpment efflclency gains were varled from case to case. In the base case, a discount rate of 258 was reduced to 238 in 1983 to reflect the effects of better information. In the low case, the discout rate dropped from 258 to 208 after 1980 , while in the high case it increased from $25 \%$ to 408 after 1980 . - A number of budgeted BPA conservation programs could not be addressed explicitly by the ORNL model (e.g. shower flow restrictors, efficient lighting, water heater wraps). The demand reductions for these measures were calculated externally and the values subtracted from computed demand. In the baseline, these savings were judgmentally reduced by 208 to account for double counting of savings attributed to BPA programs whlch would have been induced by price. In the low case, the same set of savings was reduced by only 108 . For the high case, savings were halved and then reduced by 208.

The NEPP Econometric Model. For modeling energy use in the industrial sector, a portion of the Northwest Energy Pollcy Project econometric model was used. This model was flrst developed by Math Sciences Northwest (MSNW) in 1977 as 
part of an energy research project sponsored by the Pacific Northwest Regional Commission and has since undergone a number of modifications and revisions. Most recently, the basic equations of the model were reestimated as part of a contract between BPA and Applied Economics Associates (AEA), the principals of which had been working at MSNw when the model was first created.

The full NEPP model calculates long-term projections of energy demand for four major fuel types (electricity, natural gas, o1l, and coal) for five comsuming sectors (residential, commercial, Industrial, irrigation, and transportation). This output is provided for the region as a whole and each of the four states comprising 1t. For reasons described in the addendum which follows this discussion, BPA staff chose to use only the portion of the model applying to the industrial sector (and an algorithm for calculating street lighting loads described below). The industrial model (or, more correctly, submodel) is econometric in character and relatively slmple in its basic structure. In contradistinction to the ORNL models used by BPA for forecasting in the residential and commercial sectors, the industrial model produces, for each of 21 standard Industrlal classlfication (SIC) categorles, breakdown of consumption by fuel using a top-down approach. Total energy use is first calculated for a given SIC, and only secondar $11 y$ are the shares of the total energy value allocated to 
varlous fuels. No end-use breakdown is provlded. As an econometric model, the NEPP model is not nearly as data intensive as the ORNL models, requiring a relatively small number of 1nputs, though it cannot explicitly address the conservation policy questions which were, in large part, the Impetus for the design of the latter models. Table VI enumerates the Inputs to the NEPP Industrlal Model. Again, asterisks denote inputs obtained from Economic studies.

TABLE VI

INPUTS TO THE NEPP INDUSTRIAL MODEL

Inputs

Base Year (1979) Energy Consumption (total and by fuel type)

*Employment (by state by sIC)

* Fuel Prlces (by Euel by state) electricity gas 011 coal

* Value Added (by state by SIC) Heating Degrees Days (by state) Growth Rate in Productivity
Units Btus X 106
No of persons-base year,
5 yr AARGs - 1980 thru
2000
1979 -prices: 5 yr AARGs
1980 thru 2000
dollars $/ 1000 \mathrm{kwh}$
dollars $/ 1000 \mathrm{cu} \mathrm{ft}$
mlllion $\$ / 1000$ barrels
million $\$ / 1000$ short tons \$5-1979; 5-Yr AARGs 1980 2000

No of days

rate $(8 / y r)$

Figure 20 deplcts, in broad stroke, the operational flow of the NEPP Industrlal Model. In the July 1982 forecast, this model was employed to project non-DSI industrial 


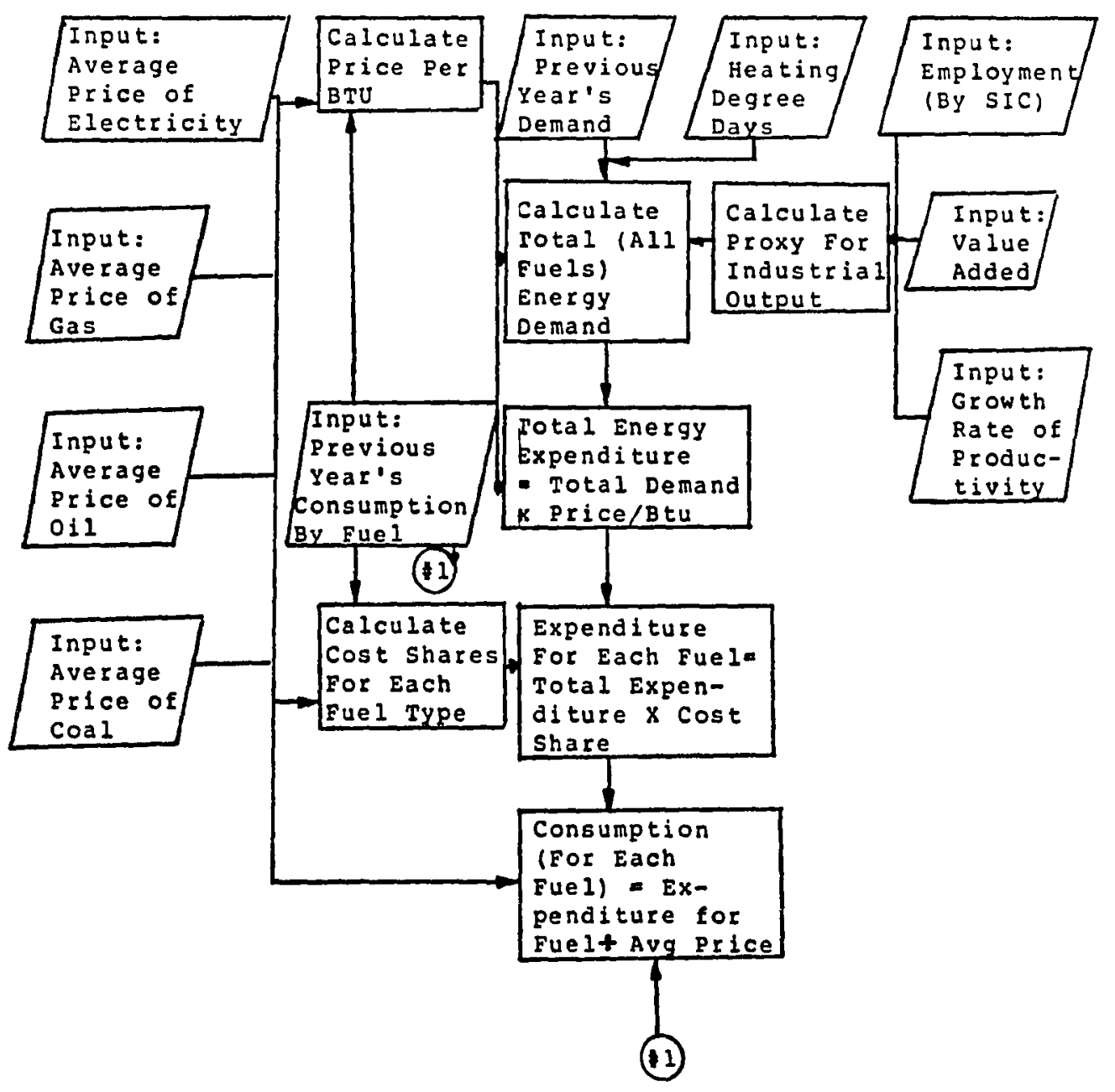

Figure 20. An overview of the structure of the NEPP industrial energy use model. 
loads with the exception of the pulp and paper Industry (which was modeled by Brookhaven National Laboratory, as discussed in a later section).

The internal logic of the model is baslcally simple, utilizing two types of equations: a total energy demand equation and a cost share equation to distribute total energy among different fuel types.

The ayerage prices of each of the fuels modeled (electricity, gas, o1l, and coall are used to calculate both an average price per Btu (welghted by the previous year's consumption by fuel) for all fuels and the cost shares for each of the fuel typed (i.e. the proportion of total industrial demand to be met by each basic fuel). The NEPP model uses 1979 as the base year for fuel prices and uses five-year growth rates of these prices over the 20 -year forecast perlod in its calculations. A lag structure, based upon the values of the prevlous year's consumption of each fuel (glven as an input in the base year and calculated for forecast years) was added to the cost share equation so that Euel switching would not be instantaneous as the average prices of different fuels altered.

The average price per Btu is subsequently used in two calculations. To derive total energy demand it is used along with the number of heating dearee days and the volume of industrial outout. The growth pattern for the last var1able is proxied by the model using the growth of employment 
or yalue added (depending upon the SIC for which demand is being projected) adjusted for changes in productivity. This growth pattern is applied to the previous year's demand (given as an input in the base year and calculated elsewhere), and the resulting ser!es of values used in the computation of total demand. In the second calculation, price per Btu is multiplied by the value derived for total demand, yielding the total expenditure (as a dollar amount) on energy for all Euels.

The resulting amount can then be multiplied by the cost shares to derive the expenditures for each fuel type considered by the model. In turn, these expenditures are divided by the average price for the appropriate fuels to arrive at the value for consumption of each fuel (lag adJusted using previous year's consumption by fuel).

As with the other sectors, the public/private service territory split was based on different sets of input values. Baseline, high, and low cases were calculated using different sets of economic/demographic projections and by altering Internal model parameters to enhance the differential effects of labor productivity on the high and low cases. Addendum: The Roads Not Taken. Earlier it was mentioned that the first phase of the BPA forecasting process was constituted by a public review of a preliminary set of economics/demographlc projections and a technical review of the models being considered for use. Before going on to the 
nert component of the BPA forecasting system, the electricity supply pricing model, it is worthwhile to consider briefly the models net selected for use in the 1982 forecast.

The technical review of the models was intended to acquaint the interested public with the tools under consideration for use by BPA, not to produce a forecast. As such, the models were not run iteratively with an electricity supply pricing model, though they were subjected to sensitivity testing (of key inputs and parameters) and scenario analysis.

As developed by BPA staff, the scenario analysis consisted of a serles of model runs deslgned to assess how explicitly the impacts of varlous types of conservation programs could be dealt with. The flrst scenario focused upon only price-1nduced conservation savings. A second scenario examined the effects of BPA conservation programs taken to the end of their buageted Iifetimes while a third extended the savings attributable to these programs through the end of the forecast perlod. Finally a fourth scenarlo added further cost-effective conservation measures (e.g. retrofits, bullding codes, heat pumps) to those of the third scenario.

of the four models consldered, only the ORNL Residentlal and Commercial Models could deal with the scenarlos without requiring excessive external calculation. This 
performance is hardly surprising, since the model-bullding efforts at Oak Ridge explicitly almed at producing computerized tools deslgned to address such policy considerations. The two other models considered could not deal with these policy options internally: hence the "four scenarios" were 1dentical. One of the models was the NEPP Econometric Model described above. In addition to the Industrlal sector submodel, ultimately employed in the draft and final 1982 forecasts, the residential and commercial sector components were run. In the residential sector, the NEPP model provides a breakdown of energy consumption by three fuels (electricity, gas, and heating oil) and $s i x$ end-use categorles (space heating, air conditioning, water heating, ranges, clothes dryers, and net-use) but does not distingulsh between housing types, in the commerclal sector, the NEPP model forecasts total energy demand, distributes it among the three fuels, and performs a separate calculation for total streetlighting demand. The other model was the PNUCC Econometric Model, first developed by National Research Associates in 1976 to serve as a cross-check for the traditional sum-of-Utilities (sou) forecast. Unlike the NEPP model, it forecasts only electricity demand, though it does so for all sectors. Like the NEPP model, it produces some end-use detall in the residential sector, analyzing seven categorles (space heating, water heating, ranges, clothes dryer, dishwashers, electric cars, and net-use). In 
the commercial sector, a single econometric equation forecasts demand per customer (which is subsequently multiplied by the total number of commercial customers). No further disaggregation of commercial demand is produced. Finally, in the industrial sector a single econometric equations is used to calculate electricity demand per unit of value added for each of twelve industries (these values are then multiplied by the value added for each industry).

The ORNL models were selected by the staff because of their apparent superlority in producing finer degrees of disaggregation of output and because of their explicit conservation modeling capabilities. The NEPP Industrial Model was selected over its PNUCC counterpart for inclusion in the BPA system of forecasting models primarily on the basis of three technical criteria: it was more recently reestimated (by AEA), it provided a more detalled breakdown of industrial demand (1.e. more SIC categorles), and it dealt with three fuel types rather than only one.

\section{The Supoly pricling Model}

Interacting with the demand models descibed in the previous section was the BPA Supply Pricing Model (SPM). Prior to Its modiflcation in 1982 , to reflect the mandates of the Reglonal Power planning Act, the model was known as the Integrated Supply Demand Model. First prepared for BPA's 1979 Rate Environmental Impact statement, the model originally contained both supply and demand components (as the name 
suggests). The operation of the demand component was based. upon a paper prepared by Kent Anderson of National Economic Research Associates for the PNUCC while the supply portion was developed internally by BPA staff. The 1982 version of the SPM, as noted earler, uses the loads produced by the three sector-specific demand models as inputs and produces a set of prices by rate pool which are fed back into each of the demand models. This process is repeated until equilibrium, or convergence, is reached.

In most general terms, the Supply Pricing Model performs two fundamental calculations. First, it determines which resources are selected to serve the loads of the different rate classes in the region. Second, it develops a set of wholesale and retall rates based upon the cost of the resources used to meet regional demands. Underlying the model's operation are the assumptions that, by 1985, private utilities in the region exchange all of their residential and small farm loads with BPA in accordance with the terms spelled out in the Regional Act $170 \%$ in 1982, with 108 yearly increases thereafter); that all public and private utilities sign net requirements agreements with BPA; and that BPA acquires power from thermal plants currently under construction at the dates they are scheduled to come onIIne. The input variables used by the model in performing the abovementioned calculations are summarized in Table VII. 
As has been the custom in previous sections, the inputs provided by Economic studies are noted by an asterisk.

TABLE VII

INPUTS TO THE SUPPLY PRICING MODEL

Inputs

Loads (by sector, public/private)

*Inflation rate

*Escalation rate

Interest (by project or plant)

Amortization (by project or plant)

Replacement costs (by project or plant)

Generation costs (by project or plant)

Construction costs (by project or plant)

Distribution costs (by sector)

Secondary Power Markets
Units

Gigawatt hours Rate (real no.) Rate (real no.) Percentage Thousands 1980 \$ Thousands 1980 \$ Thousands 1980 \$ Thousands 1980 \$ Mills/Kwh Loads (av MW)

Most basically, the SPM compares loads for a given year with the power supply avallable and determines the cost of whatever resources must be acquired to meet demands. While this is quite elementary in principle the accounting framework embodied in the model is rather elaborate. Figure 21 provides a simplified representation of the operating $\log 1 \mathrm{c}$ of the model.

The SPM taps three resource pools for the power needed to meet regional loads: exchange resources (power generated by IOUs entering into exchange agreements with BPA), new resources, and the Federal Base system (FBS). The histor1cally low electricity rates in the Pacific Northwest have primarily been due to the availability of cheap hydropower, and it is the question of the equitable allocation of this power that was perhaps the primary impetus of the Reglonal 


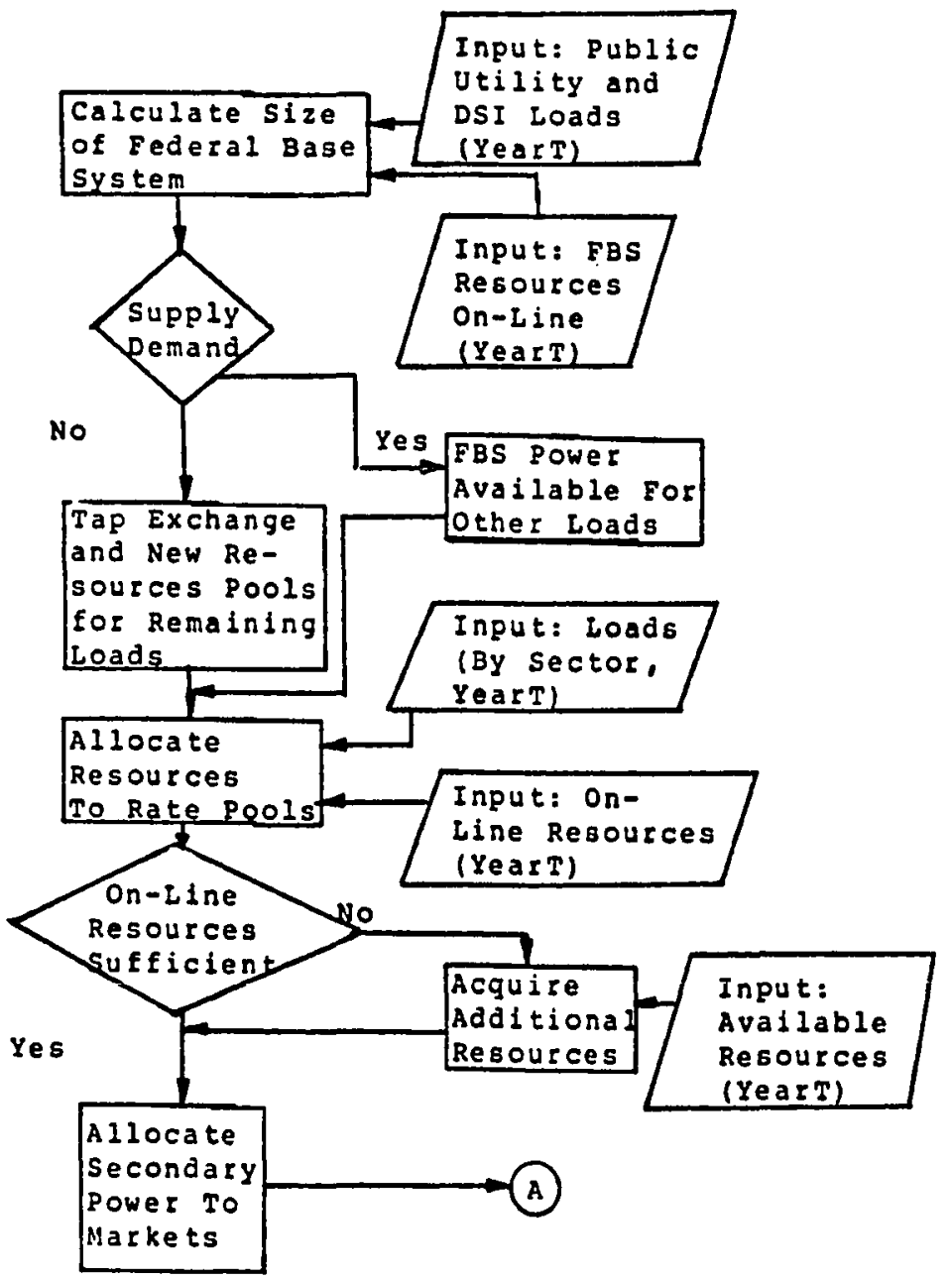

Eiqure 21: An overview of the structure of the BPA supply pricing model. 


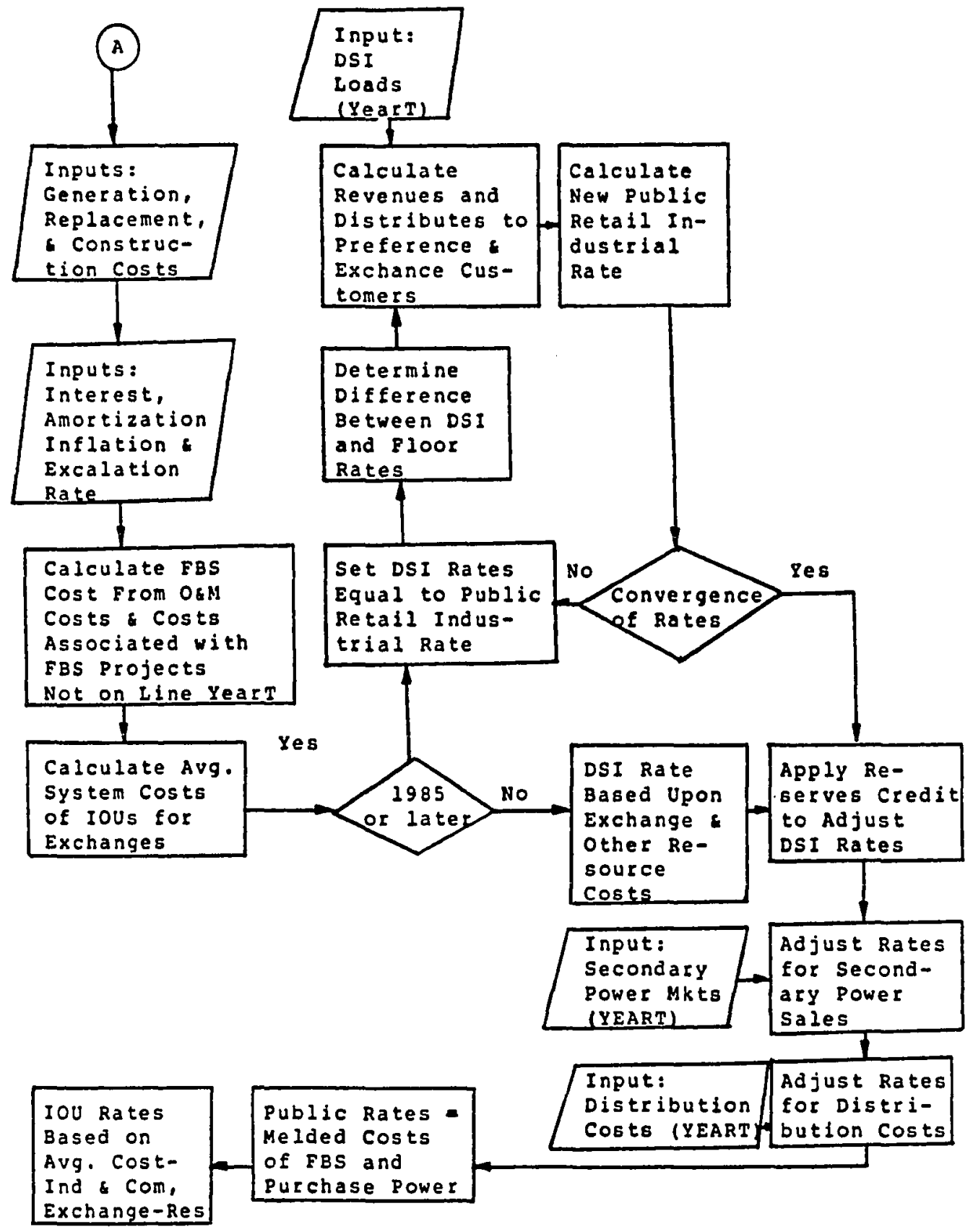

Figure 21 (cont'd) 
Act. The FBS is defined to Inciude all Federal hydro resources plus any thermal resources under contract with BPA at the date of the enactment of the Regional Power Bill (this included Hanford and BRA's shares of Trojan and WNP 1, 2, and 3). The FBS becomes fixed when the last of the three WPPS nuclear plants comes on-1ine. Prior to this date, however, it is necessary to calculate the size of the FBS and determine whether the power supplied by its resources in a given year is adequate to meet the demand of the load pool comprised for public agency, federal agency, and residential and farm exchange customers. If FBS supply exceeds the demand of these customers, the remaining EBS power is available for meeting the loads of other customer classes. On the other hand, if demand exceeds FBS supply, new resources must be tapped (first exchange, when new resources) to meet the needs of the above described load pools.

The final allocation of resources to rate pools occurs after the accounting for FBS generating capacity has been completed. Prior to 1985, DSI customers receive first access to any remaining FBS power, whlle after 1985 any remaining FBS capacity is pooled with other on-line resources and used by both DSI and net requirements IOU customers. should on-line resources not prove sufficlent to meet reglonal loads the model adds other avallable resources not currently on-line or, after these are exhausted, generic 200 
megawatt thermal facilities untll supply matches demand. Resources are acquired so as to conform to the requirements of a least-cost mix determined external to the SPM (using a linear programing model, not run iteratively with the forecasting system, by BPA's Power Resources Division).

Finally, the model allecates secondary eneray avallable from the Federal hydrosystem during seasons where temporary surpluses are available.

After having determined which resources will serve which load pools, the SPM calculates both wholesale and retail rates for the various consuming sectors based upon the generation, replacement, and new construction costs associated with hydro profects and thermal planes. (These calculations take account of inflation and escalation rates, interest, and amortization). For any forecast year, FBS costs are calculated based upon the operation and maintenance costs assoclated with the working system and additional costs assoclated with FBS projects not then on-line. For LOUs entering into exchange agreements with BRA, their average system costs are determined. For DSI customers, rates are determined differently prior to and after 1985 (at which time the DSIs, in effect, provide rate relief for resldential and small farm exchange customers). Before 1985, DSI rates are based upon exchange and other resource costs (including FBS power when avallable). After 1985, the model calculates a public retali industrial rate and sets 
the DSI rate equal to this value. If this value is less than the floor rate set for DSIs by provisions of the Regional Act (which one would expect to be the case) the difference between the two DSI rates is derived. This difference is multiplied by the projected DSI loads and the resulting revenues are distributed to preference and exchange customers. Subsequently, a new public utility retail industrial rate is calculated and the procedure for determining DSI rates continued iteratively until the difference between the DSI rate and the public agency industrial rate is less than one mill per kilowatt hour. After this convergence is reached, DSI rates are adjusted by apolying a reserve credit which reflects the value of interruptible load provisions in the DSI contracts (This adjustment is also made for pre-1985 DSI loads). Calculated rates for all customer classes are then adjusted to account for projected secondary sales revenues and distribution costs. Final retail rates for public utility customers are based upon a melded cost of FBS and purchase power. For IOU customers, residential rates are based upon exchange costs whereas industrial and commercial rates are based upon average system cost.

The disaggregation of economic/demographic projections and reglonal loads to correspond to the service territorles of public and private electric utilities was conducted explictly for the purpose of iteration with the SPM. The SPM 
utilized public and private loads (by consuming sector) simultaneously in calculating electricity prices, whereas the demand models were run twice (for each iteration with the pricing model), first using public, then private inputs. For the high and low cases, the SPM used the approprlate corresponding set of high or low inputs. Additionally, several of the internal operating assumptions of the model were modifled. In the high case, the secondary power rate was double that of the baseline and low case. The low case assumed a two year scheduling delay in WNP-3.

Brojections of Reqlonal Energy consumotion: outouts and Adjustments

Having depicted both the derivation of the key inputs and the operation of the major models used by BPA in the preparation of their first independent long-term demand forecast, it is now approprlate to conclude the technical description with a discussion of the results. Before doing so, however, it is necessary to describe several adjustments performed on the outputs of the demand models so that the loads of all customer classes were represented in the forecast results. With one exception, these adjustments were performed on each iteration of the demand and pricing models.

Adjustments of Regional Loads. The demand models descibed above projected the loads for the major consuming sectors: the residential, the commerclal, and the Indus- 
trlal. Taken together, however, the outputs of these models are still less than the total regional loads: they must be adjusted to include streetlighting, irrigation, and contract demands.

Streetliahting loads are calculated using a single econometric equation taken from the NEPP all-sectors model. Total electricity demand is a function of two independent variables: the average price of electricity and population (by state). The streetlighting model is run twice per iteration, once for public and once for private service areas. The resultant loads (produced for the region as a whole as well as for the individual states) is added to those produced by the ORNL Commercial Model before being input to the Supply Pricing Model. (Any savings attributable to BPA conservation programs are subtracted from the econometrically produced demand values). Public/private splits, and high, baseline and low outputs are determined strictly by the values of the independent varlales used as inputs and the estimated levels of associated conservation savings. The streetlighting model performs new calculations each iteration.

Irrigation loads, like streetlighting loads, are added to public and private demands for each iteration with the prlcing model. Unllke streetlighting loads, however, the irrigation values are not calculated anew with each iteration. Though values differ for public and private, high, 
low, and baseline, they are determined only once in an external calculation: hence the same value for, say, baseIine public irrigation loads is added to the total demand each iteration. The irrigation model (11ke the Economic Base Model, a series of paper-and paper calculations) projects irrigation demands, by state, in three steps. First, per-acre crop irrigation water regulrements are determined for different types of crops. Next, the welghted per acre farm water delivery requirement (1.e. crop needs plus evaporation and transpiration), the water diversion requirement, and the assoclated per acre energy requirement (1.e. pumping) are computed. Finally, total water and energy needs (reguirements per acre times acreage) are derlved. Irrigation loads are added to ORNL Residential Model output before being entered into the SPM. High case profections assume greater irrigated acreage while the low case assumed both reduced acreage and increased priceinduced conservation.

The demands for those customerg with whom BPA has contractual obligations were entered into the demand totals each iteration. These loads for DSIs and Eederal agencies were estimated outside of the modeling system and simply added onto other reglonal loads before being input to the pricing model. Since these customers receive power directly from BPA they were classified neither as 'public' nor 'private'. Demand values remained constant from iteration 
to iteration but did vary between high, baseline, and low cases for DSIs.

One final adjustment was-carried out on each iteration of the pricing demand models. Inspections of the outputs of initial runs of the NEPP Industrial Model revealed a conspicously low set of demand values for the pulp and paper category, not appearing reasonable given industry estimates of future growth. As a result, load projections developed by Brookhaven National Laboratory for BPA using their process model were substituted for the NEPP pulp and paper projections. The Brookhaven model is a process optimization model which selects the combination of materials and processes that minimize the cost of meeting a specified level of demand for paper products. Because the Brookhaven model could not be iterated with the other models in the BPA system, its "optimal" cost-minimizing solution does not reflect the electricity prices developed during the final iteration of the demand models with SPM (1.e. pulp and paper demand remained constant across all iterations).

Results: Reqional Electricity consumption. After iterating the demand and pricing models until convergence was reached, the baseline, high, and low forecasts were produced. Overall, the BPA forecasts were significantly lower than others prepared in the region (with the exception of the Independent Review of WPPSS 4 and 5 carried out by a task force at Washington State University) and posited a 
near-term power surplus rather than the power deficit previously believed to be imminent. The average annual rates of growth for baseline, high, and low cases were 1.6, 2.4 , and 0.8 percent respectively. Table VIII provides a summary of the results of the baseline, high, and low case forecasts produced by BPA in its July 1982 forecast. Of the three major sectors, the commercial sector displays the greatest AARGs: 2.38 in the baseline, 3.78 for the high case, and 1.18 for the low case. For each of these cases the commerclal growth rates are identical for public and private service areas. Industrial and residential sectors did not similarly display equal growth rates for public and private sectors. In the resldential sector, public and private AARGs were, respectively, 1.28 and 1.68 for the baseline: 2.28 and 2.68 for the high case: and 0.38 and 0.98 for the low case. For the industrial sector, public and private loads grew at annual rates of 1.48 and 1.88 in the baseline, 1.98 and 2.38 in the high case, and 1.58 (for both service territories) in the low case. Because of the rate equalizing provisions of the Regional Act embedded in the SPM, electricity prices grew more rapidy for public utility customers between 1980 and 1990, more strongly curtalling consumption per customer. For the contract demand customers, consumption growth is severly constrained. For Federal agency customers, the growth rate is Invarlant between cases: 3.98 per year on the 
TABLE VIII

SUMMARY OF FORECAST RESULTS BY SECTOR (1000 MWH)

\begin{tabular}{|c|c|c|c|c|c|c|c|}
\hline \multicolumn{2}{|c|}{ BASELINE } & 1980 & 1285 & 1290 & 2925 & 2000 & $\begin{array}{l}20 \text { Year } \\
\text { AsRG }\end{array}$ \\
\hline \multirow[t]{5}{*}{ Public } & Res & 22973 & 24047 & 27222 & 25583 & 29000 & 1.2 \\
\hline & $\operatorname{Irr}$ & 3360 & 3579 & 3957 & 4254 & 4589 & 1.5 \\
\hline & Com & 8623 & 9796 & 10714 & 11968 & 13569 & 2.3 \\
\hline & $s t 1$ & 406 & 308 & 239 & 253 & 271 & -2.0 \\
\hline & Ind & 16263 & 17227 & 18008 & 19278 & 21418 & 1.4 \\
\hline \multirow[t]{5}{*}{ Private } & Res & 27946 & 30283 & 33506 & 36013 & 38699 & 1.6 \\
\hline & IrI & 3228 & 3726 & 3857 & 4254 & 4589 & 1.7 \\
\hline & com & 14146 & 16197 & 18087 & 20032 & 22360 & 2.3 \\
\hline & $s+1$ & 312 & 215 & 179 & 183 & 179 & -2.7 \\
\hline & Ind & 15631 & 16433 & 18136 & 19942 & 22234 & 1.8 \\
\hline \multicolumn{2}{|l|}{ DSI } & 21904 & 22588 & 26762 & 27035 & 27217 & 1.1 \\
\hline \multicolumn{2}{|c|}{ Fed Agency } & $710^{\circ}$ & 1445 & 1515 & 1515 & 1515 & 3.9 \\
\hline \multirow{2}{*}{\multicolumn{2}{|c|}{$\begin{array}{l}\text { Losses } \\
\text { Total }\end{array}$}} & 10155 & 10938 & 12048 & 12896 & 13923 & 1.6 \\
\hline & & 145558 & 158782 & 172696 & 184845 & 199563 & 1.6 \\
\hline \multicolumn{8}{|c|}{ HIGH CASE } \\
\hline \multirow[t]{5}{*}{ Public } & Res & 22959 & 26089 & 28983 & 32183 & 35601 & 2.2 \\
\hline & $\mathbf{I r} \mathbf{r}$ & 3360 & 3613 & 4008 & 4455 & 4882 & 1.9 \\
\hline & Com & 8623 & 10739 & 12608 & 14884 & 17713 & 3.7 \\
\hline & Stl & 406 & 351 & 291 & 303 & 326 & -1.1 \\
\hline & Ind & 16471 & 17738 & 18533 & 20304 & 23802 & 1.9 \\
\hline \multirow[t]{5}{*}{ Private } & Res & 27930 & 32852 & 37700 & 42052 & 46964 & 2.6 \\
\hline & I $\mathbf{r}=$ & 3228 & 3761 & 4008 & 4455 & 4882 & 2.1 \\
\hline & Com & 14187 & 17622 & 21015 & 24740 & 29108 & 3.7 \\
\hline & Stl & 312 & 259 & 240 & 244 & 245 & -1.2 \\
\hline & Ind & 15626 & 17031 & 18806 & 20973 & 24411 & 2.3 \\
\hline \multicolumn{2}{|l|}{ DSI } & 21804 & 22588 & 27174 & 27445 & 27638 & 1.2 \\
\hline \multicolumn{2}{|c|}{ Fed Agency } & 710 & 1445 & 1515 & 1515 & 1515 & 3.9 \\
\hline \multirow{2}{*}{\multicolumn{2}{|c|}{$\begin{array}{l}\text { Losses } \\
\text { Total }\end{array}$}} & 10171 & 11557 & 13116 & 14516 & 16281 & 2.4 \\
\hline & & 145787 & 165645 & 187997 & 208069 & 233369 & 2.4 \\
\hline & & & & & & & 20 Year \\
\hline \multirow{2}{*}{\multicolumn{2}{|c|}{ LOW CASE }} & 1980 & 1985 & 1990 & 1995 & 2000 & AARG \\
\hline & Res & 22973 & 23168 & 23684 & 24264 & 24605 & 0.3 \\
\hline \multirow{4}{*}{ Public } & I r r & 3360 & 3415 & 3621 & 3723 & 3835 & 0.7 \\
\hline & com & 8582 & 8909 & 9107 & 9692 & 10606 & 1.1 \\
\hline & $s t 1$ & 406 & 306 & 238 & 248 & 254 & -2.4 \\
\hline & Ind & 15038 & 14348 & 15594 & 17532 & 20049 & 1.5 \\
\hline \multirow[t]{5}{*}{ Private } & Res & 27946 & 29119 & 31024 & 32262 & 33385 & 0.9 \\
\hline & IrI & 3228 & 3555 & 3621 & 3723 & 3835 & 0.9 \\
\hline & Com & 14078 & 14755 & 15418 & 16340 & 17625 & 1.1 \\
\hline & $s t 1$ & 312 & 213 & 182 & 189 & 181 & -2.8 \\
\hline & Ind & 15543 & 15543 & 17122 & 18927 & 20956 & 1.5 \\
\hline \multirow{3}{*}{\multicolumn{2}{|c|}{$\begin{array}{l}\text { DSI } \\
\text { Fed Agency } \\
\text { Losses }\end{array}$}} & 21804 & 21278 & 20857 & 21055 & 21105 & -0.2 \\
\hline & & 710 & 1445 & 1515 & 1515 & 1515 & 3.9 \\
\hline & & 10049 & 10204 & 10649 & 11210 & 11846 & 0.8 \\
\hline \multicolumn{2}{|l|}{ Total } & 144029 & 146253 & 152632 & 160680 & 169797 & 0.8 \\
\hline
\end{tabular}


average. For the DSIs, baseline and high case growth is nearly identical, 1.1 and 1.28. Most of the growth is accounted for by the assumed addition of the Alumax plant. In the base case DSI customers use $98.9 \%$, rather than the high case's 1008, of contracted demand. In the low case, where Alumax is not assumed to be built and existing aluminum production declines 20\%, consumption declines at an AARG of -0.28 over the forecast period.

In all these cases, streetlighting can be seen to display "negative growth" over the forecast period. Although the number of lighted streets and highways grows modestly, BPA budgeted conservation programs substantially reduce demand by 1990.

Finally, it should be noted that the regional demand totals are adjusted upward to account for inevitable line losses, capacity reductions that occur during power transmission through the reglonal grid. Losses are strictly proportional to the total load and, consequently, display identical AARGs.

THE REGIONAL DEMAND FORECAST: EVALUATION FROM THE T-PERSPECTI VE

Now that the BPA modeling system, its components, and its output (i.e. the July 1982 forecast) have been described, it is possible to perform and evaluation from the technical perspective. As the underlying leitmotif of the 
T-perspective is one of analysis, objectivity, rationality, abstraction, and causal influence, so this evaluation of the forecast correspondingly focuses upon such characteristics as validity, methodological consistency and completeness, model performance, and goodness-of-fit between the techniques employed and the objectives addressed. Necessarily, such a technical analysis ralses a varlety of broader 1ssues which cannot be understood without further explication of related organizational and personal factors. Such 1ssues are identifled below and will be more fully dealt with in the later chapter describing the cross-cuing of perspectives.

The technical evaluation begins with a reconstruction of the BPA forecasting system in its entirety, this time examining the relationships and connections between the various models (and their operating assumptions) in much greater and more revealing detall than was done in the introductory overview. This laying out of the full network models facilitates the next step of the technical analysis, tracing the core assumptions of the forecast back to their origins. In turn, the identification of core assumptions serves as a point of departure for an assessment of the risk and rellability associated with the forecast. The evaluation concludes with a critlcal look at the goodness-of-fit of the forecast methodology with BPA's stated planning ob- 
Jectives and poses some larger questions to be answered in the final chapters of this dissertation.

\section{Inputs, Qutputs, and Data Flows: The Forecasting System}

\section{Revisited}

As the above descriptions have revealed, there are a large number of interlinked models in the BPA forecasting system. The outputs of one model may be the inputs to one or more of the other models in the system, and, to the extent that the latter models are sensitive to those inputs, their performance is at least in part determined, or constrained, by the performance of the former model. In effect, the assumptions made to run any given model are "inherited" by any other models they feed with data. The significance of such assumptions may range from trivial to paramount and their effects may be amplified or dampened as they are "transmitted" through the network of models. As a first step in the technical evaluation of the forecast it is necessary to trace out the data flows between the models and establish and "audit trail" which traces assumptions back to their sources.

Two tools useful in this exercise are what are known in digraph theory as adjacency and reachability matrices. An adjacency matrix provides a graphic summary of the immediate impacts of a row variable on a column variable. In Figure 22 the variables are the models used by BRA staff in preparing the July 1982 forecast. An ' $x$ ' in one of the boxes 


\begin{tabular}{|c|c|c|c|c|c|c|c|c|c|c|c|}
\hline & 思 & $\dot{\phi} \dot{\omega}$ & 品 & $\stackrel{\omega}{\omega}$ & $\underset{\mathbf{z}}{\mathbf{z}}$ & $\dot{a}$ & 岕 & 号 & $\underset{\mathbf{r}}{\mathrm{z}}$ & 岂 & $\frac{\sum}{\sigma}$ \\
\hline PRI & & $x$ & $x$ & $x$ & $x$ & $x$ & & $x$ & $x$ & & $x$ \\
\hline ECON BASE & & & $x$ & & $\mathrm{x}$ & & & $x$ & $x$ & & \\
\hline POPULATION & & & & $x$ & $\mathrm{x}$ & & & $x$ & & $x$ & \\
\hline HOUSING & & & & & & & $x$ & & & & \\
\hline FNCOME & & & & & & & $x$ & $x$ & & & \\
\hline FUEL PRICE & & & & & & & $x$ & $x$ & $x$ & $x$ & \\
\hline RESIDENTIAL & & & & & & & & & & & $x$ \\
\hline CONMERCIAL & & & & & & & & & & & $x$ \\
\hline INDUSTRIAL & & & & & & & & & & & $x$ \\
\hline STREETLIGHT & & & & & & & & & & & $x$ \\
\hline SPM & & & & & & & $x$ & $x$ & $x$ & $x$ & \\
\hline
\end{tabular}

Eiqure 22. Adjacency matrix for models in the forecasting system.

Indicates that the outputs of the row model are inputs to the model in the assoclated column. Thus, an entry in any matrix cell indicates that assumptions embedded in the row model may affect the operation of the column model and the matrix as a whole provides a quick overview of the number of connections between a given model and the others in the system. (Note that the diagonal of the adjacency matrix is blank. While a number of the models make profections using outputs for previous years as independent varlables in their calculations -- e.g. the NEPP model's cost-share equations -- none reenter model outputs as inputs). Perhaps the most striking insight obtained from inspection of the adjacency matrix is the criticality of the DRI national economic pro- 
jections as direct inputs to virtually all of the models employed lexcepting the resldentlal and streetlighting models). Despite the fact that regional economic or demographic projections developed by BRA may differ from DRI's, it is the latter firm's characterization of national economic trends which shape the BPA projections, their ranges, and the bounds of "credibility" for their values. Also apparent is the centrality of fuel prices (both electric and non-electric) as inputs to all of the demand models, whether econometric (industrial and streetlighting) or end-use hybrids (residential and commercial).

Perhaps more revealing is the reachability matrix (Figure 23) which, in contradistinction to the adjacency matrix, provides a summary representation of the pltimate impacts of a row variable on a column variable. As with the adjacency matrix above, the row and column variables are the models used in the BPA forecasting system. An entry in one of the celis of the matrix indicates that the output values of one model will affect the outputs of another model, either directly (if the output of the row model is an input to the column model, as in the adjacency matrix) or indirectly (if the output of the row model is an input to one or moze of a chain of models whose outputs "feed" the column model). To the extent that the output of a model may serve as inputs to models which in turn produce its inputs, the cells in the diagonal of the matrix may be non-empty. 


\begin{tabular}{|c|c|c|c|c|c|c|c|c|c|c|c|}
\hline & 咅 & $\dot{\dot{\omega}}$ & 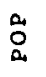 & $\stackrel{\omega}{\omega}$ & $\underset{\sim}{\mathbf{Z}}$ & $\dot{a}$ & $\begin{array}{l}\stackrel{n}{\omega} \\
\stackrel{\omega}{\approx}\end{array}$ & $\begin{array}{l}z \\
0\end{array}$ & $\mathfrak{z}_{-1}^{a}$ & 岕 & $\begin{array}{l}\Sigma \\
\vdots \\
\vdots\end{array}$ \\
\hline DRI & & $x$ & $x$ & $\mathrm{x}$ & $x$ & $x$ & $x$ & $\mathrm{x}$ & $\mathrm{x}$ & $x$ & $x$ \\
\hline ECON BASE & & & $x$ & $x$ & $x$ & & $x$ & $x$ & $x$ & $\mathrm{x}$ & $x$ \\
\hline POPULAIION & & & & $x$ & $x$ & & $x$ & $x$ & $x$ & $x$ & $x$ \\
\hline HOUSING & & & & & & & $x$ & $x$ & $x$ & $x$ & $\mathrm{x}$ \\
\hline INCONE & & & & & & & $x$ & $x$ & $x$ & $\mathrm{x}$ & $\mathrm{x}$ \\
\hline FUEL PRICE & & & & & & & $x$ & $x$ & $x$ & $x$ & $x$ \\
\hline RESIDENTIAL & & & & & & & $x$ & $x$ & $x$ & $x$ & $\mathrm{x}$ \\
\hline COMNERCIAL & & & & & & & $x$ & $x$ & $x$ & $x$ & $x$ \\
\hline INDUSTRIAL & & & & & & & $\mathrm{x}$ & $x$ & $x$ & $x$ & $x$ \\
\hline STREETLIGHT & & & & & & & $x$ & $x$ & $\mathbf{x}$ & $x$ & $x$ \\
\hline
\end{tabular}

Elqure 23. Reachability matrix for models in the forecasting system.

Again, the breadth of effect of the DRI long-term projections is apparent -- this time, because of the 1terative cycling of demands and prices, literally all of the models felt DRI's influence. Most visually striking is the solid rectangle of cell entrles extending from the residential model column through the supply pricing Model column. Because of the loop structure of the demand-price iterations the outputs of each of the demand models ultimately affect the values of all the demand models. By extension, the economic and demographic inputs to any of the demand models ultimately affect all of them (and the supply Prlcing Model as well). Thus, for example, although the outputs of the housing model only serve as direct inputs to 
the residential model, the volume of residential demand codetermines (with industrial, commerclal, streetlighting, and irrigation demands) the amount of resources needed to be acquired and the distribution of the associated costs. The resulting electricity prices feed back into all of the demand models until iterative convergence is reached.

Also significant is the "trlangle" of cells in the upper left hand corner, representing the interlinkage of models employed in deriving the economic an demographic projections. In the first phase of the BPA forecast, during the technical review of the demand models proposed for use In the 1982 forecast, each model was subjected to a series of sensitivity tests. The purpose of these tests was to establish the responsiveness of each of the models to changes in the values of critical driving variables. The sensitivity of each of the models to the particular set of economic/demographic inputs serving as its independent variables was so tested and the results recorded.

Sensitivity tests, however, are often also accepted as a type of risk analysis by potentlal model users or critics. The responsiveness of a particular model to variations in the values of a given input is often taken as providing an indication of the magnitude of forecast uncertainty resulting from errors which might occur in the input. When the models for developing inputs are interlinked, however, sensitivity testing of individual driving variables is com- 
pletely insufficient for even an informal risk analysis. An over- or undercalculation of basic employment would affect subsequent calculations of population, housing, and income. Each of the demand models uses several of these variables: thus, for example, a true assessment of the risk involved in the miscalculation of employment on the industrial model would have to include a corresponding adjustment of population inputs. Overall, this would be a test of what could be called, for lack of a better name, the "concatenated sensitivity" of the models in the system. This would involve altering the values of the outputs of the first economic model in the chain by a certain amount and monitoring the effects at each link in the network through the convergence iteration of the demand and pricing models.

The intricacy of the connections existing between the models in the BPA forecasting system is better captured in the detail of Figure 24 which maps the entirety of the data flows between models. Included in the diagram are several data sources in the audit trall not produced as BPA economic/demographic projections (residential and non-residential surveys and least cost mix of resources). These sources, and the diagram as a whole, provide a useful point of departure for analyzing the basic core assumptions lying behind the forecast and the risk and rellabllity associated with it. 


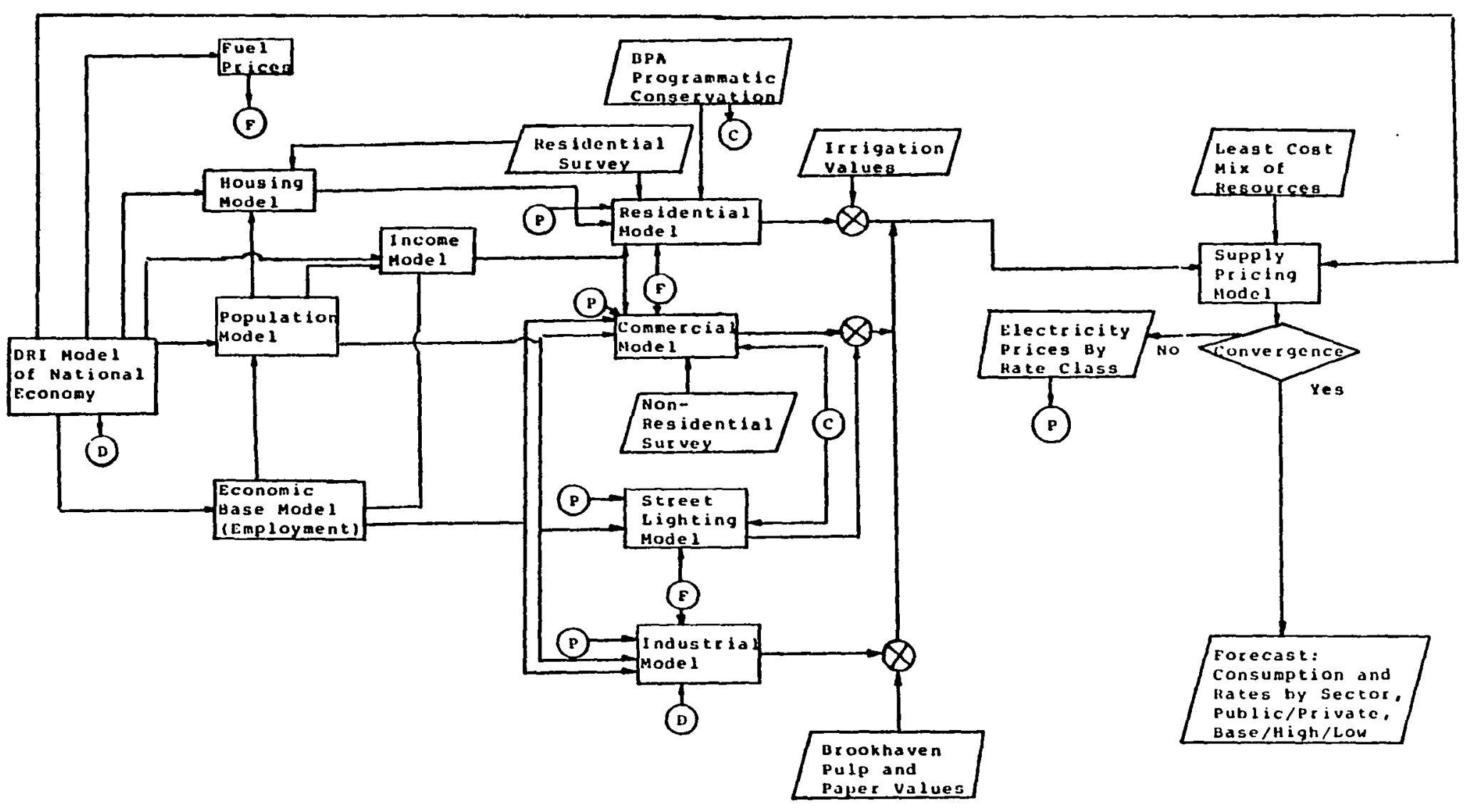

Figure 24. Input-output diayram of bpa forecasting system. A detailed representation of
data flowg in the modeling system 
Eorecasts core Assumption: White and Black Boxes

Although accuracy is not the sole criterion by which the quality of a forecast may be evaluated it is probably the most commonly used standard of fudgment. In h1s 1978 volume Eorecasting: An Appraisal for Policy-Makers and Rlannexs, William Ascher concluded that the major determinants of a forecast's accuracy are its core assumptions, underlying suppositions representing "the forecaster's basic outlook on the context within which the specific forecasts trend develops" (p199). Core assumptions may be embedded at various depths in a forecast (e.g. methodologies, models, or judgments) and may be stated with various degrees of explicitness. Ideally the forecaster will render these assumptions naked -- laying them out in their fullest detail as "white boxes" for inspection and evaluation. For various reasons, however, virtually all forecasts embed basic assumptions in "black boxes" which register only their effects.

The adjacency and reachablity matrices (shown in the previous section), along with the system input-output diagram, provide a good layout for ldentifying points at which core assumptions are operating along the data audit trail. Necessarily, a critical analysis of forecast core assumptions and their consequences must proceed from a touchpoint of theoretical objectivity and purity, even though "real world forecasts" are invariably saddled with various practi- 
cal constraints which render them far less than perfect. Before scrutinizing the forecast audit, trail, however, four caveats are in order. First, most of the criticisms leveled at BPA models could also be applied to other demand forecasting models used in the region. Despite certain undeniable shortcomings, the models used by BPA are state-of-theart for the region. Second, although one may identify a variety of modeling limitations, inconsistencles or omissions, their overall impacts may not be particularly significant. For example, hundreds of thousands of dollars of contract money could be spent to correct missing feedbacks between models by interlinking their software with this effort producing virtually no effect on final forecast outcomes. Third, the identification of an unspoken core assumption should not be considered its refutation. Such "Iimiting" assumptions may Indeed be quite correct. They are merely unacknowledged or taken for granted by those making them. They should, however, be made expliclt and subjected to scrutiny. Finally, it should be acknowledged that the BPA system of models is "living" -- it is continuously being revised and improved.

Returning to an examination of the audit trail it will be noted that one of the most striking features of both the adjacency matrix and the master input-output diagram presented above was the criticality of the gutputs of the DRI model to virtually every model in the BPA system. The DRI 
model of the national economy is a huge econometric model which, for its users, such as BPA staff, is largely a black box. For the most part, staff members access 1 ts varlous outputs remotely but do not actually run the model. Though general characteristics of the model are known, the finer details of its operation are not. As a result, BPA staff, like virtually all of the subscribers to DRI's service, must trust that the national economic model performs its multitude of calculations correctly and that each of its components produces credible outputs.

Despite the opacity of major aspects of the DRI model, a number of characteristics of its basic projections (TRENDLONG2006, ORTIMLONG2006B, and PESSIMLONG2006B) are transparent and, as such, their consequences may be examined. Most noteworthy is the smoothness of all three trends, which differ quantitatively, primarily in the rates of growth of key variables or indicators. No major economic (and presumably social and political) mishaps are assumed to occur over a twenty-five year perlod. While this is no doubt an artifact of the inability of DRI's econometric model to forecast unique disruptive or discontinuous events (1.e. catastrophes and windfalls), undisturbed economic trends are unlikely and certainly contradict the last 25 years of history.

Furthermore, DRI's long-term trends and projections tend to reflect the same short-term bias that more generally 
colors long-range forecasting: the long-term future conspicuously reflects the recent past. For instance, twentyfive year projections of oil prices were quite high when the effects of the Arab oil embargo and the Iranian hostage crisis were being felt but the entire forecast trajectory dropped significantly, as soon as it began to reflect its author's perceptions of the recent (and no doubt temporary) oil glut. Thus, in many ways, these long-term projections fit Ackoff's definition of reference projections: "extrapolations from the past into the future under an assumption we know to be false: that things will continue to be done and to happen as they have in the past: that is, without significant interventions by decision makers or the environment" (1978:60). What is of cruclal Importance is how consclous users are of this assumption of constancy and the uses to which they put the results. These issues w111 be addressed below in the discussion which concludes this chapter.

As noted earlier, the economic base model is, in fact, a serles of techniques for projecting employment in each of a number of basic industries and from the resulting values infering the size of the non-basic industry workforce. Though employment is a central driver for many of the models the procedures for its derivation (by major industry category) are perhaps the least well-structured of any modeling carried out in the BPA system. Judgmental ad- 
Justment of industry trends is necessary because of (not in spite of) the sensitivity of the various components of the forecasting system to changes in employment: economic activity in regional basic industry is too intimately inked to specific business enterprises and developments to entrust its projection to mechanical trending. Unfortunately, however, such an approach to basic industry employment estimation leaves the forecast vulnerable to (or dependent upon) the quality of not one but a number of data sources (e.g. industry estimates, state employment records, Census of Agriculture, etc.). From the standpoint of "consumers" of the BPA forecast, each of these sources constitutes yet another black box.

A fundamental underlying assumption of the economic base model is that the $\mathrm{mix}$ and primary characteristics (e.g. mode of production, resource requirements, labor intensiveness, etc.) of basic industries will remain unchanged. Allowances were made for such factors as anticlpated productivity increases, but no explicit consideration was given to such possibilities as the wholesale out-migration of key industries (e.g. aluminum), the impacts of significant technological breakthroughs, or the effects of planned, industry-selective regional economic development. Events of this sort should they occur could not only push employment levels outside the range considered for the forecast by also sig- 
nificantly alter the pattern of growth (or, possible, decline).

The calculation of future values of non-electric fuel prices utilizing DRI projections as inputs, mirrors the latter in its assumption of no major economic or political upheavals. As such, the impacts of such political economic events as further embargoes on imported oll or the collapse of OPEC as a cartel (neither an implausible scenarios) are not consldered explicitly. Moreover, the calculation does not take into account the influence of electricity prices on those of non-electric fuels (a fact recognized by BPA and to be adjusted for in future forecasts). While changes in regional natural gas and oil prices are certainly constrained by international and interstate markets, they must remain competitive with electricity. For all practical purposes, projected non-electric fuel prices were inelastlc with respect to changes in the price of electricity.

Within the demand models are embedded a number of assumptions which, if not rendered explicit, silently influence predictions of future loads. The NEPP Industrial Model is econometric in nature, projecting future demands based upon historical relationships between electricity consumption and a set of price and employment related var1ables. A basic assumption behind any econometric model is that the real world causal relationships reflected by (but not necessarily described by) the model's regression equa- 
tions will not differ appreclably in the future from what they were in the recent past. At least in the Pacific Northwest, real electricity prices were not only low in relation to the rest of the United states but also displayed a trend of "negative growth" (i.e. real prices actually fell). The rapid increases seen in the prices of electricity and other fuels are recent and proceed unevenly, sometimes in parallel with one another, at other times not. Though the NEPP model was recently reestimated using pooled national data to describe general consumer responses to price more accurately, the question remains of whether or not a national data serles can adequately map or represent anticipated regional "rate shocks" or the economic reaction to a power surplus when a deficit was expected and planned for: two very likely near-term possibilities for the Pacific Northwest.

The hybrid econometric/end-use structure of the residential and commercial models, designed to allow users the explicit capablilty to manipulate key model parameters for policy analysis purposes, makes them somewhat less sensitive to the problem of regional economic change than the industrial model. Nonetheless, several components assume that certain key economic relationships remain stable. Most notable are those governing consumer fuel switching (choice of fuel used for equipment) and utilization (level/amount of use) behavior. Both of the ORNL 
models were adapted to the Paciflc Northwest. Originally, they were national models which predicted nation-wide patterns of energy consumption. Adapting them to the Pacific Northwest entailed the introduction of region-specific inputs (i.e. the economic/demographic projections) and the modification of base year values using information obtained from regional surveys (also part of the audit trail not often evaluated critically). The reglonal residential survey was conducted for BPA and PNUCC by Elrlek and Lavidge. The commercial survey lof reglonal bullding characteristics), performed by Westat Inc., is not truly regionally representative, focusing upon Seattle, Portland, and the Tri-cities. An assumption underlying its use by BPA was that the floorspace per employee ratlos and proportions of floorspace serviced by different fuels in these three sites adequately reflect regional patterns (despite the fact that no rural areas are represented in the sample). Aside from these changes, however, the models were left basically "national" in their character. In effect, this entails assuming that persons accustomed to low electricity prices (and, concomitantly, high per capita electricity consumption) w1ll respond to falrly rapld increases in prices in a manner conslstent with the national "norm". Elasticlty of response is a function of, among other elements, perceptions of cost and price trends and may vary across regions and perlods of time. 
Technologlcal innovation 13 worthy of note as a variable with significant real world consequences which is, rarely dealt with explicitly (or adequately) by energy forecasting models. In the case of the industrial model, technological improvement is embodied nowhere other than in the growth rate of productivity which serves as an input variable (i.e. some portion of the productivity increase results from new technology). The ORNL models explicitly address technological improvement, though not innovation, by use of efficiency/cost tradeoff curves. These plot equipment and appliance efficiency changes against changes in initial capital cost. A life-cycle cost minimization function specifies that as fuel prices increase, equipment owners will invest in more efficient equipment to offset operating costs. In principle, both of the ORNL models can use a series of tradeoff curves, each representing a further development in cost-effective technological efflciency. In practice, however, only one curve was used in each of the models. Even were a series of curves available for use, there exists no mechanism in the models for predicting what sort of innovations would occur lalthough this is, in many ways, a moot point since the model deals with end-uses and fuels, not specific equipment configurations), what their operating characteristics would be (i.e. on which curve), or when they would occur (i.e. which year the model user should select to "activate" a particular curve). The assumption 
underlying the resldentlal and commercial models, as they were run in the 1982 forecast, is that the building or home owner will select the more efficient among currently available equipment options but that the basic set of technological options will not change.

The adjustments to demand made to account for BPAsponsored conservation are predicated upon several assumptions. The savings estimates, developed independently by BPA's Office of Conservation, were, for purposes of the 1982 forecast, black box estimates (i.e. their paper-and-pencil derivation was not documented). Conservation remains a relatively unexplored region, making the estimation of the penetrations (i.e. percentages of customers affected) and savings associated with a particular measure highly fudgmental. Implicit in any BPA estimates, however, are the assumptions of continued institutional budgeting support for the anticipated power surplus. BRA's heavy empasis upon conservation in recent years, like its priority treatment in the legislation of the Regional Power Act, reflects an attitude cultivated in the shadow of an impending deficit which very likely will not materlalize. This casts some doubt upon the region's continued receptiveness to conservation as its chlef, near-term energy source.

The operating structure of the supoly oricing model, in its algorithm for allocating costs among different rate classes, embodies the priorities of the Regional Act. In 
doing so, it explicates an otherwise unstated, but nonetheless central, assumption of the forecast: the perpetuation of the Regional Act, its mandates, and the authority of the agencies or bodies it empowers. The centrality of this assumption is not surprising given the legislatively-defined obligations of the Bonneville Power Administrator (and the agency as a whole) and the lead time required in resource acquisition decisions (e.g. WNP 1 and 3 ). From a broader vantage point, however, there is no reason why the Regional Power Act might not be amended or even repealed given altered socioeconomic circumstances.

The least cost mix of resources, providing the power supply for the Pacific Northwest, is determined by a single, non-iterated run of a linear programing model developed by BPA's Division of Power Resources. This model assumes that resources will come on-line at their scheduled completion dates and (to the extent that the least cost mix determination was not performed iteratively with price-induced demand revisions) that the optimal mix is essentially static or fixed. The not uncommon slippages of completion dates of both thermal plants and non-thermal resources (and assoclated costs) suggest a more flexible (or less determinant) scenario.

Table IX provides an abbreviated summary of the forecast core assumptions identifed above. 
TABLE IX

SUMMARY OF FORECAST CORE ASSUMPTIONS

Associated Model(s)

DRI National Economic

Economic Base

Fuel Prices

Demand Models

(industrial)

(residential/

commerciall

Conservation

Supply Pricing Model

\section{Core Assumption(s)}

- no major economic or political mishaps

- smooth patterns of economic growth

- trends differ quantitatively, not qualitatively

- long-term future trends reflect those of short-term past

- mix and primary characteristics of basic industries remain unchanged

- no significant supply disruption

- natural gas prices independent of changes in electricity prices

- static technological capabilities (though cost-effectiveness of existing equipment may change)

- elasticity of national price response better representative of likely PNW future than regional pattern of recent past when cheap hydroelectric power was prevalent

- future regional fuel choice and utilization response reflect national patterns of recent past

- continued institutional budgetary support of BPA programs

- continued consumer receptiveness during possible power surplus period

- perpetuation of Regional Power Act

- Institutional stability

- supply avallablilty on schedule 


\section{Eorecast Evaluation: Risk and Reliablitity}

Having identified a set of basic core assumptions shaping, or framing, the forecast is now somewhat easier to assess the risk and reliability associated with it from the T-perspective. (Other dimensions of risk and uncertainty are revealed through the use of 0 - and $P$-perspectives, and the slgniflcance of these dimensions is discussed in Chapter VI). In his article on model evaluation (1982: 159-168), Labys distinguishes between two distinct assessment tasks. Model verification procedures, or tests, determine whether or not a model has been synthesized in a manner faithful to its conception. At issue are how a particular model's operating structure embodies theoretical principles or conceptual elements and whether that model displays internal consistency. By contrast, model yalidation is concerned with adequacy of the model in representing the underlying real world processes or events being modeled. But differently, verification is concerned with relationships, or mappings, among internal elements while valldation centers upon relationships between model elements (most notably its outputs) and external events, characteristics, or processes. This distinction is useful in evaluating the BPA forecast, first examining what validation and verlflcation efforts were undertaken and then delineating the areas of uncertainty which then remain. This analysis must be carried out 
on two distinct modeling levels: the level of the system as a whole and that of the individual models.

Though not all of the individual models depicted in Figure 24 are operationally interlinked (in the manner of, say, the varlous portions of a computer program) the larger system they comprise does, in the strict theoretical sense, constitute a model (in this view, each individual model constitutes a component submodel of the system as a whole). Given the data interdependencies existing between the components of the forecasting system -- models developed individually and differing both in methodological bases and conceptual approaches -- the basic evaluative criterion of model verification, internal consistency, is of central importance in evaluating the performance of the system as a whole. Such consistency is perhaps most conspicuously absent where internal model assumptions conflict or where necessary feedback linkages are missing.

In the real world, the state of the social economy of the Northwest is highly dependent upon the price and availability of the relatively inexpensive electricity which has been perhaps the primary source of its growth since the late 1930s. Clearly, cheap hydropower has been instrumental in attracting businesses, creating job opportunities, and encouraging a continued influx of population. Changes in its price or availability could curtail economic growth or cause a relocation of key industrial or commercial customers to 
areas outside the region. In short, the connections between basic economic and demographic factors and electricity prices are rich and bidirectional. As a model, the BRA system, however, is not geared to deal with the bidirectional influences between basic economic and demographic drivers, on the one hand, and demand and price variables, on the other: a fact which even cursory inspection of the reachability matrix depicted above guickly reveals. The models used to develop economic and demographic projections are insensitive to changes in the price of electricity: any internal assumptions which might relate these varlables to electricity prices are invariant (e.g. assumptions about high case electriclty prices on employment in the aluminum Industry) despite the fact that demand and price are dynamic. The risk associated with the overall organization system is thus proportional to the strength and significance of the feedback linkages not modeled (e.g. electric to non-electric fuel prices, demands to least cost mix, demands to irrigation, etc.). These linkages may, in fact, be of slight slgniflcance (In which case the exlsting model structure satisfices), however, this should be proven rather than assumed. A more fully representative modeling system would closely resemble a macromodel of the reglonal economy, though empasizing those factors most intimately concerned with the market for energy. At the time of this writing, 
however, no reglonal modeling system approached this level of sophistication any more closely than BPA's.

The "composite" nature of the BPA forecasting system renders model validation difficult in anything more than the most elementary sense (i.e. checking the accuracy of its output values as actual electricity sales data becomes available). Statistical evaluation criteria, such as those, which can be utilized in association with econometric or regression techniques but not with the performance of the end-use models. Moreover, without the addition of critical feedback loops the system as a whole cannot run to reach a complete equilibrium state. Ex post forecasts of historical demand are not particularly helpful, even if the necessary data should prove available, because of the pivotal role of the pricing assumptions of the Regional Act which did not operate historically but which constitute the most significant of foreseeable policy constraints. As a consequence of these limitations, the "risk assessment" carried out by BPA staff in association with the forecast was confined to a Judgmental evaluation of the probabilities of actual demands falling within the bandwidths defined by baseline, high, and low case projections (1.e. 158 likelihood loads will exceed the high case, $35 \%$ between low and baseline, $40 \%$ between high and baseline, and 108 below the low case). Without a more precisely defined method of evaluating the validity of the system as a whole, however, assessment efforts must 
direct attention toward the separate components, desplte the possibility that the system could function suboptimally even if all submodels performed as intended.

Individually, the models incorporated in the BPA forecasting system have been evaluated with various degrees of explicitness. For many of the models (usually those involved in developing economic or demographic projections) the principal criterion of evaluation seemed to be the general acceptability of the reasonableness of the results by the forecasting and user communities. Though the income model is econometric in nature, and was subjected to statistical analysis at the time of its development, the other economic and demographic projections models cannot be simllarly valldated. All can, however, be verifled to the extent that the mathematical algorithms used in making the profections can be 1dentifled and assessed.

The model validation and verification efforts actually undertaken during the first phase (i.e. the technical review) of the forecast taking place in December of 1981. The models finally chosen, one econometric (industrial) and two end-use hybrids (residential and commercial) display unique (and constrasting) strengths and weaknesses which become most readlly apparent during model evaluation. The NEPP model used for forecasting demand in the Industrial sector displays three distinct strengths which characterlze many econometric models: it is basically simple 
in its structure (relative to the models used in the res 1dential and commercial sectors), it requires relatively little data as input, and its performance may be evaluated statistically. In the recent past, model verification efforts included the reestimation of the model's equations (by $A E A$ ) and the addition of a lag structure rendering price response non-instantaneous, both of which presumably rendered the model more falthful to the economic realities represented. Model validation of the NEPP model, as with all econometric models, consisted of the standard test of statistical goodness of fit (of predicted to actuals over the historical period) and sensitivity analyses.

The ORNL models display somewhat different characteristics. As amalgams of engineering simulation and economic (or econometric) models, they embody the potential of displaying the strengths of both approaches. As simulation models (with "white box" structures) they are designed to calculate a number of useful "Intermediate outputs" (e.g. average energy use per unit, number of profected units, usage intensity levels, fuel choice) in the process of deriving their final products (projections of energy use levels). The outputs such models produce are thus potentially more varied and useful than those produced by similar econometric models. End-use models, however, are extremely data-intensive, requiring large numbers of varied inputs in order to operate. Though their basic conceptual structures 
may be reasonably simple, they embody a large number of internal equations to arrive at their final results. Finally, they contrast with econometric models in that their overall operation cannot be evaluated statistically (though their econometric components may be). These characteristics impose definite limitations (and demands) upon model evaluation efforts. The rather elaborate internal structures of the ORNL models render model verlfication a more complicated process. To test for internal model consistency, a large number of basic varlables must be tested. During the technical review phase, both ORNL models were subjected to extensive sensitivity testing of key inputs and fundamental model parameters. With the exception of a noticeably weak cross-price response (1.e. the effects of a change in price of a fuel on the consumption of substitute fuels) the models responded appropriately. Model validation is even more difficult to perform than model verfication on end use hybrids. Without statistical goodness-of-fit procedures, validation is 1 imited to ex post forecasts (forecasting for historical perlods) or comparison of forecast values with actuals as they become avallable. At least in this regard, the commercial sector model was somewhat better validated since, being based in 1970, it could be "fine tuned" to "track" ten years of history (1.e. hit 1970 and 1979 energy consumption control totals). The residential model was based in 1979 and hit the appropriate target total for that 
year, though it could not be tested against any historical period.

Several areas of risk associated with the demand models remain in spite of verification and validation efforts. In the case of econometric models, such as the NEPR model, the real significance of statistical evaluation criteria can be misunderstood. statistical goodness-of-fit ind lcators apply to the past (1.e. the historical relationship between independent and dependent variables) but not necessarily to the Euture. Though the terms (1.e. varlables) in the regression equations of an econometrlc model characteristically mirror fundamental relationships posited by economic theory, they do not imply causal connection. Correlations (or regressions) may reflect a series of diverse, but implicit, causal relations within which the independent and dependent variables are situated. The apparent stability of the relationship between a given dependent and independent variables may thus be predicated upon the constancy of socioeconomic "background factors" which, if disturbed, alter the relationship between the terms embodied in a regression equation. More simply put, the structure of the portion of the real world modeled may be more intricate than that of the econometric model and may undergo sufficient change that the model equations no longer represent it well. Only under stable economic and political conditions will the goodness- 
of-Elt of historical relationships between varlables be meaningful in the long-range future.

The very detailed structure of end-use models which is touted as a major strength is also a source of potential weakness. Both of the ORNL models are extremely data-intensive: they each require a large volume of diverse inputs in order to function. Generally, as the number of required Inputs increases so also does the likellhood that needed data will not be avallable. In such instances, key input values must be developed by extrapolation, simulation, estimation, or, frequently, Judgment. Though the use of judgment does not necessarily entail decreased accuracy (e.g. Ascher, 1978:82), in fact, notes that, in survey of econometric models "Judgment-free econometric models are considerably less reliable than comparable models using some judgmental input") it does tend to mask a model's "normal" performance and, if its role is not explicitly acknowledged, obscure the validity and generalizability of results. Though BPA staff members were quite explicit about the sources of inputs and parameters, it was not possible to assess the full Implications of judgments (or errors in Juagment) on the forecast (e.g. a portion of the historic floorspace additions data used as input to the commerclal model was estimated by the model bullders at ORNL, though the procedure was not explicated in detall). Thus, desplte credible results from sensitivity tests, a band of uncer- 
tainty assoclated with judgmental adjustment (or development) of inputs surrounds the utilization of the end-use models.

The SPM is a simulation model -- a sort of automated accounting structure for spreading anticipated construction, generation, and operation costs over a number of rate pools and customer classes. Verification of such a model is routine and necessary, carried out in the debugging of the associated computer code and, subsequently, in test runs. Validation, however, is not particularly critical since the SPM is not a forecasting model and does not itself predict the future (though it is driven by predicted demand). What is critical is that the model's embodiment of assumptions about ratemaking (as outlined by the Regional Power Act) and resources acquisitions are credible and consistent -- something determined by verification.

To summarize, as with all forecasts the uncertainty associated with the future imposes certain risks (in the non-technical sense of the term) and limits the reliability of the findings produced by BPA. Forecast reliability is determined by an evaluation of the models and methodology employed -- their verification and validation. The models employed in BPAs forecasting system were tested and subjected to perhaps greater public scrutiny and comment than any previous regional forecast. In many cases, this examination of the various elements of the forecasting system by 
the forecasting and user communities in the reglon was a primary mode of evaluation (e.g. assessing the credibility of assumptions and resulting values associated with key economic and demographic projections). Demand forecasting models were subjected to a technical review (including detailed scenario analyses and sensitivity tests) several months prior to the draft and final forecasts. Despite relatively extensive evaluation efforts, a number of areas of risk remain. (As noted above, some of the areas of risk fall in the province of the 0 - and P-perspectives, and will be discussed in the concluding chapter to this dissertation). The forecasting system, taken as a whole, lacks certain feedback loops which presumably are present in the real world. Effects which are in reality bidirectional are given unidirectional representation. A true system equilibrlum, however, may, in fact, differ only marginally from forecast values. In other words, this lack of feedback from demands and prices to economic/demographic projections (also, it should be noted, conspicuously absent from other regional demand forecasting systems or models) casts additional doubts on forecast reliability, though, it in no sense conclusively constitutes a signiflcant flaw.

The Pacific Northwest has displayed a unique set of circumstances surrounding electricity usage: abundant power, falling real electricity prices, and mild weather. Econo- 
metric models must be specifled using either region-specific historical series (which reflect conditions no longer existent) or more general (pooled or cross sectional) national data. The NEPP Industrial Model's equations were estimated in the latter fashion. Thus, risk is associated with the underlying assumption that industries accustomed to unusualIy high levels of electricity consumption will, when faced with rather abrupt rate increases, respond with "average" consumptive behavior. The operation of data-intensive end-use models used for resldential and commercial forecasts rests upon a larger volume of questionable date (and judgmental adjustments) than most econometric models, offsetting to some extent the benefits of their detailed, well-structured outputs and policy testing capabilities. Risk and reliability, however, must be assessed in the context of stated forecast objectives, (and ultimately evaluated in terms of actual forecast needs). The next section, which concludes this chapter on the T-perspective focuses upon the fit of the BPA forecasting methodology to the planning purposes it was designed to address. In Chapter VI, the appropriateness of these planning objectives are evaluated from T-, 0-, and P-perspectives, with significant additional insight resulting. 
Ends and Means: The Forecast in the context of Planning objectives.

At the beginning of this chapter it was asserted that from the standpoint of the traditional T-perspective approaches both the overall methodological strategy and the specific techniques associated with a forecast are, or should be, determined by the planning objectives to be addressed. However much the competent use of models and methods may reduce uncertainty, the final product must answer the correct questions if it is to be useful. An evaluation of a forecast must assess the appropriateness of the procedures followed to broader planning objectives.

The nominal objective of BPA's first independent forecast was to provide the Administrator with information necessary for him to make defensible decisions about which resources to acquire to meet his obligations to the reglon under the Power Act. Thus, in the parlance of the opening section of this chapter, the "set of decisions for action in the future" constituting the power plan were speciflc acquisitions to be needed to maintain a workable load-resource balance. The forecast provided information on those anticipated loads and the corresponding rates to be charged to different customer classes. On the methodologlcal level, a "most likely" (1.e. baseline) forecast was developed along with high and low growth scenarios to provide resource planners with credible limits on the range of acquisitions 
to consider in developing an optimal generation mix. On the level of models, the demand forecasting capabilities reflected a need to address the important effects of conservation while the ratemaking algorithm of the SPM embodied the priorities of the Regional Power Act.

Given that the objective of the $B P A$ forecast was indeed to determine what quantities of generation capability (or in the case of conservation, generation substitutes) will need to be acquired in the near future, a range approach renders a measure of the associated uncertainty described above less critical. What is cruclal, from the standpoint of planning, is that a number of "parcels" of new resources can be identified which can be acquired as needed to meet future load requirements. The flexibility associated with such a planning strategy -- mapping out a series of resource alternatives to address a range of load growth scenarlos provides additional latitude for actual demand to differ from that predicted by the forecasting system. Under such a planning philosophy, actual loads may deviate from the baseline trajectory without serious consequence, so long as they do not fall outside the "boundaries" formed by the low and high cases. In the context of this planning philosophy land stated objectives) the method (i.e. range forecast) and the models underlying the BPA forecasting system are appropriate choices (though, for the purposes of resource and conserva- 
tion acquisitions, the demand models actually are far more disaggregated than necessary).

Establishing that a forecast is well-fitted to stated objectives and planning priorities begs several larger questions, ones which cannot be addressed fully (or appropriately) by the $T$-perspective with its analytical emphasis on formal techniques. The first question is whether or not the nominal objectives which the forecast addresses define the full (or true) set of uses to which it will be put. As a general rule, the more plentiful and accessible a given resource, the less stringent the planning requirements associated with its use. In the case of Columbia River hydropower, during the era when the system of dams was conspicuously "overbulit", reglonal power marketing was much simpler. In the current situation, with cost escalations of the WPPS projects and the Reglonal Act legislation severely constraining power marketing decisions, ratesetting and revenue planning begin to resemble, more ciosely, reglonal economic planning as the anticipated impacts of electricity prices on different rate classes (and industries) are given explicit consideration. clearly, such considerations go beyond the task of matching resources to loads and define new, expanded uses for forecast results. This implies a second more fundamental question addressed more fully in Chapter VI: whether the planning process is approprlate 
given observable social, political, cultural, and economic trends in the region.

Since forecasts are an integral part of the decisionmaking process, they help give shape to the future (rather than merely attempting to describe inevitable outcomes). The forecasts upon which the decision to build the WPPSS nuclear plants was based proved, at least in part, selfdenying: the high costs incurred trying to meet anticipated high demand raised rates to the point that consumption fell below the levels which would otherwise have been attained. Detractors of BPA's forecast similarly argue that a low forecast could be self-fulfilling in that needed resources would not be built based upon forecast conclusions, thereby restraining normal growth. Both the decision-influencing effects of the forecast and the novel challenges the region must face as it experlences a serles of "rate shocks" suggest that a more ambitious approach to power planning and, correspondingly, forecasting may be required. A range forecast (driven by smoothed national economic "reference projections") may adequately define a "bandwidth" of resource needs within which actual loads may fall but it cannot address qualitative socioeconomic shifts or serve to prepare decision makers for the type of critical situations they might have to face.

The chapters which follow investigate the BPA forecast through the lenses of the 0 - and $P$-perspectives, define the 
broader arena of energy issues related to power planning decisions, and suggest where information needs surpass what current forecasting techniques are capable of providing. Chapter $V$ cross-cues insights from the three perspectives, looking at key relationships between them. The concluding chapter, taking as its point of departure the insights of all three perspectives and the cross-cues, will suggest another possible approach to regional energy forecasting: one geared to a wider spectrum of issues and considerations. 
CHAPTER III

THE O-PERSPECTIVE

ORGANIZATIONS AND THEIR PRODUCTS: AN INTRODUCTION TO THE O-PERSPECTIVE

While BPA's flrst independent long-term forecast reflected a wide varlety of often diverse technical considerations, it was also the product of a large, internally differentiated organization. As such, its contents were additionally shaped by a number of considerations to which a purely technical outlook is blind. To recognize the imprint which organizational processes and procedures left upon the forecast, it is necessary to employ a paradigm of inguiry alternative, but complementary, to that of the technical analyst: the organizational or 0 -perspective.

The 0-perspective examines the manner in which organlzations actually operate, viewing their decision-making, problem solving, and production processes as the output of one or more internal units responding to both the challenges and causal factors that comprise its social, economic, technological, and physical environments. Characteristically, organizations display internal structural and functional differentiation. While the units created by this internal division of labor appear at least nominally integrated in the overall organizational scheme, they 
are additionally characterized by parochial priorities (which may conflict with those of others) and both formal and informal rules for behavior. Operating procedures for dealing with ongoing day-to-day activity are generally standardized, though organizations may develop ad hoc procedures in response to new challenges or situations. In many cases, standard operating procedures (SOPs) evolve from the routinization of ad hoc procedures (AHPs). Due to the division of labor and responsiblitty in organizations, problems (and their solutions) are characteristically fractionated, with portions assigned to the appropriate organizational division. Even in cases where basic decision making is localized, the information supporting it tends to originate from a number of different sources. The habits, experiences, and professional credentials which form a large part of an organization's history or institutional memory predispose it towards incremental change and slow adaptation. In this context, problem solving proceeds not by optimizing but by satisficing (1.e. using, where necessary, satisfactory or workable, but not necessarily the best, solutions), observing both objective and subjective criteria. A strategy of satisflcing endeavors to avold uncertainty to the greatest extent possible, sometimes to the point of ignoring it where it actually exists (Linstone, et al, 1981:57). 
organlzations, then, manlfest an array of common characteristics and operational dynamics which are both mirrored and llluminated by the o-perspective. Organizations, however, also vary along a number of significant dimensions. These variations are what give particular organizations and their products their uniqueness. These variations are also the organizational features which are identified and explained by the o-perspective.

Perhaps the most obvious, though not necessarily the most important, dimension that organizations may differ along is that of size. BPA, in its entirety, employs over 3,000 persons while some of the interest groups or consulting firms it deals with are composed of a handful of individuals. A more important dimension of consideration, in terms of the o-perspective, is the degree of internal segmentation or differentiation which an organization displays -- a characteristic which is not solely dependent upon its size. Organizations may be internally differentiated according to structure (e.g. chain of command) and/or function (e.g. task assignments). The degree to which the operation of such units or segments is integrated forms yet another dimension of variation. Integration is not necessarily stronger in simple organizations. The operations of extremely differentiated organizations may fit well together while those of internally simple organizations may display poor goodness-of-fit and coordination of activity. 
Clearly, however, the possible problems resulting from operational misfits or from organizational divisions working at cross-purposes are greater in more complex organizations. organizations also differ as to the number and kind of missions they attempt to fulfill. They differ with respect to their rates of internal change (expansion, rearrangement, or contraction) and the degree to which their operating procedures are standardized or fixed. They display a variety or spectrum of management and decision-making styles (often in different parts of the same organization) which range from strict autocracy to consensus. Organizations also vary in terms of the degree of congruence between structure and function. Informal or functional authority may crosscut the legltimate structural hierarchy of control or complement $1 \mathrm{t}$.

A fundamental dimension across which organizations can be seen to vary is that of the environment which they must confront. Environments range from highly stable or placid to extremely turbulent and risk-fllled (Emery and Trist, 1975). Moreover, a given organization's relevant environment may change over time: new, or different, elements may appear which need to be addressed (e.g. environmental protectionists) or older, established elements may change their behavior (e.g. fast food restaurant patrons seeking salads and a wider dietary fare). Organizations vary according to the quantity, quality, and rate of feedback 
they receive from their environments, making the degree of difflculty involved in directing their actions highly variable. Organizations also differ in both the degree and flexibility of their adaptations to their environments. Those that are unable to adapt to the conditions which constrain their actions (and provide opportunities) eventually fail. Those that adapt strongly to their surroundings tend to be successful in fulfilling their missions provided the adaptation is not so rigid that it prohibits necessary change when key contours of the environment undergo significant alterations.

Finally, organizations (or parts of them) differ in terms of both the cohesiveness and type of their "corporate cultures" (Deal and Kennedy, 1982). Corporate cultures are constituted by the basic concepts, values, beliefs, and rituals maintained by an organization. They are personified by the "heroes" who serve as exemplars or role models for an organization's employees and carried (i.e. transmitted and maintained) by formal and informal networks of communication. strong corporate cultures spell out how people are to behave and, by doing so, provide a sense of organizational identity which is a key determinant of success. Unique cultures may evolve in organizational subunits and may wax or wane over time.

This chapter then looks at BPA and its forecast using the paradigm of the 0 -perspective. It begins by looking 
inward at the intraorganizational dynamics of BPA -- changes in its structure, revisions in agency missions, and evolution of operating procedures. Next, the chapter looks outward at the interorganizational environment (or power planning arena) within which BPA finds itself. The redefinition of BPA's duties under the Reglonal Act altered its relations with a number of parties in the region. As a result, these parties offered new challenges to which BPA had to respond. The significance and the implication of these challenges may be better understood by identifying the principals and examining their organizational motives, histories, and modes of operation. The chapter concludes by describing the BPA forecast as an organizational output, drawing upon the findings of the previous sections and integrating them into a coherent picture consistent with the paradigm of the 0 -perspective.

\section{THE INTRAORGANIZATIONAL DYNAMICS OF BPA: A LOOK INWARD}

\section{overview: The climate within the organlzation}

In the chapter introducing this dissertation, the role of $\mathrm{BPA}$ in the continuing development of the Pacific Northwest was outlined. As an agency of, first, the U.S. Department of the Interior and later the Department of Energy, BPA functioned to market the power generated by Federal hydroprojects and to maintain the transmission network necessary to dellver this power to its customers. For most of 1 ts 
history, engineering and construction functions comprised the lion's share of the agency's activities and employed the bulk of its staff. As long as the primary form of resources developed were high-head dams and the base of residential, commerciaI, and industrial customers grew steadily, BPA's duties and responsiblities were unambiguously defined and its organizational medus eperand highly routinized. In many respects, power planning was itself an engineering problem during these early years. The market for power grew steadily of its own accord. Bonneville's chief mission was to construct and maintain transmission facilities.

Beginning with the initiation of the Hydro-Thermal Power Plan, however, the focus of BPA's regional responsibilities began to shift, subtly at first, later more dramatically. The challenges of net billing agreements, emerging southwest power markets, growing sentiments of environmental protectionism, excessive cost overruns assoclated with the wPPSS nuclear projects and, ultimately, Regional Act legislation provided the impetus for augmented marketing, forecasting, and resource and conservation planning efforts. During this time period, the organization grew in size as its functional emphasis shifted. In 1980, immediately preceding the passage of the Regional Act this trend of growth was reflected in an agency-wide "nomenclature change" in which all units were upscaled: Divisions became offices, Branches became Divisions, and sections 
became Branches. Subsequent disproportionate growth of particular organizational units (such as Conservation's evolution into a Division within Power Management and, ultimately, an independent office) in turn mirrored the shifts in functional emphasis.

As the agency and the region entered the 1980s, load growth futures were shrouded in uncertainty. It had become clear in the late 1980 s that the high growth scenario justifying the construction of flve nuclear plants would not materialize as expected. Whether the growth would merely slow enough to lessen the anticipated deficit or drop off so dramatically that the region's resources would provide a surplus of power in years to come was a question immediately In need of being answered. Under the terms of the Regional Act, Bonneville became responsible for obtaining whatever resources were needed to meet the requirements of any of the region's utilities entering into wholesale power contracts with them, giving priorlty to conservation and renewable resources over thermal generation. The Act, however, had been first drafted at a time when a seemingly inevitable deficit situation would have unquestionably motivated the region's utilities to enter into power exchange agreements with BPA in order to minimize rate impacts of resource expansion on their residential and small farm customers. Such power exchanges would provide a mechanism for enforcement of the Councli's long-range plan. In a surplus situa- 
tion, however, utilities might not find such power exchanges cost-effective and Bonneville could instead find ltself in a situation where its chlef problem would be how to market power from overbuilt generating resources rather than how to attain the maximum possible savings from conservation.

In the wake of the passage of the Regional Act, Bonneville found itself confronting just these issues. The changes in the organization's structure, with the waning of the relative importance of its traditional engineering functions parallelled by a waxing of that of its planning decision support system (e.g. forecasting, financial analysis, conservation and resource assessment), reflected a recognized need to address these uncertainties as effectively as possible. This section on intraorganizational dynamics looks at those units within BPA participating in (or affecting) the forecast process, examining their chief characteristics and describing their change and development over time.

\section{Rower Requirements: Projecting Loads and the Regional} Economy

As noted in the introduction to this chapter, organizational units not only operate using habitual standard operating procedures but develop ad hoc procedures in response to both external and internal challenges during periods of change. These AHPs may be transitory, reflecting temporary, non-recurring circumstances or may "ossify" into 
SOPs. At the time of the 1982 forecast, the Division of Power Requirements (DPR) was in the midst of a period of relatively rapid organizational growth and change. The nature and significance of this change, as well as its influences upon the shaping of the forecast, may be most clearly seen using a perspective which contrasts the Division's organizational structure and function in 1982 with that of earlier periods.

In the late 1960s, at the time of the conception of the Hydro-Thermal Power Plan, forecasting functions were performed by the organizational ancestor of DPR, then called the Branch of Power Marketing of the Division of Power Management. As discussed earlier, demand growth in the region, up to that point in time, had proceeded regularly and rapidly -- forecasts were basically extrapolations of relatively steady trends and engineer ing, not resource planning, challenges were the ones BPA as an organization was compelled to address. As the name Power Marketing suggests, the problem which had traditionally been addressed by the agency was how to sell the power having its source in the network of high-head hydroelectric facilities overlaying the Columbia River system. With a heavy influx of both population and large electricity-intensive industries in the 1940 s and 1950s, and a corresponding relatively stable growth of reglonal hydroelectric potential, BPA's mission as a marketing agency was clearly and simply deflned. When 
trend extrapolations of the early 1970 s indicated an imminent condition of demand exceeding regional hydroelectric capabilities, the complexion of the mission began to undergo change.

Power Marketing had in many ways been one of the few havens for economists in an organization overwhelmingly dominated by engineers and engineering considerations. By 1971, an increasing attention paid to economic concerns within the agency was reflected in the formation of two Sections within Power Marketing: Economic Studies, and Load Forecasting. Load Forecasting functioned primarily to assist the region's small public utilities which lacked technical staffs in the preparation of their submittals to PNUCC's Sum-of-Utilities forecasts. Economic studies prepared analyses of regional and subregional economic and demographic trends to support the preparation of load forecasts.

In the face of apparent forthcoming power shortages, shifting priorities in agency policy were reflected in the form assumed by the organization's internal structure. Had the high-demand sou forecasts of the early 1970 s proven accurate, the combined output of the Eive scheduled WPPSS nuclear plants would have proven insufficient to meet loads by the end of the century. Under such circumstances, the evident problem would not be to find new markets for surplus power but to encourage efficient resource development and 
prudent use of conservation in the region. When the Branch of Power Marketing was renamed 'Power Requirements' (without any structural change at the section level) in the early 1970s, it mirrored a progressive shift in organizational priorities. Subsequently, in 1975 Power Requirements devolved organizationally to become a section within the Branch of Power Resources. The Requirements section performed the same basic functions as before until 1977 when PNUCC purchased an econometric model to be used as a cross-check to the soU forecasts. Because, at this date, PNUCC did not have its own independent forecasting support staff (relying entirely upon the staffs of the member utilities) this model was made resident on BPA's computer system and attended to by BPA staff.

By the late 1970s, however, problems with the region's earlier forecasts had begun to become apparent. Growth in the region had slowed and showed evidence of slowing further. Additionally, legislation being prepared would place the region's electric power planning under the authority of a council composed of representatives of each of the four states. Given the fallure of past planning and the need for more varled and flexible forecasting capabilitles, BPA made a decision to expand both the role and the scope of 1 ts forecasting efforts.

In 1980, Reguirements became a Branch of the Division of Power Resources, as an agency-wide nomenclature change 
elevated all organizational units one level in the bureaucratic hierarchy. Shortly thereafter, however, in early 1981, Power Requirements became a Division structurally independent of Power Resources. Within this newly-formed Division were two Branches: the Branch of Economic and Utility studies and the Branch of Energy Modeling and Analysis. In this reorganization both the Division's responsibilities and staffing levels were increased. Utility studies functioned in many ways in the same fashion as the Load Forecasting section of the Power Requirements Branch had years earlier: it participated in the sou forecasts by reviewing forecast submittals of small utilities and preparing demand projections for those not having their own technical staffs. Economic studies again prepared regional economic and demographic projections as had its earlier counterpart. This time, however, the projections were tallored to the input data requirements of the new, sector-specific demand models to be used in developing BPA's first and subsequent independent regional load forecasts. The development and maintenance of these models, along with specialized data bases used to support their operation, were the key responsibilities of the Energy Modeling and the Energy Analysis sections.

By 1982, Power Requirements was no longer one of the few havens for economists in the agency. The principal actors in the Division responsible for the preparation of 
the long-term forecast were, however, all trained as economists, and the inherent strengths and limitations of their disciplinary perspective strongly colored the character of the forecast. This organizational precedent of disciplinary specialization undeniably exerted a strong influence upon both personnel selection and problem-solving approaches. The general approach of utilizing economic and demographic projections to feed input data into complex end-use forecasting models reveals certain assumptions. In brief, the approach assumes that profections of key economic and demographic drivers are sufficient to acquire a picture of the future adequately well drawn for long-term resource planning. Contrariwise, it is assumed that social and political trends, as well as true innovations in energy technology need not be dealt with explicitly -- the range of their significant impacts, in other words, is treated as entirely embedded within the three economic/demographic scenarlos incorporated into the forecast. Social, pollt1cal, and technological forecasting were apparently so forelgn to the forecast princlpals that they were treated as unworkable or unimportant, despite the fact that the structure of the demand models would have permitted scenario analyses along such lines.

Though SOPs are somewhat helpful in understanding how Power Requirements operated during the period coincident with the production of its first long term forecast, AHPs 
developed as the Division grew and internally differentiated itself prove more revealing. SOPs played their strongest role in the Branch of Economic and Utilities studies. As noted above, the Utility studies section, reviewing utility forecast submittals and providing technical assistance to small public utilities in the region, functloned, in large measure, as the Load Forecasting section of Power Marketing had nearly a decade earlier. Economic studies fulfilled the same mission as lts predecessor of the same name, though its roles and responsibilities were augmented considerably as BRA prepared to develop an independent forecast. Although part of the same Branch as Utility studies, Economic Studies was linked by function more strongly to the Energy Modeling and Analysis Branch. The specific economic and demographic projections prepared by Economic studies served as inputs to the demand models maintained by Energy Modeling and Analysis. Though "trled and true" extrapolation techniques were used to prepare some of the projections le.g. industry-speciflc employment) new, more elaborate computerized models were developed (e.g. population) or accessed (e.g. DRI model of the national economy) to develop the majority of the section's products.

For all practical purposes, Energy Modeling and Analysis was something new organizationally. Prior to 1982, BPA had not prepared an independent long-term forecast. Prior to 1980 , the models ultimately used to develop the 
demand projections were not even resident on the BPA computer system. Energy Modeling and Analysis was the product of organizational expansion. Though the models used to prepare the forecast were well-structured with regard to their data and operating requirements, there existed no SOPs governing their use. The new Branch, in addition to producing load forecasts, expended a large measure of its energies acquiring, developing, and analyzing data about the sectors modeled. The Energy Modeling and Energy Analys is Sections were distinguished not so much by function but by focus -- the Energy Analysis section concerned itself with residential and commercial sectors while the Energy Modeling Section handled the industrial sector as well as peak, hourly, and short-term forecasting.

The evolution of AHPs proceeded somewhat by trial-anderror as Power Reguirements responded to four basic challenges in the period preceding and coinciding with forecast production. First the end-use models developed at oak Ridge National Laboratory had to be adapted to the Pacific Northwest as the territory was defined by the Regional Power Act. This entalled the acquisition of data through surveys, the reestimation of certain key model parameters, and extensive model testing and sensitivity analysis. second, anticlpated savings attributable to BPA-sponsored programs had to be incorporated into the forecast. Next, the demand models needed to be linked to the Supply pricing Model so 
that an equilibrium state of prices and loads could be determined. Finally, speciflcs of the forecasting process had to be subjected to public review and in some cases modified. The results of these four tasks inevitably bore the stamp of the emerging Branch's style and, in many respects, the manner in which they were arrived at generated many of the assumptions at the core of the forecast. Figure 25 graphically depicts the changes in BPA's organizational structure over time. Section level detail is provided only for those parts of the organization which in 1982, were Involved in the production of the long-term forecast.

\section{Bates: Lessening Disparities Under the Terms of the}

\section{Regional Act}

During the 1982 long-term forecast it was the output of the Supply Pricing Model (SPM) maintained and operated by BPA's Division of Rates that was the element of the 1982 forecast most critically scrutinized by both special interests and the general public. It is through wholesale rates charged by BPA to both public and investor-owned utilities that the forecasting and planning process has its most direct, and most clearly understood, impact upon the region's residential, commercial, and industrial consumers. Moreover, the resource scheduling and electricity pricing assumptions reflected in the operation of the SPM were more controversial than those constraining the results of the 


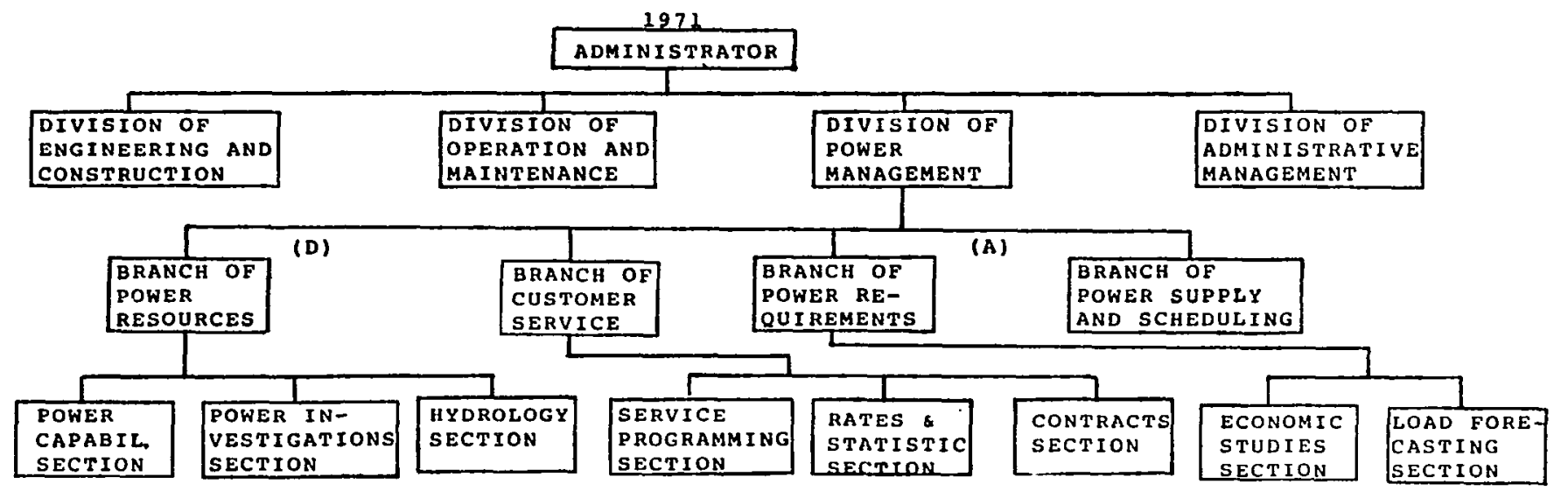

Fiqure 25. Organizational charts of BPA 1971 - 1982 (selected detail) A look at the growth of power requirements (A), rates (B), conservation (C), power resources (D), and financial management (E) 


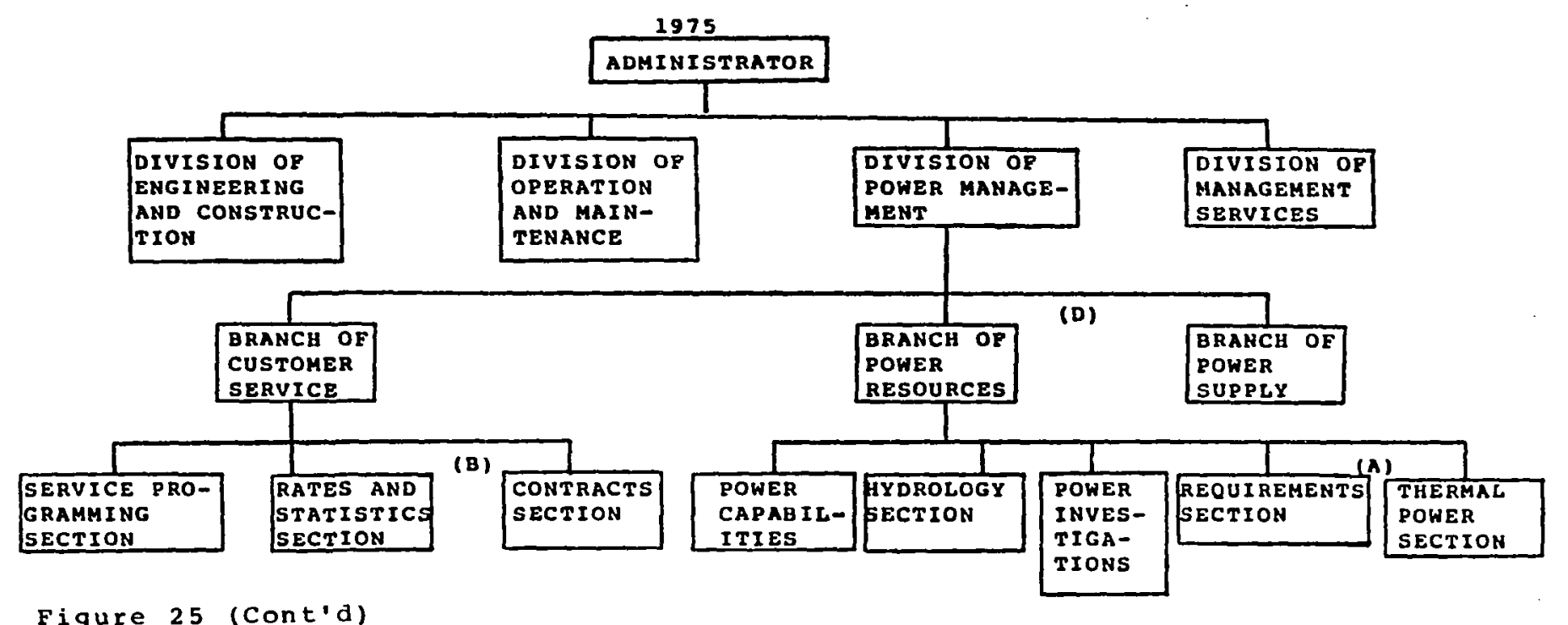


1980 (post nomenclature change)

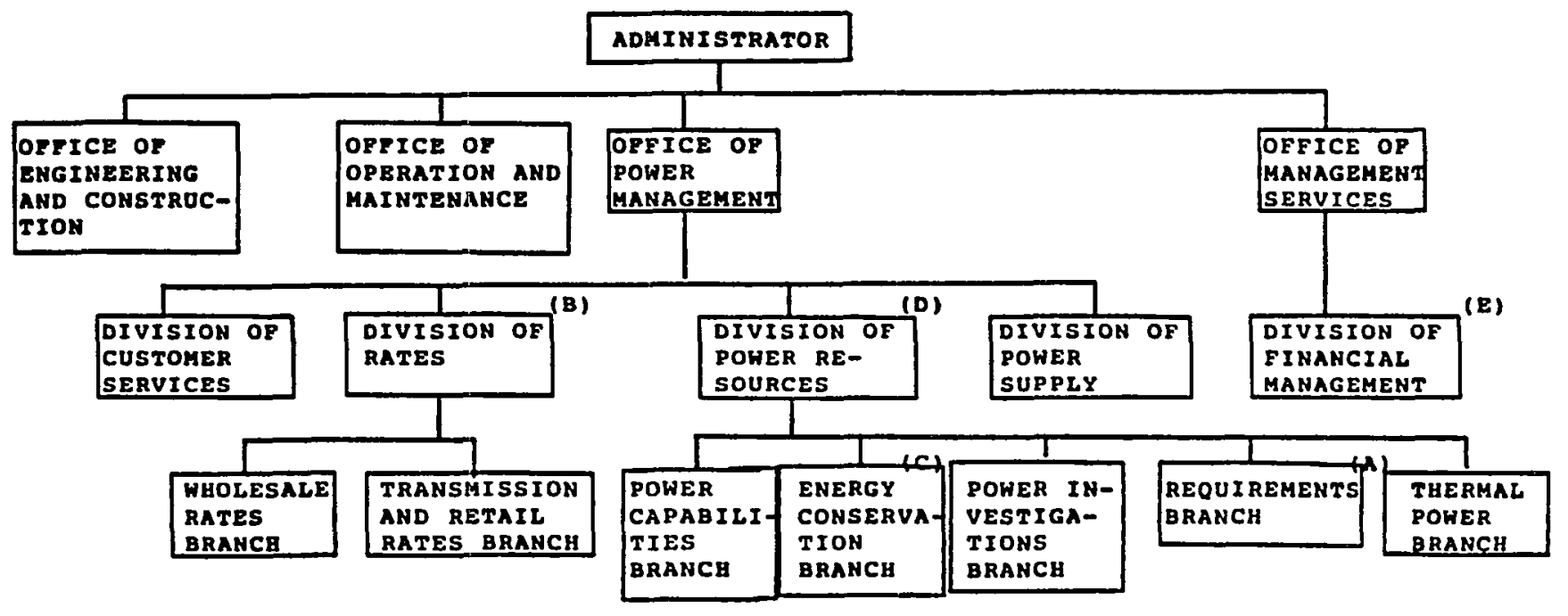

Figure 25 (Cont'd) 
1981

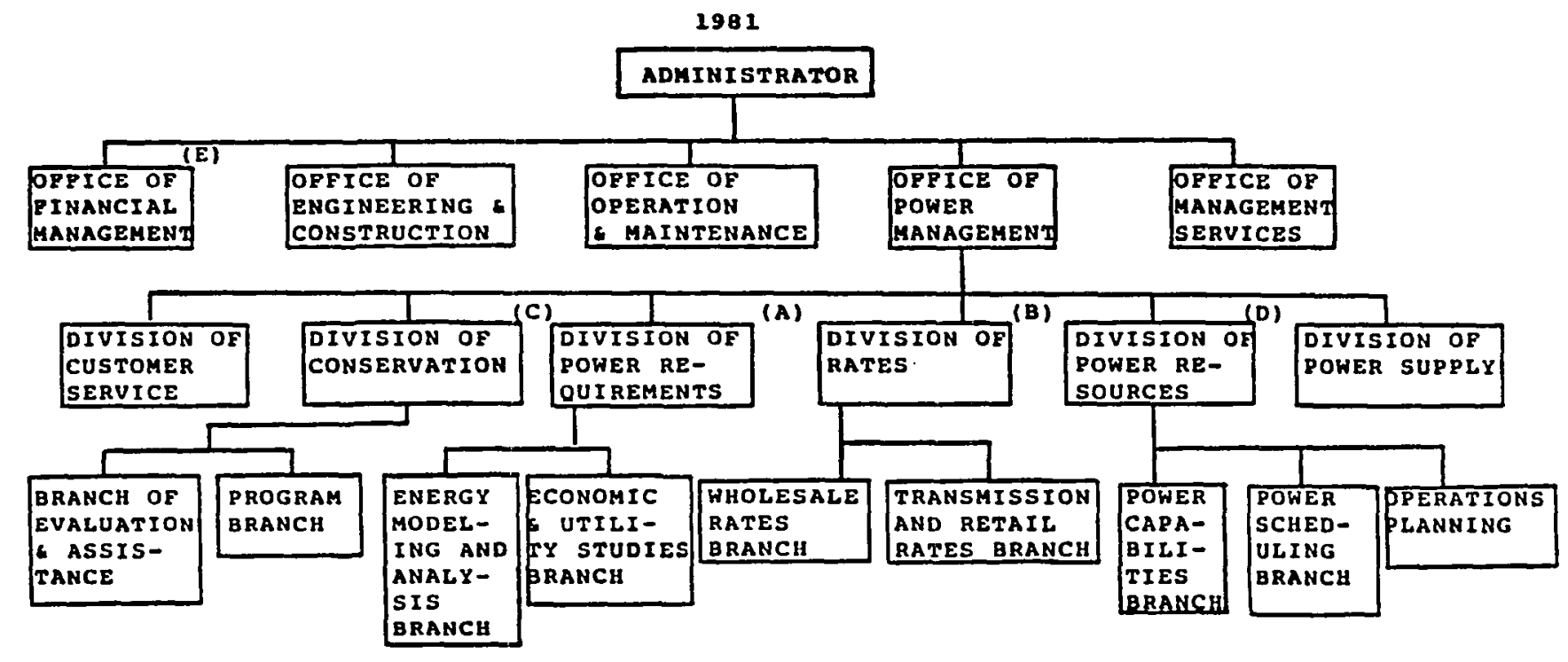

Figure 25 (Cont'd) 


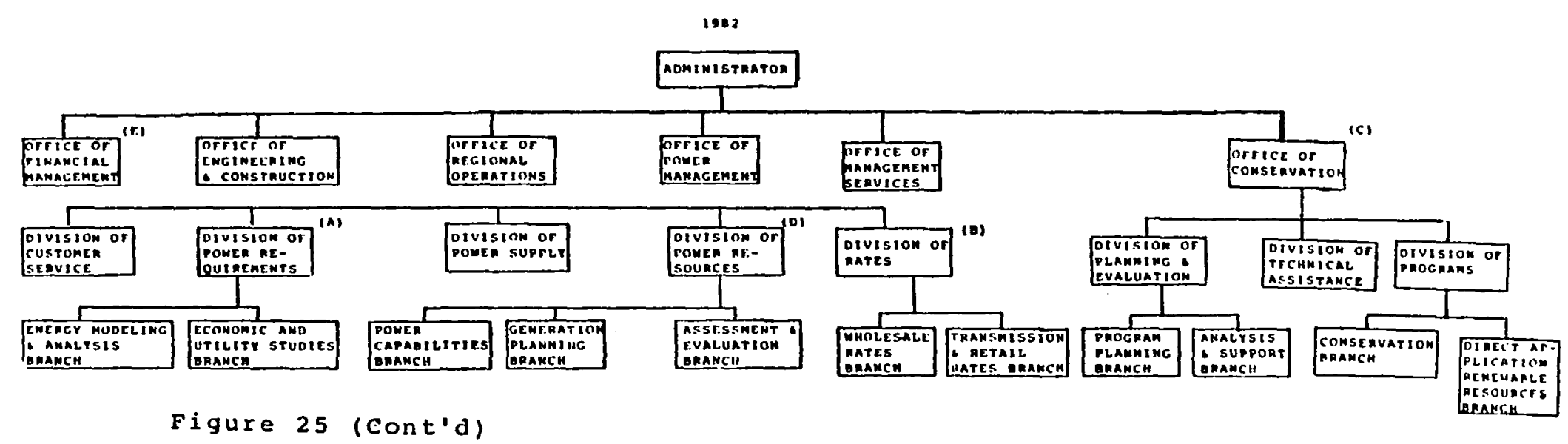


demand models. As noted in the previous chapter, electricity demand and price are linked; higher prices lower demand which either delays or eliminates the need for certain key resources within the forecast perlod. While increased electricity rates seemed a foregone conclusion for the region, the magnitude of the increases as well as their differential effects on various rate pools were unresolved 1ssues. Thus, the assumptions built into the SPM strongly influenced who would bear the brunt of rate increases and which utilities would be able to retrieve some of their sunk resources. (Costs of construction of generation projects may be included in a utility's rate base only when the resource is generating power. Utilities which had invested in the WPPSs plants thus had a vested interest as to which plants came on line in what year.)

Like the other units within BPA involved in the longrange planning process, Rates found its role expanding and becoming more complicated during the late 1970s. The Bonneville Project Act which created the agency ldentified Its preference customers and established guldelines for distinguishing between rate pools. As long as the only resource was a steadily growing network of hydroelectric facilites, wholesale ratemaking was a straight-forward process. The introduction of the Hydro-Thermal Power Plan, the Canadian Treaty, the Intertie sales to California, and the passage of the Reglonal power Act all added new wrinkles 
to the ratemaking picture and though only a very small number of the Division's staff directly participated in the production of the forecast, virtually all were affected by the outcome of the forecasting process.

Up until the early 1970s, ratemaking was one of a number of functions carried out by the Customer services Branch of the Division of Power Management. The subdivision of this Branch into service Programming, Contracts, and Rates and statistics sections, with their corresponding specializations, mirrored the increase in attention which changing regional circumstances required of the agency. By the time of the 1980 agency nomenclature change alluded to earlier, Rates had become a Division with two Branches: Wholesale Rates and Transmission and Retail Rates. The former Branch was the one actually participating in the 1982 forecast since the SPM was operated under Its "sponsorship" by staff in its Economic Analysis section. The entire Division, however, was affected by the rate design challenges offered by the Regional Power Act, a projected energy surplus, and the troubled WPPSs construction projects.

Rates, like Requirements, has traditionally been a haven for economists in an organization which had been heavily devoted to engineering concerns. In recent years, however, further specialization has accompanied a numerical growth in staff. These specializations are reflected in the names of the sections comprising the Division. In addition 
to the Economic Analyses Secticn, Rate Design and Rate Evaluation Sections made up the Wholesale Rates Branch. Cost and Transmission Rates Branch, by contrast, was divided into Transmission Rates, Cost Analyses, and Revenue Forecast Sections. The organization of the entire Division centered upon dealing with alternatives, contingencies, and uncertainties where, before a certain stability could be assumed to characterize the ratemaking environment. Thus, forecasts and new planning strategies figured prominently in the Division's evolving operations. Individual staff members were required to be innovative while, in many respects narrowing their focus of concern. While the ratemaking provisions of the Reglonal Power Act, the troubled WPPSS flnanclal situation, and the determinant structures of computerized modeling tools defined very specific problems to be solved, the procedures to be used to deal with these rate and revenue problems had to be developed ad hoc. Thus, economists with specialized training in ratemaking, modelIng, and forecasting found their way into the center of the Division's new mission.

\section{Eenservation: A New organizational Prlority in the 1980s}

OE all the organizational units within BPA taking part in the production of the long-term forecast, by far the fastest growing was the office of conservation. The officlal BPA forecast, as noted in the prevlous chapter, reflected conservation savings attributable to BPA-sponsored 
programs. This explicit introduction of savings estimates into the BPA forecasting and planning process signalled an increasing significance of the new office to the agency. In the early and mid-1970s, when an apparent power deficit loomed over the region, conservation first entered into the long-range power planning process, though admittedIy overshadowed by the planning of large thermal generation projects. Within the legislative arena the seeds of the Regional Power Bill were being sown and within the utility industry the need for considering conservation as an integral part of resource planning was slowly, and somewhat grudgingly, being recognized. In the late 1970s, an Energy Conservation Section (soon to become a Branch with the 1980 nomenclature change) appeared within the Power Resources Branch of Power Management, side-by-side with Power Capabilites, Power Investigations, Requirements, and Thermal Power sections. At its inclpience, Conservation's chief concern was the development of energy savings programs aimed at lessening the likelihood of a severe deficit.

In early 1981, shortly after the nomenclature change, the newly-formed Division of Conservation split off from Power Resources (at the same time that Power Requirements underwent a similar organizational expansion). This fledgling Division was further subdivided into a Program Branch and an Evaluation and Assistance Branch. The former group had the responsibility for designing and implementing 
gPAs various conservation programs while the latter unit began the task of determining the regional markets for conservation and assessing the effectiveness of conservation programs already in place. The growth of Conservation as an organizational unit, spurred both by technical necessities and the same political forces giving impetus to the Regional Act, continued to proceed at a conspicuously rapid pace. By early 1982 the Division had become the office of Conservation with its two Branches each becoming a Division (joined by a third, the Division of Technical Assistance). Rapid expansion, such as that experienced by Conservation in its growth from a section to an office in less than three years time, provides numerous problems along with the resulting opportunities. First and foremost, there is a great deal of personnel turnover. Not only are large numbers of new, relatively inexperienced (at least at their duties at BPA) employees added to the staff but more experlenced persons are applying for newly-opened highergraded positions, leaving berths behind them which must in turn be filled. Secondly, the mix of educational background, tends to change, sometimes drastically. In its earliest days, Conservation was staffed primarliy by engineers (having experience with the technology behind the conservation measures constituting the core of BPA's programs) and "advocates" (i.e. champions of conservation or renewable resources) with diverse academlc backgrounds often 
only tangentially related to their duties and responsibllities (e.g. soclology, history, mathematics, political sclence). Given the relative youthfulness of conservation research and development this was not surprising -- most schools don't offer a 'conservation' major so most experlence was obtained through special programs or other jobs. By the time it had become an office, however, conservation had begun to specialize internally. As such, more staff members foined the units with more quantitative technical backgrounds (e.g. economics, statistics, planning) needed Eor revaluating regional savings potential.

A third and final problem area resulting from rapid organizational expansion is that of functional integration, both among the units within Conservation and between Conservation and other offices. As Power Requirements expanded, the well-structured character of its demand models and their input requirements made functional Integration straightforward, if not simple. Economic studies provided inputs needed to operate the models maintained by the other Branch. How Conservation's numerous organizational Eunctions would be coordinated was not nearly so obvious. In broad concept it was recognized that the Planning and Evaluation Assistance Division would assess both the effectiveness of conservation programs and the potential savings yet attainable, while Programs would develop and implement specific strategies to obtain energy savings. No 
clear-cut methods, let alone deterministic computer models, presented themselves, however, making the internal coordination of activities problematic and necessitating more "trlal-and-error" with technical approaches.

Conservation's integration with BPA's planning, forecasting, and resource development also begs some questions as to its continuing role in the organization. Most fundamentally, Conservation's mission is to obtain the maximum possible cost-effective power savings. Its contribution to the forecasting process is the determination of future savings attributable to its own programs. Yet what appears cost-effective during a projected deficit may not prove so during a surplus (Insofar as resources already under construction may be adequate for many years to come). Both the initiation of Regional Bill legislation and the emergence of a conservation unit within BPA were predicated upon a feared power deficit in the 1980 s and 1990s. Ironically, with a projected surplus the need for conservation within the region becomes called into question. Thus, at the time of the first forecast, the role of Conservation within the organization paradoxically was growing while its necessity given new regional conditions was becoming suspect.

\section{Rower Resources: New options for Electricity Supoly}

The opposite side of the planning equation from demand is supply. The Columbla River system, as noted in the introductory chapter, is overlaid by a network of high-head 
dams and transmission lines. This network, one of the largest of its kind in the world, has supplled the Northwest with most of its power since the 1930 s when the Bonneville and Grand Coulee Dams were first completed. The construction of these dams using funds from the U.S. Treasury yielded the abundant, low-cost electricity which was for some time enjoyed by all but more recently reserved for BPA's preference customers. First with the Hydro-Thermal Power Plan, and Einally with the Regional Act, the task of finding resources adequate to meet the demands of Bonneville's customers has become progressively more complex. The Division of Power Resources within Bonneville's Office of Power Management is the group tasked with preparing a load-resource balance in conjunction with the long-term forecast.

The role of Power Resources, and the relative Importance of certain of its functions, have changed considerably since the early 1970s. At the beginning of that decade, Power Resources was a Branch within the Division of Power Management. Its three sections were Power Capabilities, Power Investigations, and Hydrology -- Sections which reflected a primary emphasis upon the use of hydropower. These functions remained the central concern of the Branch through the perlod when resource planning was based upon the assumption of imminent power shortages. Though BPA championed the construction of the WPRSS plants to meet the 
loads of its public utllity customers, the Reglonal Act was still being concelved and the agency was not yet obligated to acquire resources needed to provide power to any and all utilities requesting it. By 1980, however, a change in the Division's (this followed the nomenclature change) internal structure foreshadowed the role to be played under the terms of the Act, reflective of the same issues and consideratlons. Two of the three former sections had become Branches (Hydrology was absorbed into other units), but these traditional functions were joined by three others also reflected in the Branch names: Requirements, Energy Conservation, and Thermal Power. As noted earlier, within a year of this time, the rapidly-growing Requirements and Conservation became separate Divisions, leaving Power Capabilities, Power Investigations and Thermal Power Branches as principal subdivisions. By the time of the 1982 forecast reorganization was more thorough, embodying concerns of the Regional Act. The Power Capabilities Branch was jolned by Generation Planning and Assessment and Evaluation.

Power Resources participated in the 1982 forecast through the use of two models maintained and operated by the Assessment and Evaluation Branch. One model was a linear programming model called the Least Cost Mix Model (LCMM), the other a Systems Analysis Model (SAM). The LCMM solved a complex objective function which determined what mix of 
potentially available resources should be obtained by certain years to meet anticipated loads at a minimum cost. The SAM simulated the operation of the entire gridwork of resources, evaluating its peaks and patterns of usage. The results of these models determined the cost and scheduling of the resources selected by the Supply Pricing Model to meet forecasted loads. Thus the supply slde of the resource balance equation incorporated into the forecast.

\section{Siqnificant "Non-participants": Financial Management and}

\section{the Policy Committee}

Two of the more significant organizational role players within BPA were, in the strlct sense of the word, nonparticipants in the forecast: the Division of Financial Management within the office of Management Services and the agency's Policy Committee. Unlike the other organizational actors within BPA described above, these two "non-participants" did not play any part in developing elther the forecast projections or the inputs used to produce them. Both were, however, central participants in the particular (and particularly important) decision making process which the forecast was supporting. Their specific informational needs, however, did help shape the forecast in a number of ways by requiring the forecasting staff to ask very welldefined questions, often in a rather narrowly circumscribed fashion. 
The Division of Financial Management grew out of the (pre-nomenclature change) Branch of Finance and Accounts and the Budgeting and Planning offices of the Management Services Division in 1980. Its expansion within the agency was roughly coincident with that of Power Requirements and Conservation, all reflecting the changing priorities of the power planning environment of the late 1970s. The slowing of load growth in the region along with the costly delays associated with the five WPPS construction projects placed BPA in an unprecedentedly awkward financial situation. At the same time that successful completion of the WPPSS nuclear plants required a continued high rating for additional bonds, BPA was, for the first time in its history, falling behind in its repayment of the U.S. Treasury for the financing of the network of hydroelectric projects along the Columbia. Analysis of the bond market and the feasibility of issuing further WPRS bonds was a separate, but parallel input to the load projections to be used by the Administrator in arriving at a scheduling decision for the completion of WNP 1,2 , and 3 .

The other "non-particlpant", BPA's Policy Committee, is a group comprised of the Administrator, his Deputy and Assistants, the heads of each of the Offices at BPA, and lat least on some occasions) assorted higher staff personnel. The members of the Policy Committee are the principal 
decision makers of the agency. It is their decision-making needs that ultimately determine the research, analysis, and modeling efforts, albeit indirectly, in several ways. First, the types of issues they must address influence the selection and use of modeling tools and techniques. The selection of detalled forecasting models for sector forecasting was, in part, the result of their ablilty to deal straightforwardy with varlous types of conservation programs which the agency needed to consider as many options in making resource decisions. Second, the scheduling of major policy decisions (often dictated by Congress) sets firm time limits within which forecasts must be prepared. These time limits may, under some clrcumstances, force the pace of forecast development, limiting the exploration of alternatives and thus the reduction of forecast uncertalnty. Third, members of the Policy Committee make internal budgeting decisions on mafor allocations of agency funds. Thus, major data or model development presupposes upper management agreement with the broader goals and objectives of the technical staff in the various Divisions. Finally, it is the members of the Policy Committee who most directly deal with the crises and opportunities affecting the agency as a whole. Since such matters are often unpredictable so are the additional demands for analysis which they, often quite abruptly, place upon the forecasting staff. All these in- 
Eluences, however indirect, uitimately have a substantial effect upon the forecast and its outcome.

THE INTERORGANIZATIONAL POWER PLANNING ARENA: A LOOK OUTWARD

overview: The Texture of changing Roles and Responsibli it les

As a marketer of wholesale power, BPA has always been firmly established in an arena of actors having interests in the way the region's power was used and how its development was planned for. The hydroelectric output of the Columbia River system for many years provided the bulk of the power distributed by, the reglon's utilities, whether publiclyoperated or investor-owned, or used by Direct Service Industries. Difficulties concerning the allocation of power from BPA's transmission system or the resource mix used to meet demand were minimal -- englneering, rather than politlcal or economic, problems. With the advent of the HydroThermal Power Plan matters grew more complex. Investorowned utilities found themselves more reliant upon their own, somewhat more costly, sources of electricity while public utilities were being encouraged to "swap" the more expensive outputs of thermal generation for less costly hydropower.

As the decade of the 1970s progressed, the power planning arena grew progressively more political and more 
varied in texture. Increasing rate disparities between public and private utilities resulted in movements to turn Oregon's residential and small farm customers into a gigantic People's Utility District which would become entitled to a siare of the low-cost power which BPA would be obligated to provide. Long-term contracts drafted by BPA guaranteeing non-interruptable power to the region's Direct service Industrles were looked upon with increasing disfavor by preference customers forced to develop thermal plants to meet their own needs. Strong environmentalist opposition sprang up in response to the introduction of coal and nuclear-fired generation facilities in the region, while advocates of renewable resource and conservation chlded planners for all but ignoring "soft energy alternatives". One of the significant outcomes of the turbulence generated by these conflicting interests was the formulation and ultimate enactment of the Regional Power Bill. Even after this legislation had been ratified by Congress, however, organizational interaction within the arena was heated and representative of many different groups.

The impacts of the decisions based upon BPA's 1982 forecast were obviously going to be significant and widely felt. As a result, many organizational actors participated directly or indirectly in the process initiated to disseminate information and solicit critical comment. This process 
involved public meetings for a technical review of the demand models and a presentation of the draft forecast, each followed by a comment period.

The sections which follow identify the principal actors in the interorganizational power planning arena, their history of involvement with regional forecasting or planning, and their special set of interests, clrcumstances, and organizationally-based biases.

\section{The PNUCC: A Waning of Traditional Author ity in Forecasting}

During most of the Pacific Northwest's growth as a region, the PNUCC (Pacific Northwest Utilities Conference Committee) has been a central actor in the electric power planning and resource development arenas. A consortium of the region's utilities, PNUCC has, since its formation in 1946, largely acted in partnership with BPA in the production and distribution of power. While BPA was responsible for marketing the power generated from the Federally-owned hydroelectric facilities along the columbia River system and maintaining the network of transmission lines connecting them, it was the member utilities of PNUCC that "wheeled" the power purchased from BPA, while investor-owned utilities met significant portions of their demand with Federallysupplied electricity. As noted in the introductory chapter, beginning in 1954, PNUCC's load forecasting committee prepared the sum-of-Utilities forecast for long-range power 
planning. The reglon's utilities thus have been instrumental in the planning of both large and small scale generating resources and have entered into a number of joint capacity expansion projects over the last several decades. Most of these projects have involved BPA directly or indirectly, the most obvious and significant examples being the HydroThermal Power Plan, wherein BPA "swapped" low-cost hydropower for more expensive thermal generation, and the construction (or attempted construction) of the five wPPSS nuclear plants, the construction costs of which were underwritten by BPA.

The Sum-of-utilities forecast was, until the early-tomid 1970s, the only document used in reglonal power planning. Naively extrapolating the region's earlier growth in electricity consumption (essentially ignoring the factors or dynamics underlying the growth), the sou forecast tended to underpredict loads during the 1950 s and 1960s. In the 1970s, however, a watershed decade for the region, the dynamics underlying regional growth altered sufficiently that the consequences of the naive approach at the methodological foundation of the sou began to be seen. Growth slowed to the point that the forecasts made in the early 1970 s appeared at first to be somewhat optimistic, then later to be serlously overpredicting increases in regional loads. This led, first, to the development of a regional 
econometric model in 1977 by National Economic Research Associates to cross-check the sou findings. This model was resident on BPA's computer system and operated by BPA stafe in accordance with the directions provided by BNUCC's Load Forecasting Committee, comprised of members of the forecastIng staffs of the region's utilities. Later, in 1980, PNUCC established a permanent staff of lts own for dealing with forecasting and technical issues.

Politically and economically, the 1970 s provided a climate of change, and sometimes turmoil, for many of the region's utilities. For a long period, virtually the entire region's utilities and industries were preference customers, in that they were served by then-abundant hydropower (whether they were, in fact, public utilities or not). In the late 1960s and the early 1970s, however, concern over the differential access to inexpensive power grew. Privately-owned utilities relied increasingly upon their own more costly resources to meet their customers' demand. Public utilities, the true preference customers in the eyes of the law, found themselves in the unaccustomed role of building their own generating resources to meet the portions of their loads not covered by available hydropower. At the same time, the wisdom of guaranteeing Federal hydropower to the region's Direct Service Industries under long-term contracts (drafted when plentiful inexpensive electricity 
appeared available for many years to come) was more and more being questioned.

The Regional Act, as noted in the introduction to this dissertation, was an attempt to resolve these issues through legislation. In the power planning arena, however, growing rate disparities signalled new and somewhat divergent interests within PNUCC.

The 111-fated WPPSS nuclear plants, constructed as a result of high (and, in retrospect, quite naive) demand forecasts of the 1970 s became something of a bone of contention among PNUCC's member utilities. Though nominally the property of public utilities in Washington, several of the plants had been heavily invested in by other utilities. In particular the region's investor-owned utilities had sizeable shares of WPPSS nuclear plant (WNP) number three. BPA, which championed the development of these plants during the Hodel and Munro Administrations, underwrote the public utilities' investments in the plan.

BPA's 1982 forecast, to be used as a critical input in timing the construction of WNP 1, 2, and 3 was inevitably looked upon with concern, and to some degree suspicion, by many of PNUCC's member utilities. Severely slowing rates of regional demand growth not only forced WNP 4 and 5 to be mothballed but ralsed new questions about the reliability and accuracy of any forecast used in the resource planning 
process. A law known as Construction Works in Progress (CWIP) prevents utilities from incorporating resource construction costs into their rate bases until the projects are actually completed and producing electricity. Up to that time, funds used for construction are a sunk cost. While the mothballing of plants 4 and 5 was a foregone conclusion, the fate of WNP 1, 2, and 3, and the funds sunk into their partial construction, had yet to be decided. BPA's problem was to determine which timing scenario for the completion of WNP 1, 2, and 3 would allow the agency to get the necessary bonding on Wall street while still meeting regional power needs. This would be determined, in part, through the 1982 forecast. Given the inherent uncertainty surrounding the future of load growth in the region, however, a relatively slight difference in projected growth rates could determine when (and if) particular PNUCC member utilities could recover their construction costs. Thus, both PNUCC's resident staff and its load forecasting committee, comprised of representatives from the region's utilities had strong interest in BPA's forecast, its details, and its implications.

\section{The Reqional counc1 1: A New Look at Resource Planning}

In early 1981, a new, but significant, organizational actor made its entrance into the power planning arena -the Northwest Power Planning Council (or Regional Council). 
As noted in the introductory chapter, the Council was the creation of the Pacific Northwest Electric Power Planning and Conservation Act, passed by Congress in late 1980 . Drafted during a period of concern over growing regional rate disparities and the implications of a changing resource base, the Act not only augmented BPA's regional responsibilities and powers but also established a new political body, the Regional Council, to oversee the development of a long-term forecast and power plan for the Pacific Northwest. The Reglonal Council was developed as a regional, not a Federal, body, comprised of two appointments by each of the governors of the four states in the region, Washington, Oregon, Idaho, and Montana. Chaired by Dan Evans from Washington, the Council included Chuck Collins, also from Washington, Roy Hemmingway and Alfred Hampson, from Oregon, Larry Mills and Robert Saxvik, from Idaho, and Keith Colbo and Gerald Mueller from Montana. Under the terms of the Act, the Council was required to produce its first Plan in the spring of 1983, so during the flrst six months of its existence, the Council recruited the core of its technical staff and initiated contract work for the development of forecasting models and planning tools.

In the year and a half between its formation and the July 1982 publication of BPA's first independent forecast the Councli began an ongoing process of deflning ltself and 
its relation to both BPA and PNUCC. Though the terms of the Act clearly empowered the council to produce the definitive resource development plan for the region, they did not detail how much latitude or flexibility the established power planning bodies, BPA and PNUCC, had in implementing the Plan. The council members' rendering of the terms of the Act saw BPA following the Council's 20-year Plan to the letter. From their perspective, BPA's independent long-term forecast was at worst an unnecessary duplication of effort, at best an interim planning tool to be superceded by the Council's 1983 effort. BPA, by contrast, argued that their In-house forecasting capablitity was needed for several reasons. Most immediately, a decision on the fate of WNP 1 , 2 , and 3 had to be made in mid-1982, not 1983, and the policy analysis supporting the decision required a more sophisticated forecasting system than any that had been previously available in the reglon. In the longer run, BPA argued that their responsibility for implementing the Plan required dealing with many details not explicitly identified by the Council (i.e. the Plan would not be specific enough to anticipate the problems BPA would face and consequently could not be treated as an action plan delineating a precise series of tasks to be followed without interpretation). Successful implementation of the Plan would, according to this line of argument, require BPA to test the feasibility 
of a wide array of speciflc rate design and resource development alternatives -- a requirement necessitating an in-house demand modeling capability.

The Regional Act, in many ways, curtailed PNUCC's influence as a forecasting and planning body. Though its member utilities all maintalned the option not to enter into exchange agreements with $B P A$ and rely upon their own resources to meet demand, many had invested heavily in the WPPSS plants and had definite interest in their completion. Assuming that the utilities would enter into power exchange agreements with BPA and that rates would be set based upon forecasted loads and revenues, they would also have a strong interest in long-term resource planning. Their own forecast, following the establishment of the Regional Council, would no longer carry the welght it formerly had, taking a back seat to the council's with regard to major resource acquisitions by BPA.

The potential for adversarial relationships between the Regional Council and BPA (and, to a lesser degree, PNUCC) was great during the initial stages of the development of a long-range Power Plan. Any major differences between the Council's officlal forecast and any of those used by BPA in rate design could be assumed to engender major conflicts and administrative difficulties. For the most part, the relationship which evolved between the Council and BPA up to the 
time of BPA's 1982 forecast, though characterized by a number of disagreements on specific issues, could not be termed truly adversarial.

A great deal of potential friction between BPA and the Council was dampened by virtue of the newness of the longrange forecasting and planning task confronting each group. Neither group had rigidly defined sops to deal with these common problem areas and, as such, both groups could still be somewhat flexible in the manner in which they addressed them. Moreover, the technical staffs of each organization were quite similar, both in terms of their backgrounds and their general approach to the problem at hand. Though much smaller in size, the Council's technical staff displayed backgrounds similar to those involved in the production of BPA's forecast -- primarlly economists and engineers with strong skills in computer modeling. The Council's forecasting system, being developed under contract at the time of BPA's first forecast, bore very strong similarity to BPA's, containing sector-specific demand models run iteratively with an electricity supply pricing model. The residential and commercial models were simply evolutions of the econometric/end-use demand models used by BPA. As such, they addressed the same basic policy issues and used the same basic input variables (the values for which were developed by a Council staff member formerly employed by 
BPA's Division of Power Requirements). These strong similarities of modus operandi considerably lessened the likelihood of conflict between the two groups.

Thus, at the time of BPA's first forecast the council was at odds neither with $B P A$, which was required to implement the Plan, nor with PNUCC, the member utilities of which could be affected favorably or unfavorably by its consequences. Significant questions of how BPA might implement a poorly concelved resource strategy, how the council would deal with noncompliance or reinterpretation of the Plan on BPA's part, or how the actions of the region's utilities and Direct Service Industries could influence the Plan's success would have to remain unanswered until the council actually released its own product in 1983.

QDOE: The council's precursor in oregen?

The Oregon Department of Energy (ODOE) represents one of the more unique organizational actors in the arena of energy politics surrounding BPA's first forecast. Created by the oregon state Legislature in 1975, in the wake of the OPEC 011 embargo and a severe Northwest drought, ODOE might be thought of as a precursor to the councll. Though operating on different geographical political levels, the two organizations were developed largely for the same reasons and to perform similar functions. 
An examination of the major policy issues identified by ODOE (and described in the 1979 edition of their annual energy report, oregon's Energy Future) reveals a close correspondence to those enumerated in the Reglonal Power Act: the timing and mix of generation plants, appropriate energy rates, coordination of the operation of the state's electric utility systems with those of the region, acquisition of cost-effective conservation, and the development of renewable resources. The legislation which created ODOE did not specify its tasks and responsibilities with the same detail as that embodied in the Regional Act, though it did prescribe forecasting and planning (though for all fuels, not only electricity).

In a number of respects, ODOE's technical approaches foreshadowed those later employed by BPA in its 1982 forecast. ODOE used several sector-specific energy demand models to produce its forecast. Residential sales for the state were projected using an end-use model explicitly considering three housing types, four age groupings, five energy types, and twelve end-uses. An econometric model was used to forecast energy use of commercial, industrial, transportation, and agricultural sectors. All of ODOE's models were "all fuels" models (since the Department is concerned with energy, not electricity, futures) and the forecasts they produced had the added distinction of being the first 
to diverge from the more traditional high growth patterns characterizing 1970 s forecasts in favor of lower demand projections consistent with energy use in the early 1980 s. of the actors in the regional power planning arena ODOE was thus unique in its prior experience with many of the issues and technical tools central to BPA's 1982 effort. Moreover, unlike the Council, the member utilitles of PNUCC, or any of the special interest groups concerned with the outcome of BPA's forecast, ODOE had little vested interest in a particular set of findings. It was in no sense in competition with BPA, with its decision-making powers at an entirely different level of governmental influence: it did not serve utilities investing in thermal resources with schedules of completion which were in feopardy; and, while no organization can be completely value-neuter or blas-free in its research, ODOE has characteristically approached fuel and resource mix planning as a problem-solver, not as an advocate of particular technologies or developmental strategles.

\section{NRDC: Alternative Futures for Alternative Energy}

The Natural Resources Defense Council is a San Francisco-based organization concerned with, as the name suggests, the protection of the environment. Different mixes of power-generating resources will result in widely divergent impacts upon the natural environment. Forecasts, as 
noted at various points above, provide the basis (or at least one of the bases) for generation planning. As such, BPA's first independent forecast, influencing decisions affecting a large (and as yet relatively undeveloped) geographical area, was of particular concern to NRDC. In many respects, NRDC's view of BPA's forecast differed diametrically from that of most of the organizational actors in the power planning arena. During the late 1970s when the high growth scenarios of the sum-ofUtilities forecasts were first being challenged, NRDC prepared a report funded by the Energy Research and Development Administration (now part of USDOE) suggesting that the region would need only a fraction of the capacity in 1995 that PNUCC was then predicting. NRDC has consistently acted as a watchdog on larger power planning organizations, challenging both the technological and behavioral assumptions underlying their forecasts and energy analyses and offering alternative scenarios emphasizing conservation and renewable resources.

Being a small public interest organization, NRDC has been compelled to make extensive use of somewhat limited resources. Its stafe has been composed of persons with a variety of professional backgrounds (e.g. physics, engineering, and law), all sharing a common philosophy regarding the use of energy and the treatment of the natural environment. 
Lacking the large mainframe computers and complex models used by utilities and energy commissions in power planning, NRDC has nonetheless been very effective in using professional and public involvement channels to obtain the means for conducting its analyses. Where possible, NRDC may get direct access to computer facilities or have special alternative model runs performed by the organizations preparing the forecasts, analyses, or plans under scrutiny. A common approach used by NRDC is to perform an expost analysis of forecasts, identifying areas where particular judgments or assumptions were applied, substituting alternative assumptions (and corresponding numerical values) and recalculating the results after the changes. (As an example, NRDC might look at the market penetrations for home weatherization used in a forecast, substitute more optimistic values, and assess the impacts). These calculations are often made with "pencil and paper" rather than computers but serve to highlight critical areas of uncertainty and force viable, but often ignored, alternatives into consideration as power planning decisions are made.

At the time of BPA's 1982 forecast, the region was looking upon high growth forecasts with more than a modicum of suspicion. Though it seemed clear that revised forecasts would be considerably lower than those of the mid-1970s, and while many utilities and rate payers had definite interest 
in seeing WNP 1,2 , and 3 all completed on schedule, many also feared that even the lowered forecasts would be overly optimistic. The pattern of decelerating growth of the late 1970 s and early 1980 s had resulted in regional loads at levels nearer to those predicted by NRDC (in its abovementioned 1977 report) than by the sou forecasts. Given this background, NRDC entered the 1982 forecasting and planning arena as a credible champion of conservation and alternative resource planning.

\section{DSI's: New Contracts, New Conditions}

The region's Direct Service Industries (DSIs) have played a significant role as consumers of Federal hydropower. The DSIs are comprised of a small number of large industries (chiefly aluminum, primary metals, and chemicals) which receive power directly from BPA rather than from one or more of the region's utilities. The first of the DSIs arrived in the region during World War II, its output deemed essential to the U.S. war effort but requiring the abundant, readily-available electricity which the Pacific Northwest was able to provide. After the War, the DSIs situated in the region remained to be joined by others in need of cheap power. The DSIs are extremely electricity-intensive; a large aluminum plant consuming roughtly the same amount of power as a medium-sized city. Since the region's hydrosystem was constantly growing (and always somewhat over- 
-bulit) the DSIs were able to sign long-term contracts with BPA guaranteeing them low-cost power over periods up to 20 years. The DSIs maintalned and used their own transformers which allowed them direct access to BRA's transmission network.

While power was plentiful, the existence of the DSIs in the Northwest was largely without controversy. When it became obvious, however, that BPA's designated preference customers, the public utilities of the region, would have to begin construction of thermal resources for their own power while the DSIs still received the hydropower guaranteed by their contracts, public opinion began to shift. When the impacts of the WPPSS plants on rates was clearly recognized, negative sentiments became stronger and many consumer groups argued that the DSI's would be "disconnected" from BRA's transmission system.

In the interim, the DSIs were lobbying for the passage of the Regional Act. Although the legislation would increase their rates substantially (since they would, under its terms, be providing rate relief for IoU residential and small farm customers) the rates would, at least on the surface, be less than in other locations and firm power would be guaranteed.

The low power costs in the region have more than offset the increased transportation costs, both for the import of 
raw materials and export of industrial output, which the DSIs had to bear by virtue of locating in the northwestern corner of the U.S. Though the DSIs calculated that the expected rate increases would not be so severe as to render maintaining their locations no longer cost-effective, many in the region had serious doubts about both the future of rate increase and the market value of the DSIs products. Were the DSIs to close all, or even some, of their plants, the region's ratepayers would be forced to bear the costs of both the unpaid portions of the hydrosystem and any thermal plants on-line at the time of the DSIs departure. While this was not a major concern of the DSIs at the time of the 1982 forecast, many of the other actors in the power planning arena Justifiably viewed their behavior as a major uncertainty.

The Northwest Natural Gas Distributors: The other Guys

Given the abundance of hydropower which has been routinely available in the Pacific Northwest, it becomes easy to overlook the fact that reglonal energy futures encompass more than just electricity. Although BPA's models project usage of "all fuels", the forecasts they produced were never intended to be anything other than electricity forecasts. The consequences of decisions based on anticipated load growth, however, impact not only consumers of 
electricity but, less directly, consumers of natural gas (as well as other fossil fuels).

The formation of the Northwest Power Planning Council in 1980 signalled an imminent increase in the degree to which energy policy in the region would be subject to deliberate direction. One option avallable to consumers of electricity confronted with price increases is to select natural gas (or oil) as a substitute fuel for space heating, water heating, and boiler operations.

As noted in the previous chapter, in any areas of endeavor where the shape of the future is determined, or at least influenced, by the outcome of the present decisions, forecasts (and plans) may serve as self-fulfilling prophecies. In large part because of the low cost of electricity in the region, natural gas has never played the role in the Pacific Northwest that it has in other parts of the country (though its role has hardly been insigniflcant). In the late 1970s, natural gas prices began to follow the increases of its sister fuel, petroleum, and concern about the wisdom of becoming overly dependent upon fossil fuels grew. In the early 1980s, however, the economics of energy in the region began to show signs of change, as the nation regained its balance after the second major oll shock concurrent with the first series of rate increases resulting from the higher costs associated with new thermal generation projects. 
Potential existed for new regional markets for natural gas, but this potential could be affected by electricity resource and conservation planning decisions. For example, if, in an attempt to prevent anticipated power deficits, the region's electric utilities offered residential customers significant rebates or subsidies for adopting conservation measures in all-electric homes, this could serve as a major disincentive for home owners (or builders) to install natural gas heating. Given the added political authority of the newlyformed Regional Council to enforce its regional power plans, the gas companies were not unreasonably concerned about how their industry would be affected.

Because BPA would, under the terms of the Reglonal Act, be the key force in implementing regional power plans, and because BPA's first forecast would precede the Council's by a year, the natural gas distributors in the Northwest considered it to be a document meriting critical attention. Most important to the gas companies was that non-electric fuel price profections be reasonable (by their reckoning) and that the demand models capture fuel choice and fuel switching over the forecast perlod. High natural gas prices (relative to electricity) and poor representation of fuel switching would tend to elevate load profections, resulting In further acquisition of resources and conservation by BPA. 
This, as noted above, could potentially affect the natural gas industry's regional market.

The "Expert" Groups: Consultants and Research Organizations

Yet another set of participants in the power planning arena are what might generally be termed expert groups, consulting firms and research organizations loften university-based) with expertise in model development and evaluation or famliarity with speciflc issues underlying or related to the forecasting and planning process. These groups have, at a bare minimum, a professional interest in participating and, in the case of consulting firms, potentially a financial interest as well, since the research contracts could result from issues raised. These expert groups are spokespersons for various types of modeling, analysis, or policy considerations and, if they display organizational biases, these are the result of past experlence or research speclalization rather than financial interests in resource decision outcomes.

of the many expert groups addressing varous aspects of research crucial to power planning only a few had direct influence upon the forecast, usually through the public involvement process but sometimes by virtue of independent investigations in the same research areas conducted in parallel with BPA. These groups are identified below. 
Charles Rivers Assoclates (CRA) is a Boston-based consulting firm with considerable experience with energy forecasting models. In 1981 and early 1982 CRA developed a series of regional forecasts with the same research group at Washington state University that spearheaded the NEPP project. These forecasts were developed using modified versions of the end-use models employed by BPA in their forecast. One of the members of the wSU research team had earller been a member of BPA's Power Requirements staff. Two consulting firms performed independent evaluations of BPA's forecast. One was National Economic Research Associates, the developers of the PNUCC econometric model. The other was Energy Ventures Analysis, a New York-based firm with experlence analyzing energy trends in various parts of the country.

Three other research organizations contributed to the forecasting process through public involvement channels. The Survival Center located at the University of oregon, is a group chiefly concerned with environmental protection and energy alternatives. POWER (People's organization for Washington Energy Resources) is a ratepayer's protection group concerned largely with the impacts of potentlal resource decisions upon the electricity consumer. Finally, the Futures Research Institute, located at Portland state University, is concerned with all forms of forecasting and 
prediction, with special emphasis upon issues of technological change and its impacts upon society.

\section{The Media: Selectively Reflecting the Issues}

One last organizational "actor" must be mentioned -the mass media covering both BPA's forecasting effort and other significant energy issues in the region. The role of the mass media is complex; both direct and subtle in its operation. Investigative reporters, editorial columnists, or television personalities may confront participants in the energy arena directly concerning critical issues. More often the media work indirectly, as their name suggests, occupying a position between the actors and between their arena and the public at large that comprises the news audience. Objectivity in reporting the news is an ideal which is in some sense approachable but in no way attainable. Few major newspapers or electronic media with a general audience deliberately falsify or color their reporting. News, however, may never be sterile data but must be presented in a fashion such that it will relate to the lives and interests of those receiving it. News reporting, therefore, invariably presents its subject matter in a particular context. It serves to reflect the world, but in a selective manner, attaching importance to the portion of events and issues which it presents to its audience while relegating other portions into an oblivion of non-acknowledgement. This 
selective attention reflects what is of interest to those in a reporter's particular audience (e.g. the impact of nuclear plant construction delays on employment in the Tri-cities area) often reinforcing or strengthening existing perceptions or opinions. The media also may serve as opinion leaders (rather than merely as indices of opinion), actively drawing attention to events, 1ssues, or interests which may have been otherwise overlooked or lgnored by most of the audience. Thus, in organizational arenas, such as that characterizing regional power planning, the media serve to bring the general public into the decision-making process, albeit indirectly, and may, in some instances, be used by key actors to exert influence upon their co-participants. The specific influences of the region's media representatives upon the forecasting process will be detalied in the chapter on cross-cuing. A general observation can, however, be made that, in light of the above discussion, media in areas potentially more serlously affected by decisions resulting from the forecast (e.g. the Tri-cities) would be expected to view BPA and its actions in a much more critical light than other parts of the region. 
THE ENERGY FORECASTING ARENA THROUGH THE O-PERSPECTIVE:

SUMMARY AND CONCLUSIONS

The above sections have described the participants in the production of BPA's first independent forecast. Some had major roles, others participated as minor organizational players, often affecting the final forecast product indirectly. This chapter has, consistent with the 0-perspective, focused upon the forecast as an organizational output (or more precisely as a multiorganizational output), identifying the constellation of actors both internal and external to BPA, and, to the extent possible, enumerating their organizational habits, operating procedures, work priorities, and channels of influence. In Chapter $v$, which traces the cross-cues between the $T-, 0-$, and P-perspectives, the players' moves and their subsequent impacts on both forecast process and product are addressed speciflcally and in detail. In most cases, the challenges to which BPA was asked to respond were made through the public involvement process as in the form of comments on specific technical cholces made by BPA in model, input, and forecast development. Table $x$ below summarizes the findings of this chapter, listing each of the organizational actors involved and identifying corresponding chief characteristics, operating procedures, Interests, biases (vis-a-vis the BPA forecast), and channels of influence used in affecting the forecast 
A SUMMARY OF ORGANILATIONAL ACTORS IN THE FORECASTING PROCFSS

I. Intraorganizational

Power

Requirenents

Pxpanded fron Power Resources Because most of the to become a separate Division Division's functions tasked with producing an independent forecast; had proviously helped produce a portion of the soU forecast and worked with PNUCC to run econonetric nodel

\section{Conservation}

Gron extremely rapidly in late 1970s, first in response to anticipated deflc1t then to BPA's increased respons $1 b 11$ itles under the terms of the Regional Act forecast was gulded by

few sols--these related to the development of some of the economic projectlons used in demand models; procedures for enerBy forecast development were evolvod largely from 1) model input requirements and 2) agency pollcy

support needs

Fen SOPs at tine of first forecest, method for determining est1mates of future savin from BPA programs

(subtracted from forecast) newly developed and in process of revision) were new the first
New Division wanted to establish itself and 1to professional status, both ithin BPA and in the

region at large, wanted more rellable forecast than earlier ones used to plan WPPSS plents Preponderence of Division decision makers held degrees in economics and tended to seo forecasting as economist chore, Invarlably sought econometric solutions to modeling problens

Channels; Direct- staff produced dewand forecast and nost of the inputs

Wanted to establish 1 tself as reglonal leader in area of conservation and give BPA good reputation Aobitious and sonetines optiolistic vien of needed or attainable regional conservation; favored. forecasts which would show 
Interests/B1ases Channels of Influence

at most a small and short-11ved surplus Channels: Direct- sevings estimates used in forecast Indirect- feodback through upper mgnt. via policy committee representation

Rates

Role and duties changed after Hydro'thermal Power Plan and. later, passage of Regional Act; home for both Power Requirements and Conservation before their growth and separation
Ongoing role in establishi customers expanded and complicated by passage of Reglonal Act and recent addition of thermal resource costs into rate base

\section{Establishod ratemaking Hented to provide} procedures amended to credible and rellable conform to terms ofAct information for AdninisNew responsibilities trator's decislons and include operation of minimize conflict between Supply Pricing Model in BPA and wolesale custoners forecast and conducting over rates analyses of alternative Channelsi Direct-produced rate schemes electricity price forecast in conjunction with demand forecast; indirect-through frequent feedback to Power Mgr. and Administrator

Trad1tional calculatlons of hydrosys tem output and rellability supplemented to account Direct- as participant in for new types of re- forecast and resulting source acquisitions; load/resource balance

LP model developed to indirect- through Power determine least cost Mgr. 
TABLE X (Cont'd)

\begin{tabular}{|c|c|c|c|}
\hline Actor & Background/Characterlst1cs & Operating Procedures & $\begin{array}{l}\text { Interests/Blases } \\
\text { Channels of Influence }\end{array}$ \\
\hline $\begin{array}{l}\text { Flnancial } \\
\text { Managenent }\end{array}$ & $\begin{array}{l}\text { New and conspicuously } \\
\text { important organizational } \\
\text { function in wake of } \\
\text { WPPSS difficulties }\end{array}$ & $\begin{array}{l}\text { Few SOPs because of } \\
\text { newness of unit; } \\
\text { analysis of resource } \\
\text { cost impacts on bond } \\
\text { market akin to tech- } \\
\text { niques commonly used } \\
\text { in private sector }\end{array}$ & $\begin{array}{l}\text { Wanted to establish } \\
\text { reputation for providing } \\
\text { sound financial advice } \\
\text { in particular regarding } \\
\text { WNP } 1,2 \text {, and } 3 \\
\text { Channels I Ind irect- } \\
\text { Results of financial } \\
\text { analysis suggests } \\
\text { additional questions to } \\
\text { be answered in fore- } \\
\text { casting process }\end{array}$ \\
\hline $\begin{array}{l}\text { Pollcy } \\
\text { Conmittee }\end{array}$ & $\begin{array}{l}\text { Committee comprised of } \\
\text { top BPA decision makers }\end{array}$ & $\begin{array}{l}\text { Mixture of old \& new, } \\
\text { Existing comittments } \\
\text { to underwriting WPPSS } \\
\text { constrains actions. } \\
\text { New responsibilities } \\
\text { under Reglonal Act } \\
\text { and unresolved WPPSS } \\
\text { problems necessitated } \\
\text { new solutions of which } \\
\text { forecast and financial } \\
\text { decision support are } \\
\text { an integral part }\end{array}$ & $\begin{array}{l}\text { Needed to ensure that BPA } \\
\text {-fulfill obligations } \\
\text { under Act } \\
\text {-stab1lize rates as } \\
\text { nuch as posilble } \\
\text {-continue orderly } \\
\text { repayment of U.S. } \\
\text { Treasury for hydro- } \\
\text { project loans } \\
\text {-resolve HPSS dilenme } \\
\text { as palnlessly as } \\
\text { possible } \\
\text { Expected lower forecast } \\
\text { and viewed delay of HNP } \\
\text { as viable resource } \\
\text { alternative } \\
\text { Channels, Chain of comnand }\end{array}$ \\
\hline
\end{tabular}


TABLE $X$ (Cont'd)

Actor

Background/Characteristics
Operating Procedures

Interests/Blases

Channels of Influence

II. Interorganlzational

PNUCC

Consortium of Northwest

ut1lities; prepared sou

forecast since 1950s (BPA

partlcipated in behalf of

small public utilities

lacking forecasting staffs).

SOU underforecasted through

1960 s but serlously ove $r$

forecasted in mid-1970s

resulting in WPPSS plants:

many member utilities had

invested in WNP 1-5

(WPPSS ut1lities are also

PNUCC members)

Regiona

Counc1l forecasting connitteo
Newly established body under Reglonal Act legislation: empowered to produce long-range reglonal resource and conservation acquisition plan in spring of 1983

\section{Sun-Of-ut111t1es \\ individual utility \\ forecast :subaittals, \\ econometric model used \\ as crosscheck 1977- \\ 1981, small in-house \\ staff began routine \\ analysis of regianal \\ forecasts in early \\ 1980s, load forecast \\ committee (comprised \\ of staff fron member \\ ut1lities)provide \\ critical comments on \\ forecast under \\ evaluation}

Nothing standardized. though Act provided

broad guldelines for

Desired to

-reestablish forecasting crediblilty in region

-ensure falr inter-

protation and 10ple-

mentation of Reglonal

Act

-ninimize WPPSS-related

financial difficultiea of menber ut1l1t1es

Wanted BPA forecast to be reasonably low but

high onough to allow

HNP completion

Channels, D1rect- load coments through public invol vement, indirect-PNUCC upper mgat to BPA upper momt.

\section{Wanted to}

-establish reputation -establish and exercise activities forecasting authority in region system similar to BPA's Heavy omphesis upon under development in identifying and realizing 1982 


\begin{tabular}{|c|c|c|c|}
\hline Actor & Background/Characteristics & Operating Procedures & $\begin{array}{l}\text { Interests/Biases } \\
\text { Channels of Influence }\end{array}$ \\
\hline & & & $\begin{array}{l}\text { Channels; Direct- through } \\
\text { public Invol veaent } \\
\text { Ind1rect- Council nenbers } \\
\text { Hith BPA upper agmt. or } \\
\text { through gedia }\end{array}$ \\
\hline ODOE & $\begin{array}{l}\text { State agency establlshed } \\
\text { In mid-1970s-empowered to } \\
\text { prepare energy (all fuels) } \\
\text { projectlons and plans for } \\
\text { state of Oregon }\end{array}$ & $\begin{array}{l}\text { Prepares annual report } \\
\text { containing sector } \\
\text { (some models highly } \\
\text { slmilar to BPA's). } \\
\text { established ODOE } \\
\text { planning function } \\
\text { simllar on state level } \\
\text { to that of Council on } \\
\text { Reglonal level }\end{array}$ & $\begin{array}{l}\text { Hanted to maintain } \\
\text { leadersh1p role in } \\
\text { forecasting and planning } \\
\text { Channols : Direct- } \\
\text { through public Involveaent }\end{array}$ \\
\hline MRDC & $\begin{array}{l}\text { Organization dedlcated to } \\
\text { onvironmental protection and } \\
\text { the development of conser- } \\
\text { vation as a najor energy } \\
\text { resource provided critical } \\
\text { comment on high Northrest } \\
\text { estimates of load growth } \\
\text { in late } 1970 \text { in report } \\
\text { sponsored by ERDA }\end{array}$ & $\begin{array}{l}\text { nxtensive critical } \\
\text { evaluation of forecast, } \\
\text { planning, or anslysis } \\
\text { results and assumptions, } \\
\text { frequently generate } \\
\text { al ternative scenarlos } \\
\text { by changlns specific } \\
\text { key assunptions and } \\
\text { observing lopacts }\end{array}$ & $\begin{array}{l}\text { Des1red ambltious } \\
\text { conservation progran } \\
\text { 1mplementation 1n } \\
\text { sorthwest; Low forecast } \\
\text { preferred to ginimize } \\
\text { liklihood of add1tional } \\
\text { thermal plant cons truction, } \\
\text { Channels Direct- through } \\
\text { public involvement, } \\
\text { Indirect- through legal } \\
\text { processes ongoing with } \\
\text { BPA }\end{array}$ \\
\hline
\end{tabular}


TABLE X (Cont'd)

\begin{tabular}{|c|c|c|c|}
\hline Actor & Background/Charrac teris $\pm 1 c s$ & Operating Procedures & $\begin{array}{l}\text { Interes ts/Biases } \\
\text { Channels of Influence }\end{array}$ \\
\hline DSIs & $\begin{array}{l}\text { Large users of power buyling } \\
\text { electricity directly from } \\
\text { BPAI first located in region } \\
\text { during WW II and signed long- } \\
\text { term contracts withi pushed } \\
\text { for pessage of Reglonal Act } \\
\text { when anticipated deflcits } \\
\text { seemed to jeopardize future } \\
\text { firm power contracts }\end{array}$ & $\begin{array}{l}\text { Anticlpated demands } \\
\text { established as terms } \\
\text { of power contracts }\end{array}$ & $\begin{array}{l}\text { Hanted to naintain access } \\
\text { to guaranteed firm power } \\
\text { at low rates } \\
\text { Channels, Indiroctm- } \\
\text { with BPA agt. In } \\
\text { contract negotiations. } \\
\text { through nedia }\end{array}$ \\
\hline $\begin{array}{l}\text { Natural Gas } \\
\text { Distributors }\end{array}$ & $\begin{array}{l}\text { Operated under circumstances } \\
\text { strongly influenced by } \\
\text { world petroleum market } \\
\text { (characterized by rising } \\
\text { prices and uncertainty } \\
\text { during 1970s) imminent } \\
\text { increases in formerly cheap } \\
\text { electricity prices opened } \\
\text { possibilities for new } \\
\text { reglonal markets }\end{array}$ & $\begin{array}{l}\text { Newly developed, at } \\
\text { least regarding } 188 \text { ses } \\
\text { emerging frod BPA fore- } \\
\text { cast--gas price pro- } \\
\text { jections and respons- } \\
\text { lveness of BPAs models } \\
\text { to fuel switching } \\
\text { foci of critique }\end{array}$ & $\begin{array}{l}\text { Desired to prevent power } \\
\text { planning or resource ac- } \\
\text { quisition strategles which } \\
\text { strategies which would } \\
\text { deter switching into natural } \\
\text { gas(lower'forecasts with } \\
\text { lor fossil fuel prices } \\
\text { preferred so electric-only } \\
\text { conservation policles } \\
\text { would be ninimiged) } \\
\text { Channels Direct-through } \\
\text { public Involvement (gas } \\
\text { distributors represented } \\
\text { by law firm) }\end{array}$ \\
\hline $\begin{array}{l}\text { Experts } \\
\text {-CRA, NERA. } \\
\text { EVA }\end{array}$ & $\begin{array}{l}\text { Consulting firms with enerBY } \\
\text { related experlences CRA } \\
\text { worked on Wash. State U. }\end{array}$ & $\begin{array}{l}\text { Hork by contracts to } \\
\text { explore energy use, } \\
\text { develop data, and/or }\end{array}$ & $\begin{array}{l}\text { Desired to maintain or } \\
\text { onhance professional } \\
\text { reputations (and earning }\end{array}$ \\
\hline
\end{tabular}


TABLE X (Cont'd)

\begin{tabular}{|c|c|c|c|}
\hline Actor & Background/Characterlstics & Operating Procedures & $\begin{array}{l}\text { Interests/B Lases } \\
\text { Channels of Infiluence }\end{array}$ \\
\hline & $\begin{array}{l}\text { project to develop regional } \\
\text { forecast sinilar to BPA's in } \\
1981 \text {, NERA bullt PNUCC } \\
\text { model and along with EVA, } \\
\text { provided independent evalua- } \\
\text { tion of BPA forecast }\end{array}$ & bulld aodels & $\begin{array}{l}\text { potentials) I NERA blased } \\
\text { somewhat upward in eval- } \\
\text { uation (in line with } \\
\text { their model's predictions) } \\
\text { EVA blased downward by } \\
\text { forecast by analogy with } \\
\text { TVA service territory } \\
\text { Channels D Drect- NERA } \\
\text { and EVA reports comis- } \\
\text { sloned by BPA Ind1rect- } \\
\text { CRA results used as } \\
\text { evidence of BPA forecast } \\
\text { credibility }\end{array}$ \\
\hline $\begin{array}{l}\text {-FOKER \& } \\
\text { Survival } \\
\text { Conter }\end{array}$ & $\begin{array}{l}\text { Groups concerned with } \\
\text { protecting consuners and } \\
\text { natural environment }\end{array}$ & $\begin{array}{l}\text { Both groups act as } \\
\text { watchdogs on energy- } \\
\text { related matters \& POWER } \\
\text { concerned more with } \\
\text { rate lmpacts and } \\
\text { resources (particularly } \\
\text { WHP declslons) }\end{array}$ & $\begin{array}{l}\text { Wanted to mininize adverse } \\
\text { effects of energy develop- } \\
\text { ment } \\
\text { Channels, Direct-through } \\
\text { public involvement }\end{array}$ \\
\hline $\begin{array}{l}\text { - Futures } \\
\text { Research } \\
\text { Institute }\end{array}$ & $\begin{array}{l}\text { University-based research } \\
\text { organization focusing upon } \\
\text { forecasting. planning. and } \\
\text { other forms of futures } \\
\text { research }\end{array}$ & $\begin{array}{l}\text { In forecasting } \\
\text { context provides } \\
\text { critical comment and } \\
\text { evaluation }\end{array}$ & $\begin{array}{l}\text { Hanted to ensure that } \\
\text { lssues of technology and } \\
\text { multiple factors affecting } \\
\text { futures dealt with in non- } \\
\text { simplistic fashion } \\
\text { Channelsi Direct- public } \\
\text { involvement }\end{array}$ \\
\hline
\end{tabular}


TABLE X (Cont' $d$ )

\begin{tabular}{|c|c|c|c|}
\hline Actor & Background/Characteristics & Operating Procedures & $\begin{array}{l}\text { Interests/Blases } \\
\text { Channels of Influence }\end{array}$ \\
\hline Med1a & $\begin{array}{l}\text { Disseminate inforration on } \\
\text { energy issues and events in } \\
\text { a manner which selectively } \\
\text { acquaints prevlously un- } \\
\text { informed populace with issues } \\
\text { and/or reflects concerns and } \\
\text { sentiments of significant } \\
\text { portions of reader- or } \\
\text { vlewerships act as catalyst } \\
\text { and reactant }\end{array}$ & $\begin{array}{l}\text { Turn events and In- } \\
\text { formation into "news" } \\
\text { by selective exposure } \\
\text { to public influence } \\
\text { audience through edit- } \\
\text { orlal pollciesi often } \\
\text { develop detalled and } \\
\text { coherent pictures of } \\
\text { energy arens through } \\
\text { lnvestlgative re- } \\
\text { porting }\end{array}$ & $\begin{array}{l}\text { Want to } \\
\text {-sell product to } \\
\text { public by naking } \\
\text { ovents interesting } \\
\text {-look out for } \\
\text { community interests } \\
\text {-police institutions } \\
\text { in energy arena } \\
\text { slant towards forecast } \\
\text { varlable depending upon } \\
\text { area served and hou } \\
\text { affected } \\
\text { Channels: Indirect- } \\
\text { through Influence } \\
\text { upon population at } \\
\text { large and key decision } \\
\text { making figures }\end{array}$ \\
\hline
\end{tabular}


outcome. Though the actors (and organizational interests or positions) are diverse a number of generalizations can be made about the organizational dynamics underlying the forecast.

First, the numerous issues and concerns addressed by the forecasting process configurate around a central focus: the decision concerning the fates of WNP 1, 2, and 3 and its myriad consequences. Though the 1982 forecast was far richer than its predecessors in terms of the number and variety of policy considerations (or core assumptions) which it explicitly recognized and addressed, its breadth was nonetheless limited or constrained by its preoccupation with these resources. Internal to $\mathrm{BPA}$, scheduling the completion of these two plants land obtaining the highest possible rating for additional bonds) was perhaps the first major task of the new Administrator. Much of the post-1980 reorganization, which elevated the organizational importance of Power Requirements, Rates, and Financial Management could be described as the development and mobilization of an internal apparatus tallored to support this and similar decisions. External to BPA, virtually every participant had some strong interest in the outcome of the decision and its implications. A large portion of the member utilities of PNUCC had financial interest in one or more of the "endangered" plants. Though conceding the potential problems of a 
surplus of electricity, most wanted to be able to recover some of their costs by including them in their rate bases -something attainable only after the plants were on-line and generating electricity. Environmentalists and strong advocates of conservation, such as NRDC, were concerned that the plants be brought on-line if and only if absolutely necessary, that no further overbullding of thermal resources be undertaken, and that conservation be pursued ambitiously as a viable resource alternative. Finally, ratepayers associations, confronting unprecedented rate increases, were concerned with the impact of the new large plants upon their pocketbooks. Bringing new plants on-line prematurely (i.e. before there is adequate load in the region to balance the resource output) would cause more dramatic increases in cost per unit of electricity, something ratepayers never want to see.

A second important generalization following an 0-perspective review of the forecasting process is that, for many of the key actors, standard operating procedures serve as a very poor explanatory tool for predicting (or accounting for) organizational behavior. In many respects, the characteristics of the power planning arena of the $1980 \mathrm{~s}$ (including the passage of the Regional Power Act) are the direct result of the fallure of standard operating procedures of an earlier era. For much of the region's recent 
history, steady robust load growth met by Federallysubsidized hydroelectric facilities was a reliable pattern which could be confidently extrapolated into the future by means of the sum-of-Utilities forecast. Slowly growing land for some periods declining) power costs attracted enough new industry and people that overbuilding resources was a reasonable strategy -- resources did not remain overbuilt for any length of time. By the mid 1970s, however, the factors underlying the regional growth dynamic had changed, though the region's naive methods of forecasting and resource planning had not. It took several years of obvious overforecasting before standardized procedures were first amended then abandoned for more sophlstlcated alternatives. Examination of the principal actors in the forecast development process reveals a preponderance of young organizations with few established procedural habits. Though BPA was hardiy a new participant in the power planning arena, the Reglonal Act had augmented its responsibilities and the organizational precedents for producing the sou forecast were of little use in the development of the first independent regional forecast with its array of new priorities and models. Likewise post-Act ratemaking and Elnancial management were virtually new organizational functions as was the assessment of reglonal conservation potential. Formal alterations in BPA's internal organizational struc- 
ture reflect the explicitly recognized importance of the new challenges facing Bonneville but they provide, at best, a partial description of the changes taking place during this transitional period. Perhaps most significant of the emerging organizational characteristics was the interdepartmental basis of the forecasting process. Lines of influence (and control) over forecast development crosscut formal chains of command as often as they followed them. Within those portions of the organization most heavily involved in the preparation of the tools and models used in the forecasts, at least, management styles bore less resemblance to traditional bureaucracy than to the corporate cultures of innovative research and development organizations with little standardization or routinization of activity, a premium on innovative problem solving, and open, "lateralized" communicative relationships among participants (irrespective of their relative organizational rank or status). Outside of Bonneville, operating procedures were similarly tentative or transitional. At the time of the 1982 forecast, the Regional Council had just filled its key staff positions and was setting up the apparatus needed to produce its own 1983 forecast and resource plan. PNUCC had abandoned the use of its econometric model and recognized the need for a thorough revision of the sum-of-Utilities forecast, though a number of utility representatives were 
reluctant to revise their judgments of future load growth downward to the unprecedently low levels that seemed to characterize the future. Almost ironically, the two participants which seemed to operate most frequently from standard procedures were NRDC, which had critigued a number of earlier forecasts both inside and outside the region, and ODOE, which had a "head start" working with end-use models and dealing with the implications of lower anticipated load growth.

A third important generalization which can be made about the organizational dynamics of the forecasting process concerns the channels of influence. A number of established channels for communication with BPA which had been used for other types of decisions still remalned functional when BPA produced its first independent forecast (e.g. PNUCC committee meetings, hearings, public dealings with BPA executives, etc.) but the mechanism used most frequently and by the largest number of organizational actors was the public involvement process. While public involvement per se was not new to $B P A$, the type of interaction of outside parties with the decision support process encompassed by forecasting was unprecedented. Though not a legal requirement, public Involvement was virtually a necessity given the expected variance of the BPA forecast results from those earlier used to guide regional planning efforts and the gravity of the 
decisions to be based upon them. All comments and criticisms were addressed by BPA staff though not all resulted in substantive changes in forecast methodology or findings.

Fourth, though one can speak somewhat of the Interests and biases of the various groups regarding forecast outcomes, it is clear that virtually all groups would be hurt, one way or the other, by a grossly inaccurate forecast. Upward and downward biases are really a matter of degree. An unrealistically low forecast would indicate a need to delay the wPPSS plants and largely abandon any vigorous efforts to obtain conservation, but would result in power shortages and lost opportunities. Unrealistically high forecasts would burden the region with excess (and probably unsalable) power, high rates, and a large volume of conservation which, given hindsight, would probably not prove cost-effective. The questions in effect addressed by the groups affecting (and affected by) the forecast were "How wide a band of realistic uncertainty surrounds the Northwest's load future?" and "Within this band, what forecast would minimize our problems or maximize our opportunities to achieve our goals?".

Finally, a look beneath the changing or newly forming operating procedures characterizing most of the organization reveals a sense of an emerging new stability of perception in the power planning arena, though one that may take 
several more years to materlalize fully. The 1982 forecast marked a critical watershed. It was the first major decision-supporting process to reflect the change in roles and responsibilities wrought by the Regional Act. The regional power planning community was in the midst of a transitional perlod of organlzational change, but organizations are notorious for being resistant both to initiating such change or living with it for any length of time. (In fact, the Regional Act would have been more effective had it been passed five or six years earlier, when organizational realignment might have delayed or avoided altogether the plans for the 5 wPPSs plants). One thus can see, the core of new SOPs crystalizing as the power planning organizations stake out their new territories and define new tasks. 
CHAPTER IV

THE P-PERSPECTIVE

WHEN INDIVIDUALS DO MAKE A DIFFERENCE: THE P-PERSPECTIVE IN OVERVIEW

Coordination and organization of the numerous activities comprising a project the size and complexity of the BPA forecast required both formal and informal structuring of procedures by those groups responsible for their successful completion. In some instances, the actions of key individuals are fully determined by operating constraints of the positions or offices which they occupy within their organizations. Such actions are appropriately handled using the 0-perspective. They are as habltual, routinized, and reflexive as the sOPs governing group and intergroup behavior. other actions of individuals are not the result of the prescrlptions of office and their ultimate effects may range from almost imperceptibly subtle to highly directive and dramatic. To comprehend how and why such actions or declslons are undertaken, a different perspective is needed than either the highly rational one used to expose the logic of technical cholces or the process-delineating one used to understand the dynamics of organizational behavior. The perspective which tightens its focus upon unique character- 
istics of an individual's training, attitudes, personality, and style is the personal or P-perspective.

Individuals are unique, and it is the task of the investigator utilizing the $\mathrm{P}$-perspective to probe this uniqueness to understand which of a person's idiosyncracies are able to explain how and why an individual behaves, responds, or thinks in a certain way. This emphasis upon specifics and particulars, however, should not be construed to mean that the $\mathrm{P}$-perspective is devoid of general defining characteristics or foci of consideration. The personal perspective can be seen to contrast both technical and organizational perspectives along a number of critical dimensions.

The P-perspective is, above all else, subjective rather than objective in its orientation towards the world, reflecting the individuality of actors in a planning, forecasting, or decision-making process. Individuals are responsive -- they meet the challenge of the world in the present in a manner consonant with their unique past learning and experlence and with their own set of priorities and goals for the future. Behavior which often seems somewhat irrational to the outside observer may appear perfectly rational from the viewpoint of the Individual under consideration, given his or her Iimited information and understanding. This "partial" rationality is most often grounded in an individual bellef system which reflects a 
deeply rooted need for certainty, stability, and control. Images, data, or interpretations of events which are inconsistent (or cognitively dissonant) with past experience are censored, blocked, or filtered out and there is an equally strong tendency to simplify the complexities of the world into frameworks or variables which can be more easily dealt with.

Individual views of the world are also strongly colored by both underlying personality characteristics and immediate circumstances which are highly variable from person to person and situation to situation. As such, they must be examined closely in the context of their occurrence. To varying degrees, all persons seek security, and much behavior is predicated upon doing what will maintain one's livelihood and preserve one's status. Those who might be characterized as "followers" within their organizations (and within the world) tend to follow such a risk-adverse strategy most of the time. By contrast, others' motives are strongly characterized by the need to influence, dominate, or otherwise wield power. status improvement, more often than status preservation, constitutes an underlying objective for such individuals who, depending upon their degree of competence, function as leaders or troublemakers. Finally, for many individuals, a drive towards self-fulfillment constitutes a key determinant of their actions. This drive may express itself as a need for meaningful challenges, for 
creative opportunities, or for public recognition, but in all cases its expression becomes a key to understanding why certain individuals view the world and behave as they do. In addition to these motivational factors, which often are the prime movers for individual action, the P-perspective is, last of all, characterized by conspicuously short decision-making time horizons and a high discounting of the consequences of current activitles. Individuals normally expect (and plan for) rather quick return on investments of their money, time, skill, and loyalty and often lose sight of or abandon priorities or projects which do not come quickly to Eruition.

In analyzing complex decision-making areas, and their consequences, one must understand how particular individuals look at the world and the ways in which their viewpoints either influence an outcome or provide insight into possibly unanticipated consequences or impacts of proposed courses of action. In prospective studies, such as technology assessments, where the objective is to discover how society will be affected by the introduction of a new development, analysts should target on both the perspectives of the principals promoting the new ldea, procedure, or product, as well as those of the numerous parties to be affected. In retrospective studies, where the intent is to account, as fully as possible, for something whlch has already been done, the focus is somewhat tighter, since one does not have to guess 
who possibly might be a significant participant in the process studies but may concentrate upon persons of knewn involvement. This dissertation, dealing, as it does, with a 1982 forecasting, planning, and decislon-making process which has already been completed, falls into the latter category. To complement the insights of the two previous chapters, the "prime movers" of the forecasting process will be identifled. Their particular decisions or choices which affected the process will then be described and, to the extent possible, be discussed in terms of past training, experience, or decision-making style.

\section{MANAGING THE ORGANIZATION: A VIEW FROM THE TOP}

As 1llustrated in the previous chapter, BPA's 1982 forecast was the product of a large number of persons both within and outside the organization. But whereas the 0 -perspective examines the operating procedures and habitual responses of formal and informal groups to the challenges the organization faces, it is the task of the $\mathrm{P}$-perspective analysis to zoom in on the unique capabilities and directive influences of the individuals involved in these same processes.

At $B P A$, the Administrator through his or her direction (or lack of it) exerts a strong influence upon both general organizational policy and, in certain instances, specific projects. As with many high-ranking office holders, though 
the position dictates certain actions, the Administrator has relatively great latitude in expressing a personal management style and orientation towards facing and dealing with the agency's problems. Peter Johnson, the BPA Administrator since 1981, brought a unique combination of skilis and experlence into the decision-making situation of which the 1982 forecast was an integral part. Before focusing upon the current Administrator, it is instructive to examine the contrasting situations which his two predecessors faced along with their notably different ways of dealing with them.

The decision-making environment of the 1982 forecast, as illustrated in earlier chapters, was shaped by a number of forces over the last several decades. One could, in principle, trace its roots back to any number of specific points in the region's recent history, but, for explanatory purposes, perhaps the best place to begin is the onset of Donald Hodel's five year appointment as the Bonneville Power Administrator in 1972 .

Donald P. Hodel was appointed to the position of Administrator in December of 1972, shortly following Nixon's reelection and preceding the Arab Oil Embargo of 1973. The calm preceding the storm proved short, however. While the oil embargo was redefining energy politics, a low water year was straining the hydrosystem regionally. Under Hodel, a graduate of Harvard and the University of Oregon School of 
Law, an energy conservation program was quickly organized in response. Its success resulted in the new Administrator receiving the Department of the Interior's Outstanding Service Award for the effort. This confrontation with a short-lived, but rather ominous, energy crisis served to underscore one implication of the high-growth sum-ofUtilities forecasts: the era of cheap, abundant power was ending and new resources would have to be tapped if the region's energy needs were to be met. This conclusion, first voiced in Hodel's 1973 annual report and amplified in subsequent pronouncements ultimately resulted in the issuance of a notice of insufficiency to BPA's preference customers on June 24,1976 . This notice stated that "after June 30,1983 , BPA would not be able to serve new load growth of its preference customers" (Norwood, 1980:262). This perception of the possibility of imminent deflcit led to the establishment of a conservation group within Power Resources (as described in the previous chapter) and, more importantly, a push for nuclear generation capability in the region. Three of the WPPSS plants had been scheduled and construction begun early in Hodel's administration. The planning of two more plants soon followed, though Phase II of the Hydro-Thermal Power Plan became held up by legal challenges in 1975 pending the completion of a comprehensive environmental impact statement. 
Hodel operated under an acute perception of impending power shortfalls (or at least their possibility) and, though the policies underlying the Hydro-Thermal Power Plan were not long established at the time he took office, power planning was still something which he could treat fundamentally as an engineering problem. Generation capacity had to be added to meet anticipated demand. Private contractors replaced the Corps of Englneers in the construction of the facilties and Bonneville dealt with the projects indirectly by underwriting the investments of the specific public utilities but otherwise continued to fulfill its traditional functions.

In January of 1978, Sterling Munro succeeded Hodel as Bonneville Power Administrator. Munro had recelved a bachelor's degree in polltical science and fournalism from George Washington Universlty and, like Hodel, had studied law. Signiflcantly, he had been a member of Sen. Henry Jackson's staff from 1953 to 1975, making him a prime candidate for an appointment to the Administrator's position under the Carter Presidency. BPA had, the year prior, become part of the newly-formed Department of Energy, though maintaining the same responsibilities it had as part of the Department of the Interlor. Though some members of the region's forecasting community were beginning to look upon their high load growth projections with suspicion, at the time Munro took office, decision makers were still readying 
for an anticipated deficit. Munro's style was decidedly political: he immediately concentrated "on BPA's external relationships, and proceeded to contact the four Pacific Northwest Governors and other leaders and groups throughout the region, focusing "... on the reglon's faltering power program for inclusion in a new legislative proposal for consideration by Congress" (Norwood, 1980:262). Munro's former mentor, Henry Jackson, took charge of this bill, which was ultimately passed in late 1980 as the Regional Act.

Munro's Administration witnessed growing regional concern over rate disparities, environmental impacts, and resource development. The WRPSS plants were very obviously in difficulty even as Munro took office, due to escalating cost overruns and repeated construction delays. But while the Administrator ordered an investigation by outside consultants and repeated warnings of impending power shortages, he treated the problems of the supply system as more local than regional, reguiring little or no intervention or direction by Bonneville. In 1979, the cost escalations resulted in a rate increase for BPA's customers which was totally unprecedented. Munro left office in 1981 with the WPPSS problem intensifying and new, more significant rate increases foreshadowed for later that year.

Peter Johnson topk office in May of 1981, roughly a half year following the enactment of the Regional Power Bill 
and just prior to the second major "Iate shock" for BgA's preference customers alluded to above. The problems with WPRSS were coming to a head, and it was obvious to all within the power planning community that the first priority of the new Administrator would be timely resolution of these difficulties. Though the region's forecasting authorities were becoming increasingly aware of a slowdown in load growth, no consensus about a new pattern had been reached and many still feared an impending deficit. Within Bonneville (as noted in the previous chapter) in-house forecasting and conservation capabilities continued to expand. Specifically how their expanded functions would dovetall with BPA's revised mission under the Regional Act, however, was not something whlch had been completely resolved during Munro's final months as Administrator. Johnson's background differed noticeably from that of his two Immediate predecessors in the Administrator's office. Though experienced with the operations of the public sector (he served on Idaho Governor John Evans' Management Task Force) Johnson's strengths were within the sphere of business. At Dartmouth he earned both bachelor's and master's degrees in business administration, later applying those skills at McGregor Trlangle, a Bolse, Idaho heavy construction company, and Trus Joist, a manufacturer of wood products used in home construction. Under the budget-and cost-consclous eyes of the flrst Reagan Admin- 
istration, these skills were viewed as essential to the resolution of the supply system's problems, leading to Johnson's 1981 appointment to the Administrator's position. Consonant with his background and experience, Johnson viewed WPPSS as a business, rather than an engineering or political, problem. Under his leadership, Bonneville would not deal with the construction problems and their myriad regional consequences indirectly but instead confront them head-on. A preoccupation with generating capacity, reservoir water levels, and transmission lines was eclipsed by stronger concerns with "the fiscal integrity of Bonneville", "the best interests of present and future ratepayers", and "professional excellence", expressions which not only appeared as new guiding principles in BRA's mission statement but which also thoroughly infused the language of Johnson's public statements and internal memoranda (e.g. Johnson's May 17, 1982 guest editorlal in Portland's dally newspaper The Qregonian). In particular, Johnson's experience as chief executive officer of Trus Joist provided a unique precedent for his approach to the disposition of the WPPSS plants.

When Johnson assumed leadership at Trus Joist in 1974, the company, like others in the wood-products industry, was facing a changing environment, one increasingly stirred to tubulence by the numerous repercussions of the then-recently transformed world petroleum market on both national and 
regional economies. Under the new CEO's direction, Trus Joist's planning strategles were modifled to reflect the financial realities of the new economic climate. Financial analysis of Trus Joist's uncertain future during a period of projected inflationary increases led Johnson to close four of the company's twelve manufacturing plants while weathering the storms of the late 1970s. While most of its competitors found themselves serlously over-extended, Trus Joist prospered, eventually reopening two of its closed plants. By the time of Johnson's departure after six years as corporate head, Trus Joist's annual sales mushroomed from 6 to 76 million dollars. Though other factors were undoubtedly involved, it was Johnson's careful planning (as Paul Richert-Boe notes in his profile of Johnson in the July 13-19, 1982 issue of Portland's Willamette Week) that constituted the key determinant of the company's success. The similarities between the situation Johnson confronted at Trus Joist in the 1970 s and the one he later confronted at BPA in the early 1980 s are striking. In both cases, the respective organizations found themselves in transformed, and transforming, environments where traditional methods of problem solving (or comfortable standard operating procedures) were no longer completely appropriate. Trus Joist faced the economic uncertainties of the inflationary 1970s, when energy and production costs grew rapid1y. BPA faced a situation characterized by construction 
difficulties, slowing demand growth, and rapidly escalating WPPSS resource costs. Trus jolst found itself questioning its need for production capacity. BPA, after years of anticipated imminent power shortages, found itself questioning its need for generation capacity. Within its newly transformed environment, Trus Joist experienced a concern over protecting its assets. Within its new environment BRA was similarly concerned with maintaining a rating for wPPSS bonds which would permit additional sales to finance further construction and with assuring the greatest possible rate and revenue stability.

The problem-solving approaches (and, ultimately, the solutions) implemented by Johnson at both organizations also displayed a striking similarity -- so striking that the guidance of the same chief executive officer in both instances is obvious. At Trus Jolst, a thorough financial analysis of the company's assets and capabilities in light of predictions of economic behavior provided the information for Johnson, the CEO, to make the difficult, but in retrospect prudent, decision to close four of the company's manufacturing plants. At BPA, newly organized financial management and forecasting units provided analysis which similarly recommended delaying the completion of WPPSS 1 and 3 . The analysis produced two important conclusions: first, that chances for adequate additional financing were slim if immediate completion of more than one plant was attempted, 
and, second, that delayed completion of wNp projects 1 and 3 would not result in regional power shortfalls. Armed with this information Johnson, the Administrator, virtually repeated his precedented successful decision, shutting down the ongoing construction of two nuclear plants in order to make the successful completion and functioning of a third possible.

While it is arguable that BPA was already turning towards a more "businesslike" approach to managing the development of the region's generating resources, this is true only in the most general sense. Though the necessary forecasting approaches (as well a some of the agency's financlal analysis capablilties) began evolving during Munro's term of offlce, it was Peter Johnson's unique experience (and P-perspective) which gave the organization's support system its specific character. Whereas another Administrator might have sought to make the WPPSS decision based upon regional consensus, Johnson brought the responsibility fully upon himself and BPA, making internal forecasting and financlal analysis groups a necessity. Whereas a different CEO might have second guessed the judgments of his forecasting and financlal management staffs, Johnson (along with the rest of BPA's Pollcy Committee) accepted the often sensitive findings of his technical experts (though not without careful and critical scrutiny). This gave the organizational units involved the opportunity to make many 
key decisions about their own development while, at the same time, establishing the context defining the purpose of their intraagency missions. Finally, whereas an Administrator lacking a successful precedent such as the Trus Jolst outcome as part of his experience might not have had enough confidence to make and stand by a difficult project-delaying decision, Johnson opted for the unpopular, but technically warranted, choice to delay WNP 1 and 3 . This notified the region unequivocally that the operations of the forecasting and financial management units were to be taken seriously as integral parts of BPA's organization.

The character of the region's resource development problems thus changed significantly over a ten year period. Equally significant was the change in the manner that the Bonneville Power Administrator perceived the problem and the method of its solution. Table XI summarizes the different regional conditions faced by Hodel, Munro, and Johnson, the experience they brought to bear, and the ways in which they percelved and framed the problems confronting them.

To summarize, Hodel entered office in the early 1970s at a time just before the Arab Oil Embargo. The region's economic growth was as robust as its load growth, and forecasts projected these trends out to the end of the century. The perceived need for large thermal generation projects to avoid power shortages was accentuated by the impacts of the drought year which welcomed the new Adminis- 


\section{Administrator}

\section{Donald Hodel}

sterling Munro

\section{Regional Conditions}

High levels of regional economic and load growth continuing from the 1960 s through most of Administration resulting in high load growth projections: severe drought and 1973 Arab oil Embargo served to underscore need to avert power shortages through resource and conservation development

First indications of slowing regional growth, though regional forecast projections still high: growing rate disparities between public and private utility customers: WPPSS construction cost estimates escalations becoming source of concern and controversy; conservation promoted by carter Administration

\section{Background/Experience Development seen as---}

Degree in law; three years as Deputy Administrator under Henry

Richmond--in on ground floor of Hydro-Thermal power plan

\section{science and law: member of Sen. Henry Jackson's staff from}

Degrees in political 1953 through 1975

\section{ENGINEERING (Or}

Administrative)

problem: new capacity

development was

thought to be straight-

forward with BPA

back Ing investments

of public utility

customers for ther-

mal plant construc-

tion

POLITICAL problem:

while WPPSS cost es-

calations were treat-

ed primarily as a

"local" problem of

the utilities in-

volved, BPA's role

under Munro aimed

at the development

of Regional Act leg-

islation to ease

growing rate dispar-

$i$ ties and in effect

expand the resource

development provis-

ions of the Hydro-

Thermal power Plan 
TABLE XI (Cont'd)

\section{Administrator}

Peter Johnson
Regional conditions

Load growth falling off in region: naivete of earlier forecasting process recognized and acknowledged. though no consensus of "new vision" of future; WPPSS 4 and 5 mothballed and financial fate of plants 1, 2, and 3 uncertain: Regional Act legislation in place but its implementation still problematic
Background/Experience

Business degrees from Dartmouth; served on

Idaho Governor's Mgmt.

Task Force; CEO at

Trus Jolst for six

years during which

time annual sales grew

dramatically, in large

part due to strategic

decision to close 4

of 12 plants during

inflationary climate

of late 19708
Development seen as-

FINANCIAL/BUSINESS problem: future of WPPSS plants seen as contingent upon bond sales: decision to delay plants 1

and 3 followed from

financial analysis

(and forecast)

similar to that

supporting Trus

Joist plant closing 
trator into office. The regional resources development plan, centering upon the construction of the wppss plants, was handled primarily as an engineering problem. This is not to say that Hodel, trained in the field of law, approached the problem as an engineer would. Rather, the problem was seen as a technical one: to add sufficient capacity (and conservation) to accommodate future demand. The Administrator, who had earlier served as Deputy to Henry Richmond from the onset of the Hydro-Thermal Power Plan, rather straightforwardly followed the provisions of that Plan, letting private contractors construct the plants for the region's participating public utilities while BPA underwrote the construction costs incurred by the WPPSS member ut111t1es.

By contrast, sterling Munro treated regional resource development as primarily a political problem. By the time Munro took office in 1977, the first indications of a slowdown In reglonal growth were becoming evldent, though forecasts did not yet reflect a signiflcant shift in perceptions. A key issue was the growing rate disparity between public and private utilities. Rather than deal directly with WPPSS's emerging problems, Munro focused Instead upon the promotion of Regional Act legislation developed principally by Henry Jackson, for whom the Administrator had served as an aide between 1953 and 1975 . 
Peter Johnson entered office after acquiring extensive experience in construction and wood products industries. By 1981, WPPSS 4 and 5 were doomed by the combined effects of slowing load growth and sky-rocketing construction costs and the fate of the three remaining plants was in doubt. Johnson framed the situation as a business problem -- one which required BPA to adopt a leading role in its solution. Drawing extensively upon his experience with a closely similar situation at Trus Jolst, Johnson utilized BPA's newly developed forecasting and financial analysis capabilitles to arrive at a difficult, but in retrospect, seemingly prudent, decision to delay the construction of WNP 1 and 3 in order to render the completion of plant number 2 possible.

Thus, an examination of Peter Johnson's personal background and perceptive concerning the resource development situation confronting the region at the time he assumed the office of Bonneville Power Administrator provides vital insights into the manner in which the organizational apparatus surrounding the production of BPA's 1982 forecast was given its shape. Further significance of these insights will become clearer in the next chapter which cross-cues the three perspectives. 
MANAGING THE FORECAST: A VIEW FROM THE MIDDLE

As noted in the previous chapter, Bonneville's longterm forecast was an organizational product of a variety of groups within the agency. Using the P-perspective to look at the top of the organization -- the Administrator's office -- provides significant and sometimes penetrating insight Into unique managerial styles which strongly direct the manner in which the organization is structured and the way in which it functions. By itself, however, this focus only provides a portion (albeit a significant portion) of personal influences helping to shape the forecast process and its ultimate product. A P-perspective examination of middle-level management and technical staff operations within the units specifically tasked with producing the forecast provides additional insights whlch are both necessary and complementary to those displayed in the previous section.

In certain ways, each level of an organization displays unique characteristics. At the top, the Administrator presldes over the entlre line organization and may exert strong direction on the course which the agency follows. At the midale levels of the organization, such strong unilateral influence is lacking for two reasons. First, the span of control of middle managers 1s, by definition, smaller, addressing only a segment of interdepartmental projects such as the long-term forecast. Second, and of possibly greater importance, forecasting is a problem-solving activity which, 
at best, might be characterized as semi-structured. The production of a forecast is a team effort requiring diverse expertise. This means that although process and product may alike bear the imprint of the authors, no single individual directs the forecast as a plant supervisor would manage a highly routinized production function. The forecast, in a very real sense, evolves from the coordinated interaction of a number of contributing individuals.

As such, a slightly different emphasis guides the P-perspective investigation of the forecasting process in this section. While individual personalities and backgrounds remain as important foci of inguiry, greater attention is placed upon understanding the unique circumstances confronted by the principals in the forecasting process and the nature of the interplay between them. As with the previous section, though the events most immediately and directly assoclated with the 1982 forecast will be examined in greater detail, a significant amount of background information is also provided about the forecast's antecedents, beginning with the midale years of the Hodel Administration. This, more than $\mathrm{T}$ - or 0 -perspective analysis, helps illuminate the specific events and issues providing motivation for the development of an independent forecasting capability at BPA.

As described in the previous section, Donald Hodel's term as Bonneville Power Administrator began at a 
time when regional drought, international petroleum price escalations, and continuing strong Northwest economic growth all contributed to a picture of future power shortages. The Sum-of-Utilities forecasts had proven generally reliable as indicators of load growth, and no new role was seen for BPA forecasting staff beyond their usual contribution to the sou on behalf of small public utllitles in the region. Power Requlrements (renamed from Power Marketing, a title more appropriate to periods of abundant electricity) was functionally subordinate to the Power Resources Branch of Power Management, its dutles clearly, and modestly, defined in a seemingly stable load environment.

While the organizational analysis (presented in the previous chapter) of the development of Power Requirements into a forecasting body independent of BNUCC revealed a sudden growth in staffing and capabillty in the 1980-81 perlod, the seeds of its transformation had actually been planted some years earlier. It was during the middle of Hodel's term of office, in 1976, that the first traces of cognitive dissonance began to cast a shadow on the consensus perception of sustained load growth dominating the power planning community. Relterating a point first made in the introductory chapter of this dissertation, it was at this point that BPA acquired the services of the consulting firm of Skidmore, Owings, and Merrill (SOM) to conduct an independent evaluation of the need for flve wPPS nuclear 
plants. The findings, which concluded that increased conservation would significantly reduce, if not eliminate, the need for five plants, set in motion activity within BPA which would eventually culminate in the establishment of the agency's 1982 forecasting capability.

As a result of the SOM report, several members of Power Requirements undertook a new exercise beyond the group's traditional missions of contributing to the sou forecast and conducting power marketing studies. Along with Terry Esvelt, then working for BPA's Environmental office, Don Hoffard and Mark Roberts attempted to develop a framework which would render the Skidmore, Owings, and Merrill findings more useful. SOM had developed their percentage conservation savings estimates largely from other sources: engineering simulations of building energy performance, documented performance of test structures, and miscellaneous "expert" studies. Different savings levels were attrlbuted to proposed education, incentive, and mandatory programs in residential, commercial, and industrial sectors.

The sources tapped by som usually expressed their research results in a form such as "A building constructed to ASHRAE 90-75 standards results in a savings of ' $x$ ' percent relative to a typical 1974 structure". To be useful for utility planning, however, this information needed to be translated into a Eramework breaking down savings by end-use and consuming sector -- that is how much of the savings 
could come from, say, heating, cooling, or lighting loads in commercial buildings. Hoffard, Esvelt, and Roberts attempted to derive an end-use decomposition of the sou forecast using a variety of sources for relevant data (perhaps most notably the economic statistics and projections prepared by Don Morey who had worked in the group's Economic studies section). The results of the exercise proved enlightening to all those involved. Bullding up load profections from sector-specific forecasts of key economic variables le.g. number of houses $x$ percent electric heating $x$ heating use per household) resulted in electricity consumption values conspicuously below those of the sou forecast. Only by assigning the differences to conspicuously overlarge 'other' and 'miscellaneous' use categorles could the sou totals be captured by an end-use framework.

The following year, PNUCC first used the econometric model developed under contract by National Economic Research Associates to corroborate the results of the sou forecast. For the BPA staff members who had worked on the end-use decomposition exercise, this corroboration, suffice to say, proved unconvincing. Although their perspective was a minority one, both within the $\mathrm{BPA}$ and the larger community of reglonal forecasters, and although their efforts resulted In no immediate revisions in Power Requirements' mission all would carry the insights gained from the exercise with them through the years of the Munro Administration when they 
would take leading roles in developing the technical apparatus for BPA's first independent forecast.

At about the same time that PNUCC was "crosschecking" the sou forecast with its newly received econometric model, an independent effort, the Northwest Energy Policy Project, was beling conducted at washington state University. As noted in the introductory chapter this project resulted in the development of several forecasts somewhat lower than those of PNUCC, produced using a differently specified econometric model. Significantly, two members of Power Requirements staff, Don Hoffard and Bob Lewis, worked on the project. Though, at this time, Power Requirements was one of the few bastions of economists within an agency dominated principally by engineering concerns, few of the staff economists had strong backgrounds in computer modeling and quantitative forecasting methods (in sharp contrast to the 1982 staff). Hoffard and Lewls were notable exceptions, accounting for their participation in the NEPP modeling effort. From the standpoint of the eventual development of BPA's 1982 forecasting system, this participation raised issues which further underscored the need for a harder and more thorough look at the varied factors underlying regional load growth.

Even after sterling Munro took office in early 1978, however, skepticism concerning continued high growth in regional electricity consumption still represented a minor- 
ity viewpoint. Although PNUCC had revised the sou forecast downward for several years in response to the first unmistakable signs of slowing load growth, these revisions were modest rather than a significant departure from precedent. For the majority within the power planning community this slowdown connoted a temporary aberration in an otherwise stable pattern rather than the onset of a new trend. Given the characteristically slow and conservative responses of both organizations and the individuals populating them to changes in their environments, it is not surprising that the "conversion" to a new vision of the future proceeded unevenly and was generally met with resistance by those who had made heavy personal, professional, or financial investments In the "offlclal" future of high growth. In this regard, BPA differed little from other organizations within the region. Even within Rower Requirements, which was specifically tasked with anticipating Northwest electricity futures, the overriding emphasis was upon fulfilling the traditional missions of contributing to the sou forecast and conducting marketing studies, rather than exploring alternative possibilities.

At first, any pressure for development of an independent forecasting capability at BPA during Munro's term of office was slight, originating from (and largely confined to) the group within Power Requirements that had taken the critical look at the sou forecast earlier. Two critlcal 
characteristics of the load and resource planning environment during the Munro's years, however, provided the particular milieu which the "bottom-up" organizational effort to build a forecasting capability internal to BPA needed to take root and grow. One was simply the general late 1970 s pattern of load growth, which, though still strong, continued to fall below the downwardly revised sou forecast predictions. This gave greater respectability to the assertion that the Northwest might be viewing the onset of a new trend as opposed to a transient aberrational development. The other characteristic was the strong push, from many parties in the region (including Munro himself) for the development of the Regional Power Act legislation. Within Bonneville, it then became more apparent that should BRA assume a new role of acquiring resources to meet the loads of any of the region's utilities requesting power exchanges, it would need to be able to perform a variety of internal forecasts and analyses beyond its previous capabilities. Moreover, it also became rather obvious that models other than those in use in the region at that time would be needed.

As the Regional Act legislation was being debated during 1979 and 1980 , several efforts were undertaken within Power Requirements which would in many respects, form the core of the demand component of the BPA forecasting system. Oak Ridge National Laboratory, as mentioned 
earlier, had, under the Carter Administration, developed residential and commerclal sector energy forecasting models for the Department of Energy. These models had become part of the public domain, and, after BPA had become part of the USDOE it was simple for the members of the Power Requirements staff to acquire Federal Reglon X (Washington, Oregon, Idaho and Alaska) versions of the models "off the shelf" (i.e. ready-made rather than specially developed for BPA under contract). Not surprisingly, their acquisition was initiated by Hoffard, Roberts, and Esvelt of Power Requirements, both in response to the obvious weaknesses of other forecasts in use at that time and in anticipation of new demands to be placed upon the organization. Even had the Reglonal B1Il not been enacted, BPA was commltted to conservation assessments which would require some defenslble method of projecting both electricity sales and savings. The ORNL econometrlc/end-use hybrlds were, very literally, tailor-made for the purpose.

Very shortly after the acquisition of the ORN models, Mark Roberts and Terry Esvelt had a regional survey of residential housing and electricity consumption characterlstics conducted, under contract, by the firm of Elrick and Lavidge. Within a year a somewhat different, but parallel effort was underway in the commercial sector. The Energy Information Administration of USDOE was having a survey conducted by westat, Inc., to explore the feasibility of 
using utility billing records as the basis of conducting commercial energy surveys. One of the test sites under consideration was in the Pacific Northwest. By adding funding to the project, BPA arranged to have all three sites selected in the Northwest (Portland, Seattle, and the Tri-Cities), resulting in a more useful, but not fully regionally representative commercial survey. These surveys were needed for three purposes, each consonant with the directions that the organization was at that time expected to go. One purpose was simply to gain detailed empirical familiarity with one or more of the major consuming sectors. The efforts made several years earlier, to develop end-use framework explaining the sou forecast had raised many questions, and ldentifled many data needs, which such a survey could resolve. Second, because the ORNL models needed to be callbrated to the Pacific Northwest, as opposed to Region $x$, the survey could be used to obtain (or approximate) regionally representative values for key model input variables. Finally, survey results could, if and when needed, form the basis for further analysis needed to adapt or modify the models as required.

Last of all, a third, somewhat new effort was begun in what had been (and soon would again be) the Economic studies group within Power Requirements. Don Morey had, since the 1960s, conducted various economic analyses as part of the marketing studies forming one of the unit's central mis- 
sions. These analyses had both judgemental and quantitative underpinnings, but were not performed using complex or sophisticated computer models. When the demand models were received from Oak Ridge their data requirements were identified and efforts were made to develop regional values for key variables. In addition to survey data on characteristics of the two consuming sectors represented by the models, projections of specific economic variables on both national and regional levels were needed. This resulted in a new agenda for economic analyses -- projections had to be tailored to match the form and format of the input variables and, in some cases, new models had to be developed expressly for this purpose. This last need would ultimately usher in a connected serles of computerlzed economic (and demographic) models.

While "bottom-up" organizational pressure for an In-house forecasting capability origlnated with key members of the technical staff, the proposed change of mission had the support of the Chief of Power Requirements (then a section within Power Resources), George Gwinnett. Formerly one of BPA's Area Economists, Gwinnett headed the section beginning in the mid 1970 s and, during the years when the Regional Act legislation was being debated, acted as a key spokesperson for the group, representing its new interests to other portions of the organization. Up until the passage of the Reglonal Act, however, support within the larger 
organization was less than wholehearted. Though there was no significant internal resistance to the idea of an independent forecasting capability, neither was a niche being readied in the larger functional hierarchy of the organization. In 1980, the newly obtained models were employed in the preparation of a series of sector-speciflc conservation assessments, but resource planning was still grounded in the forecasts produced by PNUCC.

The enactment of the Regional Bill in late 1980, in large measure provided the direct impetus for Power Requirements' reorganization and reorlentation. Despite the fact that one of Ronald Reagan's first actions after inauguration was to put a freeze on Federal hiring, BPA managed to open a number of new positions made necessary by the agency's augmented responsibilities. Though the hiring freeze made it temporarily impossible to fill some of these slots, $B P A$, and Power Requirements grew in the wake of the passage of the Regional Act (and, as noted in the previous chapter, Power Requirements grew disproportionately fast during this period). With BPA legally responsible to acquire the resources needed to meet the loads of whatever utilities willing to accept the terms of the Act, an improved, and independent, forecasting system became a necessity. It was in this organizational climate that the proposals being advanced by a contingent within power 
Reguirements were given the wholehearted support of BPA's upper and middle management.

Approximately half a year separated the passage of the Regional Act from Peter Johnson's appointment to the position of Bonneville Power Administrator in mid-1981. It was during this interval that Power Requirements emerged as a Division within BPA and staffed itself to levels needed for the performance of its newly defined (and organizationally accepted mission of producing an independent forecast to guide resource acquisitions. As noted earlier in this chapter, a precise and specific definition of the Division's mission awaited the design and development of a decision support system geared to perform the Elnancial analysis required by Administrator Johnson for his 1982 decision on the WPRS nuclear plants. During the last months of Munro's term of office, however, the Division's organizational structure was established.

The staffing chart for the infant Division straightforwardly reflected the key issues raised since the mid-70s publication of the som report. George Gwinnett, who had been Chief of Requirements when it was a section within Power Resources, retained his position of leadership as Director of the Division. Don Morey, who had performed most of the economic analyses for the unit's marketing studies a decade earlier headed the Economic and Utility studies Branch which was responslble for preparing economic inputs 
for the new demand models as well as fulfilling Requirements' traditional mission. The other Branch, Energy Modeling and Analysis, concerned Itself with development and operating of the new long-term forecasting models. The three supervisors in this new Branch were the same persons who had attempted, four years earlier, to develop an end-use framework to explain the sou forecast. Don Hoffard headed the Branch while Mark Roberts and Terry Esvelt respectively chiefed the Energy Modeling and Energy Analysis Sections. The minority viewpoint which the three had earlier shared concerning plausible Northwest energy futures was now the predominant one within the Division.

A slight reshuffling of key personnel took place prior to the production of the 1982 forecast. George Gwinnett returned to the Lower Columbia Area office, this time as its head, vacating the Power Requirements Division Director's slot. This was soon fllled by Don Hoffard, whose vacated Branch Chief position was subsequently filled by Terry Esvelt. John McConnaughey then became Chief of the Energy Analysis Section, while in Don Morey's Branch, Geoff Moorman and Gerry Lenzen respectively headed Economic Studies and Utility studies sectlons (the latter unit reviewed individual utility forecasts and continued BPA's participation in the sou but did not have a role in producing the new longterm forecast). Though George Gwinnett continued to act as the Division's key spokesperson through the early phases of 
the 1982 public involvement process, it was this lineup that oversaw the development of BPA's first independent forecast.

From the standpoint of the $P$-perspective, a central investigatory concern is the background or training of key participants in a technical or decision process. While the past experlences of those Power Requirements figures managing the forecast was perhaps not as critical as that of the Administrators managing the organization, it is still of significance in understanding the factors which, over a period of time, shaped the development of the long-term forecast.

As noted in the previous chapter, Power Requirements was one of the first groups within the traditionally engineering-based BPA to employ economists. As economic and financial considerations became more central to BPA during the 1970s, training in economics became correspondingly more widespread organizationally. Not surprisingly, under these conditions, all of the Power Requlrements staff supervising the 1982 forecast had degrees in economics.

It must also be noted, however, that during the latter half of the 1970s, when the Implications of the som studies were first recognized, most of those involved in producing (and endorsing) the sou forecast were also schooled in economics, with its emphasis upon the effects of price upon present and future consumption. Obviously, then something else characterized those who flrst recognized the limita- 
tions of the traditional sou outlook and spearheaded the development of the forecasting apparatus used in 1982.

A closer look at the background of the economists who pioneered Power Requirements' development suggests several factors which predisposed them to revise the traditional outlook for power futures. First, and most immediately obvious, was the circumstances they found themselves in. BPA's involvement with both PNUCC and the contractors at SOM made it imperative that someone be given the task of attempting to reconcile the two disparate points of view. Thus, it seems likely that whoever received the assignment would be compelled to reevaluate, to at least some degree, the power planning status quo. Given that the task was an unprecedented one, however, it could have been approached in any of a number of different ways with varying results. That it proceeded as it did was the consequence of a second factor, the speciflc tralning of the individuals involved. Terry Esvelt and Mark Roberts were, at the time of the som review, both relatively new employees at BRA. As such, they had much less investment in the organizational precedents which were responsible for the malntenance of the "official" interpretation of the future. Esvelt worked for the Environmental office and, in this capacity, brought several new emphases to the assignment. Though both Don Hoffard and Don Morey had been with Power Requirements since its days as Power Marketing, both had special areas of expertise which 
proved significant to the sou evaluation project. Hoffard was one of the first in Requirements to have a strong and extensive background in computer modeling. Computerized models require formal, explicit, and consistent explanatory principles, though this is not generally true of economicbased interpretations of load growth. Morey provided experience in identifying, monitoring, and projecting economic and demographic factors which drive changes in levels of electricity consumption. The availability of both $h$ is expertise and his projections of economic activity in the region allowed (or possibly predisposed) the team evaluating the soU forecast to build up a forecast from basic trends, developing a (noncomputerized) model of sorts. This model, In effect, undermined any confidence they might have had in the sou profections.

Though the 1982 forecast was the product of many persons, and though a large portion of the form which it finally assumed was determined by the structure of the models selected, the imprint of the key figures in Power Requirements' reorlentation is clear. Don Morey had developed (or supervised the development of) the methods used to produce the economic and demographic projections used in the demand models, in particular, the paper-andpencil techniques underlying the Economic Base Model used in producing the regional employment projections. In 1981, Morey became Branch Chlef, handing control of the Economic 
Studies Section over the Geoff Moorman. For the first forecast, however, the methods in place were Morey's. As noted above, Don Hoffard was one of the first computer-proficient members of Power Requirements' staff. In the mid-1970s, along with members of NERA (developers of the PNUCC Econometric Model), he particlpated in the creation of the Integrated Supply and Demand Model (ISDM). The demand component of ISDM was the creation of NERA: the supply (or resource costing) component was hoffard's contribution. It was the supply component of ISDM which, when separated, became the basis for the Supply Pricing Model which provided electricity prices based upon the costs of scheduled resources and the priorities of the Regional Act.

Finally, Terry Esvelt and Mark Roberts were largely responsible for designing (or at least supervising the design of) the model review and forecasting methodology. The test runs performed, the evaluation criteria considered in the modeling selection procedure, and the form which the modeling system ultimately assumed in many ways reflected the issues which they had earlier confronted in dealing with PNUCC, SOM, and NRDC (Natural Resources Defense Council). At the outset of this section, it was asserted that at the mid-levels of organizations, where activities such as the BPA forecast are managed or directed, there is less decision-making freedom (at least over central issues), than 
near the apex where a key individual's style or operating priorities may shape the behavior of an entire bureaucratic structure. It was also asserted that at these lower levels effective use of the $P$-perspective requires a close examination of specific circumstances. The description of the gradual shift in the perception of regional power futures given above provides an lllustration of how the personal and circumstantial elements so central to the $P$-perspective interact. The summary comments below, which conclude this section, should serve to highlight these important interactions.

In reviewing the specific personal factors prerequisite to the development of the 1982 BPA forecast, three interacting elements stand out as determinants. First, and most generally obvious, is the specific backgrounds of those leading the movement towards a computerized system of models. All of the principals in this movement who were employed at BPA at the time of the sOM report were economists in an organization dominated by engineers. This training emphasized a focus upon the effects of price upon supply and demand which contrasted with the assumptions underlying the nalve extrapolation methods employed in the sou forecast. More speciflcally two of the key actors were new to BPA, less bound to "official" images of the future and more concerned with newly recognized issues such as conservation potential and resource pollcy implications. 
The two other key figures, though long-time employees, had unique training in computer modeling and regional economics, which made them perhaps more attentive to the numerous factors underlying load growth. In toto, these background profiles provided a predisposition for the group members to look at forecasting somewhat differently. Second, the specific circumstances these individuals found themselves in served as a trigger or catalyst to the gradual reformulation of an image of the future. As noted above, the attempt to reconcile the SOM report with the sou findings led to the development, on paper, of an end-use framework which would not account for large portions of the loads anticipated by PNUCC. The resulting cognitive dissonance led both to a general mistrust of continued high growth rates in regional forecasts and to a perceived need for a substantially revised approach to forecasting.

Finally, the general political environment (as embodied in the policies of the relgning Administrator) provided the milleu in which rapid expansion of forecasting capability either was or was not possible. Initial investigations into conservation assessment began during Hodel's Administration, where the problem was perceived to be avoiding severe forthcoming deficits. With Munro taking office, and regional power legislation a front-running issue, the organization became more receptive to developing an in-house forecasting and resource planning apparatus, though tradi- 
tional views still predominated. Full support for the expansion plans of Power Requirements was forthcoming soon after the passage of the Regional Act, and in 1982, Peter Johnson's need for wPpss financial analysis merged with the efforts to develop sector-specific forecasts to produce BPA's decision support system.

THE P-PERSPECTIVE - CONCLUDING REMARKS

Examining a decision process from the vantage point of the P-perspective, then, entails a focus upon the unique attributes of the individuals involved. The next chapter, which cross-cues the insights derived from the three perspectives, should provide a fuller and rlcher understanding of the significance of the P-perspectlve. Before moving on, however, it is worthwhile reiterating (and to some extent expanding upon) several key points regarding the character of the P-perspective.

First and foremost, investigation from the standpoint OE the $\mathrm{P}$-perspective, to repeat a point made above, centers upon what is unloue to individuals involved in decision processes. All actions are ultimately carried out by Individuals, but it is only where choices or alternative courses of action are avallable that the $P$-perspective is the appropriate tool of investigation. If an individual reflexively follows "cookbook" technical procedures or stralghtforwardy carrles the actlons prescribed for an 
office holder in a particular situation, these behaviors are the objects of, respectively, the $T$ - and 0 -perspectives, regardless of how large the impacts are which can be traced back to the particular individual undertaking the action. By contrast, if an individual had the latitude to select one technical procedure over another or one course of action over another, P-perspective research would be appropriate to explore elements of the individual's background, training, character, motivation, or style which could explain the choice.

A second point worth emphasizing before undertaking the cross-cuing exercise is that the individual factors affecting complex decision processes should never be dismissed merely as distorting biases or as personal agendas undertaken to the detriment of larger goals or organizational activities. While these individual factors (e.g. education, problem-solving style, experlence) clearly may have significant impact upon decision processes, they are by no means typical, or characteristic, of the focus of P-perspective investigation. In fact, unique individual views or operating styles may, in certain situations, be unique strengths (as Johnson's business orientation to management was in the context of the wPPSS decision) and individual interests may complement rather than conflict with organizational or public priorities. 
Finally, it should be noted that though many ind ividuals with their own idiosyncratic views of the world incrementally affect decision processes only a few truly exert shaping influences. These individuals are always the prime foci of the P-perspective research and their identification is the investigator's foremost problem.

The next chapter, focusing upon the cross-cuing of the three perspectives, will better 111 ustrate where and how individuals made a difference. 
CHAPTER V

\section{CROSS-CUING THE PERSPECTIVES}

INTRODUCTION: CROSS-CUING - THE DECISION PROCESS IN 3-D

Having looked at the decision process surrounding the development of the 1982 BPA forecast from each of the three perspectives in isolation, it is now time to explore the larger theoretical and methodological potential of the Multiple Perspective Concept by cross-cuing the perspectives and the insight's derived from their use. More traditional analyses of complex decision processes usually contain some Implicit cross-cues, in that researchers will veer briefly from a dominant perspective to explain a particular outcome (e.g. a predominantly organizational analys ls may note how a specific technical factor, such as software limitations, predisposed a decision). In such instances, however, there is rarely an explicit recognition by the analyst that alternative paradigms of inquiry are being used and, in consequence, no attempts are made to explore the alternative perspectives with any thoroughness.

In this dissertation, an attempt was made to make the T-, $0-$, and $P$-perspective investigations as independent of one another as possible. The idea behind this strict separation of the three paradigms of exploration was, first, to 
characterize each of the perspectives and their use as clearly as possible and, second, to encourage an investigative thoroughness within each of the individual domains of inquiry. Additionally, this segregation of findings allows a similar clear illustration of the nature and synthetic capabilities of the subsequent cross-cuing procedure. Cross-cuing represents the integration of the three distinct perspectives, each with its own unique focus of interest and mode of inguiry. This integration, however, is not simply a synthesis of findings into a single unified picture nor a reduction of the varied insights of the $T$-, $0-$, and P-perspectives to a common denominator. The strength of the Multiple Perspective Concept lies in the entirely different approaches each of the perspectives takes in viewing a single decision process. Any attempt at synthesis or reduction would simply strip away the very elements which make Multiple Perspectives useful. Rather, the process of cross-cuing illuminates how the perspectives both harmonize and conflict along a number of dimensions, conveying a deeper understanding without any necessary resolution of disparate inslghts. As Linstone (1984) has described:

\footnotetext{
"The process of integration is not merely one of assembling a composite plcture from Jigsaw puzzle pieces, nor ironing out contradictions by some rules of thumb, nor arranging the information hierarchically. Integration resembles the task of conceptualizing a three-dimensional object from one-dimensional descriptions and two-dimensional drawings (p. 82)".
} 
In many respects, cross-cuing is the "meat" of a Multiple Perspective investigation. It is here, where the insights of the different perspectives interweave, that the "reasons" behind a decision become apparent, or the possibilities arising from a new technology begin to become evident in their fullness. In the case of BPA's first independent forecast, it is in the cross-cuing of the perspectives that the interacting forces which shaped the final product may be ldentified and their relative influence assessed. Procedurally, the cross-cuing of the different insights Into the 1982 forecast is developed below in several steps. First of all, T-, $0-$, and P-events, projects, or decisions are laid out on three parallel timelines, each representing the domain of one of the perspectives used in the investigation. Because the focus of this dissertation is on the development of the 1982 forecast, heaviest emphas is is given to the year immediately preceding the release of the offlcial forecast document, since this is when both the largest volume of relevant technical work was carried out and the most vigorous interchanges took place among actors in the power planning community. To the extent that they provide a necessary explanatory context, however, events from earlier years (such as decislons made during Hodel's term of office) are included in the timelines. Although such a tripartite chronological ordering, in and of itself, 
hardly provides a Elinal explanation to a decision process as complex as the one forming the subject of this investigation, this picture does provide insight through its comprehensiveness.

The second step is to determine where and how the perspectlves cross-cue one another. Several distinct Investigatory activities are encompassed by this step. The organizational challenges, both orlginating from inside and outside BPA during the forecast perlod are examined and the extent to which they influenced the core assumptions underlying technical choices is assessed. In similar fashion, the personal influences of policy makers, planners, and profect managers are ldentified and the effects on the substantive output of the forecast process are evaluated. The extent of the actual impacts of technical findings on organizational decisions and actions is evaluated. Finally, these cross impacts are mapped conceptually between the timelines to provide a representation of how the perspectives interact.

To deepen the insights conveyed by this two-dimenslonal map, digraph analyses of relationships between elements uncovered by each of the three paradigms of inguiry are developed in the third and final step of the cross-cuing process. Returning to the analogy of cross-cuing as a means of conceptualizing a three-dimensional object from a series of partial descriptions, the digraphs provide cross- 
sectional representations of the "depth" of the decision process and some of the dynamics operating along this dimension. Often the unique "rationale" underlying a decision process has its locus in these dynamic interconnections between $\mathrm{T}-, 0-$, and $\mathrm{P}$-perspectives, and can be most clearly understood by tracing the sequence of impacts methodically from one node of a digraph to the next.

Following the completion of this digraph exercise is the final chapter of this dissertation which presents conclusions on what the Multiple Perspective Concept reveals about the process by which BPA prepared its 1982 forecast and on what the case study of the 1982 forecast reveals about the uses of Multiple Perspectives.

\section{CROSS CUING: THE "MAP"}

\section{Describing the Timelines $-T$, 0 , and $P$ in Parallel}

The first step in identifying, enumerating, and analyzing the cross-cuing relationships between the $T-, 0-$, and P-perspective descriptions of the BPA forecast, as noted in the introduction above, consists of laying significant events side by side on distinct timelines in order to make comparisons and posit linkages. Figure 26 provides the graphic representation of these comparisons (The Iinkages Indicated between the perspectives will be discussed in the section that follows. In the text, a cross cue from, say, T onto 0 -perspective will be denoted ' $T-0$ '). 


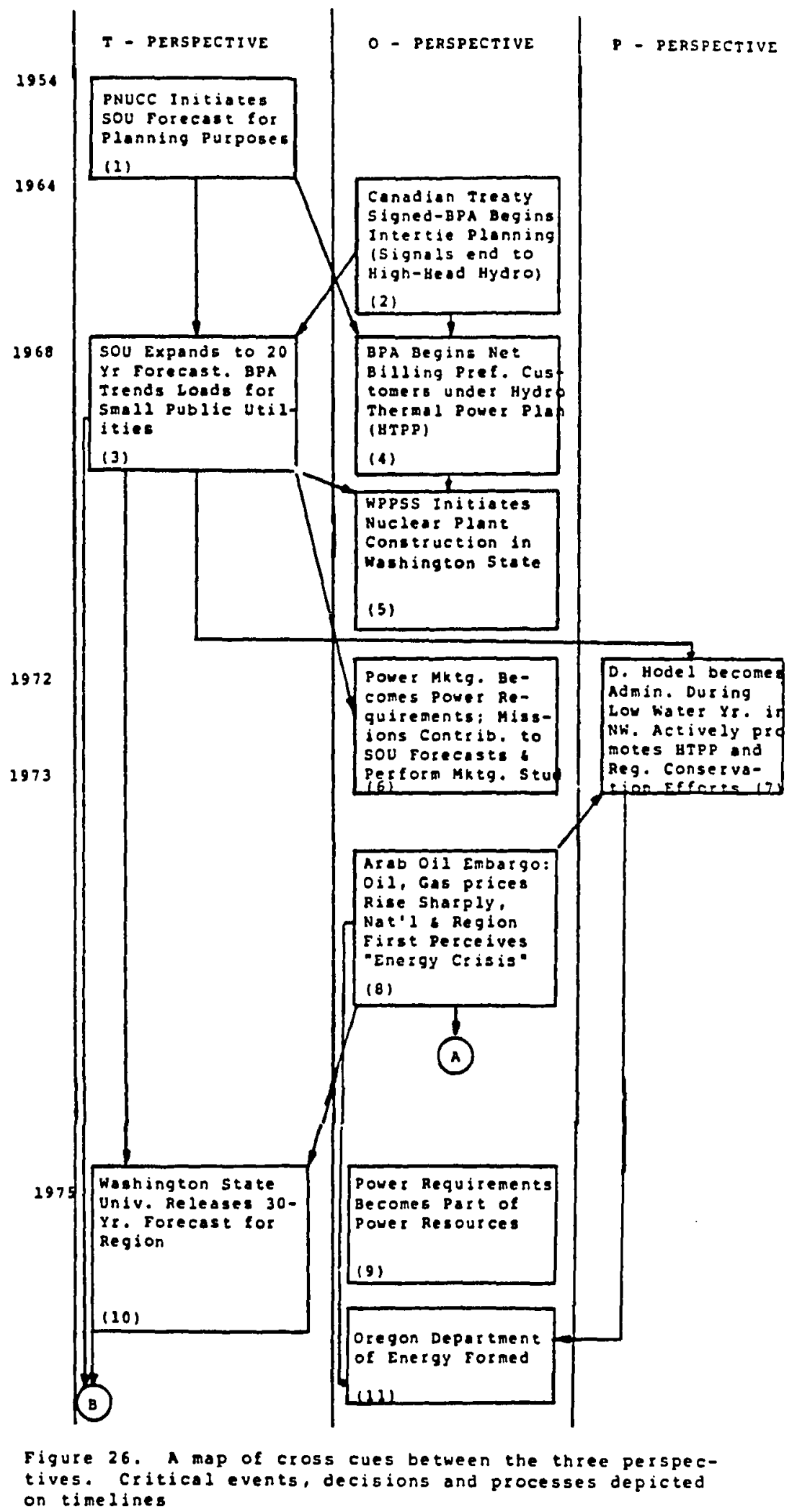




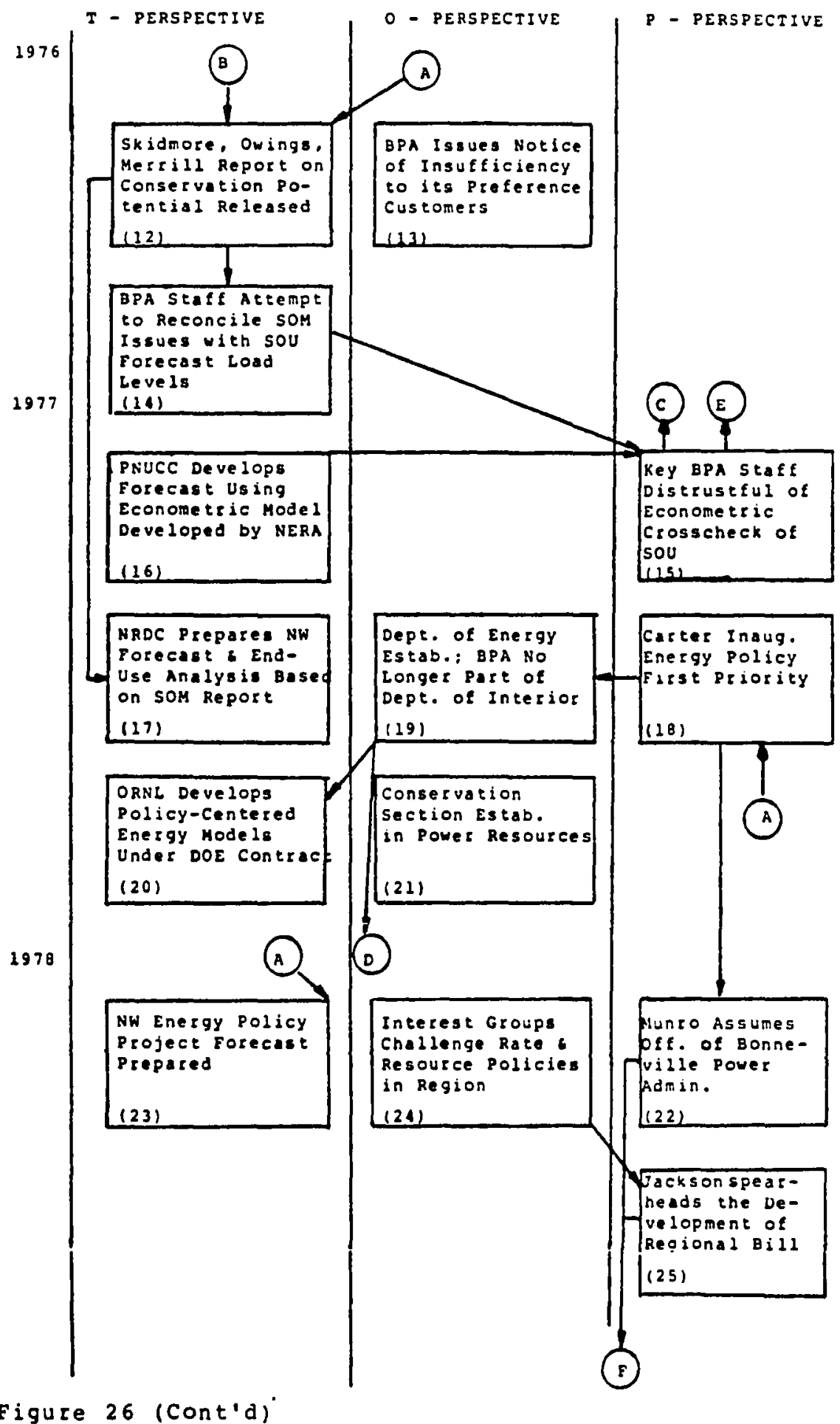




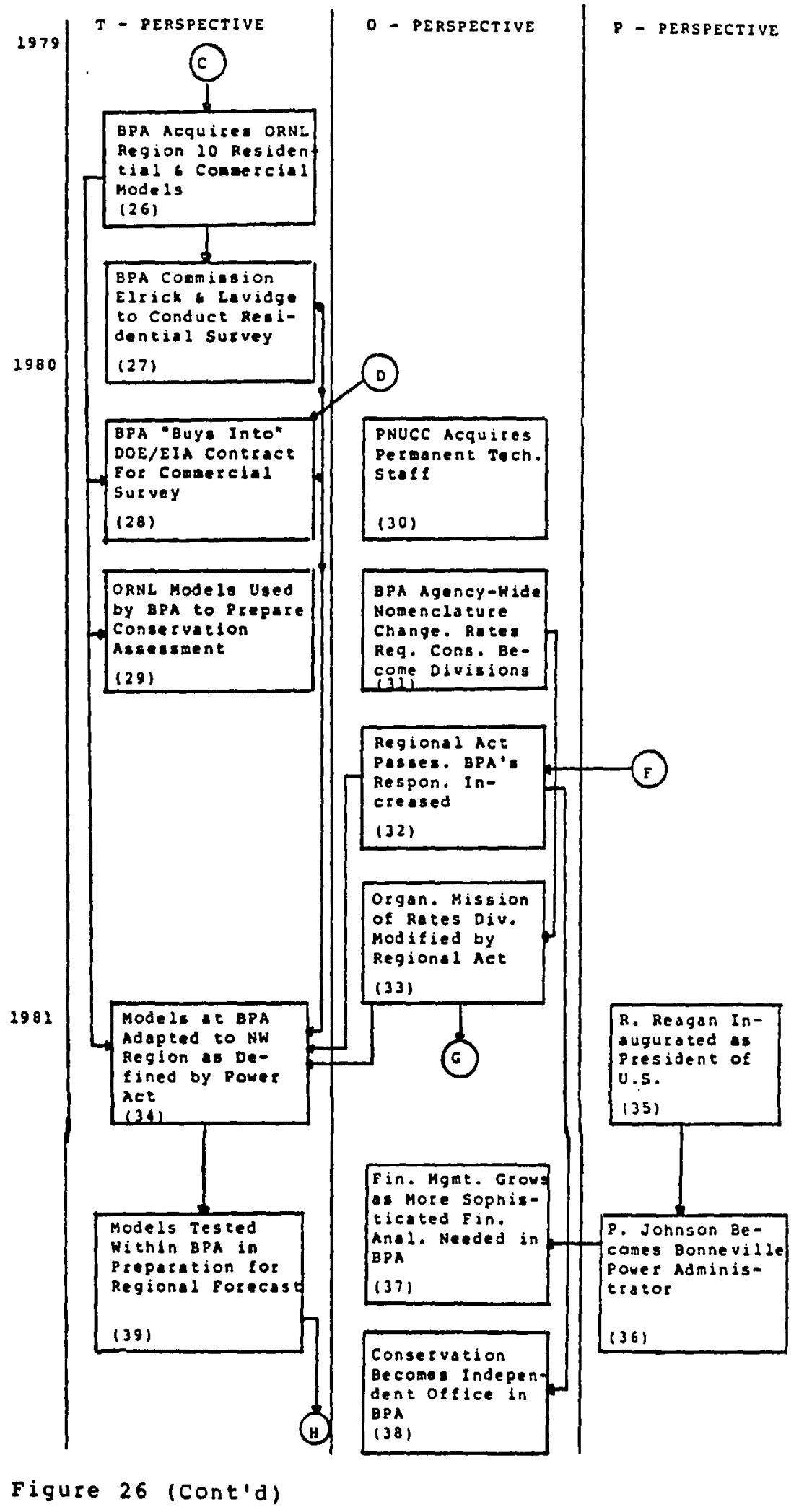




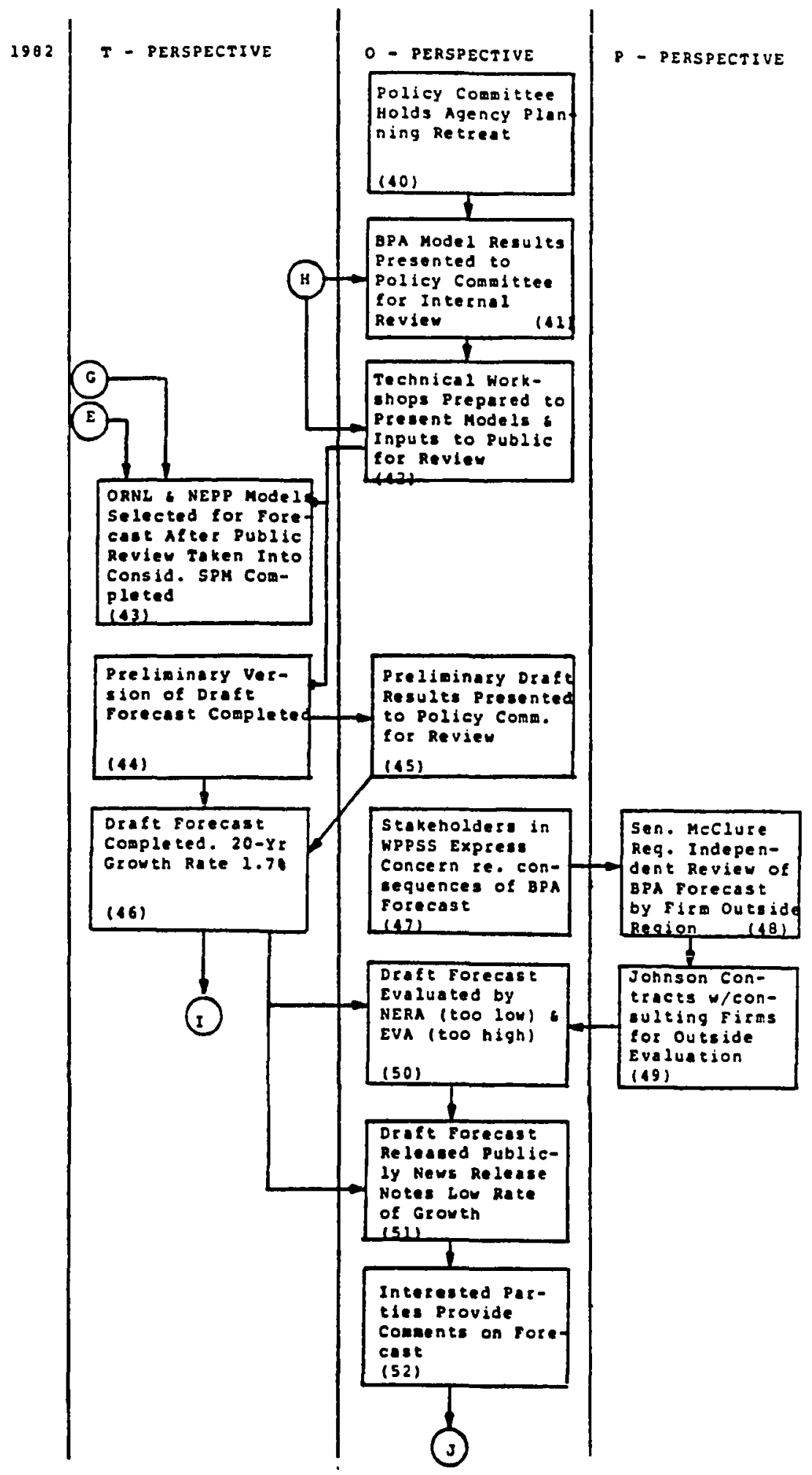

Figure 26 (cont'd) 


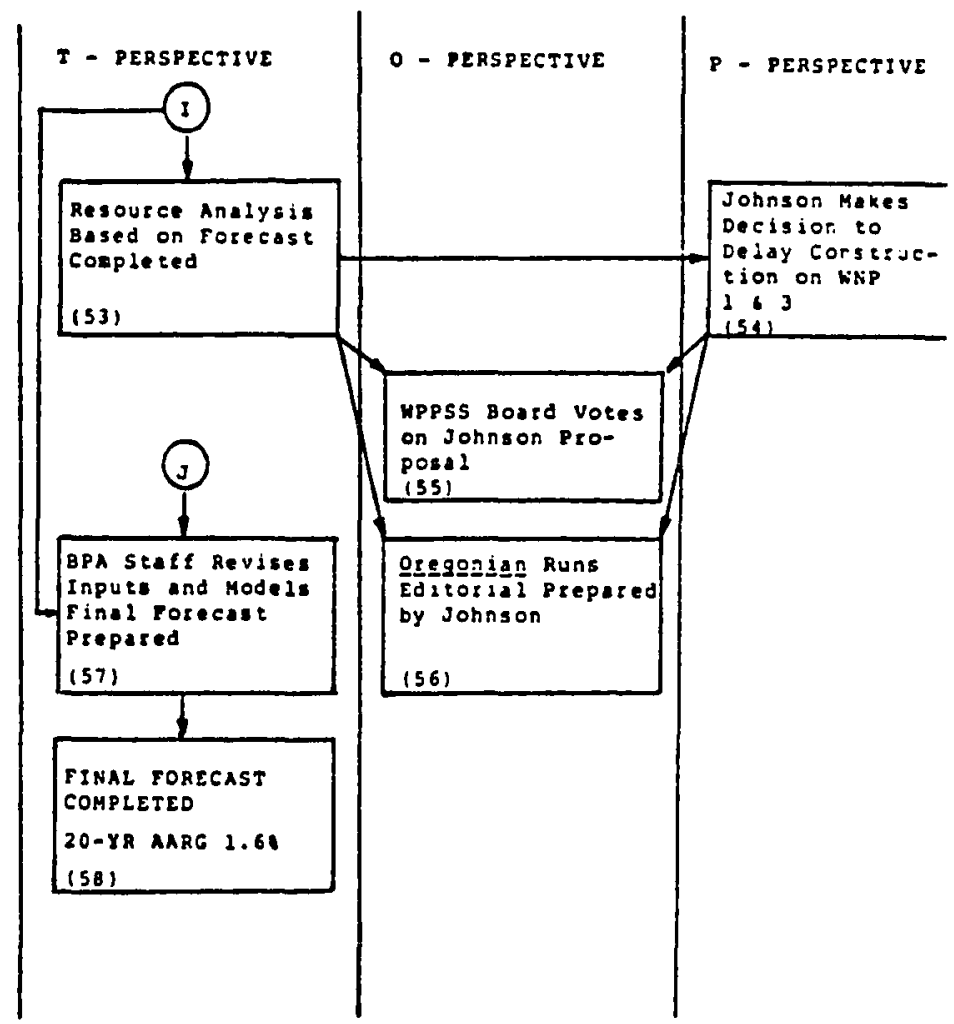

Figure 26 (Cont'd) 
To reiterate yet another point made above, because this research focuses upon the development of the 1982 forecast, heavlest emphasis is placed upon its immediate determinants. Hence, the map is "most dense", as would be expected, in the 1981-1982 perlod where the lion's share of the technical work and interaction between parties interested in the Implications of the forecast took place. Descriptions of these events, or map elements, are correspondingly detalled and at the same time, go beyond what each of the perspectives reveal in exclusion of the others. Particular attention is given to the specifics of the public involvement process surrounding the 1982 forecast, for it is through this process that technical, organizational, and personal factors most intricately (and most significantly) intertwine as the region's varled interests attempt to influence resource decisions. Events which can be seen ultimately to have a signiflcant effect upon the forecast process (e.g. the institutionalization of the sou forecast, the Hydro-Thermal Power Plan, the 1973011 embargo, etc.) are also listed and discussed brlefly, since they form the Erames (or contexts) within which decisions of the region's power planning community take place. Although the consequences of all such events wlll be discussed in very general terms, their effects are long-lasting and often continuous, shaping organizational decisions and technical cholces for prolonged perlods of time. 
Events and Impacts - A Discuss lon of the Elements and Cross cues in the Map

The earliest event (1) in the map occurs in 1954 and is significant as a frame for any discussion of Northwest power planning. At this time, PNUCC members first produced the sou forecast by simple aggregation of individual utility forecasts. As noted in the introductory remarks above, historical events forming the background for the 1982 forecast are to be sketched in less detail than those within the 1981-82 production cycle. Although the sou forecast is listed under the T-perspective for simplicity sake, it also was the product of organizational and personal elements which, if traced out, would greatly expand the size of the map. Rather than do this, key 0 - and P-features of the forecast will merely be noted (as will be the case for other pre-1982 forecasts included on the diagram). The organlzational perspectives at the time of these early forecast were firmly rooted in a falth in growth which, in retrospect, can be seen to be naive. The utility representatives of the time were far less versed in mathematical economics and modeling than their heirs would be, and the techniques they applied reflected their orientation towards the future. Many consequences followed from this initlal enterprise: a long lasting precedent was set for simple trend forecasts as an input to the region's power planning decisions. Until the early 1970's, stable (and robust) regional growth (erec- 
ted, in many ways, upon the infrastructure of Federallybased hydropower) posed little challenge to this, in retrospect, simplistic forecasting methodology. These early forecasts, with their 11-year time horizons were later supplemented by 20 year versions (element number 3 on map) in 1968 .

The signing of the Canadian Treaty (0-perspective) in 1964 (event number 2) simultaneously set new policy and foreshadowed the end of business-as-usual for BPA. This treaty, negotiated by U.S. and Canadian governments (and involving the Army Corps of Engineers, the Department of the Interior, and $B P A$ ) established the sites for the final set of high-head dams along the Columbla River system, concluding an era where additional cheap hydroelectric power could be treated as a given. At the same time the immediate power surplus resulting from the newly acquired generation in turn resulted in the establishment of the California Intertie so BPA could market the power it was required by Treaty to purchase from Canada, but which was not yet needed in the Region. From this point on, Intertie sales became a critical part of BPA marketing strategles.

Element 3 on the map, the expansion of the sou forecast to 20 years, was influenced by both the previously mentioned events $(T-T, O-T)$. The connection with the flrst element is both alrect and obvious -- the methodological precedent established in 1954 was carrled over. The forecast remained 
a simple sum of utility-specific trend extrapolations (with BPA preparing forecasts for small public utilitles) -- the extrapolations simply went further into the future. Indirectly, the signing of the treaty provided something of an impetus for longer forecast horizons in that the 0 -perspective considerations underlying the formulation of the terms of the Treaty (e.g. continued Federal participation in generating resource development, future regional marketing challenges for BPA, etc.) ralsed questions about the longer term future which an extended forecast would help to answer. These concerns, however, did not extend to challenging the assumptions underlying the sou or to exploring qualitatively different futures.

A number of factors influenced the formulation and implementation of the Hydro-Thermal Power Plan in 1968 (element 4, listed in the ' $O$ ' column). The T-perspective findings of the sou forecasts (both 11-, and 20-year) prepared in that (and preceeding) years indicated a continually growing need for power $(T-0)$. This methodologicallygrounded perception posed an organizational challenge for BPA to provide continued high levels of service to its customers, particularly its preference customers. Also supporting the plausibility of these challenges were the aforementioned realizations stemming from the signing of the Canadian treaty $(0-0)$. Decision makers and functionaries alike had just taken a hard look at the anticipated 
Iimitations of the regional power supply system (even yith its newly proposed additions) and were just beginning to assess the possible consequences of tapping different resources for generation.

Undoubtedly, the most significant of the decisions made in response to the passage of the Hydro-Thermal Power Plan (0-0) was that of WPPSS to begin construction of a series of nuclear plants (0-perspective: element 5). The Power Plan, with its provisions for net billing arrangements with the region's public utilities, provided an umbrella for the financing of such construction projects. The sou forecasts, at that time the sole picture of Northwest power futures, Indicated an imminent need for generation beyond the capacity of the Columbia River hydrosystem. It was these load projections which further reinforced the deeply ingrained perception in the power planning community of continued high growth, and which reaffirmed the traditional strategy of building in advance of need $(T-0)$. This initial decision, later augmented to include additional nuclear faclities, was clearly destined to provide the all too fixed context for power planning in the $1980 \mathrm{~s}$.

within BPA, the perception of anticlpated power shortages in the not too distant future resulted in some organizational changes $(T-0)$. Though functionally the unit charged with participating in the sou forecasts remained essentlally the same, a 1972 change of name reflected a 
somewhat altered perception of its mission within the organization. Power Marketing became Power Reguirements (0-perspective: element 6$)$, the name change was indicative of the attitude that the unit would no longer be seeking markets for abundant surplus power but rather searching for ways in which to meet Its customers' essential needs, or requirements. Though they were perceived or framed somewhat differently, the unit's missions, contributing to the sou forecast and producing marketing studies, did not, in fact, change substantially at this time.

It was in late 1972 that Donald Hodel became Bonneville Power Administrator, bringing his own particular managerial style and personal expertise ( $P$-perspective: element 7 ) to the office. As noted in the previous chapter, Hodel was Immediately confronted by a low water year, taxing the generation capabilities of the hydrosystem, and, not long after, in 1973, the repercussions of perhaps the singlemost significant event in recent energy policy making history: the Arab 011 Embargo (element 8: 0-perspective). America, and the world at large, suddenly became acutely aware of their heavy dependence upon oll (particularly oll from foreign sources) and of the sensitivity of their economies to political events half a world away. These conditions created a sense of an "energy crisis" requiring strong and perhaps drastic remedial responses by government and industry $(0-P)$. In the wake of such developments, and in 
the face of high sou growth projections (T-P), it is hardly surprising that the touchstones of Hodel's Administration were the timely and efficient development of thermal resources (under the Hydro-Thermal Power Plan) and, to a lesser degree, the exploration of possibilities for promoting regional conservation.

By the midpoint of Hodel's term of office, 1975, the new energy-consclousness in the reglon (mirroring that of the nation) had produced a certain polarization of attitudes. BPA and PNUCC were more committed than ever to a policy of supporting and promoting the growth in power consumption expected to continue throughout the reminder of the century. Within BPA $(P-0)$, Power Requlrements was organizationally subordinated to Power Resources (element 9: o-perspective), in a limited sense, foreshadowing the more pronounced support role for resource decisions the unit would have later under Peter Johnson.

On the other hand, the "energy crisis" left increasing doubt and discomfort about the shape of the future in its wake. In 1975, this uncertainty about energy futures led to both technical (O-T) and institutional developments $(0-0)$. In the former area, the research group at Washington state University's Environmental Research Center prepared thirtyyear projections of energy futures using end-use models (T-perspective: element 10), and several sets of assumptions regarding population and fuel process. They arrived at a 
very difierent perception of the future than PNUCC, one characterlzed by much lower rates of load growth. Unllke PNUCC, the organizational agenda of the wSU group centered on the effects of various economic and demographic factors on energy consumption behavior and conservation. Their methods originated in engineering and economics and in some ways prefigured the orlentations of future forecasting groups. In the latter area, the state of Oregon responded organizationally to the challenge of the energy crisis by forming ODOE, the Oregon Department of Energy (O-perspective: element 11). This group focused an unprecedented set of resources to the tasks of forecasting, planning, and siting energy facilities for the state of Oregon.

This growing dispute over energy futures significantly provided the Impetus (O-T, T-T) for the publication of the Skidmore, Owings, and Merr 111 report under contract to BPA (element 12: T-perspective). BPA's issuance of a notice of Impending insufflciency (element 13: 0-perspective) took place at roughly the same time, reflecting the firmness of the consensus view of impending shortages. There was, however, sufficient legitimate disagreement over the differences betwen wSU and sOU forecasts and concern about the severity of Impacts of more 1 imited energy resources to mandate a study of reglonal conservation potential. The results of this study, which seriously questioned the need for several of the wpps plants before the end of the 
century, raised in turn, Further doubts about the pleture of the world governing energy development in the Northwest.

Within BPA, the most direct and immediate consequence (T-T) of the SOM findings was a Power Requirements' staff effort to develop a framework by which the sou forecast could be decomposed into a sector and end-use breakdown (element 14: T-perspective). With such a breakdown, the plausibility of the conservation savings estimates of the sou report could be assessed. Working from avallable economic and demographic statistics and progresslons, however, the group was unable to develop a framework which would account for the forecasted sales of the sou without masslve 'other' and 'miscellaneous' categorles for residual loads.

The most signlficant consequence ( $T-P$ ) of this falled resolution of SOU and SOM reports was the enduring change of perspective it engendered in the key participants: Don Hoffard, Terry Esvelt, Mark Roberts, and Don Morey (element 15: P-perspective). In 1977, when PNUCC obtained its econometric model from National Economic Research Assoclates to cross-check the soU (element 16: T-perspective), the BPA staff members could only be skeptical of its corroboration of the sou, given their experience of the previous year. (PNUCC's choice of econometrics reflected the rise of quantitatively trained techniclans in their ranks. Complex models were becoming accepted as desirable if not neces- 
sary.) This sheptlclsm regarding forecasts of contlnued high load growth would remain with each of the members of this group and eventually supplant the "official" view of the late 1970s in Power Requirements.

At about the same time that PNUCC was acquiring its econometric model, to some extent a response to a growing regional debate over desirable energy futures, the Natural Resources Defense Council was releasing a forecast of its own (element 17: T-perspective). NRDC developed this forecast, based upon the earlier SOM report $(T-T)$, in a fashion similar to that attempted earlier by BPA. Not surprisingly given NRDC's stated goals of protecting the environment and promoting conservation as an alternative to thermal generation, their forecast for the Northwest was characterlzed by much lower rates of load growth, and much heavier institutional development of conservation than Northwest planners had envisloned.

At roughly the same time, new President-elect Jimmy Carter brought an overwhelming concern for the development of a national energy policy to the office with him (element 18: P-perspective). Heavily influenced by the then widespread perception of a world energy crisis (O-T), which had been swelling since the time of the Arab oil Embargo, Carter, a former nuclear engineer, set in motion the estab11shment of a Department of Energy (element 19: 0-perspective) tasked with planning and managing the nation's energy 
resources. Under the departmental reorganization (P-0), BPA ceased being part of the Department of the Interior and became subordinate to DOE.

One of the key organizational divisions of the fleding agency was the EIA: the Energy Information Administration. Functionally, this unit was tasked with collecting data, developing models, and preparing forecast of energy. signiflcant among its early efforts was its contract with oak Ridge National Laboratory to construct energy forecasting models for the commercial, residential, and industrial sectors $(O-T)$. The structure of the completed models reflected the desires of the Carter Administration, tailored to test varlous energy policles and conservation strategies, displaying the results in an end-use categorization of great detall (T-perspective: element 20 ).

Also not surprising was the appearance of a Conservation Section with BPA's Power Resources at about the same time (0-perspective: element 21). Though conservation had been among the prloritles of the Hodel Adminlstration since the flrst suggestions of impending power shortages, it was In the climate of late 1970 s organizational politics that the function obtained its own reorganized niche at BPA. On January 1, 1978, sterling Munro replaced Donald Hodel as the Bonneville Power Administrator (element 22: P-perspective), a political appointment perhaps reflecting changed priorities of the Carter Administration (P-P). 
Hunro, significantly, had earlier worked as a staff member for Senator Henry Jackson. His approach to administration (as noted in the previous chapter) was a decidedly political response to increasing interest, and controversy, about the regional management of energy resources. This centered, chiefly, on particlpation in the development of the Regional Act legislation designed to promote conservation and orderly resource expansion while minimizing disparities between rate pools.

A technical project completed during this time period was the Northwest Energy Policy Project forecasts of regional energy growth (element 23: T-perspective). The NEPR research team was comprised of representatives of academia and the utility industry with extensive quantitative backgrounds, most fundamentally in the area of econometrics. As a result of the issues raised by the energy crisis and the increasing diversity of views of desirable (or predictable) energy futures, NEPP independently prepared a twelve-volume report $(0-T)$. This report, evaluating regional energy issues and policy options in some detall, included three forecast scenarios of possible load growth. Significantly, though not nearly as low as BPA's first independent forecasts of four years later, the NEPP econometrically-derived forecasts were considerably lower than the official planning forecasts produced by PNUCC, the medium case displaying an average annual rate of growth until 2000 of 2.93 percent as 
compared to the nearly 5 percent AARG of the sOU and the PNUCC econometric forecasts. Though the NEPP forecasts did not supplant the soU, they offered a credible alternative projection and served to illustrate better the sensitivity of images of the future to the particular set of models and modeling assumptions employed in their derivation.

By early 1979, problems assoclated with the management of the region's power supply had become acute, and diverse interest groups and organizations became both more vocal and more forceful. For purposes of discussion, these organizational responses may be treated as a cluster lelement 24: o-perspective), since the power planning community was challenged to respond to virtually all of the concerns expressed. Ratepayer groups, increasingly incensed by the disparities between rates charged to IOU and public utility residential customers, pressed for rate reform with the state of Oregon attempting to turn its entire population Into one large public utility district through the proposed Domestic and Rural Power Authority. Both ratepayer groups, and organizations promoting conservation and natural resources, questioned the legltimacy of the DSI's claim to hydropower while the reglon's designated preference customers were compelled to participate in the financing and construction of thermal resources. The DSI's, by contrast, feared that their power contracts, soon due to expire, would not be renewed and sought the promise of a guaranteed long- 
tarm power supply. Finally, and most slgnificantly, the key players at WPPSS were suffering one construction cost overrun after another and were hard pressed to maintain their planned construction without assistance.

This turmoll spurred on the development of Regional Power Act legislation $(O-P)$, with Senator Henry Jackson spearheading the effort in Congress (element 25: P-perspective). Jackson and Munro were old friends from the days when the BPA Administrator had served on his staff, and shared both perspectives and goals regarding the proposed legislation. Munro worked hard within BPA to satisfy the varied Interests, and the equally varled problems, of the region through the legislative vehicle, while leaving the growing WPPSS problem relatively untouched. Though BPA offered some assistance with the financing and construction problems, responsiblilty for resolving the difficulties was left with the supply system.

Beginning in 1979, a number of technical projects were undertaken within Power Requirements which would ultimately have great bearing upon the 1982 forecast. Though staffing levels had not increased appreciably, the tone set within the larger organization by Munro, and the anticipation of BPA's augmented responsiblilties under the proposed Power Act, suggested the need for an independent forecasting capability within BPA. Terry Esvelt, Mark Roberts, and Don Hoffard, remembering the lessons of their 1976 exercise, 
recognized the need for a new approach to forecasting which was capable of addressing the plethora of newly raised issues $(P-T)$. As a part of DOE, it was easy for BPA to obtain the ORNL residential and commercial end-use models for Region 10 "off-the-shelf" -- (1.e. In finished form without additional contract work) (element 26: T-perspective). Reglon 10 excluded Montana and included Alaska. Much of the data in the model input sets had been imputed or calculated by the developers, so a need for better input data triggered two survey efforts $(T-T)$. The first was a regional residential survey conducted under the contract for BPA by Elrick and Lavidge. This survey was delivered in 1979 with analysis of the residential sector almost Immediately following (element 27: P-perspective). The following year, 1980, BPA "bought into" a commercial survey already underway for DOE, adding funds to ensure that the experimental data collection sites were all in the Northwest (element 28: T-perspective). Both of the new models were used in 1980 to prepare a conservation assessment ( $T-T$ ) for BPA service territorles (element 29: T-perspective), though nelther model had, at the time, been fully "loaded" with new regional data.

Organlzationally, 1980 was the "calm before the storm". PNUCC acquired its own in-house technical staff, instead of relying entirely upon utility representatives (element 30: 0-perspective). Within BPA, an agency-wide "nomenclature 
change" (element 31: 0-perspective) upgraded each of the organizational units (Sections to Branches, Branches to Divisions, etc.) because of the smallness of DOE relative to DOI, but compared to what was soon forthcoming these changes were minor. As 1980 drew to a close, the Regional Power B111 was enacted in Congress (0-perspective: element 32), establishing a new and substantially revised set of groundrules for the power planning arena. The Act, to relterate, established the Regional Councll, comprised of two representatives from each of the four states, empowered to develop a long-term resource development plan for the region. It established provisions by which the DSI's would provide rate relief for residential and small farm customers of the IOUs, In exchange for guaranteed long-term power contracts. It established prlorities for resource acquis 1tion, giving conservation and renewable resources preference over conventional thermal resources. Finally, it added resource acquisition to BPA's traditional power marketing duties, making the agency responsible to the needs of not only its public utility preference customers but to any utility desiring to enter into residential exchange contracts. In a very real sense, the passage of the Regional Act ushered in the beglnning of the process whlch culminated In the release of $\mathrm{BPA}^{\prime} \mathrm{s} 1982$ forecast, for it was the added responsibilities assumed by BPA which transformed a sectorspecific, regional forecast from a luxury to a necessity. 
By early 1981, the organizational structure of BPA displayed several alterations reflecting its new priorities (0-perspective: element 33). Both Power Requirements and Conservation underwent a sort of organizational fission, separating from Power Resources and becoming independent Divisions. At the same time, the Division of Rates reorganlzed to modify their wholesale and retall ratemaking procedures in accordance with the provisions of Regional Act $(0-0)$. These changes signalled the genesis of the decision support apparatus which would underlie later decisions concerning the fate of the wPpss plants.

In direct and almost Immediate response to the passage of the Act $(0-T)$, Power Requirements began adapting the models resident on BPA's computer system (ORNL, PNUCC, and NEPP) to the Paclfic Northwest, defined as Washington, Oregon, Idaho, and Montana west of the Continental Divide (element 34: T-perspective). This involved obtaining, or calculating, such key input values as commercial electric space heating shares or number of multifamily dwellings using data from the Elrick and Lavidge and Westat surveys (T-T) as well as reestimating key model parameters and coefficients (as AEA did for the NEPP model).

In January of 1981, Ronald Reagan was Inaugurated as President of the United States (element 35: P-perspective). In contrast to his predecessor, Reagan favored private sector development and management of energy resources to the 
largest degree possible. He also sought to reduce the size of government wherever possible. One of his first actions after Inauguration was to place a freeze on additional Federal hiring pending an assessment of the staffing levels thought to be needed by various agencies. Though affected by the freeze, BPA was able to grow slightly at a time when most of the Federal bureaucracy was beset with cutbacks because of the additional responsibilities it was assigned under the Act. In an even more dramatic move, Reagan sought, though ultimately unsuccessfully, to abolish DOE -an action which presumably would have returned BPA to the Department of the Interior. This move was folled by a combination of Congressional resistance and bureaucratic Inertia.

A new Republican in the whlte House, however, had numerous less direct repercussions. One whlch would prove extremely significant was the appointment of a seasoned businessman to the position of Bonneville Power Administrator (P-P). In May, 1981, Peter Johnson took office, bringIng his business and financial management skills, so consonant with the philosophy of the Reagan Administration, to bear upon the WPPSS problem (element 36: P-perspective). Because Johnson's background proved to have a great Influence upon the shape the BPA decision structure would assume, it deserves a summary recounting. Johnson earlier headed Trus Joist, a lumber and wood products company which, 
during the 1970s, guffered the fortunes of a slowing market along with the rest of the industry. After evaluating production and operation costs in light of sales projections, Johnson made a difficult decision and closed several of the company's plants so that the remalnder might prosper. While other companies floundered, Trus Joist flourished and eventually reopened several of the closed facilities when profits were once again on the increase. The situation Johnson encountered at BPA with the WPPSS plants displayed many of the same elements -- escalating costs, a questionable demand for the product, and over extended financial commitments -- and, not surprisingly, his approach to the problem reflected what had proven successful in the past. Johnson soon discovered that BPA lacked the apparatus needed to answer many of the financlal questions which required resolution if decisions were to be made on the five WPPSS plants. In response to this need (P-O), Financial Management, prior to Johnson's arrival a small niche in the large organlzation, followed the direction which had recently been taken by the Power Requirements and Conservation Dlvislons, and began a perlod of rapld growth (element 37: o-perspective). This growth was reflected both in numbers (staffing levels) and organlzational importance (involvement in key organizational decisions).

At roughly the same time, Conservation entered a final cycle of growth, detaching itself completely from Power 
Management and becoming an independent office (element 38: o-perspective). Given the high prlority given to the development of regional conservation potential in the Act (0-0), the number of the tasks assigned to the group grew substantially and its change of status reflected the recognition of this change in prloritles by BPA upper management. Wholehearted organizational support for BPA's forecasting effort came with the enactment of the Regional Power B11l, since it was then obvious that BPA would need to perform certain types of analyses to support resource acquisition decisions. After the abovementioned models had been successfuliy adapted to the Pacific Northwest region they were subjected to a series of tests within BPA to determine their potential usefulness as policy planning and decision support tools (element 39: T-perspective). Four scenarios were constructed to see how well the models under consideration -- the PNUCC and NEPP all-sector models, the ORNL Resldential Model, and the ORNL Commercial Model -could deal with various conservation savings -- no special implementation mechanisms or programs were assumed to be in place. The resulting values produced by the straightforward (i.e. trend- or data-driven) operation of the demand models served as a reference agalnst which to assess the userdetermined (1.e. program-driven) alternative. The second scenario examined the impacts of BRA-sponsored conservation programs taken to their full budgeted lifetimes. A third 
scenario extended these savings through the end of the forecast period (2000), describing a situation where the programs would have their funding maintained or renewed. A fourth and final scenario added further cost-effective measures (e.g. retrofits, building standards, etc.) to those considered in the third scenarlo. Only the two ORNL models, deslgned speciflcally to answer energy policy making and planning questions were able to distingulsh between the scenarios -- for the NEPP and PNUCC models, all four scenarios were identical. This difference would later prove to be a significant one.

In late 1981, prior to "going public" with its technical reviews and economic projections (T-0), Power Requirements provided a detalled briefing to members of BPA's Policy Committee (element 41: 0-perspective). Though the preliminary profections were noticeably lower than previous reglonal power planning forecasts, they were received without pressure for revision. Some minor industry-specific economic forecasts were, however, modified based upon information provided by members of the policy committee. In part, this "hands off" approach to the staff's forecasts may be attributed to Johnson's modus operandl of using "hard" analysis for decision support -- a strategy which had proved successful for him earlier at Trus Jolst. In general, however, the Policy Committee knew that the changes seen in patterns of regional electricity use were not anomalles but 
forces that needed to be dealt with. At a strategic planning retreat held at Mccall, Idaho in the autumn of 1981 (element 40: 0-perspective), a number of Policy Committee conclusions supported the revised perception. It was expected that "regional load will increase at the rate of 2 to $21 / 2$ percent per year in the next two years ... but that the rate of growth will slack off to $11 / 2$ percent later", so generally lower forecasts were not expected. Moreover, it was anticipated that "the region's reaction to our first official and ensuing load forecasts will be a little better than heretofore, and that many will credit its competence, but that there is the potential for conflict with many sectors of the public" -- a clear, but not particularly novel insight given the late 1970 s political climate. Added to this inslght, however, was the comment "We would like to be known as the premier regional entity demonstrating this expertise" -- a sentiment recognizing the need to develop, and trust the judgments of, a qualified technical staff. Finally, the members of the retreat expected that "the region might believe that we are not doing enough to achieve conservation" (McLennan, 1981:1-2). Given this "mind-set" the Policy Committee gave Power Requirements the go-ahead to release the controversial findings of its model review, complete with its low growth rates and ambitious modeling of conservation. 
Following approval by the Policy Committee, Power Requirements began a public involvement process which would span nearly six months. While public involvement is a common practice for Federal agencles, it was particularly important that BPA's first independent forecast be fully exposed to the public. Though the Regional Act had passed, much of the controversy which prompted its formulation lingered in the region. Moreover, how the Power Act would be Implemented was of special concern to many of the interested parties in the power planning arena, with the impending WPPSS decision weighing most heavily in the minds of the actors. Rates, financing decisions, and environmental impacts would all follow as consequences of the forecast.

In addition to imparting information to those to be affected by BPA's decision, public involvement also served to provide useful feedback to Power Reguirements' technical staff. Though their tools and techniques were "state-ofthe-art" for energy modeling, data which the staff used for forecasting had limitations, as did the models themselves. The public involvement process allowed BPA to tap the forecasting expertise in the region. This could result in anything from a greatly strengthened product on one extreme to its general discrediting on the other end of the spectrum. 
The forecasting process went through three stages -technical review, draft-forecast, and final forecast -- with public comments recelved in the interim periods. This sort of interaction is of critical importance to understanding the development of a forecast using Multiple Perspectives, for the comments constitute interorganizational challenges which BPA had to respond to using patently technical means. This six- to seven-month period was when the largest variety of forces were shaping the forecast; thus the detail of description which follows is greater than for any other period illustrated in the cross-cuing map.

Some qualifications need to be stated about what BPA's public involvement was and what it was not. The public involvement process was never intended to be a means of using consensus or consultation in structuring the overall technical decision process, and was not presented as such. BPA staff was tasked with developing an independent forecasting system in a rather short period of time, given the urgency of the wPPS decision. The resulting In-house capability was intended to enable the staff to ask rate and resource questions over and above what could be expected from the Regional Council once its planning apparatus. Basic research has been prohlbited at BPA. As such, models or techniques must be developed under contract or obtained "ready-made". The models selected, prior to public involvement, were of the species with which the utility industry is 
most famliar, econometric and end-use models. Lack of familiarity with other approaches (or of how to implement them or adapt them to the region's perceived power planning needs) 1 imited the potential selection. Since public involvement began after this selection had taken place, its agenda was constrained or focused upon selection between alternatives and modeling improvements which could be made within the rather narrow band of time available.

This public involvement agenda had two effects of significance. First it precluded, or at least minimized, the number of first-order methodological considerations which could be meaningfully raised or addressed. Attention to model detall tended to eclipse more baslc questions of the risk and uncertainty and core assumptions associated with the overall planning and forecasting process. Second, the focus tended to limit the membership of the involved public. All persons desiring to make verbal or written comments were free to do so. Given the highly technical nature of the procedures and modeling tools under consideration, fluency in the language of trenas, econometrics, or complex models was virtually a prerequisite to particlpation. This largely limited the views expressed to those of the utility community and conservation groups with extensive training in analytical fields such as mathematics, economics, and engineering. 
As 1981 drew to a close, BPA conducted a series of public involvement workshops designed, as noted above, to familiarize the public with the methodology and models which would be used to develop Its first independent forecast and to solicit technical feedback in the form of critical comments. Though depicted as a single cell or block in the cross-cuing map, (element 41: 0-perspective), the technical workshops in fact spanned a period of over a month. The cell is deplcted as falling within the 0 -perspective because the workshop session provided an arena for organizations to represent themselves and their concerns. (Backgrounds of the individual representatives, in principle P-perspectives, are, however, discussed where relevant.) On December 9, 1981 a first workshop was given, focusing exclusively upon the economic and demographic projections used to drive the demand forecasting models. The models in turn, were revlewed approximately one month later in a second, two day long workshop on January 11-12, 1982. The rationale behind the month lag was that should critical flaws be discovered in the economic and demographic projections they could be corrected over the 30 day period. Otherwise, the subsequent demand projections would be founded upon flawed inputs. Practically speaking, even when forecasting models appear to be behaving reasonably well, a few surprises generally emerge when new inputs are entered which require recalibration or perhaps even correction. Thus, from the Power 
Requirements staff's point of view, the delay between meetings was a desirable one.

All the meetings were set up with essentially the same format. BPA stafe members made formal presentations on materials which had been made available in printed form. Next, "expert" panels presented prepared comments on the models, methods, or results under consideration. Finally, audience nembers were provided the opportunity to ask questions or make comments (verbal or written). All of these pleces of the process were transcribed by a court reporter and made avallable for subsequent review.

The first workshop sessions, focusing upon economic and demographic projections, comprised two separate presentations, each followed by a discussion by four expert pane1ists and by five statements also prepared by experts in the field. The morning presentations dealt exclusively with the profection of employment, population, and households. By contrast, the afternoon presentations centered upon forecasts of fuel price, interest and inflation rates, and miscellaneous economic variables used by the various demand forecasting models. Panelists were selected both based upon their familiarity with the region's economic conditions and with the methods used by BPA staff to arrive at their projections.

The morning presentation by BPA staff explained the methodology by which employment, population, and housing 
projections were derived (see Chapter II) and highlighted important trends. Employment in lumber and wood products, was expected flist to recover from the early 80 s recession but trend steadily downward through 2000. Pulp and paper employment was expected to remain relatively steady across the forecast period, transportation employment was expected to increase slightly, while agricultural employment was expected to decline. Robust growth, however, was foreseen In the electronics industry, where year 2000 employment arrived at a value double that of 1980. Population was likewise expected to grow, but less rapialy than the labor force. Much of the increase was attributed to migration and with heavier female participation in the labor force the slze of some of the young cohorts were predicted to shrink. As a result of these population trends, the number of households was foreseen to increase, though the percentage of single family detached homes was anticipated to decrease (1.e. more heads of households but smaller families).

The morning's panelists included figures from both business and government. Rlchard slaughter, a former Professor of Political science, was, at the time of the sessions, Chief Economist with the state of Idaho's Division of Financial Management. His responsibilities with that agency Included publishing the state's economlc forecast. His comments focused upon BPA's electronics industry forecast, which he thought was overly optimistic. 
Richard Conway, the second ganelist, also had earlier roots in academia, having been a Research Associate in University of Washington's business school. With degrees in both englneering and regional sclences his work had included the preparation of economic inputs on WNP 4 and 5 for the Washington state Legislature and the development of both input-output and econometric models for the Hawailan Department of Planning and Economic Development. His then-current vocation was economic consulting. Conway's remarks stressed the need to reexamine the relationship between population and employment, and the importance of quantifying forecast uncertainty.

Willam Jeske, the third panelist, had received his academic training in both mathematics and economics. Coming to the session as special projects Manager for the Economic Development Council of Puget Sound, he had also previously served with both Pacific Northwest Bell Telephone Company and Seattle Trust and Savings Bank. Jeske generally liked BPA's approach to developing economic and demographlc variables, but asserted the need for industry-specific employment multipliers and questioned the assumptions of the housing model, noting that it seemingly ignored the effects of disposable income.

The fourth and final panelist for the morning's discussion was Phillip Brooks, Senior Economist for the Research and Information Systems Division of the Montana 
Department of Administration. With both business and economics degrees he had previously taught economics and statistics at universities in both Kentucky and Nevada. In his position with the state of Montana, he was responsible for their state population projections. Brooks gave a limited endorsement to BRA's population projection methodology but felt that the factors underlying migration were not well understood. He also believed BPA's economic base model was better suited to smaller geographic areas than the region as a whole.

A number of attendees responded to the panel with comments. Steve McLaughlin of Battelle Human Affairs Research Centers felt that BPA should break out its projection of households by persons per household. Brian Wall of the U.S. Forest service noted that projections of wood products employment should show feedbacks from housing profections. Wes Engstrom of Boelng commented that BPA's forecast reflected transient problems in his company's past, and that apparent productivity increases at Boeing were the result of more preliminary work done outside the region. Cleveland Anschell of Rainier Bank pointed out that the savings and loan industry would no longer, in effect, subsidize the housing and timber industries. Finally, John Savage of Oregon Department of Energy, suggested that BPA dovetail near-term and long-term forecasts of economic activity. 
The afternoon presentations focused upon another set of critical projections developed by BPA staff, per capita income, interest and inflation rates, and non-electric fuel prices. Per capita income projections were developed by a non-econometric modeling approach driven by population and employment. The regional trends represented modifications of DRI projections, and, as in the historic period, were forecasted to grow slightly faster than the national average (20-year AARG 1.95 percent vs 1.8 percent).

Interest rates for the region were projected to be essentially the same as for the nation as a whole, with residential mortgage rates projected to fall from $123 / 4$ to 10 percent by 2000 . Commercial and industrial rates were seen to fall from $113 / 4$ to 8 percent over the same period. Inflation rates, then at about 11 percent were calculated to fall to a low of 6.3 percent by the end of the forecast period.

Fossil fuels estimates included 20 -year projections for petroleum, natural gas, and industrial coal. 011 prices for the region were, on average, envisioned to grow at 3 percent per year to the forecast horizon. Natural gas prices were broken out by sector, growing at AARG's of 4 percent for the residential sector, 4.3 percent for the commercial sector. and 4.8 percent for the industrial sector. Lastly, coal prices were seen to grow at a rate of 4.4 percent per year. 
Once again, four expert panelists were on hand to evaluate and comment on BPA's economic and demographic projections. The first panelist Don Reading was Director of Policy and Administration at the Idaho Public Utilities Commission. His training was in the field of economics, which he had taught prior to obtaining his position with the state of Idaho. His remarks advocated the use of interactive modeling to supplant trending approaches and criticized an underlying assumption of BPA's forecast, namely that regional wage rates would move towards national averages over the forecast period.

Sam van Vactor, a Professor at Portland State University, was concurrently working as a consultant with the Northwest Energy Policy Workshop. Bringing expertise on the fossil fuel market to his position on the panel, van vactor had previously served with the International Energy Agency in Paris, France and had been the Director of Planning at the Oregon Department of Energy. van Vactor, focusing on fossll fuel prices, belleved that the DRI base case upon which BPA's fuel price forecast was based was more of a high case, and should be lowered accordingly.

The third panelist, James scherzinger, recelved academic training in both mathematics and economics. At the time of the BPA workshop, he worked as an economist in the Oregon state Legislative Revenue office where his responsibilities included oversight of the state economic and 
revenue model. His opinion, like Reading's, was that an interactive model should be used for developing economic profections (rather than the sequential approach used by $\mathrm{BPA}$ ). He also belleved per capita income and employment to be too high (at least for oregon).

The final panelist was scott Hannigan, an economist who was manager of Pacific Power and Light's Load Forecasting and Analysis Department. Hannigan had earlier worked for the Oregon Department of Economic Development and was a member of PNUCC's Load Forecasting Committee. Hannigan thought BPA's results reasonable but felt the projections were too aggregated for many of the planning purposes for which they likely would be used.

As had occurred in the morning, several attendees chose to make statements. Milan Brace, representing a BNUCC task force set up to evaluate BPAs forecasts, noted that their consensus was that the economic and demographic projections were reasonable, but felt that a fully developed economic activity model should replace judgments in many portions of the forecast. Glen swift, who did not state an organizational affiliation, questioned whether the assumption that the economic downturn of the early 1980 s was indeed temporary. Charlie Allcock of Portland General Electric recommended that BPA hold a workshop where underlying forecast assumptions be identifled and evaluated. Cleveland Anschell noted most risk assoclated with the economic forecast was 
downward and suggested BPA evaluate its baseline again. Finally, Adele Newton of the League of Women Voters asked how disagreements with the council's upcoming forecast might be resolved.

Slightly over a month later, on January 11th and 12 th of 1982, the demand models considered for BPA's residential, commerclal, and industrial sector forecasts were similarly subjected to public scrutiny. The entirety of the January 11th session was devoted to the residential sector, while the following day's session was divided evenly between commercial and industrial sectors. The adaitional time and attention devoted to residential sector modeling issues was the consequence of the fact that better data collection and analysis had been carried out in that sector.

Three residential models were reviewed by BPA staff at the January 11th meeting: the Oak Ridge National Laboratory (ORNL) Resldential Model and the residential components of the all-sector NEPP and PNUCC Econometric Models. In general, the ORNL results showed noticeably lower rates of growth over the forecast period. More importantly, however, the ORNL Model produced different results for each of the four conservation scenarlos, whereas the NEPP and PNUCC models did not.

Four panelists had been invited to make prepared presentations on the model's methodologies and inputs and to model a result and sensitivity analysis following BPA staff 
presentations on the same areas of focus. They were selected with the intent of providing a variety of viewpoints on the models and issues under consideration.

In selecting the panel, BPA obviously attempted to bring in qualified and experlenced speakers representing diverse professions. Academia, the utility industry, state government, and environmental protectionists all found a volce in the discussion. But despite these apparent differences, panelists displayed some important common characterlstics. All were, of course, well versed in modeling and forecasting and had rich backgrounds in their fields. But beyond this, all had specifically worked with, or developed, end-use models (the ascendant methodological form since the early Carter years) and all had been extensively involved with conservation. To the extent that these were focal issues at the time of this forecast, these emphases could be approprlate. It is worth noting, however, that none of the panelists acted as methodological folls to the others. No one, for instance; sought to champion econometric models as a generally preferred approach to forecasting nor did anyone take a "laissez faire" approach to the development of conservation in the region (1.e. eschewing programs altogether). More importantly, none attempted to promote a third alternative approach to residential forecasting which employed neither econometrics nor end-use frameworks. The participants apparently 
accepted that BPA's model development agenda was $f 1 x e d$, thereby limiting avallable alternatives or were unfamiliar with other possibilities.

John Duffield, an Associate Professor of Economics at the University of Montana, "represented" the academic community in the panel. After obtaining his Ph.D. from Yale In 1974, Duffield had done research in the area of environment and energy pollcy: alr pollution standards, oll and gas leasing, solar energy, and super-insulated buildings. Additionally, at the time of the workshop, he was involved in the development of a forecasting model for Northwestern Great Plains Coal. Duffield gave what might be termed a guarded endorsement of the ORNL end-use model for the residential sector. He thought it superior to the other models considered, but felt that the model's treatment of technology too simplistic.

Pat king, the second member of the panel, was a senior Load Forecasting Analyst for the Pacific Power and Light (PP\&L) Company, a PNUCC member utility. Also an economist, King had been responsible for developing PR\&L's first residential end-use forecasting model and had been involved in evaluating the company's conservation programs. He also preferred the ORNL model somewhat because of its specific policy testing capabilities. Like Duffield, he thought the technology curves underlying the efficlency cholce component 
were weak, particularly where miscellaneous electricity use was concerned.

A staff member of Oregon Department of Energy also appeared as a panelist. Tom wilson, trained in mathematics, had extensive modeling experience. He had, at the time of the BPA model review, written the code for two end-use models, one of whlch was being used for ODOE's residentlal forecasts. Beyond this, his forecasting expertise extended to issues of electricity pricing and solar economics. Wilson confined his attention to what he considered to be the preferred model for the residential sector, the one developed by ORNL. He noted weaknesses in the technology curves, questioning the specifics of the efficiency choice calculation, and belleved that projections of new resldential space heating did not account for increasing use of wood stoves. He suggested developing a hybrid model whlch could compensate for some of these weaknesses.

The final panelist was David Goldstein, a physicist employed by the Natural Resources Defense Council, the group which had, following the 1976 publication of the som study, questioned the need for the wPPSS plants and the serlousness with which conservation was consldered as a viable alternative. Goldstein had become intimately familiar with forecasting issues through his involvement with the California Energy Commission and had performed extensive bullding conservation potentlal assessment with Lawrence Berkeley 
Laboratory. Goldstein felt that the ORNL model was clearly superior to the alternatives based upon its capabilities for dealing with conservation policy analysis. The structure of the model, he claimed, led the energy debate in the proper direction. Though data-intensive, the model only required data needed for other purposes as well, and thus its use, in effect, improved knowledge about the residentlal sector. Iike the other panelists, he felt the technology curves needed reestimation.

Aside from presentations by BPA and the expert panelists, the public meeting allowed any attendees to make comments or raise questions. Milan Brace, a forecaster and energy analyst who had read a prepared statement at the economics workshop as a representative of the PNUCC technical team a month earlier, suggested that BPA find some way of adjusting the ORNL model to "track" a path somewhere between those of the PNUCC and NEPP models (which he thought more statlstically valid) and then use it to perform policy analysis.

Sam van Vactor, one of the panelists in the December economics workshop, believed a simplified econometric model could better handle the effects of conservation programs in its coefficients than end-use models, since the latter had to deal with each program indivldually. Mike Mchugh of AEA suggested that the optimal solution to the modeling problem was a "midale of the road" approach which relied on aggre- 
gate data to the fullest extent possible and then used policy-oriented components to carry analysis further. Lastly, Doug Woodfill of Math Sclences Northwest expressed concern that the discount rate used in the ORNL model's fuel and equipment choice was too high.

On the following day, the models under consideration for the commercial and industrial portions of BPA's forecasts. Each of these sesslons were a half day in length. There were several reasons that these sectors recelved less attention than the residential sector.

The commercial sector consumed the smallest portion of electric energy of the three being modeled, but was also the fastest growing. Perhaps more importantly, it was (and remains) the most diverse in terms of bullding structure configurations and consumption patterns. Because of this, however, data on the sector was sparse. In consequence, modeling efforts in that sector relied more extensively on judgment and, correspondingly, it was more difflcult for audience participants to substantlate any disagreements they might have with BPA's modeling methodology or results. The industrial sector was better understood. The types of productivity improvements and energy saving programs which might be implemented were reasonably well known and, from a modeling standpoint, the number of decision points (e.g. factories, plants) were far fewer than in the other two sectors. Additionally, the two models being consldered by 
BPA both employed an econometric methodology. Thus, much of the methodological controversy surrounding the model choices for the other sectors were afforded less time than the residential sector in the technical review with little experienced paucity of coverage.

The commercial sector menu of model offerings paralleled that of the residential sector. Three models were again considered -- the ORNL Commerclal Model and commercial sector components of the NEPP and PNUCC models -- and again only the end-use model could effectively produce distinguishable policy scenarios.

Again, BPA had selected a panel of experts to comment on the commerclal models, the methodology underlying their use, and the findings of the resulting analysis. Most of the previous day's participants were once again on hand, so the expertise of the residential sector panelists was avallable for discussions and, invariably, many of the audience's concerns would resurface. Once again the panelists for the commerclal sector were selected to provide diverse views though the spectrum of orlentations did not seem as wide as that of the previous day's session in part because of the more limited information existing about the sector. (Interestingly, two of the panelists would soon become part of the Reglonal Council's technical staff.)

Tom Eckman (one of the two destined to become part of the Council's staff) was an Energy Policy Analyst at the 
consulting firm of Math Sciences Northwest. (Members of this firm had been the architects of the original NEPP model, though most had moved to AEA, a rival firm). Eckman had been extensively involved in regional energy planning, both as a member of seattle City Light's Technical Advisory Committee on forecasting and, in his consultant role, as an assistant to the newly formed Regional Council on conservation and resource development issues. Eckman noted the need for an all-fuels energy forecasting model with a disaggregated structure to perform rate, resource and conservation analysis. At the same time, he noted the problems associated with obtaining the vast amount of data needed by the ORNL End-Use Model. He concluded his remarks without endorsing any of the model cholces unilaterally, the ORNL model was clearly the best suited to meet his stated model selection criteria.

John Douglas, of the Washington State Energy office; was the second panelist for the commercial session. A professional engineer, Douglas had dealt extensively with energy issues both in government and the private sector (both as a consultant and as a designer of heating, ventilating, and air conditioning systems for Boeing). In his role as an Energy Policy speclalist, for the state of Washington, Douglas' work focused upon faclilty siting and technical assistance to Washington's two representatives on the Reglonal Councl1. Like Eckman, Douglas recognized both 
the necessity of including a conservation assessment component and the problems associated with end-use model dataintensiveness. He also identified the need for assigning probabilities to any forecast scenarios produced.

Laurel Andrews, the thlrd panelist, worked as an economist with the forecasting group at seattle city Light (SCL). Prlor to her employment at SCL, she had served as a private consultant for that utility, as well as puget sound Power and Light, U.S. Department of Energy, and the Electric Power Research Institute. Her credentials also included a tour of duty as an Energy Policy Analyst for the City of Seattle's Office of Policy and Evaluation. Her comments which centered upon a critique of the different models' actual performance, led her to conclude that the ORNL model was the preferred alternative due to its ability to distinguish between different types of commerclal customers. She also recommended econometric cross-checks on any end-use forecast.

Ken Corum, the fourth and final commercial panelist, possessed rather unique insights into the models under consideration. At the time of the meeting, Corum was departing the staff of PNUCC, where he served as an energy demand forecaster, to occupy a similar position with the Regional council. With training in both mathematics and economics he had, prior to relocating in the Pacific Northwest, worked at ORNL, where he participated extensively 
in the development of both residential and commercial sector models. Corum focused exclusively upon the ORNL model and its developmental needs. Observing that the model was first specified using national data, several components, especialIy the fuel and efficiency cholce components, needed additional work to be adapted to the specific regional conditions of the Paclflc Northwest.

The public comment period surrounding the commerclal sector presentation was less of a debate on the merits of econometric and end-use methodology than the previous days session, focusing more strongly on specifics. A noteworthy exception was the prepared statement read by Craig Casey, an attorney representing six of the natural gas distributing companies of the Northwest. It was the conclusion of the gas companies that without "finalized" models and modeling assumptions that "little of a constructive nature" might be accomplished at a public hearing. To be meaningful, the hearings would need to present electricity prices (and cost assumptions behind them), and provide an opportunity for public comment and questions regarding input data before the final forecast.

The concerns of the gas companies were legitimate, though the accusations were pretentlous. BPA and Reglonal Councll had the power to implement conservation programs which through subsidies, rebates, or credits, could glve electricity a price advantage over other fuels. Such 
programs might under certain circumstances be the result of improper representation of comparative fuel prices in models (or the models in proper response to them), so, other gas companies were correct in noting that a full assessment of BPA's models required further information. The full public involvement process, however, did provide later opportunity for evaluating the missing pieces of the forecasting system between the draft and final forecasts. Rather strangely, however, BPA chose not to reiterate this point in their own defense but rather simply let the comment be noted and avoided a debate that might have sidetracked the presentations.

Mike McHugh, of AEA, noted that he himself had attempted to build aggregate econometric models of the commercial sector with little success, largely due to lack of data about the diverse patterns of consumption. Bullding a disaggregate model, he argued, would be even more difficult, with large likelihood of serlous errors. Given these weaknesses, cross-checks for accuracy and plausibility would be imperative. Phil Carver of ODOE, after noting his preference for the ORNL model, critlclzed the bullding simulations underlying the technology curves and the model's overall price responsiveness. Lastly, Don Dohrmann of ADM Assoclates noted that the floorspace component of the ORNL model was 1solated from the pollcy-drlven aspects of the model. 
Unlike in the residential sector, no strong voices favoring the PNUCC model (or something with a similar methodology) were raised. Though weaknesses in the ORNL Commercial Model were evident, no alternative approach was given serious consideration.

The concluding session of the public involvement workshop focused upon the models proposed for use in the industrial sector. This session differed in two important ways from its predecessors. First, as alluded to earlier, both of the models under consideration were econometric; hence, critical comparisons focused upon specific model strengths and weaknesses, rather than venturing into methodological debates. Second, because it was the final session, the assoclated comment period was the last opportunity for audience participants to express themselves. As a result, the discussion often went beyond industrial sector concerns embracing broader, more general, issues relating to BPA's upcoming forecasts, its underlying assumptions, and its ultimate uses.

For both models under consideration, only one scenario could be considered, due to the inability to handle conservation programs endogenously. The NEPP model produced results which displayed an overall average annual rate of growth roughly half a percent lower than the PNUCC model. In large part, this difference was the result of latter 
models substantially higher predicted growth for lumber, paper, chemicals and transportation.

The four industrial panelists, suffice to say, all had strong backgrounds in econometrics. Frank Taussig, the first panelist, was trained as a mathematician and working as Senior Economist for the oregon Public Utilities Commission. Taussig had complied an impressive background both in academia and government, working on short- and long-term economic and energy forecasting, analysis of conservation and billing credits, and econometric analyses of electricity demand. At the time of the workshop, he served on both the Regional Council's Advisory Committee as well as PNUCC's Load Forecasting Committee. Taussig chose to present criteria for good forecast documentation as his contribution to the proceedings. Good documentation should contain clear statements of objectives, underlying theory, data sources, statistical goodness-of-fit measures, the model's performance over a historical time perlod, and relationships to other findings.

The second panelist, Jim Abrahamson, was an economist working to produce Pacific Power and Light's system load forecast. Like Taussig, he also worked with PNUCC, serving on two forecast-related committees; the Model Development subcommittee and the Model Review subcommittee. As such, his familiarlty with the PNUCC model and its continued development was intimate. Though he found the PNUCC model 
more transparent and easlex to use than the NEPP model, Abrahamson found its lag structure weak and it did not display fuel substitution effects. The NEPP model produced some counterintuitive behavior between industries but, until a fresh approach could be developed, Abrahamson felt it was the preferred model.

A representative of one of the region's DSIs served as the third panelist. Glem Smlth, senfor Energy Planning Analyst at Kalser Aluminum and Chemlcal Corporation, was at the time, involved in forecasting energy prices, business planning (related to energy issues), strategic planning, and acquisition analyses. His professional experience included work as an engineer with both Bechtel Power Corporation and Exxon. His academic training embraced both engineering and business administration. Smith, like Taussig, did not identify a preferred model. He did ldentify several critical modeling needs in the sector, including an industry-specific forecasting capability and supporting data.

The final panelist was Ed Whitelaw, a Professor of Economics at University of Oregon and President of ECO Northwest, a consulting firm. His expertise extended beyond academic through involvement with two government agencies. He was one of the Oregon Governor's Council's scientific and statistical Advisory Committee. Whitelaw raised some more basic issues about BPA's scenarlos which all centered around the Regional Act and its consequences. He pointed out the 
need for a revised approach to policy analysis, without stating a preference for elther the NEPP or PNUCC model.

Several audience members followed Whitelaw's concluding remarks with comments or concerns of their own. John Savage of ODOE suggested that during the near term, when BPA was essentially committed to using an econometric approach to the Industrial sector, some mix between the NEPP and PNUCC model be used. Lastly, Bob Keesee, a Senior Government Affairs Economist with the Georgia Pacific Corporation and Wes Engstrom cautioned against stretching the application of existing data bases too far.

The essential features of the public involvement workshop are presented in summary form in Table XII below. Though the workshop was an "event" classified as organizational (0-perspective) it is obvious that personal influences ( $P$-perspective) Impact the process at many points. The table thus identifies the participants, their organizational affiliation (and, its interest or priorities) their background, their critical comments, and the anticipated effect implementing their suggestions would have on BPA's forecast.

Before reviewing and analyzing the results it is worth making an observation about the use of Multiple Perspectives In such contexts. In the quest for explanatory simplicity, it is all too easy to treat cross-cuing relationships reductionistically. Thus, a somewhat cynical characteriza- 
TABLE XII

A SUMMARY OF COMMENTS PRESENTED AT BPA'S TECHNICAL WORKSHOPS

\begin{tabular}{|c|c|c|c|c|}
\hline $\begin{array}{l}\text { PARTICIPANTS } \\
\text { (ORGANIZATION) }\end{array}$ & $\begin{array}{l}\text { ORGANIZATION } \\
\text { INTEREST }\end{array}$ & $\begin{array}{l}\text { PERS } \\
\text { BACKGROUND }\end{array}$ & $\begin{array}{l}\text { TECHNICAL } \\
\text { COHMENTS }\end{array}$ & $\begin{array}{l}\text { SIGHIPICANCE OP COMHENTS } \\
\text { TO FORECAST }\end{array}$ \\
\hline $\begin{array}{l}\text { Richerd siaughter } \\
\text { (State of Jdaho } \\
\text { Div. of Fin. Mgat) }\end{array}$ & $\begin{array}{l}\text { - Conslistency between } \\
\text { Bph and state of } \\
\text { Idano economic } \\
\text { forecasts }\end{array}$ & $\begin{array}{l}\text { Professor of political } \\
\text { science, economibt }\end{array}$ & $\begin{array}{l}\text { Porecast of electronics } \\
\text { employment } \\
\text { optimistic }\end{array}$ & $\begin{array}{l}\text { Hould tend to lower economic } \\
\text { land load forecast) lazgely } \\
\text { through multiplier effect }\end{array}$ \\
\hline $\begin{array}{l}\text { Rlchard Conway } \\
\text { (Private consul- } \\
\text { tant) }\end{array}$ & $\begin{array}{l}\text { - Expanding sphere of } \\
\text { consultancy in econ- } \\
\text { onic areas }\end{array}$ & $\begin{array}{l}\text { Engineering, regtonal } \\
\text { ociences prepared } \\
\text { economic input for } \\
\text { NNP }\end{array}$ & $\begin{array}{l}\text { Bpa needs to quantify } \\
\text { forecast uncertainty, } \\
\text { relationship of popu- } \\
\text { lation to employment } \\
\text { needs oxamination }\end{array}$ & $\begin{array}{l}\text { Lower population or highes } \\
\text { employment projections }\end{array}$ \\
\hline $\begin{array}{l}\text { Phillip Brooke } \\
\text { (Montane Dept. of } \\
\text { Administration) }\end{array}$ & $\begin{array}{l}\text { - Consibtency between } \\
\text { BPA and State of } \\
\text { economic projections }\end{array}$ & $\begin{array}{l}\text { Taught economics and } \\
\text { statisticap prepared } \\
\text { state population } \\
\text { projections }\end{array}$ & $\begin{array}{l}\text { Higration underlyling } \\
\text { population forecast not } \\
\text { vell understood, economic } \\
\text { base model better sulted } \\
\text { to ond ller areas }\end{array}$ & $\begin{array}{l}\text { Altered population and houslng } \\
\text { population forecasts (no lindlcation } \\
\text { whether calised or lowered) }\end{array}$ \\
\hline $\begin{array}{l}\text { Steve Mclaughilin } \\
\text { (Battelle Human } \\
\text { Affairs Researeh } \\
\text { Centers) }\end{array}$ & $\begin{array}{l}\text { - continuing as recog- } \\
\text { nized professional } \\
\text { technical experts in } \\
\text { region }\end{array}$ & & $\begin{array}{l}\text { Projectlong of households } \\
\text { should be broken out by } \\
\text { persons per household }\end{array}$ & $\begin{array}{l}\text { Revised profections of households. } \\
\text { likely higher disposable income }\end{array}$ \\
\hline $\begin{array}{l}\text { Brian Mall } \\
\text { (U.S. Foreat Service) }\end{array}$ & $\begin{array}{l}\text { - Protection and } \\
\text { development of } \\
\text { tinber resources }\end{array}$ & & $\begin{array}{l}\text { Projections for tinber } \\
\text { induatry should reflect } \\
\text { bidirectionality of in- } \\
\text { pacte (feedback of housing } \\
\text { on employent) }\end{array}$ & $\begin{array}{l}\text { Higher employment (1f full potential } \\
\text { yleld accepted as pollcy assumption) }\end{array}$ \\
\hline $\begin{array}{l}\text { Wesley Engatrom } \\
\text { (Boe ing Company) }\end{array}$ & $\begin{array}{l}\text { - Continued health of } \\
\text { ond ilrcraft indug- } \\
\text { try in Northwest }\end{array}$ & & $\begin{array}{l}\text { BPA profections of Boeing } \\
\text { employment made from } \\
\text { transient problems in } \\
\text { recent pasti apparent pro- } \\
\text { ductivity increased due } \\
\text { to changes in make/buy" } \\
\text { ratlos }\end{array}$ & $\begin{array}{l}\text { Employment land load) forecasts } \\
\text { lowered }\end{array}$ \\
\hline
\end{tabular}


TABLE XII (Cont'd)

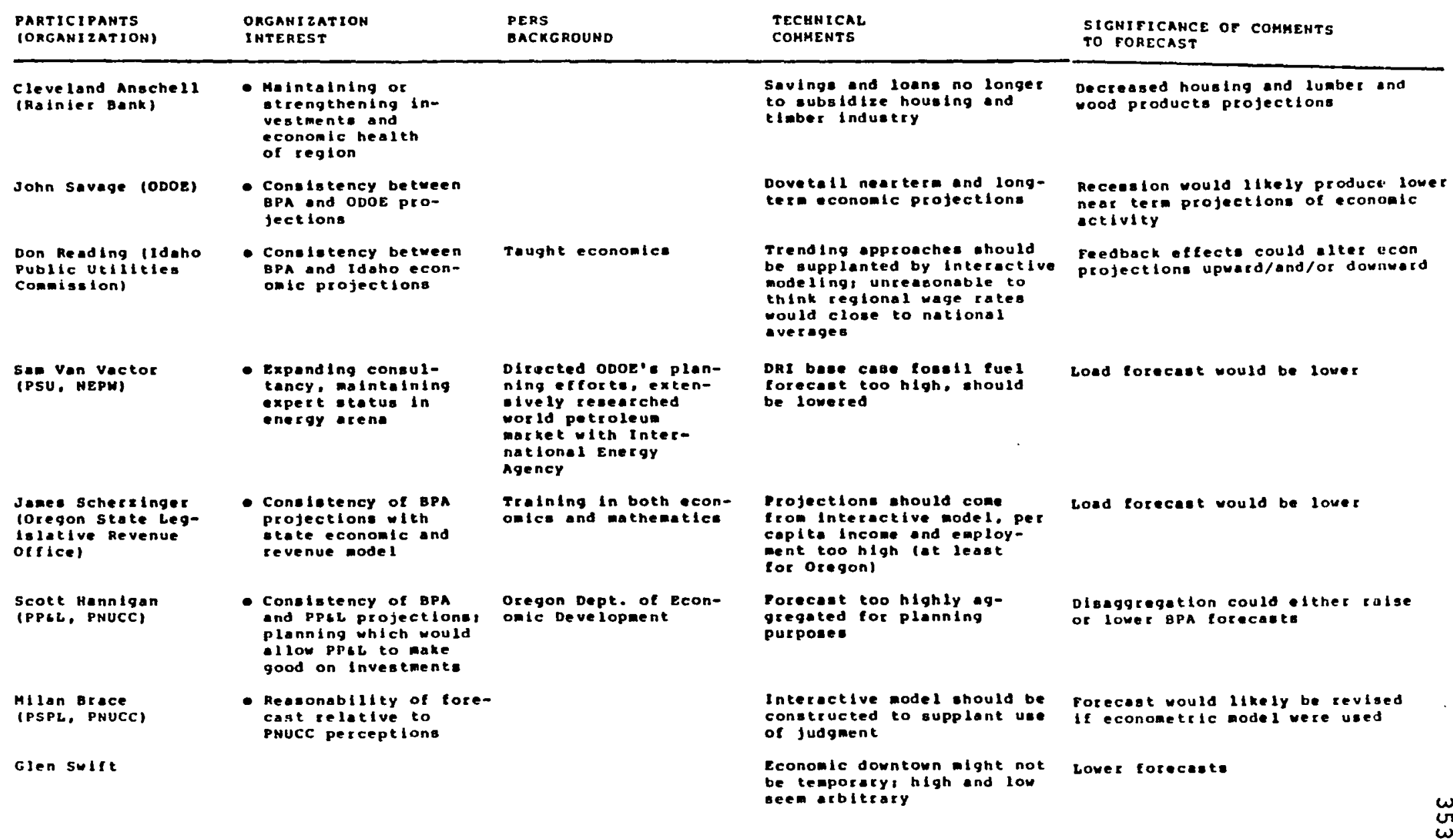


TABLE XII (Cont'd)

\begin{tabular}{|c|c|c|c|c|}
\hline $\begin{array}{l}\text { PARTICIPANTS } \\
\text { (ORGANIZATIONI }\end{array}$ & $\begin{array}{l}\text { ORGANIZATION } \\
\text { INTEREST }\end{array}$ & $\begin{array}{l}\text { PERS } \\
\text { BACKGROUND }\end{array}$ & $\begin{array}{l}\text { TECHNICAL } \\
\text { COMHENTS }\end{array}$ & $\begin{array}{l}\text { SIGNIFICANCE OF COMHENTS } \\
\text { TO FORECAST }\end{array}$ \\
\hline $\begin{array}{l}\text { Charlie Allcock } \\
\text { (PGE, PNUCC) }\end{array}$ & $\begin{array}{l}\text { - Resource plans and } \\
\text { rates should not ad- } \\
\text { versely effect PGE's } \\
\text { customers or share- } \\
\text { holders }\end{array}$ & & $\begin{array}{l}\text { Assumptions behind forecast } \\
\text { should be revealed for } \\
\text { critical examination }\end{array}$ & $\begin{array}{l}\text { Forecast could be higher or } \\
\text { g-SpH assumptions would be } \\
\text { gevealed }\end{array}$ \\
\hline $\begin{array}{l}\text { Adele Nevton } \\
\text { (League of Homen } \\
\text { voters) }\end{array}$ & $\begin{array}{l}\text { - guaranteeing volce } \\
\text { to votecs and rate- } \\
\text { payer in planning } \\
\text { decision }\end{array}$ & & $\begin{array}{l}\text { Public should know how } \\
\text { disagreegents with council's } \\
\text { forecast to be handled }\end{array}$ & $N / A$ \\
\hline $\begin{array}{l}\text { John Duftield } \\
\text { (u of Montana) }\end{array}$ & $\begin{array}{l}\text { - spearheading research } \\
\text { lnto environmental } \\
\text { and energy policy }\end{array}$ & $\begin{array}{l}\text { Troined tn economics, } \\
\text { performed research in } \\
\text { areas of alr pollu- } \\
\text { tlonstandards and } \\
\text { solarenergy and super } \\
\text { insulated bulldings }\end{array}$ & $\begin{array}{l}\text { Guarded endorsement of ORNL } \\
\text { model because of pollcy } \\
\text { teating capabilities: weak } \\
\text { representation of new } \\
\text { technologles }\end{array}$ & Lower forecast \\
\hline $\begin{array}{l}\text { Pat } x \operatorname{sing} \\
\text { (PPsL) }\end{array}$ & $\begin{array}{l}\text { - Ensuring that forecast } \\
\text { would not adverseiy } \\
\text { effect ppoL customers } \\
\text { or shoreholders }\end{array}$ & $\begin{array}{l}\text { Economists had developed } \\
\text { PPGL s is ist residential } \\
\text { end use forecasting } \\
\text { model }\end{array}$ & $\begin{array}{l}\text { Preferrad ORNL model struc- } \\
\text { tures technology surves } \\
\text { wesk. Inisc" end-ube lgnored } \\
\text { video games, etc. }\end{array}$ & $\begin{array}{l}\text { Lower forecast (though gome } \\
\text { of lowering would be vanted } \\
\text { by revised misc. categoryl }\end{array}$ \\
\hline $\begin{array}{l}\text { TOn Willson } \\
\text { (ODOE) }\end{array}$ & $\begin{array}{l}\text { - Consistency of BPA } \\
\text { methodology and find- } \\
\text { ings with odog's } \\
\text { forecasting experience }\end{array}$ & $\begin{array}{l}\text { Mathematiciani bullt } \\
\text { and operated odog:s } \\
\text { end-use godels }\end{array}$ & $\begin{array}{l}\text { Oueationed ORNL models tech } \\
\text { curves snd treatment of } \\
\text { woodheating suggested devel- } \\
\text { oping a hybrid model }\end{array}$ & Lower forecast \\
\hline $\begin{array}{l}\text { Dovid Goldsteln } \\
\text { (NRDC) }\end{array}$ & $\begin{array}{l}\text { - Protecting natural } \\
\text { gesourceg snd promot- } \\
\text { ing congervation as } \\
\text { aresource alterna- } \\
\text { tive }\end{array}$ & $\begin{array}{l}\text { Physiclat, had worked } \\
\text { ith ceg on forecasting } \\
\text { lssues had performed } \\
\text { extengive.conservation } \\
\text { assessment ot Lat }\end{array}$ & $\begin{array}{l}\text { Endorsed ORHL model, tech- } \\
\text { nology curvel outdated }\end{array}$ & Lower forecast \\
\hline $\begin{array}{l}\text { Hilan Brace } \\
\text { (PNuCC) }\end{array}$ & - (see above) & & $\begin{array}{l}\text { BPA should callbrate ORNL } \\
\text { modei to track PNUCC and } \\
\text { NEPP models }\end{array}$ & Higher forecast \\
\hline San van vactor & - (see above) & & $\begin{array}{l}\text { Sample econometric model } \\
\text { would be preferable }\end{array}$ & $\begin{array}{l}\text { Either lower (or more } 11 \text { kely) } \\
\text { higher forecautg depending upe }\end{array}$ \\
\hline
\end{tabular}


TABLE XII (Cont'd)

\begin{tabular}{|c|c|c|c|c|}
\hline $\begin{array}{l}\text { PARTICIPANTS } \\
\text { (ORGANIZATION) }\end{array}$ & $\begin{array}{l}\text { ORGANIZATION } \\
\text { INTEREST }\end{array}$ & $\begin{array}{l}\text { PERS } \\
\text { BACKGROUND }\end{array}$ & $\begin{array}{l}\text { TECHATCAL } \\
\text { COMAENTS }\end{array}$ & $\begin{array}{l}\text { SIGHIFICANCE OF COMHENTS } \\
\text { TO FORECAST }\end{array}$ \\
\hline $\begin{array}{l}\text { Mike MCHugh } \\
\text { (AEA) }\end{array}$ & $\begin{array}{l}\text { - Expending ephere of } \\
\text { consultancy anin- } \\
\text { teining high profes- } \\
\text { lonal cep }\end{array}$ & & $\begin{array}{l}\text { Middle of the rond model } \\
\text { leconometrlciend-ueel } \\
\text { needed }\end{array}$ & Higher forecest \\
\hline $\begin{array}{l}\text { Doug Woodetil } \\
\text { (Math Sciences NW) }\end{array}$ & $\begin{array}{l}\text { - Expanding ophere of } \\
\text { consultency moin- } \\
\text { calning per capita }\end{array}$ & & $\begin{array}{l}\text { Discount rete uged in } \\
\text { opplience efelciency cal- } \\
\text { culation too high }\end{array}$ & Higher forecant \\
\hline $\begin{array}{l}\text { Tou Eckman } \\
\text { (Moth sciences NW) }\end{array}$ & $\begin{array}{l}\text { - Representing profes- } \\
\text { sonel expertige of } \\
\text { consulting ilize }\end{array}$ & $\begin{array}{l}\text { Asst. to Reglonal coun- } \\
\text { cil on conservation } \\
\text { and resource develop- } \\
\text { ment isaues }\end{array}$ & 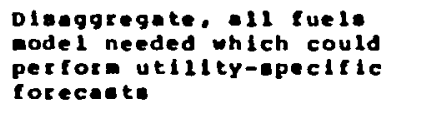 & 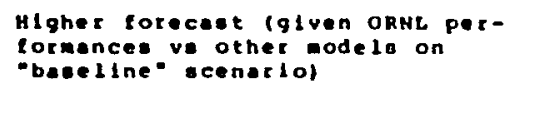 \\
\hline $\begin{array}{l}\text { John Dougles } \\
\text { (Wash State Energy } \\
\text { Uficice) }\end{array}$ & $\begin{array}{l}\text { - Conslatency of BPA } \\
\text { forecas with data } \\
\text { end research of state } \\
\text { Energy office }\end{array}$ & 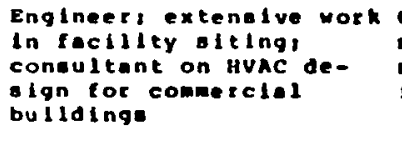 & $\begin{array}{l}\text { Conservation pollcy asess- } \\
\text { ment necessio elements } \\
\text { need tor method of asign- } \\
\text { ing probobilitles }\end{array}$ & $\begin{array}{l}\text { Higher forecast with end-use sodel } \\
\text { (for baseline) }\end{array}$ \\
\hline $\begin{array}{l}\text { Laurel Andrews } \\
\text { (SCL) }\end{array}$ & $\begin{array}{l}\text { - Consistency of BPA } \\
\text { forecast with SCL } \\
\text { research }\end{array}$ & $\begin{array}{l}\text { Energy pollcy onalyst } \\
\text { with govt. aqenciest } \\
\text { privote consulting } \\
\text { in energy lleld }\end{array}$ & $\begin{array}{l}\text { ORHL model preterable due } \\
\text { to ability to cecogntze } \\
\text { cuetomer clasees econo- } \\
\text { metrle modela should be } \\
\text { used es backups }\end{array}$ & Higher torecast \\
\hline $\begin{array}{l}\text { Ren Corus } \\
\text { (Regional council) }\end{array}$ & $\begin{array}{l}\text { - Ensuring BPA forecast } \\
\text { methodology and not } \\
\text { conflict ith ideas } \\
\text { or perception of } \\
\text { council }\end{array}$ & $\begin{array}{l}\text { Developer of ornL models } \\
\text { Iormer PNucc gtotf } \\
\text { member }\end{array}$ & $\begin{array}{l}\text { ORNL model best cholces: } \\
\text { technology curres need to } \\
\text { be adjusted to region }\end{array}$ & $\begin{array}{l}\text { Higher torecase (1ikely lowered, } \\
\text { in turn, by tech curve edjutment) }\end{array}$ \\
\hline 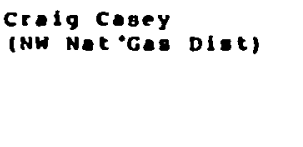 & $\begin{array}{l}\text { - Pracecting goecon- } \\
\text { panies from policies } \\
\text { which could poten- } \\
\text { tially - teal" cus- } \\
\text { tomere }\end{array}$ & & $\begin{array}{l}\text { Poreceets hould how oll } \\
\text { esumptione IIncluding } \\
\text { elec. pricel to llow } \\
\text { evaluetion }\end{array}$ & \\
\hline $\begin{array}{l}\text { Phil Carver } \\
\text { (OOOE) }\end{array}$ & $\begin{array}{l}\text { - Consiatency of BPA } \\
\text { methodology and } \\
\text { findings with odoe'. } \\
\text { forecosting exper- } \\
\text { lence }\end{array}$ & & $\begin{array}{l}\text { ORNL mosel best of three } \\
\text { considered. tech, curves } \\
\text { end price iesponsl lueness } \\
\text { flewed }\end{array}$ & Higher forecest \\
\hline
\end{tabular}


TABLE XII (Cont'd)

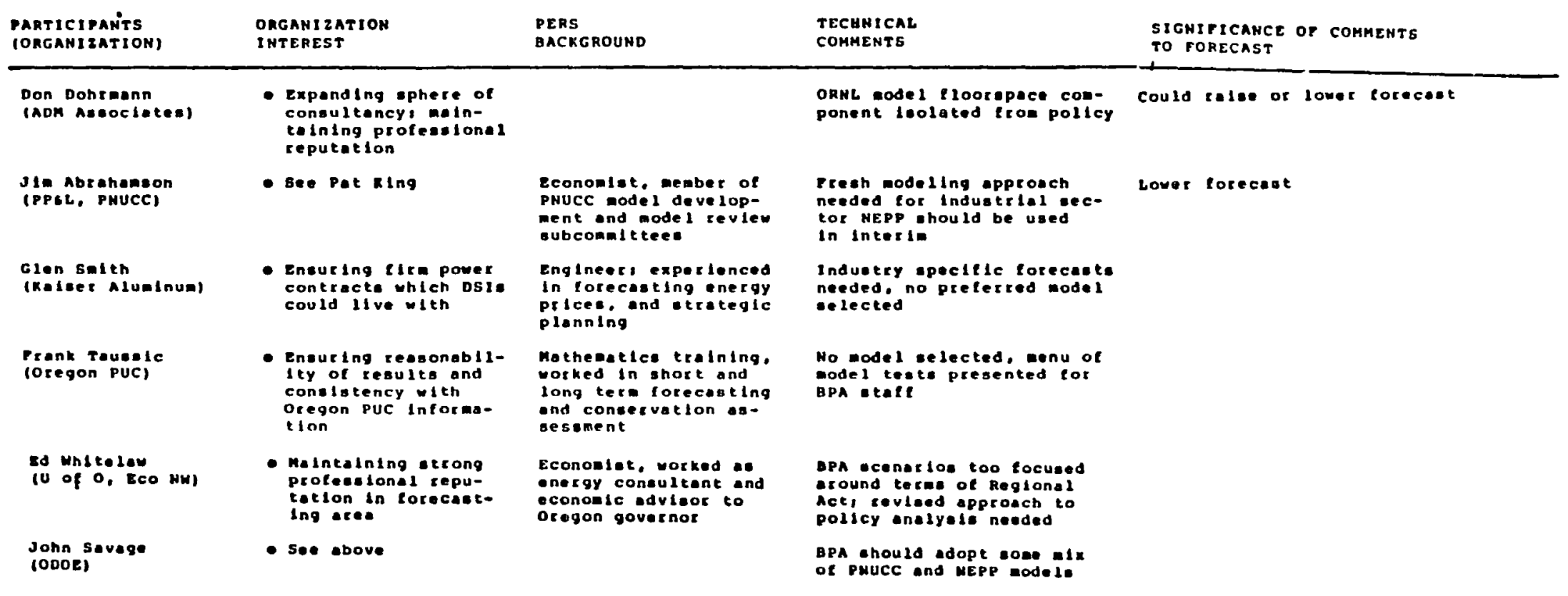


tion of the public involvement process would view the comments of different organizations' representatives as self-serving fabrications, designed solely to promote (or safeguard) the organization's own limited interests with little concern for other parties. While this type of behavior is hardly unprecedented in the business world, it is not generally representative (and is not apparent in the BPA example). The process by which organlzational interests are represented is much more subtle and not always obvious to the parties actually involved. (LIkewise, the process by which, and the extent to which, the agenda of the overall public involvement process was constrained also is often not obvious, as will be made clear in the next chapter.) The Multiple Perspective Concept, within its three distinct paradigms of investigation, gains further value as a tool by means of its usefulness in elucldating such subtletles. Technically speaking, in 1982 there was, as the verbal interchanges sketched above indicate, a great deal of uncertainty both about the load futures for the Northwest and the ability of the avallable models to represent them adequate1y. Many of the participants in the power planning community recognized that the cholce of one method (or judgment) over another, though perhaps somewhat arbitrary, could have decidedly non-arbitrary effects. It was general knowledge that the fate of the WPPSS plants would likely be decided by the forthcoming forecast, and this decision would affect 
nearly all the particlpants through their direct investments, impacts on the environment, or secondary economic consequences. Thus, there were many potential areas for debate or contention where interpretations alternative to BPA's could legitimately (from a T-perspective standpoint) be brought to bear as counterarguments. (As will be seen later, this tactic, though not prevalent at the abovedescribed model review, was to be a more common one once BPA presented an official draft forecast).

Turning to the results in the Table, several points are worth noting. First of all, it can be fairly safely assumed that all participants desire to maintain (or cultivate) their professional reputations through their actions in such meetings. This desire was explicitly listed as an organizational interest, however, only when this appeared to be the overiding interest of the organization, as with consultants and university scholars who literally earn their living by selling their ideas. secondly, for a number of partlcipants (usually those working for local or state agencles and making comments on the economic projections) consistency with their own work was cited as a key interest. While part of the desire for consistency between forecasts can be viewed as the result of professional pride of the participants own work (1.e. they felt their forecasts were "rlght"), on more practical grounds BPA's forecasts and the plans it would engender were foreseen as having significant 
economic repercussions. If the state or local forecasters were correct in their anticipations of the future, different projections by BPA would, by extension, create flawed plans as a likely consequence economic problems for their areas. The overlap between $P$ - and 0 -perspectives can be seen in the technical comments made. Inevitably, the technical comments reflect the participants past or present efforts. only in some instances do they reflect what the particlpants were then currently working on, as with the representatives from the utilities and state agencles. In a small number of cases, comments could be seen to be explicitly almed at influencing an outcome in the interest of the participant valuing it (e.g. the gas companies formal statement, or NRDC's open agenda for promoting conservation as related to model selections). But though individual participant's comments did not always exert Influence on BPA's forecasting effort to bring it more in tune with their organizations' goals, none of thelr expert oplnions could be seen to work against their organizations' own priorities in any way (1.e. individual comments were not inconsistent with the organizational interests as described in Chapter III). This pattern will be seen below to hold throughout public involvement.

In the month that followed the model technical review workshop BPA evaluated the verbal (and, where some of the participants chose to echo their sentiments along a more 
formal channel, written comments received and made its model selections (element 43: T-perspective). Not surprisingly, the choices were, as described in Chapter II, the ORNL models for the residentlal and commercial sectors and the NEPP model for the industrial sector. Given the leanings of the BPA staff prior to the workshop, these choices were comfortable ones. The Inadequacy of available econometric models had been recognized by the staff who had originally acquired the ORNL models as a result of their disenchantment with the soU forecast and its "corroboration" (P - T) and the need to account for policy impacts $(0-T)$ was well known. Though some voices were raised against end-use models, no good alternative was offered which could be implemented within BPA's forecast schedule (e.g. econometric or hybrid models). Moreover, most of the panelists had given Iimited endorsement to the approach embodied in the ORNI models, so the selection was hardly made in the face of res istance.

In the case of the NEPP Industrial Model, it was chosen over the PNUCC model largely because of the fact that the former model had been respecifled using more recent data. Debate over these two models had, at best, been lukewarm so the selection was certainly non-controversial.

A somewhat more slgniflcant development occurring at the same time was the completion of the supply Prleing Model (described in Chapter II) which determined electricity rates 
for different groups within the region. Comments at the public involvement workshop regarding BPA's "unstated forecast assumptions" were primarily aimed at the operation of this model, since it was in its structure that BPA's interpretation of the Regional Act was embodied $(0-T)$. With its completion, the key missing plece in BPA's modeling system was in place, and ready to be used in the draft forecast.

In March of 1982, a preliminary version of the draft forecast was completed ( $T$-perspective: element 44), using the abovedescribed models and incorporating a number of Ideas discussed at the January public involvement workshop. As with the model review, results were formally presented to the Policy Committee for evaluation prior to public release (0-perspective: element 45). Minor changes in both economic inputs and demand forecasts resulted from this Internal review.

The draft forecast was completed in late March (element 46: T-perspective) incorporating the considerations identified by the Policy Committee $(0-T)$, though its public release was delayed until April for a number of reasons to be discussed below. The draft forecast included a range of scenarios (baseline, high, and low) for both economics and electricity sales and a set of corresponding probabilities of occurrence. The ORNL models were used for residential and commerclal sectors, while the NEPP model was used for 
the industrlal sector. DSI sales were estimated from contract demands, streetlighting sales from another small subcomponent of the orlginal all-sector NEPP model, and irrigations sales were calculated outside the forecasting system using paper-and-pencil techniques. The only policy-based conservation included in the forecast was that expected to be obtained from BPA budgeted programs. The demand models were run iteratively with the supply pricing Model until equilibrium of prices and loads was reached. (Because of the small degree of change between draft and flnal forecasts a detailed discussion of specific technical choices is deferred until later.)

Summarizing the draft results briefly, in the base case regional economic activity was foreseen to exceed that projected by DRI for the nation as a whole. This resulted In an average annual rate of growth of 1.7 percent for total loads in the region with residential, commercial, and industrial sectors growing at rates of 1.6 percent, 2.2 , and 1.6 percent respectively. These values were unprecedentedly low for forecasts to be used in region-wide power planning. High and low forecasts likewise were noticeably lower than optimistic and pessimistic scenarios previously seen in the region. High case loads for the region grew at 2.5 percent per year over the forecast perlod (2.5 percent residentlal, 3.4 percent commerclal, and 2.1 percent industrlal). By contrast, reglonal load growth for the low case was pro- 
jected to proceed at a 0.8 percent AARG. Commercial and residential sectors both displayed a 0.9 percent rate of growth while the industrial sector grew slightly more slowly at a 0.7 percent AARG.

As the release date for the draft forecast, and the anticipated consequent decision regarding the fate of the wPPSS plants, drew near, a concern grew over what Bonneville's forecast would mean to the region. stockholders in the nuclear plants, drawling inferences from the findings of the earlier technical review (and, very likely, from "unofficial" sources within the agency), feared that the 20year forecast would be so low that work would be stopped on one or more of the construction works in progress (element 47: 0-perspective). As noted earlier, until such construction profects were completed, their costs could not be absorbed in the rate bases of participating utilities. The outcome of Johnson's forthcoming decision was of obvious concern to these actors in the power planning arena.

This concern was volced to senator James McClure (O-P) who requested that, prior to its release, BPA's forecast be subjected to an independent review and evaluation by a firm or organization outside the region (P-perspective: element 48). In response to this suggestion (P - P), Peter Johnson arranged for an independent review of the draft forecast to be conducted by National Economic Research Associates, (P-perspective: element 49 ). 
Dr. Lewis Perl of NERA arrived at BPA roughly one week before the forecast was made publicly available and began a critique of the BPA forecast (0-perspective: element 50 ). NERA, it should be remembered, had developed the PNUCC econometric model not used by BPA which had tended during the technical review period to display higher load projections than the other models consldered. As such, it was a firm whose credentials would be accepted by the concerned parties within PNUCC -- in large measure the reason for Johnson's selection ( $P$ - 0$)$. By way of technical approach, Perl essentially played "devil's advocate", challenging key assumptions or methodologlcal choices with plausible alternatives, each of which generally would have the effect of raising the forecasts BPA had developed. These challenges were generally consistent with NERA's econometric research. Regarding economic profections, NERA felt that income per employee growth was understated but that electricity prices might increase faster than anticlpated (the latter would tend to decrease load growth). Regarding models, NERA echoed some sentiments volced during public involvement, noting that the residential and commercial sector model were more disaggregate than desirable and endorsing a "multiple model" approach to forecasting loads in the various consuming sectors. The price and income elasticities in the resldentlal model were consldered unusually low. Though the resulting effects of such elasticities for electric and 
non-electric Euels would be offsetting, increasing the income elasticity to levels thought appropriate by NERA would raise the residential forecast. In the commercial sector, NERA took exception to BPA's revised method of determining floorspace based upon employment rather than income, noting that this lowered the forecast. Moreover, the naive subtraction of BPA conservation savings from commercial sales in effect "double counted" some of the savings whlch were included in the model's response, further lowering the forecast. The NEPP Industrial Model was viewed as containing several specification errors which overstated the speed and extent of price responsiveness, which would have made the forecast too low. NERA's overall conclusions, released concurrent with BPA's draft forecast, were that the growth should range from 0.8 to 3.0 percent instead of 0.8 to 2.5 percent per year and that the base case ( 1.7 percent) was biased to the low side and would more realistically fall in the 2.0 to 2.2 percent neighborhood.

On April 2, the draft forecast (and the results of the NERA study) were made publicly available, in the wake of a press release to media throughout the region (0-perspective: element 51). Three volumes comprised the forecast report: a forecast summary, and two technical appendices. The latter documents, one focusing upon economics, the other upon demand models, provided thorough detalis on the models, methods, assumptions, input values, and results embodied in 
the forecast. With three months separating publication of draft and final forecast, ample opportunity was provided for interested organizations and Individuals to respond with critical comments.

This second phase of public involvement, the response to BPA's forecast (element 52: 0-perspective), more clearly lliustrated the dynamic by which organizational interests are represented through "objective" technical comments. Unlike at the technical review, BPA was substantially committed to a specific set of models and a methodology for developing a range of forecasts. The electricity pricing assumptions, as a source of concern to many in the power planning community were at last laid out explicitly in the forecast documentation and their impacts upon electricity sales were evident. Additionally, the simultaneouslyreleased NERA document provided a ready-made set of counterpoints to which BPA's critics could appeal.

The first reactions to BPA's report were, predictably, those appearing in the region's major newspapers. As noted in Chapter III, the media shapes as well as disseminates information and attitudes. In order to make "good copy", a newspaper article must distill facts of most immediate significance to its readers, sometimes "creating" issues in the process. In general, the newspapers throughout the reglon drew out the conclusion that, given the forecast results, BPA might delay the completion of one or more of 
the three viable wPPS projects. On Apr11 6, the Portland Qregonian highlighted Peter Johnson's comment to a Seatile audience that BPA's load forecast might be low. The article treated the uncertainty surrounding the results fairly and the consequent uncertainty about when the three plants would come on line. The article's headline "Energy Predictions by BPA Sald Low" did, however, seem to cast some susplcion upon the forecast's crediblilty. By contrast, in the Trl-citles, where the postponmentof WPPSS plant completions would have stronger repercussions on those employed in their construction, the tone of articles was harsher (and somewhat slanted). In an April 7 article entitled "TriCities Being Killed by BPA Draft Report", Tri-Cities Herald reporter Jack Briggs quoted WPPSS risk analyst Jay Maldment as calling the report "shoddy statistical work put together in a political environment". In the same article he noted that NERA's reinterpretation of BPA's range and base case would call for continued construction of all three wPPSS plants, and quoted WPRSS spokesman Gary Petersen's (false) observation that nelther wPPSS nor the public had any involvement in the forecast's development.

Comments were recelved formally by BPA over a perlod lasting from April to June. In the early weeks following the release of the draft forecast, however, comments were sparse due to two reasons. First the technical appendices to the forecast, which contained detalled descriptions of 
models, inputs, and outputs were released several weeks after the summary document. This meant that a thorough evaluation of the forecast had to wait. Second, and of at least equal importance, was that the consensus in the region was that Johnson was about to finalize his decision on the fate of WNP 1,2 , and 3 .

On April 19th, the results of the analysis of regional resource alternatives was made public (element 53: T-perspective). Based upon the results of the draft forecast ( $T-T)$ and subsequent financlal analysis, the report concluded that:

"Considering the interests of the ratepayers and the region as a whole, continuing WNP 2 and $\# 3$ on current schedules and extending the construction of WNP \#1 best preserves and protects the economic and financial integrity of BPA and the region (BPA, 1982d:2).

This conclusion was based upon 1) the percelved likelihood of a power surplus in the 1980s and 1990s, (power forecast), 2) a revlew of the relative costs of different resource options and their impacts on electricity prices in the region (rate analysis), and 3 ) an analysis of the constraints on financial markets and credit worthiness of BPA under different resource development scenarios (financial analysis). The findings of the financlal analysis effectively prohibited the completion of all three plants. Sales of additlonal bonds would only be underwritten for an amount short of what would have been needed to finance the 
scheduled completion of all three plants on their intended schedule. The rate analysis suggested that the delay of WNP-1 would result in a somewhat lower rate increase than if WNP-3 scheduled completion was extended instead.

Based upon these findings ( $T$ - P), Peter Johnson made the decision to delay the scheduled completion of WNP-1 (element 54: P-perspectlve). Undoubtedly, however, his earlier experience with a similar situation at Trus Jolst helped provide a certain assurance about the decision that might otherwise be missing. At the time of his announcement of the decision, Johnson also cited a second independent review of BPA's forecast which provided sharp counterpoint to NERA's findings. Rather than prepare a point-by-point critique of BPA's methodology, as NERA had, Energy ventures Analysis Inc. (EVA) an East-coast consulting firm, evaluated the BPA forecast by means of an analogy. Comparing BPA and the Pacific Northwest with the only similar Federal marketer of hydropower, the Tennessee Valley Authority (TVA), EVA noted that, when faced with rate escalations comparable to those anticipated for the PNW, consumers in the Tennessee Valley had curtalled electricity use to the point of declining loads. Based upon this, EVA concluded that BPA loads would likely be flat through 1985 and not exceed 1.2 through the early 1990s. EVA's "counterpolnt" was used to lilustrate that uncertainties could surround the load estimates on both the high and low sides. By offsetting 
NERA's comments the EVA findings made BPA's baseline and forecast range again seem reasonable. The exerclse was not in any way intended to explore the spectrum of uncertainties surrounding BPA's forecast.

Though this announcement was not favorably recelved by all in the region, the WPPSS board of directors, influenced by Johnson's decision $(P-O)$ and the analysis underlying it $(T-0)$ accepted and adopted Johnson's recommendation on April 29 (element 54:0-perspective). Several weeks thereafter (May 19, 1982) the Portland eregonian ran a guest editorial, penned by peter Johnson ( $P$ - 0$)$, explaining the findings of BPA's resource assessment $(T-0)$, and its implications to the region (0-perspective: element 56). Over the three-month period that BRA staff received comments on their draft forecast, the prepared responses. Some of these took the form of modifications to draft inputs or modeling assumptions. Other responses to challenges which the staff determined could not or should not be met with methodological changes, were in the form of written replies (i.e. counterarguments or explanations of why requested changes were not possible.) In late June, a revised final forecast was completed ( $T$-perspective: element 57), in many ways similar to its predecessor ( $T$ - T) with an overall AARG of 1.6 percent, but containing revisions motivated by public comment $(0-T)$. On July 1 , the final 
forecast was released to the public at large (0-perspective: element 58).

Brief summary descriptions of the forecast results were presented in Chapter II. Having described the flow of events leading to the forecast's culmination, it is now appropriate to detail the numerous specific technical cholces made, primarily, in response to challenges posed by the varlous parties in BPA's audience. Because the connections between technical revlew, draft, and final forecasts are better understood by means of direct comparisons, the changes between the forecasts are listed together below (rather than spread throughout the description of crosscuing). First, the influences of the comments summarized in Table XII in the draft forecast are enumerated. The subsequent revislons between draft and final forecasts are then described. Flnally, BPA's verbal responses (and rebuttals) to technical challenges, as listed in the technical documentation, are discussed.

In 1 ts overall methodological structure, both BPA's draft and final forecasts reflected a number of concerns volced by members of its audience. While these comments were not always the declsive factor in determining these technlcal cholces, they at least contributed to the shaping of the final selections, if in some instances only reinforcing BPA staff preferences. Following the technical model review with 1 ts various conservation scenarios, BPA 
opted to produce baseline, high, and low forecast of electricity consumption (as well as economics and demographics) with distinctions between public and private utility rate pools. While this did not result in utility-specific forecasts as earller suggested by Tom Eckman of Math Sciences Northwest, it did distinguish between the customer groups distinguished by the Reglonal Power Act. As lilustrated in Table III, the three forecast scenarlos varled not only according to levels of economic activity but also numerous assumptions on energy use, conservation programs, and WPPSS plant Einancing. These assumptions might be termed overt, in that they were consciously made as parametric choices for model operation. These overt assumptions were explicitly laid out in detail, as requested by representatives of PNUCC and Northwest natural gas distributors. As also noted at varlous points in this dissertation numerous covert assumptions on such Eactors as technological innovation, institutional perpetuation, and legislative irrversibility remained unexplained in the background, essentially because they were "non-1ssues" In the minds of the BPA modelers and their audience, as will be discussed in the concluding chapter of this dissertation. Assoclated with the range of forecasts was an assignment of probabilities (which had been suggested by John Douglas of the Washington State Energy Office). These probabilities were assigned judgmentally following the finalization of the forecasts. 
Model selections for the three major consuming sectors, though based upon a set of evaluative criteria, reflected the recommendations of panelists and participants at the technical workshop. The generally preferred oRNL models were selected for residential and commercial forecasting while the NEPE Econometric Model was used in the industrial sector. Time and resource 11 mitations prevented BPA stafe from pursuing any major new modeling development such as combining the "best" elements of the models as suggested by John Savage of ODOE and Mike McHugh of AEA. For simllar reasons, no back-up models were maintained for an econometric cross check as suggested by representatives of PNUCC and SCL.

of the possible conservation options discussed at the technical review, only one was chosen by BPA to be embodied in their draft and final forecasts. The decision was made to look only at conservation savings attalnable from means under Bonneville's direct control. These more "assured" savings were those projected to be obtained from BPA sponsored programs in existence or budgeted at the time of the 1982 forecasts' production. As such, this treatment of conservation did not explore what might be obtained from Individual utility programs on those which the Regional Council might promote -- explorations which groups such as NRDC would have preferred to see. 
As noted above, the ORNL Econometric/End-Use Model was chosen to prepare the draft and flnal residential Eorecasts. With the exception of Sam van Vactor of PSU and Mike McHugh of AEA who advocated econometric (or hybrid) alternatives, all of the participants at the model review workshop had given endorsements (though not ungualified) of the ORNL model. Some modiflcations of input varlables and key parametrlc values did take place between the technlcal review and the draft forecast. Aside from revised economic and demographic projections and electricity prices from the newly-completed Supply Pricing Model (which served as inputs to all of BPA's demand models) a number of base year values were revised to fit the Pacific Northwest Reglon. The residential survey conducted by Elrick and Lavidge was used to derive values for base year energy use per appliance, energy usage, fuel saturation and penetration rates, and new appliance penetration rates. To account for savings due to BPA-sponsored conservation programs (including the effects of weatherization, shower flow restrictors, water heater wraps, faucet flow control devices, and solar or heat pump water heater replacement) some adjustments were made to the structure of the model to downscale the appropriate final end-use electricity sales. These adjustments were based upon estimates of savings per household and numbers of affected households received from the office of Conservation. Choices for behavioral and technological variables, 
the latter a major source of concern to workshop participants, reflected data provided to BPA staff by contractors continuing development at ORNL, most specifically Eric Hirst and Janet Carney. (Additionally, some technology curve parameters for retrofit homes were developed by BPA staff using National Association of Home Builders Research Foundation data). As such the technology curves, though not explicitly geared to technological frontiers, were as current as ongoing research at the time, and the staff felt that as such, they were hardly outdated, as NRDC had earller asserted. Suffice to say, John Duffield's preference, a graded serles of curves representing progressive technological developments was beyond the scope of current research.

For the commercial sector, the ORNL model had been supported almost universally as the preferred cholce at the technical workshop, and it was the one used for both draft and final forecasts. Several features of the model had concerned participants and resulted in varlous staff responses. The original econometric approach to projecting commercial floorspace centered on a simple regression equation with population and income as independent variables. Though not producing unreasonable responses overall, predictions for specific bullaing types were often improbable (e.g. high auto repalr growth). In response, BPA Just added a new, more sophisticated floorspace submodel which produced 
credible patterns of floorspace growth. Unfortunately, the new submodel systematically underforecasted over the historical period so an exogenous calculation of total floorspace was made based upon employment (described in more detail in Chapter II), and the predicted, disaggregated floorspace values were adjusted upwards correspondingly. This gave a more plausible set of floorspace estimates, but did not address the issue of the lack of pollcy feedbacks noted by Don Dohrmann of ADM Assoclates. Such a change, though desirable, was not only impractical in terms of needed time and effort but also would have been 1 mpossible to support without significant additional research. The technology, or efficiency/cost tradeoff, curves were also a major source of concern, but most suggested improvements necessitated major research to be first carried out under contract (which BPA staff was, in fact, initiating at the time). Though BPA staff recognized that reglonalized curves were needed, as noted by Ken Corum of the Reglonal Council's staff, and that there were indeed some flaws in the curves, as polnted out by Phil Carver of ODOE, only minor calibration adjustments were undertaken. These consisted of minor, Judgmental alterations of the slope parameter of the curve which increase the accuracy of the model's tracking of actual consumption from 1970 to 1980 . Finally, the model was somewhat altered to enhance its conservation policy testing capabllities. In 1 ts unaltered form, the model's 
structure accommodated the simulation of a 1978 grants programs for schools and hospitals and 1979 bullding standards affecting all commercial construction. The modification allowed savings from BPA-sponsored programs (shower flow restrlctions, water heater wraps, energy efficient lighting, and financlal incentives) to be subtracted from the appropriate end-use after projected consumption was calculated.

Participants at the technical workshop appeared to show no overwhelming model preference for the industrial sector. Jim Abrahamson of PNUCC and PP\&L had given a nod to the NEPP model as an interim solution to industrlal forecasting, but 1ittle other support was again (at the same time, it should be noted, no one champloned the PNUCC model). The model was chosen by BPA staff primarily because the data used by AEA to respecify the model's econometric equations was more current than that used in the PNUCC model. Forecast results for separate SICs (standard Industrial Classification) were presented, though separate models were not used for different industries las would be sufficient to fully satisfy Glen Smith's desire for industry-specific forecasts).

Irrigation, street lighting, and electricity pricing models (described in detail in Chapter II) had not been presented to the general public prior to the draft forecast, so none of BPA's modeling cholces for those models were 
responses to outside "challenges". Thls did not, however hold true for the final forecast (as will be noted below). Because economic/demographic projections needed to be ready for use roughly a month before forecast deadlines, the high, medium, and low projections presented at the December workshop were those used in preparing the draft forecast. All changes resulting from public comment were Incorporated into the final forecast, and are discussed below. Table XIII summarizes modeling choices made for the draft forecast in response to issues or concerns ldentifled during the earlier technical review process.

Though a number of changes took place between draft and final versions of the BPA forecast, the overall effect in terms of magnitude of change was slight. Base, high, and low regional loads respectively dropped by 202, 552, and 851 average megawatts. A sizeable portion of these admittedly modest reductions came in the industrial sector, as the result of a modified lag structure in the NEPP Model and revised assumptions concerning DSI power consumption.

For the residential sector, six baslc changes were made which were not the result of new economics or electricity prices. Based upon USDOE survey Information appliance 11 fetimes were lengthened and equipment purchase prices were revised. In response to comments from PNUCC staff following the publication of the draft forecast, new thermal integrity curve parameters for natural gas and fuel oil heating were 
TABLE XIII

TECHNICAL CHOICES MADE BY BPA FOR ITS 1982 FORECAST

Overall forecast

- High, medium, and low demand scenarios based on both different economics and modeling assumptions

- Only new conservation modeled was due to BPA-sponsored programs

- Public and private utility rate pools treated separately

- Judgmental probabilities associated with forecast distribution

- No Eundamental or structural changes to models reviewed in workshop

Residential sector

- ORNL model selected

- Revised base year values for energy use per appliance, energy usage, full saturation and penetrations, and new appliance penetrations

- Model structure altered to handle BPA conservation savings

- Behavioral and technologlcal parameters updated where possible

Commercial sector

- ORNL model selected, new floorspace component added

- Technology curves underwent minor recalibration

- Model structure altered to represent BPA conservation savings

Industrial sector

NEPP model selected

- Results presented for separate industrial classifications 
used, which were set equal to those of electrically heated homes. This change had the effect of making gas and o1l more competitive as heating fuels in new homes, lowering electricity consumption somewhat. Base year space heating usage values were altered to reflect "normal" rather than 1980 weather. Conservation estimates were also revised as a result of new estimates prepared by the offlce of Conservation. Finally, an erroneous estimate of single family dwellings in private utility service areas was corrected.

In the commerclal sector, modeling changes were equally modest. Although the floorspace profection methodology used remained unchanged from the draft forecast, revised employment values altered the percentage of total reglonal floorspace standing in public and private utility service districts at the 1980 and 2000 endpoints for the exogenous calculation. Secondly, at the request of PNUCC, base year (i.e. 1970) energy use per square for heating was weather normalized, so that the model's starting point for energy projections was not biased by meteorological conditions unique to 1970 . Finally, in response to comments contained in the NERA review of BPA's forecast, conservation savings estimates introduced as model inputs were fudgmentally reduced by 208 . The reason for this was to compensate for double-counting conservation savings. Presumably some of the efflciency improvements captured in the efficiency/cost tradeoff curves and elastlcities derived from historical 
data were the result of consumers taking the same measures In response to price increases as those encompassed by BPA programs. The adjustment thus focused on customers who would have conserved on thelr own but used BPA programs as the vehicle towards those ends.

Industrial sector modeling showed more extensive changes between draft and final forecasts. In response to comments from NERA, seattle clty Llght, and PNUCC, Bonneville staff altered the lag structure of the NEPP model, so that responses to price changes were gradual rather than Instantaneous. This both smoothed the pattern of predicted growth and lowered the magnitude of loads. Individual employment projections were prepared for the chemical Industry which permitted the NEPP model to distinguish electricity sales growth in this industry. Industrial conservation estimates recelved from the office of Conservation were also revised slightly between draft and final forecasts. Because of counterintuitive results for sales to the pulp and paper industry, demand projections for that Industrlal classiflcation were performed on the Brookhaven Pulp and Paper Process Model and substituted for those derived by the NEPP model. Finally, while contract demands were st1ll used to produce the DSI forecast, it was no longer assumed that loads would attain and stay at the 100 percent level, since they had not in the past. Rather, 
post-1985 DSI loads were, rather conservatively, reduced 1.5 percent.

Economic and demographic projections going into the final forecast were also revised substantially, though the methods of their derivation remain substantially the same. Although several participants at the December workshop (1.e. Milan Brace, Don Reading and James Scherzinger) had noted the desirablilty of an interactive model, such as undertaking was practically impossible within the timeline of forecast development (though a regional economic model was belng developed under contract at that time). The major changes in the forecast were the result of DRI's periodic revision of the national economic projections underlying the development of most of the demand model inputs. An additional general characteristic of the revised economic projection was a stronger reflection of the downturn characterizing the economy in 1982. Projections for population, income, and housing were lower through 1985, representing the effect of a longer recession land reflecting concerns expressed by James Scherzinger, John Savage and Cleveland Anschell at the December workshop). This downturn was also embodied in lowered base case lumber and wood products employment forecasts (in part, a response to Brian Wall's comments). High and low case projections were revised upward and downward respectively, widening the range of future alternatives addressed. As with the range of demand, 
subjective probablilties were assigned to the economic scenarlos (echolng Richard Conway's sentiments that forecast uncertainty should be quantified). Staff judgment was that there was a 10 percent likelihood that actuals would fall below the low, a 35 percent 11 kellhood between low and baseline, 40 percent between baseline and hlgh, and 15 percent above the high.

A number of more speciflc changes in the development of economic projections were undertaken for the final forecast. Fossil fuel price projections were lowered substantially, in response to comments made by Sam van Vactor and representatives of Northwest Natural Gas. At the same time, price differences between the consuming sectors were increased. On the basis of new Census information, headship rates were revised downward and, as a consequence of the new DRI projections, rates of new housing construction and occupancy were revised. Increased replacement rates were the result of shorter average dwelling lifetimes. The implicit price deflators used to adjust the varlous projections for Inflation were also modified slightly in response to the DRI national economic forecast update. Finally, several of the Industry-specific employment estimates were revised, often in response to 1ssues raised at the workshop. Transportation equipment and primary metals employment were downwardly adjusted. 
The response to Richard slaughter's concerns about the employment forecasts for the electronlcs industry, the ranges were broadened to capture possible business cycle variation. Last of all, at the suggestion of Wes Engstrom, Boeing staff experts were contacted and their advice used in the calculation of Boelng employment futures.

Changes were also made to the remaining component of BPA's forecasting system, the electriclty supply pricing Model. Revislons chiefly concerned the resources Included in the model's array of generation cholces and cost calculations. Five coal-fired plants formerly included in the resource schedule were removed, since their completion seemed dublous. Generic $500 \mathrm{MW}$ plants were substituted if additional resources were needed. The list of future avallable hydro resources was expanded based upon estimates compiled by PNUCC. The completion of WNP-1 was also delayed five years based upon the assessment of the need for its capacity in the draft forecast. Plant costs were revised based upon PNUCC estimates and conservation costs based upon new BPA Office of Conservation estimates. On the basis of updated information obtained from the Corps of Engineers and the Bureau of Reclamation, capital costs for Federal hydro profects were recalculated. Also recalculated were the effects of curtallment rights on DSI loads. Finally, a new component was added to the SPM to account for the effects of future income tax liabli1ty on system costs. 
Table XIV below summarlzes the changes between draft and final forecasts.

As noted above, BPA's forecast documentation contained one other element of signiflcance: written replies to issues ralsed by outside parties. This is explicit challenge-response behavior as identified by the 0 -perspective. Given the fact that this was BPA's first independent forecast, and that major decislons were made based, in part, upon its findings, it was critical that underlying technical cholces be fustified to the greatest extent possible. The appendices to the forecast documents provided BPA staff with the opportunity to respond to their critics and defend for at least explain) their methodological decisions. Described below are responses to comments which did not result in any of the modeling or methodologlcal changes discussed above. These responses are reported as they were prepared by BPA, with no evaluation of thelr accuracy or correctness. The forecast is evaluated in the final chapter of this dissertation.

Though the end-use models ultimately selected for use In residentlal and commerclal sector modeling were most heavlly endorsed by workshop partlclpants, some parties questioned the deslrablilty of such hlghly disaggregate tools. Representatives of PNUCC, seattle Clty Light, and later NERA all felt econometric models should be used, at least at a minlmum, as a cross-check. BPA staff relterated 
TABLE XIV

\section{A SUMMARY OF TECHNICAL CHANGES BETWEEN DRAFT AND FINAL FORECASTS}

Residential sector

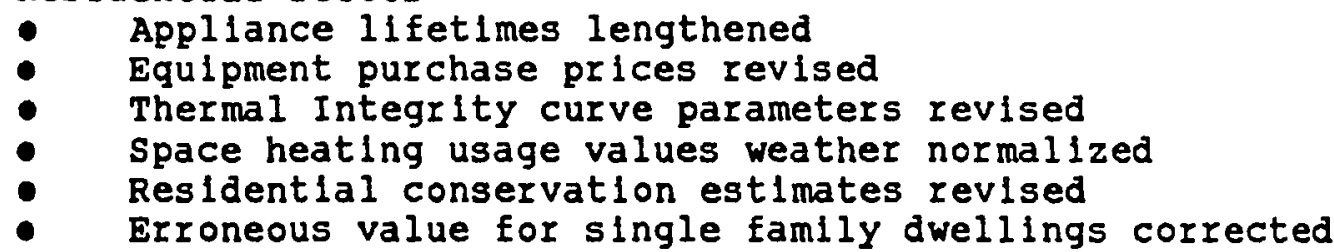

Commercial sector

- Floorspace "target" values revised

- space heating use/sq. ft. weather normalized

- Conservation savings adjusted downward to minimize "double-count"

Industrial sector

- Lag structure of NEPR model altered

- Chemical industry projections separated out by NEPP model

- Industrial conservation estimates revised

- Pulp and paper forecast prepared on Brookhaven model

- DSI loads assumed 1.5 percent below contract demands

Economic/Demographic Projections

- DRI national projections revised

- Lower population, income, and housing projections through 1985

- Lower lumber and wood products employment forecast

- Range widened, subjective probabilities assigned

- Fossil fuel price projections lowered

- Headship rates revised downward

- Housing construction and occupancy rates revised

- Implicit price deflators altered

- Employment projections for transportation equipment, primary metals and electronics industries updated

\section{Electricity Pricing Model}

- Flve coal-fired plants removed from resource portfollo
Llst of future hydro resources expanded
- WNP-1 delayed flve years
- Plant and conservation costs revised
- Curtailment rights on DSI loads recalculated
- Component added to account for future tax liability


the need for conservation analyses, consistent with the Power Act, which only the end-use models were capable of. They also noted the desirability of a cross-check with other models but noted the weakness of existing econometric models and the Impracticability of developing new ones within the timeframe of the forecast.

Several organizations questioned Bonneville's treatment of conservation. NRDC criticized BPA for not including any treatment of anticipated Regional Council-sponsored programs.

BPA responded by noting that this was its intention, and that the 1982 forecast was only to serve as a starting point for load/resource planning. NERA and PNUCC thought programmatic conservation might better be treated as a resource than as a component of demands. BPA cited the need to have end use sales reflect demand reductions due to conservation.

PNuCC, the Bureau of Indian Affalrs, the Survival Center, and Central Electric Cooperative all questioned the probability assessment and the placement of the high and low cases. BPA staff relterated that the probability assignments were purely judgmental in nature nad that the high and low cases represented scenarlos whlch were not to be conceived as absolute upper and lower bounds on load futures. Though judgmental, the judgments involved were laid out explicitly. 
NERA noted that the BPA forecasting system was so complex that knowledge of it tended to be hlghly segmented and dispersed throughout the agency. BPA acknowledged this potential problem, noting that supervisory staff had recognized the issue of consistency early and checked it carefully. The disaggregated character of the modeling system was, however, thought to be both necessary and desirable by the staff, given the complexity of issues to be addressed. PNUCC observed that BPA's models were not well sulted to capturing short-term seasonal and business cycle fluctuations whlch might be of key importance in activities such as ratemaking. Bonnevilie staff responded by noting the problem and announcing work-in-progress to develop a conslstent short run forecasting model.

Critics of the ORNL Residential Model focused upon its performance in areas of price and income responsiveness. Energy Ventures Analysis, POWER, seattle city Light, and NRDC all questioned the price rasponsiveness of the model (with EVA and POWER contending the model understated response). As a response, BPA staff presented the results of sensitivity analyses performed during the testing phase, and argued the reasonableness of the results. Seattle city Light and NERA both felt Income responsiveness was too low. staff noted that only a portion of the model's income elasticity was apparent from findings since some responsiveness was "hard-wired" in the model by means of exogenous para- 
meters. The overall responsiveness, BPA claimed, was consistent with research findings.

PNUCC critlcized BPA for using different discount rates for different appliances in determining residential ife cycle cost minima. staff replied that ilterature revealed that customers indeed seemed more willing to "gamble" with less expensive items, so different rates were approprlate. NRDC had argued that there was no evidence to support the thes is that residential customers actualiy made appliance selection decisions using 11 fe-cycle cost minimization. staff counterargued that the methodology was fully consistent with economic theory and an acceptable predictor of aggregate response.

Members of seattle city light staff noted that the declining electricity use per square foot values produced by the ORNL Commercial Model were inconsistent with the results of other econometric models with the region. BPA responded that in the end-use models certain factors increased use per square foot while others more strongly decreased it. Increases in equipment efficiency, which appeared reasonable during sensitivity testing, were the chief source of the decline in unit electricity usage. Several parties making comments questioned the complex price response mechanlsm of the ORNL model. NERA and seattle city Light both felt that the model over-responded to price increases. Energy ventures Analysis thought that it might have overestimated 
the time lag before price-induced conservation takes hold and seattle city Light also belleved it underestimated fuel switching to electric space heat. In response, BPA staff noted that most econometric models used in the region which might be used as a basis for comparison were specifled over data compiled during a period where electricity prices in real dollars were falling. This pattern no longer held, with prices increasing rapldly, and customer response was thought likely to be in the process of changing. Hence, accepted notlons of approprlate types of levels of response might be inaccurate. BPA defended the commerclal model's performance based upon its calibration to historle fuel sales between 1970 and 1980 .

The NEPR model alsplayed output elasticlties less than one (1.e. a 10 percent increase in output produced less than 10 percent increase in electricity consumption) for several Industries, and both NERA and PNUCC felt this was indicative of a specification error. BPA acknowledged a specification error, but noted that non-unlform expansion within the Industries noted could produce such results. PNUCC also noted that the model was specifled over natlonal energy data and, as such, suffered from aggregation and locational blases. BPA again acknowledged that this problem merited additional research, but defended the specification of the model, pointing to the use of pooled time series cross sectional data which allevlates the problem of locational 
bias. EVA and the Survival Center question the inclusion of the unbulit Alumax Plant among contract demands in the DSI forecast. BPA asserted its bellef that the recession would end world aluminum demand would likely justify the additional smelter. PNUCC criticized the omission of wages from the total industrial energy equation. BPA noted that AEA's specification allowed wages to be factored out of the demand function, but admitted that wages are important and that respeclfication would be considered. Flnally, NRDC claimed that the forecast ignored industrial cogeneration. Bonneville pointed out that cogeneration was being treated as a resource and, as such, was dealt with in a separate resource assessment.

The forecast for the irrigation sector, though not part of the January technical review, was the target of several critics. PNUCC noted that the model used to develop the forecast was consplcuously lacking in explanatory economic factors. BPA staff responded that an electricity price variable was being added to the model to address such issues In future forecasts. NRDC volced several criticisms, namely, that the model ignored potential conservation inducing alternatives, that BPA should treat irrigated areas on the basis of their actual locations, that BPA overestimated the trend toward sprinkler systems from gravity, and that the forecast failed to address the effect of irrigation on hydro-generation capacity. BPA responded with explana- 
tions, rather than modeling changes to all those comments, emphasizing that the model was newly-developed and did not contain all the features that might be desired (e.g., priceinduced conservation responsiveness), that irrigated acreas were assigned energy and water intensive qualities based upon 14 hydrologic subregions, that a study was being commissioned to explore the issue of sprinkler and gravity irrigation, and that hydro generation capacity issues would be dealt with in a resource assessment. Finally, Joseph Deluca, a private citizen, commented that BPA projected irrigation needs were low, based on minimum increases in land cultivation curbed by high inflation rates. BPA responded that though inflation rates partially accounted for the levels of loads, other factors (such as changing farm marketing conditions, energy and other costs) were largely responsible for the levels of sales. Even if Inflation rates were lowered, electricity sales would not change arastically.

Methodological considerations underlying the development of economic and demographlc profections were a key focus of numerous comments. The economic base model at the center of the profections had been criticized by willam Jeshe (Economic Development Council of puget sound) for not having industry-speciflc employment multipliers and by Philip Brooks (Montana Department of Administration) for not distinguishing migration which is not the result of 
seeking employment from that which is. BPA responded that, In the former case, the derivation of specific multipliers was ruled out by time constraints (but would be part of a model under construction) and that, in the latter case, the economic base model, though not designed to explain reasons for mlgration, ald profect net migration in a manner consistent with one assumption about the needs and composition of the labor force. BPA also noted that its methodology in development would allow age distributions for migrants as well as disaggregations for income projectlons. POWER suggested that BPA was using obsolete data to arrive at a 75 percent share for the single family home portion of residential housing. BPA explained that the 75 percent value was not an assumption but a constant consequence of how DRIs profections of housing starts reflect age-specific household preference rates and the changing age composition of the population. The University of oregon survival Center questioned the validity of the simplifying assumption that housing stocks adjust instantaneously to demand. BPA defended the simplifying assumption on the grounds that data was not readily available to develop such a lag structure and that staff did not feel that the absence of such lags would strongly affect out year values. Southern California Edison questioned why national, rather than regional, variables were used to project industrial productivity and why GNP price deflators were used Instead of a Producer Price 
Index in Industrial sector Inflation assumptions. BPA responded that rellable estimates of regional productivity were unavallable and that projected inflation was not a direct input to the Industrial model but only used to ensure consistency between Income and fuel prices in real terms. Hence, the particular inflation index used was unimportant. PNGC made several detailed critlcisms of BPA methodology. First, they challenged BPA's method for developlng population estimates from the "bottom-up", treating it as a function of basic industry employment. This, they claimed resulted in forecasted population growing at about half the 20-year historical rate. BPA countered by noting that, regardless of the approach taken to projecting population, the two factors decislve in historical Northwest growth, the post-war baby boom and accelerated net in-migration, could not be seen to continue growing. Thus, a "top-down" alternative would not be likely to yield much higher estimates. second, PNGC claimed that BPA's treatment of labor force participation was inadequate since they did not appear to consider the market factors affecting 1t. BPA responded by noting that the Bureau of Labor statistics profections used by BPA implicitly embody the market factors of concern. Finally, comments from the Futures Research Institute noted the primacy of core assumptions in shaping forecast projections and the likelihood of new basic technologlcal Innovations clustering in the near future. BPA responded 
that assumptions were laid out in as much detail as judged to be useful to lay readers and that new technologies and industries are somewhat included in projections of employment in existing industries. (It should be noted that sectlons of this dissertation look rather carefully at these last areas of the concerns).

A final category of comments concerned the electricity prices developed using the Supply Pricing Model. Once again NRDC and PNUCC were the chief sources of critical comments. NRDC asserted that BPA's wholesale rate increases for preference customers ( 20 percent) were not adequately reflected in projected electricity prices, that the costs of the wPPSS plants would have stronger rate effects than the price forecast indicated, that BPA's 70 percent capacity factor for thermal plants was too high, and that interest rates seemed inconsistent between thermal resources and conservation and biased against the latter. BPA responded by noting that the wholesale rates for preference customers had not been finalized (1.e. 70 percent was at best a tentative number), that the wNP costs only triggered significant increases in the near term, remaining more constant in the long run, that the 70 percent capacity factor, though high, used a portion of secondary hydro energy to displace an equivalent amount of thermal generating capacity llowering the latter proportionally), and that the borrowing rate used In resources cost calculations was set by congress and not 
subject to relnterpretation. PNuCC also questioned the accuracy of BPA's calculation hydro capacity, with particular concern about the estimate of thermal energy reduction. They suggested that BPA use an approach in which monthly hydro avallability would be modeled for each of the 40 historical water years. BPA responded that they were examining such a strategy but were uncertain as to whether or not it would yleld much additional accuracy. POWER belleved BPA had underestimated the costs of power from new resources. BPA pointed out that final forecast cost estlmates had changed from the draft and were based on a least cost mix resource analysis. The survival center also noted the problems with resource costing, suggesting that BPA first purchase cheaper resources. BPA relterated its methodology on generic resource costing using a least cost $\mathrm{mix}$ analysis and noted that this analysis was to be expanded into the forecasting process to deal with the very issue raised by the Survival Center. Finally, Joseph deluca, a private citizen commenting on the forecast, noted the absence of any mention of hydrogeneration capacity loss due to Elshing enhancement. BPA acknowledged the omission but pointed out that this was a resource analysis, rather than a forecasting lssue, and that such planning would, in any case, be premature before the Reglonal Council prepared its fisheries assessment. 
TABLE XV

COMMENTS ON BPA'S FORECAST AND RESPONSES

\begin{tabular}{|c|c|c|c|}
\hline $\begin{array}{l}\text { Topic } \\
\text { Area }\end{array}$ & $\begin{array}{l}\text { Org/Persons } \\
\text { Commenting }\end{array}$ & $\begin{array}{l}\text { Summary of } \\
\text { Remarks }\end{array}$ & $\begin{array}{l}\text { BPA } \\
\text { Response }\end{array}$ \\
\hline $\begin{array}{l}\text { Choice of } \\
\text { models }\end{array}$ & $\begin{array}{l}\text { PNUCC, SCL, } \\
\text { NERA }\end{array}$ & $\begin{array}{l}\text { - Econometric models } \\
\text { should be used as } \\
\text { cross-check }\end{array}$ & $\begin{array}{l}\text { Idea sound but } \\
\text { end-use models } \\
\text { needed for policy } \\
\text { analysis }\end{array}$ \\
\hline Conservation & NRDC & $\begin{array}{l}\text { - No treatment of } \\
\text { Council programs }\end{array}$ & $\begin{array}{l}\text { - Omission deliberate } \\
\text { conservation in } \\
\text { forecast only } \\
\text { starting point }\end{array}$ \\
\hline & PNUCC, NERA & $\begin{array}{l}\text { - Conservation better } \\
\text { treated as resource }\end{array}$ & $\begin{array}{l}\text { End use sales must } \\
\text { reflect savings, } \\
\text { therefore conser- } \\
\text { vation viewed on } \\
\text { demand side }\end{array}$ \\
\hline $\begin{array}{l}\text { grobability } \\
\text { assessment }\end{array}$ & $\begin{array}{l}\text { PNuCC, BIA } \\
\text { Survival Center } \\
\text { Central Elec } \\
\text { Coop }\end{array}$ & $\begin{array}{l}\text { - Not clear how BPA } \\
\text { arrive at probabili- } \\
\text { ties or high-low }\end{array}$ & $\begin{array}{l}\text { - Probabilities sub- } \\
\text { jective, based on } \\
\text { staff judgment }\end{array}$ \\
\hline $\begin{array}{l}\text { Forecasting } \\
\text { system }\end{array}$ & NERA & $\begin{array}{l}\text { System so complex } \\
\text { that knowledge widely } \\
\text { dispersed throughout } \\
\text { organization }\end{array}$ & $\begin{array}{l}\text { - Disaggregation } \\
\text { necessary to deal } \\
\text { with issues; care } \\
\text { taken to ensure } \\
\text { consistency }\end{array}$ \\
\hline $\begin{array}{l}\text { Forecast } \\
\text { horizon }\end{array}$ & PNUCC & $\begin{array}{l}\text { - Hodels not suited to } \\
\text { short-term fluctua- } \\
\text { tion }\end{array}$ & $\begin{array}{l}\text { - Observation correct } \\
\text { for near term; } \\
\text { short term models } \\
\text { under development }\end{array}$ \\
\hline $\begin{array}{l}\text { Residential } \\
\text { model }\end{array}$ & $\begin{array}{l}\text { EVA, POWER, } \\
\text { SCI, NRDC }\end{array}$ & $\begin{array}{l}\text { - Price responsiveness } \\
\text { questionable }\end{array}$ & $\begin{array}{l}\text { - Sensitivity anal- } \\
\text { ysis suggested } \\
\text { results reasonable }\end{array}$ \\
\hline & & $\begin{array}{l}\text { - Different discount } \\
\text { rates for appliances }\end{array}$ & $\begin{array}{l}\text { - Research indicated } \\
\text { differential wil- } \\
\text { lingness to "gamble } \\
\text { on different ap- } \\
\text { pliances }\end{array}$ \\
\hline & NRDC & $\begin{array}{l}\text { No empirical evidence } \\
\text { for life cycle cost } \\
\text { minimization }\end{array}$ & $\begin{array}{l}\text { Methodology con- } \\
\text { sistent with econ- } \\
\text { omic theory, good } \\
\text { prediction in } \\
\text { aggregate }\end{array}$ \\
\hline \multirow[t]{2}{*}{$\begin{array}{l}\text { Commercial } \\
\text { mode } 1\end{array}$} & SCL & $\begin{array}{l}\text { Declining use/sq. ft. } \\
\text { volumes inconsistent } \\
\text { with other estimates }\end{array}$ & $\begin{array}{l}\text { - Efficiency improve- } \\
\text { ments outweighed } \\
\text { factors reusing } \\
\text { use/ft }\end{array}$ \\
\hline & $\begin{array}{l}\text { NERA, SCL } \\
\text { EVA }\end{array}$ & $\begin{array}{l}\text { Model's response } \\
\text { to prise question- } \\
\text { able }\end{array}$ & $\begin{array}{l}\text { - Difficult to assess } \\
\text { responsiveness vis- } \\
\text { a-vis region's } \\
\text { econometric model: } \\
\text { consumption pat- } \\
\text { terns changing, } \\
\text { model we } 11 \text { calibra- } \\
\text { ted to } 1980-90\end{array}$ \\
\hline $\begin{array}{l}\text { Industrial } \\
\text { model }\end{array}$ & PNUCC, NERA & $\begin{array}{l}\text { - NEPP model elastici- } \\
\text { ties suggest mis- } \\
\text { specification }\end{array}$ & $\begin{array}{l}\text { Error liknly part } \\
\text { of problem; non- } \\
\text { uniform expansion } \\
\text { also possible } \\
\text { explanatory } \\
\text { factor }\end{array}$ \\
\hline
\end{tabular}


TABLE XV (Cont'd)

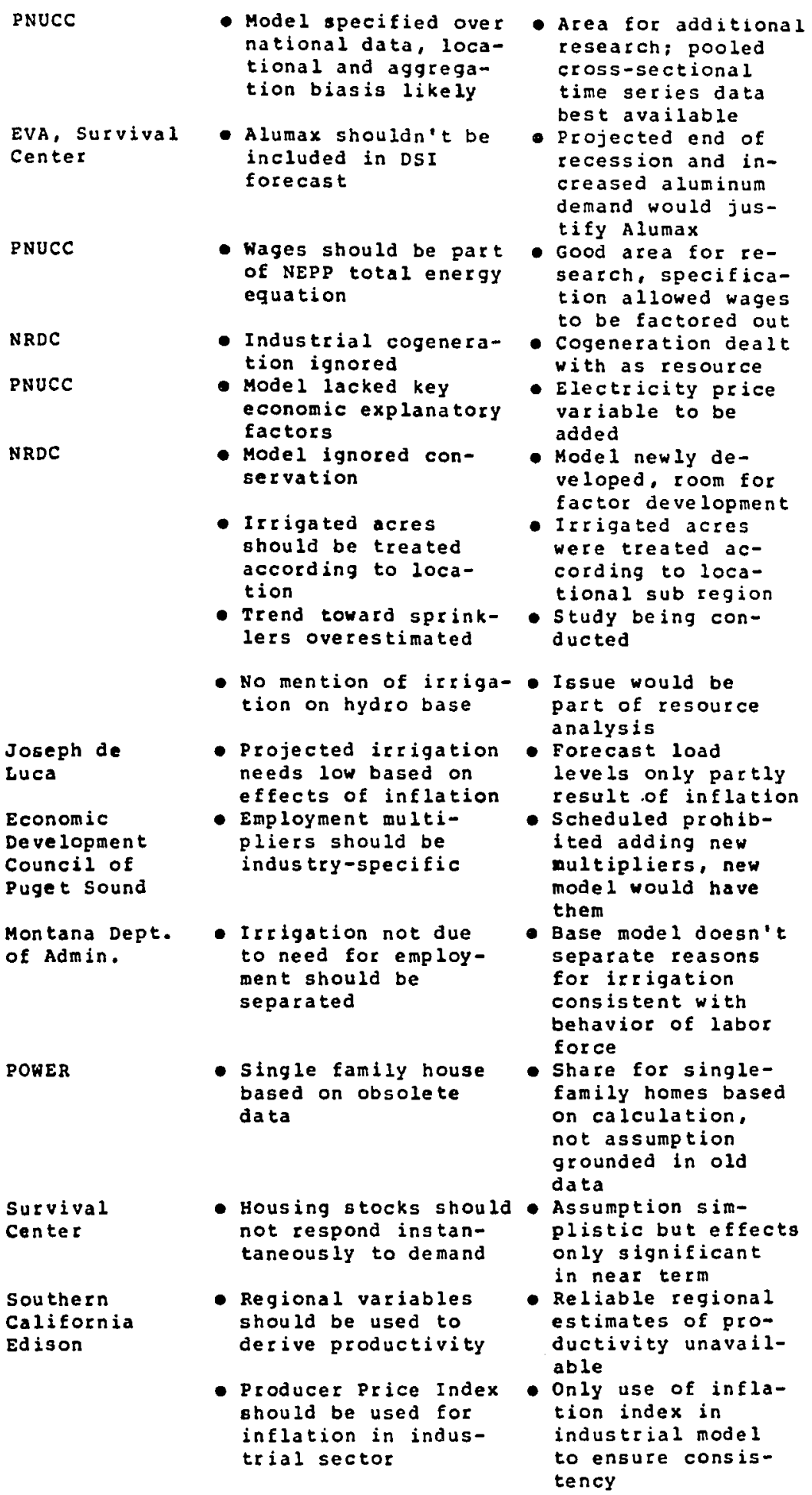


TABLE XV (Cont'd)

PNGC

Futures Research

Institute

NRDC

ricin

Mode 1
- Population estimates low as a result of BPA's approach

- Labor force participation rates ignored market

- Core assumptions shape forecast and should be 1 isted

- Cluster of new innovations likely in near future

- Wholesale rates for preference customers understated

- Impact of WPPSS costs on rates underrepresented

- Capacity factor for

hydro too high

RNUCC

POWER

Survival Center

Joseph de Luca
- Interest rates incons istent for thermal and conser vation

- Hydro capacity calculations ques tionable, should model historical years

- Costs of power from new resources underes $t$ imated

- Cheaper resources should be purchased first

- No mention of hydro loss due to fishing enhancement
- Major factors in historical growth no longer operative, population would decrease under any methodology

- Statistics used to develop projection embody market effects

- Assumptions 1 isted in detail judge adequate for intel. ligent lay audiences by $B P A$

- New technologies and industries somewhat included in employment projections for new industries

- Wholesale rates had not yet been estab1 ished, forecast values reasonable

- WNP costs result in significant increases only in water

- Capacity factor for hydro large because of thermaldisplacing secondary generation

- Borrowing rates used were mandated by Congress

- Strategy already investigation, but additional accuracy questionable

- Costs changed from new calculation based on least cost $m i x$ analysis

- Least cost mix analysis to be extended to future choices in forecast period

- Hydro loss study is part of resource analysis, not forecast: such annlyais awaited Council recommenda$t$ ions 
Table XV below summarlzes the technical challenges to which BPA provided written (as opposed to modeling) responses. Identifled in the table are the party (or parties) making the comments, a short summary of their remarks, and a "shorthand" description of BPA's responses.

In the chapter which follows, the one concluding this dissertation, a serles of structured comparisons will be made between conclusions (or inslghts) galned from the use of Multiple Perspectives in contrast to those gained from the Individual perspectives in isolation. This demonstration of the efflcacy of Multiple Perspectives Involves the detalled use of the products of the cross-cuing exercise. Rather than duplicate this process, this chapter will simply draw out more general conclusions and offer some emergent insights into the significance of BRA's forecast development to power planning in the region.

The above cross-cuing process revealed a number of significant influences between the three "streams" of events. Technical products often serve as precedents for establishing (or modifying) organizational missions, for basis individual decisions, and for comparing later technical efforts. Organizational challenges (both intra- and Interorganizational) often shape the questions which requlre technlcal response, as well as the methodology by which they are answered. Personal influences have effects on various levels of organizations, sometimes determining overall 
pollcy in ways whlch, In turn, set definlte technical directions; at other times providing the seeds for organizational reorientation (with its concommitant technical revisions). Above all, the cross-cuing exerclse lllustrated how substantive changes in policy (and decisions) is the outcome of the semi-structured interplay of $\mathrm{T}-, 0-$, and $\mathrm{p}$-elements, and identifled several areas deserving greater attention. Ultimately, the Impact of the BPA forecast must be judged interorganizationally, where it heralded a new perception of the future. Undoubtedly, at the time of the final forecast's July publication there were many parties which did not belleve BPA's forecast, did not endorse their cholce of models or methodology, or did not find that staff replies to technical comments convincing. Given the timeIine for the WNP 1 and 3 decision and the development of the supporting energy forecasts, BPA could be expected to do no more than uncover the technical alternative best sulted to the demands placed on them and openly acknowledged this. Major model development efforts were precluded during the six-month public involvement perlod, and this practical constralnt was generally recognized by participants. As a consequence, major change to load projections could only result if a a serlous methodologlcal error could be ldent1fied In BPA's operation of Its modeling system (Errors that might exist in data prepared by other sources such as DRI, would likely go undetected by elther BPA or members of 1 ts 
reglonal audiencel. BPA prepared some sort of "reasonable" response to each challenge and, in dolng so, defended its forecast. The final result was a set of numbers which would have to be treated as "official" by anyone entering into resource agreements with $B P A$, even if they felt the forecast to be in error. The forecast development process forged a new "consensus" which would 1tself help shape the future of the region. 


\section{A DIGRAPH INTERPRETATION OF THE FORECAST PROCESS}

From the standpolnt of systems research, the Multiple Perspective Concept allows complex problems to be approached not only from different disciplinary polnts of departure, but also from different paradigms of inquiry. Only findings resulting from the $T$-perspective are capable of being subjected to validation procedures in the strict scientific sense of the word. Corporate and fudiclal declsions cannot be subjected to statistical checks of reliability, validity, or goodness-of-fit. They can, however, be presented in such a fashion that the rationale of investigation as well as the evidence or information used may be reconstructed, (though not the subjectlve welghting process used for integrating the evidence). This allows potential critics to evaluate the object of description and, if desired, construct another plausible interpretation, much as two lawyers build their contrasting arguments from the same evidence.

In soclal sclences dominated by empliclsm, such as cultural anthropology, fleld researchers deal with some of these issues by, in effect, separating their roles as reporters from their roles as interpreters of the findings. They strive to keep descriptions as few of interpretation as posslble, whlch permits thelr audience to arrlve at different conclusions from the same data. In this dissertation, efforts were made to present findings of each perspec- 
tive independently. Internal consistency and, to the extent possible, comprehensiveness were sought in each case. Similarly, the cross-cuing exercise above was primarily narrative, with most of the major conclusions drawn out in the chapter which follows. The detail of description went somewhat beyond what was required to reconstruct the dissertation's concluding remarks.

But, the true strength of Multiple perspectives comes from the use of $T-, 0-$, and $P-f$ indings in conjunction with one another. This allows the multidimensionality of the object of research to be revealed. Because this goes beyond simple description, it is essential that the emerging multidimensional picture) or its most critical features) be presented unambiguously and formally. Digraphs constitute a useful and potentially powerful tool targeted. towards this end.

Although the fundamentals of digraph usage were explained in earlier chapters, further remarks on their application to the problem of tying together insights from the three perspectives are warranted. Following guidelines presented by Linstone (1984:321-327) the nodes or elements in digraphs are the perspectives, while the arrows, as always, indicate the direction of influence. The signs associated with the arrows (appropriate where relations can be presented as positive or negative) reflect the direction of the influence of one perspective upon another. A plus 
slgn $(+)$ represents "relnforcing the attltude toward, or feasiblity of, a pollcy". Conversely, a minus sign (-) connotes "counteracting the attitude toward, or feasibility of, a pollcy". In the context of the analysis below, "policy" will be interpreted broadly enough to include selections of technical methodology.

In addition to creating a plcture whlch lays out the relations between the perspectives explicitly, digraphs also allow the researcher to uncover the dynamics underlying the interactions between them. signed digraphs accomplish this by permitting the interpretation of cycles or feedback loops among perspectives. Two basic rules guide this interpretation. First, a "loop is positive or impact amplifying if it has zero or an even number of minus slgns negative or lmpact counteracting if it has an odd number of minus signs." (Linstone: 1984:323). Second, the total effect of any given point on a digraph on any other speciflc polnt is the sum of the effects of all the paths or cycles between the two points. (Effects may be direct, or indirectly expressed through intermediate polnts). When all effects are positive or all are negative, their sums are, respectively, positive and negative. The sum is indeterminate when there are both positive and negative effects via different poles.

Figure 27 below depicts the interactions of perspectives surrounding the development of the 1982 forecasts. 


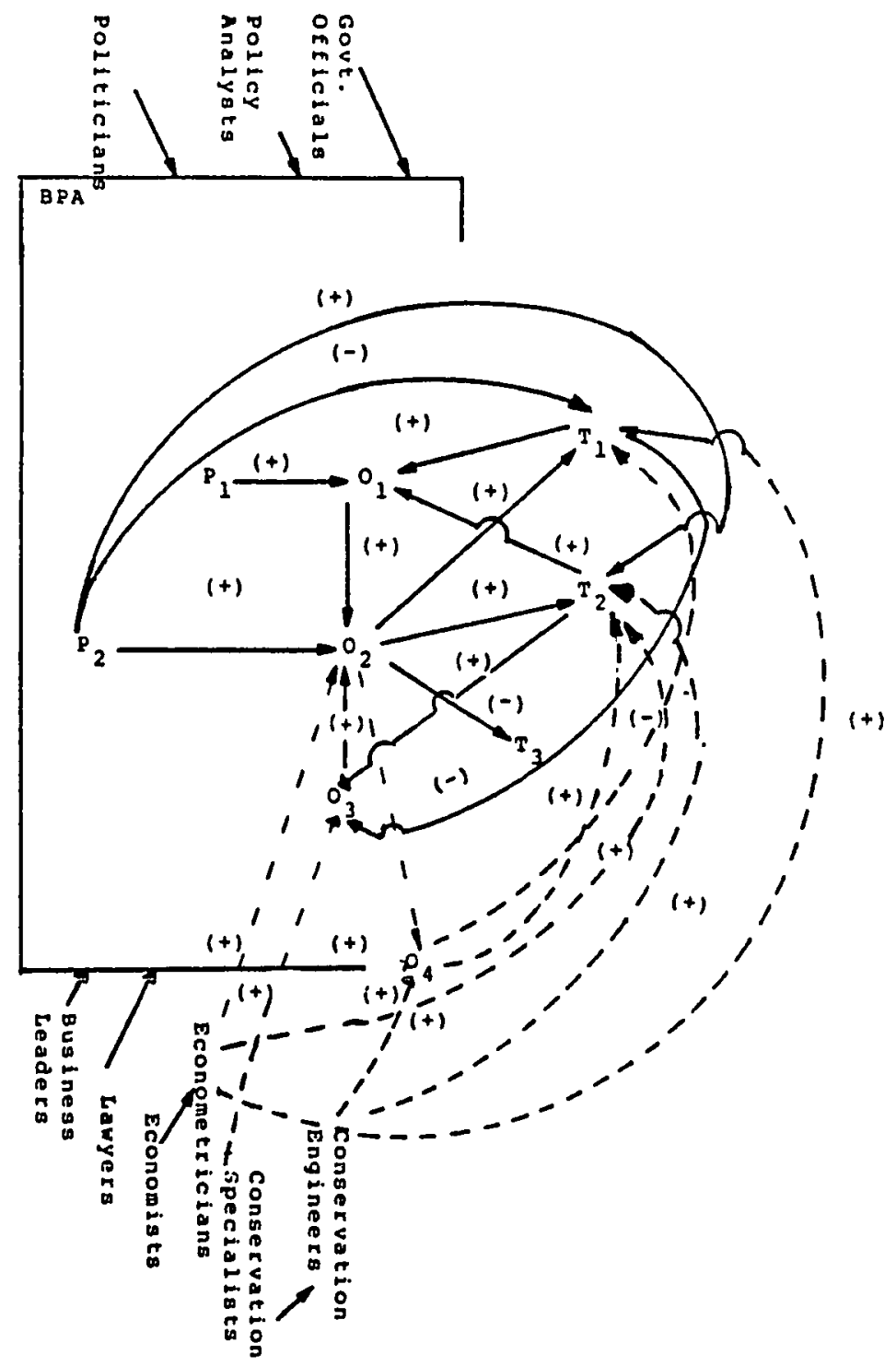

Figure 27. A digraph representation of multiple perspectives surrounding BPA's 1982 forecast 
The perspectives represented are as follows:

T1 - econometrle demand models

T2 - end-use demand models

T3 - other demand modeling techniques

01 - Flnanclal Management

02 - Power Requirements

03 - Conservation

04 - outside particlpants in BPA public involvement

P1 - Administrator

P2 - Power Requirements' leaders

Before looking at the flows and cycles embedded within the system of relations depicted in the digraph, a few linkages should be explained. P2 is split off from 02 to distingulsh between the effects of individuals' experience on model and methodology selection from those resulting from newly evolved organizational procedures. A number of specific individuals in Power Requirements (those who had earlier worked with the SOM report and later emerged in leadership positions) had negative experiences with the region's existing econometric models (P2TI negative) and more positive (or at least more promising) ones with the ORNL end-use models (P2T2 positive). P2 1s, in many respects, an antecedent to (or precedent for) 02 . From the organizational standpoint, 02 is strongly constralned by the needs of BPA's Financlal Management input (1.e. the WPPSS study (01)) and proper implementation the 
terms of the Reglonal Act by conservation (03). The former needs favor a forecast methodology which provides "a best guess" at resource requirements (range). The latter needs suggest the desirabllity of conservation and rate scenario capabilities in model selection. Financial analysis needs are given the stamp of importance by the management priorities of the Administrator (P101 positive).

From the standpoint of the forecasting unit $(02)$, both $\mathrm{T} 1$ and $\mathrm{T} 2$ are acceptable alternatives (despite individual preferences). Thus, $02 \mathrm{~T} 2$ and $02 \mathrm{~T} 1$ are both positive. Both $T 1$ and $T 2$ could easily be used in a financlal analys is context, so T101 and T201 are both positive. T2, however, is ostensibly better suited to conservation policy analysis. Hence, though T203 is positive T103 is negative in sign. The training and professlonal experlence of Power Requirements staff also left them unfamillar with other possible technlcal approaches (T3) which could have been used for forecasting purposes and might - or might not have been accepted by the power planning community. (The slgnificance of paths not considered - both models and planning strategles - is discussed at greater length in the next chapter, whlch evaluates what has thus far been described).

Looking at the cycles involved, both cycles passing through T2 (i.e. 02T20302 and 02T20102) are positive. By contrast, only one of the cycles passing through $\mathrm{T} 1$ is positive (1.e. 02T10102 is positive while 02 T10302 is 
negative). Thus, when looking at the organizational influences on technical choices (constrained, it should be noted, by the set of choices made available) the reasons for the model choices are clear.

When looking at the sum of effects on $\mathrm{T} 1$ and $\mathrm{T} 2$ other dimensions of the cholce of approaches become apparent. Influences from $P 2$ and 04 both give extra weight to the particular methodology that was developed, though these preferences are probably outweighed by the organizational consideration described above.

Several comments need to be made about 04 . Because the comments received by BPA were varied, there was no universally preferred set of models or methodology. Preferences leaned towards the end-use models, however, so the signs are placed on dashed lines to indicate a less than unified perception. More important is the reason 04 is linked only to $\mathrm{T} 1$ and $\mathrm{T} 2$. As noted in the remarks introducing the description of the technical workshops, the public involvement agenda was contrained to look among preselected models for their strengths and weaknesses. Membership in 04 was technically open to anyone wishing to participate. Techniclans, however, were the primary group 02 contacted through malling lists. Because 02 could not be selective among the techniclans particlpating (1.e. could not impose 01 or 03 concerns on outsiders) 0204 is unsigned and represented by a dashed line. Under BPA's timetable, totally different 
approaches were not deemed readily implementable, thus there is no linkage between 04 and $T 3$. Also, although technical comments influenced more than simply BPA evaluation of the end-use econometric demand models (i.e. numerous input and parametric changes resulted from the comments) it was only at $\mathrm{T} 1$ and $\mathrm{T} 2$ that major substantive methodological choices could potentially be modified (at least within the time frame of the 1981-1982 forecast cycle).

The perspectives Iisted outside of the frame labeled with names rather than symbols have been added to show broader influences which affected model and methodology selection in less direct and obvious ways. Economists and engineers have, and continue to be the dominant force in the utility industry (though there is currently a trend away from narrow specialization) and the influences of these disciplines are shown by means of dashed lines.

Econometrics was used heavily in the models represented by $\mathrm{T} 1$ and $\mathrm{T} 2$. It also was a mainstay of the training of members of 02 and most of the members of 04 . Conservation concerns also figured heavily in the forecast development process. 03 was largely made up of conservation specialists who, despite somewhat varied academic backgrounds, shared common objectives regarding the promotion of efficient energy use. In the model development community, conservation engineers have developed simulation tools for building design which permit the exploration of the effects of 
equipment changes on energy consumption. The tools were an Integral part of the development of T2 but not T1. Generally speaking, then, this lilustrates how the tools selected for consideration embodied familiar ldeas and concepts.

Also, depicted outside the process are varlous parties whose primarily qualitative insights are potential valuable for load forecasting and power resource planning, but who, lacking fluency in the lingua franca of modeling, have difficulty accessing the review process. Included in this category are many business leaders, lawyers, policiticans, and government officials.

Finally, what is missing from this digraph provides additional insight into the forecasting process. Conspicuous in its absence is another perspective to support the conslderation and possible selection of a different modeling approach (T3). Both T1 and T2 are supported by "coalitions" within the power planning community. No group can be seen to champion any alternative approaches to forecasting and modeling, however, and, given the composition of the participant groups involved in the forecast development process, none is likely to emerge. Thus, the digraph suggests the need for a stimulus from outside to prevent disclplinary Inbreeding and widen the sphere of conslderation to include additional technical approaches. Multiple Perspectives can be used as a device for obtaining these fresh alternative viewpolnts. 
To summarlze, the digraph construction exerclse produced the following conclusions.

- T1, the use of pure econometric models, was supported directly by 02 directly, P1 and 01 indirectly. It was opposed by P2 and 04. One cycle (02T10102) supported T1 while another cycle (02T10302) opposed 1t. The model was good for flnanclal analys is conslderations by weak on conservation policy testing.

- T2, the end-use model approach, was the more strongly supported alternative. P2, 02, and 04 directly supported its selection. P1, P2, 01 and 03 indirectly supported 1 ts selection. Both cycles associated with T2 (1.e. 02T20102 and $02 \mathrm{~T} 203 \mathrm{~T} 2$ ) are positive. Thus, the organizational concexns of 03 (conservation assessment) tipped the process towards $\mathrm{T} 1$.

- The review process was, as noted earlier, constralned to focus upon comparisons between models already avallable for use. As w1ll be descrlbed more fully in the next chapter, unless some mechanism is used to incorporate the Inslghts of non-economists and non-englneers, this process cannot help but manifest the symptoms of disclplinary Inbreeding.

The potential for development of digraph techniques in confunction with Multiple Perspectives is great and could, In and of itself, constitute the topic of a dissertation. One obvlous area of development, whlch could provide a 
bridge between the digraphs and avallable structural modeling technlques, is that of assigning welghts to the relations. Questions of the strength of influence of the Administrator on organizational priorities land resulting procedural cholces), for Instance, cannot be answered simply using signs.

Obviously this is not a trivial project. It would involve ascertaining the strength of perceptions (1.e. how firmly certain things are believed to be) as well as the organizational responsiveness to different influence. Pollcy Delphi could provide a starting point for this endeavor, though it would have to be carried out virtually concurrent with the decision processes under consideration to prevent perceptual or attitudinal "revisionism".

Digraphs thus explicate relationships between perspectives in ways difficult to duplicate by other means. While resolving certain issues, however, their use in turn raises other. The concluding chapter of this dissertation, in evaluating the strengths and weaknesses of BPA's forecast methodology, examines important implications of the relationships embodied in the digraph above (as well as some relationships not embodied therein). 
CHAPTER VI

CONCLUSIONS

TYING THE THREADS TOGETHER: AN OVERVIEW OF THE CHAPTER

In the preceeding chapters, BPA's 1982 forecast was scrutinized by means of three sets of lenses: The $\mathrm{T}-, 0-$, and $\mathrm{P}$-perspectives. To the fullest extent possible, these perspectives and the insights which they ylelded were kept separate and distinct. Only afterwards were the perspectives cross-cued. This strategy was deslgned to lilustrate the additional depth and dimension of inslght possible to be galned from using the multiple perspectives together. It is through cross-culng that the full explanatory power of the Multiple Perspective Concept becomes apparent. It is now time to draw out the conclusions whlch this exerclse ylelded.

At the outset of this dissertation, three research objectives were defined, all of which will be met in the conclusions that follow. The flrst two concern what the methodology of the Multiple Perspective Concept reveals about how forecasts influence resource planning and declsion making and how forecasts are produced through an ongoing, essentially interactive process. The section whlch follows lays out the conclusions about BPA's forecast, and the process by which it was produced, focusing first upon those 
conclusions resulting from the use of each perspective by itself and then identifying the additional insights derived from using the perspectives in combination.

The final section explores the third and last objective. It examines what this particular study reveals about the Multiple Perspective Concept. Here are listed the strengths and weaknesses of the MP Concept experienced in this investigation of BPA's forecast, new recommendations for its use and application to research problems, and specific areas perceived to be in need of further development.

\section{CONCLUSIONS ABOUT THE FORECAST: WHAT MULTIPLE}

\section{PERSPECTIVES SAYS}

In this section, conclusions about Bonneville's forecast derived from the use of Multiple Perspectives are presented. First, conclusions arrived at by means of the T-, 0-, and P-perspectives used by themselves are listed. To some extent, these relterate remarks made in other chapters, but they also often reflect paraphrasings which elaborate or emphasize key points which have become clearer given the blgger plcture produced by this study. Second, conclusions resulting from cross-cuings are described. These are listed according to the type of Interaction between the perspectives (e.g. $T$ on 0,0 on $P$, etc.) and, as noted above, lllustrate the additional values of a multiple 
perspective approach when contrasted with the conclusions obtained from the application of the perspectives in isolation. Finally, the forecasting and planning process is evaluated as a whole, based upon the full range of insights ylelded by this investigation, with heaviest emphasis placed upon the area in many ways most central to futures research: risk and uncertainty.

\section{Conclusions from the T-perspect lve}

1. BRA's Modeling system was More comolex than land at Least as Sophisticated as) any Previously Used for Regional Electricity Forecasting, A point which Bonneville staff ralsed at numerous occaslons durlng technlcal workshops and public involvement was that the models they selected and developed were deslgned to address selected complex issues (e.g. conservation policles, electricity pricing). In order for these models to satisfy that criterlon, they themselves embodied a complex structure.

Two points need to be noted. First, model complexity and sophistication, though often going hand in hand, are not ldentical. A model need only have an intricate and detailed accounting structure to be complex. The ldeas embodied in Its structure may actually be simple. By contrast, a model which is sophisticated embodies elaborate or elegant theory In its structure, but that structure need not be compl1cated. Second, neither complexity nor sophistication in any sense endow a model with superlority over alternative ap- 
proaches, nor do they guarantee improved performance. Complex models may simply aggregate or disaggregate simulations of real world events without changing the ultimate results. Sophisticated models may be difficult to specify or support with adequate data. In worst instances, the theory underlying their construction, however elegant and cherished by model users, may ultimately prove misguided, yielding untenable results.

The disaggregated nature of BPA's overall modeling system, and several of the models within that system, definitely produced a more complex system than used before, as asserted above. This disaggregation, however, is not necessarily more sophisticated than some of its predecessors (e.g. NEPP, ISDM). The enhanced ability to address specific conservation policy issues of concern to BPA which earlier econometric models were not capable of addressing at least outwelghs whatever deflclencles the system might have in terms of internal consistency and completeness. It is thus best Judged at least as sophistlcated as its predecessors.

\section{BPA's Selection of Disagaregate End-Use Models for} Rorecast ing roads was Technically Farranted, It seems readily possible to debate the relative merits of end-use vs. econometric models ad nauseum. Both approaches may display unique strong points; neither necessarliy produces more accurate results (nor do they necessarily produce results meaningful for decisions). While econometric models 
may be evaluated according to a number of statistical goodness-of-flt measures, the data over whlch they are specified may be poor or descriptive of a unique set of historical circumstances. End-use models $\mathrm{mix}$ their methods, and are so data-intensive that judgment must be used very freely to fill gaps in inputs. The particular end-use models BPA evaluated (and ultimately selected) responded at least as reasonably to a battery of diverse tests as their econometric alternatives. Their internal structures additionally permitted slmple and direct policy analysis. This latter capability fustifled the selection of the two ORNL models.

3. The Use of a Range of Forecasts constituted a Defintte Improvement over single prafectory Point Forecasts, As long as its methodology is carried out correctly, there is in principle nothing technically inferior about using a single "best guess" for a forecast. Given the changing pattern of load growth in the late 1970 s and the fallure of earlier point forecasts to track actual electricity sales, the establishment of baseline, high, and low forecast scenarlos was a major area of Improvement in the BPA forecast. By using scenarlog rather than statistical "confldence intervals" (not a practical alternative glven the disaggregatre nature of BPA's forecasting system) BPA made posslble more thorough evaluation of sources of forecast error. 
4. Iterating Price and Demand Models Allowed BPA to Couple the Best Features ef ISDM with its Disagaregated Modeling System. Electricity price and demand are intimately linked In the real world and it is essential that this linkage be represented in any reglonal power planning forecast. The Integrated Supply and Demand Models (ISDM) coupled a predecessor of BPA's Supply Pricing Model with an econometric demand component. By developing a pricing model embodying the often complicated rate provisions of the Regional Power Act, and allowing this to run iteratively with its demand models until an equllibrium set of loads and prices were reached, BPA enhanced its forecasting capability.

5. BPA's Technical Documentation Made the Models Used. Their Insuts. Their Results, and the Assumptions Behlnd them Exolicit to a Degree Unorecedented in Reglonal Demand

Forecasting, To be evaluated thoroughly, a forecast and its assumptions must be laid bare in full detall. BRA's three stages of documentation (technical review, draft, and final forecast) described in detall all the models under consideration as well as those actually used for the forecast. Inputs to models were 1 isted exhaustively and output results of both "official" forecasts and major sensitivity tests were presented in detall. Of at least equal importance, efforts were made to render explicit the assumptions made about electricity prices, levels of economic activity, 
conservation, and resource avallablilty underlying the three forecast scenarlos. This allowed evaluation of forecast error and the ldentification of possibly overlooked issues by BPA's primary technical audience.

There are, however, basic "core assumptions" implicit In such a forecast which go unacknowledged, not because of any attempt to deliberately conceal them, but rather because they are taken for granted by the forecast authors. (This is usually an artifact of the disciplinary backgrounds and methodologlcal leanings of the technical staff.) By way of example, the perpetuation of the Reglonal Act in its original form and BPA's roles and responsibilities were assumed unchanging. The Direct service Industries, major consumers of electrlcity energy, were also assumed to be content to remain in region as rates rise despite attractive opportunities elsewhere. Then such assumptions remain tacit they limit the number and kinds of technlcal questions asked and, by extension, the alternative courses of action considered. (The Importance of core assumptions will be discussed at greater length later in this chapter.)

\section{BPA's Treatment of conseryation in the Forecast was} Acceptable as a starting point for Policy Analysis but only as a starting Point, During the technical review of the models under conslderation for use in 1 ts forecast, BPA explored a variety of conservation scenarios designed to llistrate their capabilities. For the draft and final 
forecasts, however, conservation was treated in a fashion which the staff acknowledged to be only a starting point. The demand models were run so as to simulate only those programs already in place or those over which BPA had control. This treatment, though technically acceptable, left unexplored not only the amount of savings attainable from additional programs (e.g. Regional Council) but also the varlous factors affected by and affecting such programs.

7. The DRI National Economic Model Though in a Eundamental sense, serving as the starting point for the Eorecast, Remained Largely a Black Box to its Users. DRI (along with Chase Econometrics and Wharton) is generally accepted as a primary source for projections of national and reglonal economic and demographic behavior. Its national economic model is mammoth in both size and complexity. Because of this, most subscribers to its services do not actually operate the model but use packaged routines to access and massage its profections in light of data from reglonal sources, generally based the development of model inputs on DRI's numbers. Though the stafe understood the operation of the national model in general terms, it remained largely a black box both to them and their technical audience, opaque in terms of both operations and assumptions. Though strongly counter intuitive results of the national model would undoubtedly be recognized by users, other types of miscalculation would not. Forecast inputs 
would, In such a case, be vulnerable to any problems inherent in the national model.

8. Though very Detalled. BPA's Forecasting System reft the Effects of a Number of Potentialiy slanificant Feedbacks Unexplored. While the iterative feedbacks between electric1ty sales and prices constituted one of the basic strengths of BPA's forecasting system, its data and information flows were more generally unldirectional. Economic and demographIc Inputs were derlved in a serles orlginating with DRI's national projections and inputs to the demand models. While, in reality, changing electricity prices may directly or indirectly influence employment, migration, and linked economic factors, BPA's modeling system did not represent such interdependencies. Without additional research, it is difflcult to assess whether or not these omlssions are significant (or whether or not they are significant when changes in prices exceed critical thresholds).

9. Theuah BRA's Forecast Range was Developed Using Well-Defined and Explicit Methodologles the Probability Assianment Associated with that Range was not. The assignment of probabilitles to BPA's range of forecasts was performed by Power Requirements staff at the request of upper management following their advanced review of the draft. While the methodology underlying the development of the range had been well thought out, with consideration 
given to different levels of economic activity, resource availablity, and conservation, the probablitty assignments were made judgmentally ex post with no explicit methodology. In effect, these numbers convey a sort of "gut level" reflection of the staff's confidence in their work, not a systematic evaluation of the conditions embodied in the three scenarios compared to some set of historical behaviors.

Though such "seat of the pants" assessments are not technically sophisticated, they are perfectly acceptable provided that their authors acknowledge their fudgmental underpinnings (which BPA did). As a summary reflection of forecast confidence, however, they are somewhat inconsistent with the high degree of disaggregation in the modeling system. Attempts to improve upon such an approach by adding more formal methodological structure generally fall along one or more of these Ilnes. First is decomposition -- the factors taken (or not taken) into consideration are lald out explicitly and component probabilities assigned. This yields the advantage of allowing users and critics to assess staff Judgment and substitute their own, if felt necessary. The disadvantage is that some method of aggregation must be used. This usually leads to a second Ilne of "Improvement", the development of a statistical method for combining probabilties. Such methods confer the advantage of explicitness, but reflect the infamous computer science acronym GIGO 
(Garbage In, Garbage out). The ultimate probabllity assignment, though arrived at through the use of algorlthms, is only as strong or as weak as the underlyling fudgments. statistical techniques designed for hard, Interval-scale data cannot compensate In any way for weaknesses in fudgment or Inaccuracies in perception. The final strategy for improvement attempts to develop hard numbers from historical data. Such data is frequently unavallable. Then it can be obtalned, the resulting probability distributions may or may not capture all the Important outcomes that will be experlenced in the future. If the future differs qualitatively from the historical perlod over which data was collected, the resulting alstribution will not be applicable. The development of any of these alternatives, however, was not something that could be carrled out in the time BPA had avallable.

10. Despite the Fact that BPA Produced a "state-ef-the-Art" Eerecast, its staff was forced to rork with (and somet imes around) Mafor Data Yeaknesses in Some Sectors, Until the mid-1970s, energy forecasting, particularly in the Pacific Northwest, was largely non-problematic: both energy avallablilty and price appeared stable, as did demand growth. Because of this, little data about patterns of energy consumption and their relation to bullding, dwelling, or factory production characteristics was collected. This situation left forecasters and analysts of the 1980 s unable 
to obtain key pieces of information about the foci of their concern.

BPA expended a great deal of resources obtaining the best available data, but in some cases what was available contalned consplcuous weaknesses. Particularly in the fast-growlng, but internally diverse, commercial sector descriptive data was particularly weak. As a result, portions of the forecast were ultimately dependent on data developed by simulation or fudgment (somewhat negating the supposed strengths of the disaggregated end-use models). This potentially lessened the rellability of those portions while at the same time making them difficult to refute or contradict.

\section{BPA's Forecast was Extremely conservative in its}

Treatment of Technologlcal change, Relative to earlier reglonal power forecasts, BPA's treated the effects of technological change with both greater detall and explicitness. The commercial and residentlal sector demand models developed their projections of energy use by means of technology curves measuring efflciency improvements against anticlpated equipment operating costs. The industrial model used productivity as an input, and embedded within the values of that input were assumed improvements in technology. Technological innovations, however, were not forecasted either inside or outside the modeling system. Technological change, where modeled, was essentially 
represented as the improvement of existing technologles, rather than the development of new ones. Consequently, the resulting forecast does not allow the evaluation of the full range of Impacts of energy technology on economics and power consumption.

\section{The structure of the Demand Models somewhat Predispesed} them Towards Lower Results than their Econometric counterparts. Each generation of demand forecasting models seems to focus heavily upon the weaknesses of 1 ts predecessors. The two ORNL models placed greatest emphasis upon the simulation and representation of conservation policy. Though the answers the models produced were reasonable, their structures encouraged analysis which posed policy questions specifically about savings (as opposed to marketIng opportunities, technological innovation effects, etc.). As a result, heavier emphasis was placed upon the correct representation of demand-reducing conservation programs.

\section{The Flnal Forecast was Produced with a Number of}

Unresolyed Modeling Problems, At best, simulations represent reality imperfectly, necessarily omitting details or elements which are of potential relevance. At worst, they severely distort the reality they strive to represent. BPA staff worked with a complex set of models which provided a representation of regional economic activity and power consumption behavior which was extremely detalled (though 
such a level of detail is not necessarily the most approprlate for decision making). While the overall responsiveness of the models tested credibly, a number of problems were detected during the public involvement period which, for varlous reasons, went unresolved (e.g. NEPP elasticities, and lag coefflcients, ORNL Commercial Model price responsiveness etc.). Under certain, possibly extreme conditions, such problems could prove slgniflcant.

\section{Though Proceeding from Different Methodological Bases} and yelding Contrasting Results, Both Forecasts Were Produced Using Leqitimate Alternative Approaches, NERA chose to critique BPA's forecast point-by-point from the perspective of a "devil's advocate" contending that BPA's forecast was too low. Challenging input values and proposing alternative methods for critical calculations, NERA In effect produced a higher "forecast-by-adjustment". By contrast, EVA, maintained that the Northwest was entering new territory where old guideposts would be ineffective. Using forecast-by-analogy as a method, EVA projected BPA's future based upon the experience of the Tennessee valley Authority. This ylelded noticeably lower results (1.e. BPA's forecast too high). Both of these studies yielded some insights regarding uncertainties of load futures. Taken together, however, they only scratch the surface of the full spectrum of possibilities which confront the Northwest power community. A comprehensive technical review 
of the BPA forecast would requlre much more than the production of a palr of counterforecasts (as is discussed later in this chapter).

conclusions from the 0-perspective

1. Theugh Sops are Generally the Proper starting Point for Understanding orqanizational Behavtore the Actlons of BPA's Eorecasting Group can only be understoed by Understanding ad hec procedures, standard operating procedures are the habitual ways organizations go about doing things and, as such, they go a long way towards explaining why a group took the action they did. Organizations, however, do change, usually slowly, but under some conditlons change is, for a brief perlod, rapid. The standard operating procedures for preparing forecasts and planning for loads which had been used in the 1970 s proved inadequate. It was largely in response to this fallure that the Reglonal Bower Act was passed and that BPA expanded its resource and conservation planning capablilties. The 1982 forecast was produced by newly formed groups in Power Requirements, Rates, and Conservation. Because both the organlzations and the tasks they performed were new, in effect evolving along with the forecast process, sOPs were not particularly useful as explanatory devices. It was necessary to look more at the speciflcs of the evolving ad hoc procedures which, if successful, would become the sops of the groups involved. 


\section{At the Time of the 1982 Forecast, a Mixture of}

Corporate cultures May be Seen operating within BPA. Deal and Kennedy developed the notion of corporate cultures -groups of individuals comprising an organization and sharing common values and worldviews -- to distingulsh successful from unsuccessful companies. In large organizations, particularly ones undergoing major structural changes like BPA, it is possible and useful to identify different types of corporate cultures at different organizational levels. Thus, while the core of BPA could still be best viewed as a highly structured bureaucracy confronting slow feedbacks about its performance, the newly formed groups within it which were charged with developing the forecast functioned In many ways more like the cultures of "think tanks". Within these groups innovation was high, procedures evolved through a lot of trial-and-error, feedback through public involvement channels was qulck, and within-group communication was highly lateralized. This concept of multiple corporate cultures helghtens understanding of organizational drivers as well as misfits.

3. The Ascendancy of Forecasting and Resource Analysis in Terms of Relative Importance is Reflected in the Structural Changes Recorded in BRA's organizational chart. While it is true that Important actions do not necessarily follow formal ilnes of organizational influence, major shifts in orlentation usually result in structural changes as well. A 
revlew of BPA's organizational charts indicates a late 1970s-early 1980 s shlft in emphasis from englneering to resource planning and management.

4. The Early 1980 s Reorganization at BPA can Best be Viewed as an organizational problem-Solving Response to the Regional Act and to the Growling HPPSS Problem. As the $1970 \mathrm{~s}$ moved to their conclusion, the problem of financing the uncompleted WPPSS nuclear plants became one which BPA realized 1t would have to confront 1tself. At the same time, the outlines of the Regional Power Act, which entalled new responsiblilties for BPA, was taking shape. The reorganization of the Agency with emphasis on conservation, forecasting, ratemaking, resource planning, and financlal management prepared BPA to meet Just those challenges.

5. Functionally, the Production of BRA's Forecast crosscut Formal oraanizatienal Lines of command, Although the newly revamped organlzational structure mirrored the revised priorities of the agency, responsibility for the production of the long-term forecast was distrlbuted over several Divisions and even offices. Understanding how the coordination of the project took place thus required looking beyond, or between, the formal 11 nes of command to the subgroups actually tasked with producing the forecast and studying their procedures of operation. 
6. The Public Involvement Process was the one Most Heavily Used Channel for outside Parties to Influence the Forecast. Because Bonneville is a Federal agency answerable to the public, a number of channels (e.g. hearings, court cases, information requests, professional meetings) are available to interested parties to obtain information or action. Public involvement through meetings and correspondence is a common feature of the agency's dealings but rarely is it used as extensively as it was during the preparation of the 1982 forecast, although the agenda behind this process was admittedly limited in its scope, (as noted in the previous chapter and discussed at greater length below). In large measure this was because BPA staff recognized both the Importance and the sensitive nature of the forecast land its uses) and structured the public involvement process more than is customarily the case. Thus, almost all the "challenges" which came to BPA did so via this channel.

7. The Two Primary Groups of stakeholders particloating in the public Involvement process were those with Financlal Interests in the WPPSS Plants and those Advocating the Primacy of Conservation as a Future Resource, During the public involvement process, both at the workshops and through correspondence, a number of diverse parties revealed themselves through thelr particlpation. These included academics, utility representatives, consultants, ratepayers, environmentalists, and public officials. Two groups of 
stakeholders were represented most heavlly in the process. First were those PNUCC member utilities with investments in the wPPSs plants which would be strongly affected, in terms of both finances and thelr own resource planning by BPA's decision to complete, delay, or terminate any of the plants. Second were the advocates of conservation and environmental protection (NRDC, Survival Center) who wished to ensure that BPA took full account of conservation alternatives in their forecasts.

\section{Despite Different and Even opoosing Interests,} Virtually all parties commenting on BRA's Forecast would be Hurt by the iffects of a Grossly Inaccurate Forecast, A constraining factor on comments was the effect which would have resulted from BPA taking action on a remark. If BPA serlously overbulit resources in response to comments recelved by, say, shareholders in the wPPSs plants, they, as well as BPA, would have to bear the consequences. If the need for conservation was overestimated, the reglon would find itself obtaining savings during a surplus period, and would likely be reticent to acquire further additional conservation even were 1 t needed. Thus, subtle pressure existed for interest groups to look hard at what they were proposing and keep suggestions "reasonable". 
9. The Process surrounding the Develooment of BPA's 1982 Eorecast Slgnalled an Emeraing Reallanment in the Regienal Rower Planning community, The Reglonal Power Act had created new roles for BPA, PNUCC, and the other members of the region's power planning community. Though the Regional Councll was not a major player during public involvement, BPA's methods of forecasting and resource planing closely resembled those under development for use in the Council's Plan. In many ways (e.g. conservation alternatives considered, resource costing and ratemaking methodologies, load ranges) the development of the 1982 forecast foreshadowed the role the Council would play in the region while defining the "rules of the game" (i.e. acceptable planning ranges) for other actors as well.

\section{conclusions from the P-Perspectlye}

1. By Establishling Oyerall Agency Rolley. Each of the Three Recent Bonneville Power Administrators Defined how BRA would Percelve and Respond to the Resource Planning Situation in the Reglon. Resource planning first became something of a regional problem at the time of the HydroThermal Power Plan, when it was realized that future loads could not be met simply with hydropower. Under Donald Hodel, the development of thermal power and, secondarily, conservation, were the agency's foremost priorities. Under Sterling Munro, the development of Regional Power Bill 
leglslation was at the forefront. Flnally, under Peter Johnson, flnanclal planning, chlefly targeted at enabling the agency to deal with the wppss problem, became a new agency touchstone. In each case, the approach and orlentation of the Administrator was reflected in both the structural and characteristics of the organization.

\section{As the P-Perspective Would Predict Each Administra-} tor's View of BRA's Resource Planning Problem was stronaly Influenced by his Backaround. While it is clearly the case that the complexion of the Northwest's resource planning problems, and the region's dominant perception of them, have undergone charge since the early 1970's, it is also true that each of the last three Bonneville Administrators have approached the problems facing them in manners consistent with their backgrounds. During Donald Hodel's term of office, the region appeared in imminent danger of severe power shortfalls. Hodel, whose background entailed a law degree as well as an Assistant Administrator's position with BPA, adopted an approach very similar to traditional BPA operating procedures. He treated resource development as an englneering problem (1.e. bullaing sufficlent capacity to meet anticlpated loads) whlch would be directed according to the administrative provisions of the Hydro-Thermal Power Plan. When sterling Munro assumed leadershlp, he brought his political expertise to bear upon increasing reglonal disagreements on rate, resource and environmental issues. 
The development of Regional Power Act legislation was a key means of addressing this issue. Finally, Peter Johnson approached the festering WPPSS problem as a business problem, bringing his extensive experience in the area to bear.

3. To the Extent that Peter Johnson Defined how BRA's Forecasting Apoaratus Vould be Used in a Financlal Management situation he Helped Give it shape, The selection of models and development of needed inputs was carried out by BPA staff. A large portion of this work was carried out, or at least initiated, during Munro's term of office. It was not certain, however, at that time exactly how these models would be used. The critical questions Peter Johnson asked about the WPPSS situation, and the way he asked them, required BPA to perform analyses different from what had previously been attempted. Thls Involved the development of a financlal analysis capability and its subsequent integration with load forecasting results. The nature of this integration in turn contrlbuted to the shape the load scenarlos assumed. It was through this serles of linkages that Johnson as Administrator could be said to shape the development of the forecast.

4. Johnson's Successful Fxpertence at Trus Jolst which Strongly paralleled the situation he confronted with wPPSS. Undeubtedly Facilitated his Difficult Decision to Delay WNP 1 and 3. That the supply system was beset with severe 
flnanclal difficulties was a polnt obvlous to all in the region at the time Peter Johnson assumed offlce. For many, it seemed equally clear that BPA would be compelled to take a more directive role in dealing with the uncompleted nuclear plants. The flnanclal and load uncertainties surrounding possible resource scheduling decislons were great, and hesitancy or "paralysis by analysis" could easily have been an outcome. Peter Johnson, however, had faced a similar problem earlier in the private sector and his company, Trus Jolst, had proflted handsomely from hls difficult but in retrospect correct, decision to close several of the company's plants. This successful experience undoubtedly helped give Johnson the confidence to delay wNP 1 and 3 In the face of sometimes severe critlcism.

\section{Key Members of Power Requlrements staff were Pre-} disposed to search for new Technical Aporoaches as a Result of the Cognitive Dissonance they Fxper lenced Trying to Resolve Results of the soy study whth the sou Eorecast, The perception of imminent power deflcits remalned dominant in the power planning community in general, and BPA in particular, into the early $1980 \mathrm{~s}$. Had there not also been a "minority view" present in the late 1970s, it is doubtful that BPA could have readled itself for 1 ts 1982 forecast in time. The search for alternative forecasting approaches came as the result of a falled attempt by three key Power Requirements staff members to reconclle the result of 
Skidmore, Owings, and Merrill's study of reglonal conservation potential with the sum-of-utilities forecast. The disaggregated projections which they made of regional power consumption fell far below those ldentified in the sou forecast. Th1s, in turn, led them to distrust the corroborative results of the PNUCC econometric model and prompted the search for an alternative modeling methodology.

6. Rersonal Background Factors of Key Power Requirements Staff Const ituted a second Element Predisposing Them to rook for Part lcular Klnds of New solutions to Percelved Forecasting problems, In addition to developing a unique Insight into problems with then-current forecasting procedures as a result of the SOM study, the members of Power Requirements staff who would spearhead the development of the system of models used in the 1982 forecast also bore some distinguishing characteristics related to their backgrounds. Those who would ultimately guide the development of the 1982 forecast either were then new to the group, and not subscribing to the "official" view of the future, experienced with the representational issues associated with computer models (as distinct from simple extrapolation) or both. These factors influenced thelr search for the tools BPA would later use. 
7. The organlational cllmate under the Munro AdminlstraLen Provided the Necessary Context for the search for New Eorecasting Tools to occur. Irrespective of staff perceptions or desires, an organization will not allow the expenditure of resources on projects which are not viewed as important. Under sterling Munro, BPA was preparing itself to address the lssues central to the Regional Power Bill, then being written. It was within this context that the need for a greater forecasting capability first gained recognition. Without this recognition, Power Requirements would not have been able to begin the model and data development which they deemed necessary.

conclusions from $T$-and 0 -Perspect ive cross-cues

Before ldentifying those conclusions resulting from the cross-culng of two (or more) perspectlves, several remarks are first in order. A conclusion can be sald to result from the cross-cuing of perspectives when the use of Investigatory criterla from more than one of the approaches or paradigms are required for it to be inferred. Thus, if one observes that a party in public involvement submits technical comments, this is simply use of the 0-perspective. The technical comments are an organizational output, 11 kely the result of ldentifiable standard operating procedures. By contrast, if one were to examine the speciflc technical contents of the comments and indicate how and why the particular sops of the involved organization shaped the 
comments as they did, then $T$ - and o-perspectives would be cross-cued.

A point made earlier should be here relterated. It is not uncommon for more traditional analyses made predominantly according to the investigatory paradigm of a single perspective to occasionally venture outside that paradigms boundarles. Analysis of technical material will often identify non-technical influences on the product. This "cross-cuing", however, is at best informal. Without the explicit use of the paradigms encompassed by Multiple Perspectives, such efforts are neither systematic nor thorough. Deeper insights are thus lost.

The most fruitful area of "paradigmatic interaction" in this case study was where the $T$ - and 0 -perspectives crosscued each other, as can be seen from the sheer number of conclusions presented below. Where a conclusion derived from the use of more than one perspective specifically deepens the insights provided by one of the conclusions listed above derived using one of the perspectives in isolation, this is noted. This more clearly and directly shows the strength of using multiple perspectives of Investigation. 
1. The Relat lye pred latlye success of the sum-of-ut 111 thes Eorecast in the 1970's crystallzed the Perception of High Growth Load Futures in the Minds of Power Planners, conversely, this widespread consensus Picture of Ioad Growth and General Falth in the sou in Turn Discouraged the search for New Forecasting Approaches with Greater Explanatory Power. For a surprisingly large number of years, the sou forecast provided a reliable guide for planning despite its simplistic underlying methodology. Given background conditions of sustained economlc growth and opportunities for expansion of the Columbia river hydrosystem, profections of future growth based upon historlcal rates appeared quite reasonable. These technical projections formed the informational basis for the establishment of the Hydro-Thermal Power Plan and the construction of the wPPSS plants. Once the high growth perception was entrenched, an organizational apparatus grew up which was geared to resource development In a time of impending deficit. Within such an organization, prlority was placed upon tasks other than developing new approaches to a forecasting problem belleved to be already solved. Response to changing regional clrcumstances, as a result, was consplcuously slow.

2. The Arab o11 Embargo of 1973, Perhaps the singlemost Imoortant Eyent in Recent Energy History, was the UIt imate Cause of a Number of Model and Forecast Development Efforts. both Nationally and Regionally, While regionally, the 
stability of the electric power Industry had been taken for granted prior to the mid-1970s, worldwide the stablilty of the petroleum market similarly seemed a foregone conclusion. The sudden and sharp increase in 011 and gas prices followIng the Arab 011 Embargo of 1973 brought the dependency of the American way of life on Inexpensive energy sources suddenly into the foreground. For the first time since perhaps the second World War, the ldea of different energy futures, some of which might well entail the curtallment of consumption, was taken serlously. Both nationally and regionally, new energy policies were debated and, both nationaliy and reglonally, new models and methodological approaches were sought. The development of end-use models at Oak Ridge National Laboratory was part of the Carter Administration's reorientation to the changed world energy outlook. The NEPE and SOM studies were among early regional technical responses. Ultimately, though largely indirectly. the Embargo then had an impact on BPA's first independent forecast through the models used in its production.

\section{The Need to Leaitimize the Findinas of its First}

Eorecast promoted BRA to an unorecedented Level of rechntal Response to its critics, Characteristically, an organization's initial efforts at preparing a product are critical. Crediblilty must be established with those affected by the organization's efforts. Given the short- and long-range impacts of new WPPSS plant scheduling decisions, it was 
Imperative that Bonneville's forecasts be accepted as a guideline for resource planning. As a result, organizational factors demanded an extremely thorough technical review of the forecast. The technical workshops, the detailed model and input documentations, and the written replies to comments (which served as Justiflcation for what had and had not been done) all were Intended to make BPA's subsequent decistons as credible and defensible as possible given the methodologlcal framework chosen. Thus, organizational needs dictated the level of technical expertise expended in producing the forecast, while this expertise, in turn, strengthened the organization's position on resource development.

\section{The Percelved Theoretical sophlatication of BPA's} Modeling Aporoach Served to confer an Air of Leqitimacy to the Acency's Decislons (expands on T-perspective cenclusion 11. The perceived sophistication of models used to produce a forecast has organlzational as well as technical consequences. Often, the fact that a set of numbers is produced by a formidable looking computer model will, in and of ltself, make a technical product appear of higher quality or greater defensibility whether this is truly the case or not. Big models are more Impressive than small ones, and provided that no errors are detected in their operation, their outputs insplre greater confldence. Though some reservations were expressed about the complexity of BPA's 
modeling system, the fact that it was run without any apparent serlous problems likely enhanced the acceptance of the forecast.

5. The Mator Modeling Alternatives Available to BPA were Strongly Constrained by What was Available "OEf-the-Shelf" Lexpands on $T$-perspective conclusion (2), An organizational constraint placed upon BPA as an agency is that it is not permitted to do basic research in-house. Though models may be respecifled, tallored to specific needs, or integrated with other tools by staff, basic developmental work is prohibited. New models (and new modeling approaches) must be developed under contract or obtained "off-the-shelf" (i.e. ready-made models are purchased or obtained). Given that Eull organizational support for Power Requirements' forecasting system development came only after the passage of the Reglonal Act and given the types of models preferred by the utility industry, staff was limited to existing regional models and the ORNL models. Though the models were "state-of-the-art", they were still limited in terms of the varlety of approaches to forecasting they embodied. (The consequences of this conclusion and its immediate predecessor are spelled out in the section combining insights from all three perspectives.) 
6. The structure of the Forecast Models to the Extent That they Determined the Types of Questions Which could be Asked. Exerted a strong Influence on Forecast outcomes and Uses (expands on $T$-perspective conclus ions 2 and 121 . All approaches to modeling invarlably simplify the reality they represent. These simpliflcations are necessary, but tend to follow directions defined by user needs and data IImitations. Models are geared to ask certain questions, but not others. Those chosen by BPA put a premium upon looking at conservation pollcles (or at least those elements which could be most directly affected by such policies). They did not, and could not, look at other potentlally signiflcant factors such as marketing opportunities, technological innovations, or the effects of cyclical business activities. Thus, though the structures of the models ald not predetermine the results, they limited possible outcomes and, in doing so indirectly affected organizational decisions.

7. The Development of a Forecast Us Ing a Range Approach Set I lmits on its organizational Applicability lexpands on T-perspective conclusion (3), Just as the selection of models sets constraints on a forecast in terms of the type of questions which can be asked, the general methodological approach underlying a forecast defines how it can be used organlzationally. The range approach used by BPA represented an advance over prevlous approaches which focused 
upon a single scenario for the future. At the same time, by limiting its analyses to three "likely" scenarios of regional load futures, BPA limlted its organlzational preparedness to a wide array of possible events which might prove signiflcant (more on this issue later).

8. The Issues Raised as a Regult of BRA's Changed Role Under the Reglonal Act Virtually Necess itated Both the Acouisition of Fnd-Use Models and the Integration of a Prlce component into the Forecasting system (expands on T-perspect 1 ve conclusions $/ 2$ and $4 /$, The modeling system used by BPA for 1ts 1982 forecast was built from the bottom-up -- that is, the individual components were first developed independent of one another and afterwards integrated. This approach was virtually mandated by the Reglonal Act with its ratemaking provisions and emphasis on conservation. First emphasis was upon demand models which could represent conservation, then upon integrating them with an electricity pricing model.

9. Host of the Explicitly stated Assumptions Underlying the Forecast Can Be Seen as the Technical Representation of Eonseguences of the Reglonal Act lexpands on T-perspectlye cenclusion 51. In addition to which models were selected, BPA's responsibilities under the Reglonal Act largely determined how the models were ran. Assumptions about resource scheduling, rate levels, and conservation programs 
all reflected BPA's interpretation of their responsibilities under the Act.

10. The Scope of Exoloration and Model Development at BPA was Most Directly Limited by Practical Time and Resource Constraints (expands on T-perspective conclusions 11 , 18 , 111 and 113), when looking for the myrlad subtle ways in which an organization shapes or constrains its technical products, it is easy to overlook perhaps the most obvious. Organizations only have a limited amount of resources (time, money, and people) which they can expend in dealing with an issue or solving a problem. Though Power Requirements and other Divisions associated with the forecast's development were beneflciarles of a perlod of growth in the early 1980s, their time was fully committed under the preestablished forecast schedule. Resource limitations generally determined the avenues which could net be explored (e.g. critically examining the DRI model operation, testing the slgnificance of missing feedbacks in the modeling system, Investigating possible technological innovations, correcting weaknesses in the ORNL technology curves and the NEPP lag structure and, more Importantly, opening up first-order strateglc methodologlcal questions to wider scrutinyl. All in all, these resource limitations were significant. 
11. Given BRA's orqanizational structure, it is Likely That a Number of Different Interpretations were Given to the Eorecast Probability Assianments lexpands on $T$ perspective conclusion \#9). Power Requirements staff added probabilities to their range forecast after its completion, acknowledging the judgmental and subjective nature of the numerical assignments in their documentation. Even under such conditions, numbers often confer a false sense of certainty to users divorced from the technical process who assume more "objective" underpinnings to the probabilities. This usualiy leads them to perform further mathematical analys is (e.g. expected value calculations, averaging, factoring) which are unwarranted. Given some of the remarks made during public involvement, and some of the uses to which the forecast was put, it seems likely that a variety of interpretations were placed upon the highly subjective forecast probabilities.

\section{The Preponderant Disciplinary orientation of Power}

Requirements, Rooted Heavily in Economics, Iimited its Range of Approaches to Issues such as Technological Change (expands on $T$-perspective conclusion.11), BPA's approach to modeling addressed a wide variety of issues and load determining factors which had previously been ignored. The preponderance of staff members in Power Requirements had graduate level degrees in economics and were well schooled in the issues that discipline identified and the methods for 
addressing them. (More generally, In the utility indastry economists, englneers, and mathematicians dominate technlcal staffs and tend to select modeling approaches with which they are most famillar.) At the same time, this training generally clrcumvented (or superficlally dealt with) other lssue areas which, though potentially signiflcant, lay at the perlphery of the science. As a result, issues such as cycles of technological change were not addressed explicitly, the apparent assumption belng that whatever Impacts were not captured in demand elasticities or productivity functlons were not capable (or worthy) of being addressed.

\section{The Unresolved Problems at the End of the First} Eorecast set Directlons for organlzational as well as Technical Development in Power Requirements (expands on T-perspective conclusion 131, Resource limitations prevented Power Reguirements staff from making all the improvements to their modeling system that were desirable within the time horizon of the 1982 forecast. A number of data and model development projects were initlated under contract during, or soon after, the first forecast production cycle. New, more hlghly reglonalized versions of the demand models for each of the sectors were developed, the modeling system was fully automated, supplementary load research was initlated, and plans were made for a short-tomidterm forecast capable of dealing with cyclical business and weather effects. The development of the tools, and 
their use in resource planning became the overriding organIzational missions for the Energy Modeling and Analysis Branch of Power Requirements. The formal and informal rules for guiding this development and using the tools became the Branch's SOPs.

14. Erom an organizatlenal standoolnt the contrast Between the Results of the Two Inderendent Forecast Reviews Helped Legitimize BPA's Results (expands on T-perspective conslusion 1412 Potentially, the type of "counter-forecast" developed by both NERA and EVA can hurt an organization like Bonneville since they raise important questions about forecast results and the wisdom of using them. NERA's review was primarily a challenge to BPA on the behalf of stakeholders in Wpess fearling adverse effects if plant completion schedules were unnecessarily delayed. In effect it explored the impact of possibly conservative growth assumptions, by substituting different values for key input varlables. This called BPA's forecast growth rates into question. The EVA revlew, using an analogy between consumer behavior on BPA and TVA service areas, constituted, in effect, a "second opinion". Because the two reviews polnted in opposite directions (almost offsetting one another) they actually somewhat strengthened BPA's position, since its forecast fell roughly in the center of this bandwidth of uncertainty. In terms of addressing the wide spectrum of uncertainty actualIy facing BPA, these two "counter-forecasts" barely scratch- 
ed the surface, though using them for such purposes was never the intention. As will be noted below, attempting such an exploration involves the examination of a large varlety of qualitatively different environmental and decision scenarlos, and benefits from investigating perspectives other than the econometric and trend-based approaches almost exclusively used by consulting firms such as NERA and EVA.

15. The Development of ad hoc procedures by power Reguirements was strongly influenced by the Data Reguirements of the Forecasting Models and the Data Development Methodology lexpands on 0-perspective conclusion 11). virtually all standard operating procedures evolve by a process involving significant experimentation and a substantial amount of trial and error. For Power Requlrements staff, developing an Independent forecast was a first-time event. The specific ad hoc procedures, many of which would later become "Institutionalized", developed by the staff were structured along the lines of forecast data flows and model development priorities.

16. The Growth of organizational Complexity Among Units

Eencerned with Resource Analysis Reinforced (and was

Reinforced by) the Development of Hore Complex and Sophlsticated Tools lexpands on 0-perspective conclusion 13). Before and during the production of the 1982 forecast, a number of organizational units within BPA underwent a 
rapid and steady expansion. In addition to Power Requirements, portions of Rates, Resources, and Conservation contributed to the development of the demand forecast. The portions of these Divisions involved in the forecast productions evolved along with their tools in a mutually reinforcing pattern. New questions prompted the development of new models and the data needed to operate them. As the tools were delivered, their complexity necessitated additional positions designed speciflcally to manage the use and further development of these models. This in turn created further new needs, resulting in additional budgets and more personnel. This process continued until the major problems had been "bounded" by the organizations within BPA responsible for their solution.

\section{The Publle Involyement Process was Responsible for a} Number of Technical Changes, but BPA's Responses to These Challenges were Limited by Resource Avallability with in the organization (expands on o-perspect lve conclusion 16), BPA made a legitimate effort to produce the most technically defensible forecast it could within the 1981-1982 production schedule. This included explaining, justifying, and defending its modeling choices to critics where technical modifications were Inappropriate or impractical. (More important, from the standpoint of Multiple Perspectives, these resource limitations constrained public involvement so that potentially useful insights on risk, uncertainty, and 
the effects of varlous core assumptions were foregone. TIme Iimitations required that BPA staff confine themselves to techniques familiar both to themselves and their counterparts in the power planning community with the strongest voices.) In most cases where a critlcism was acknowledged but not acted upon, it was the unavailablilty of resources, usually time, whlch made the necessary change impractical. In many of these cases, extensive data collection or new basic research would have been required to bring about the desired modification. Thus, as with model development, the ceiling on model modification efforts were as much a function of organizational resources as technical expertise.

\section{In General the Technical comments of stakeholders in} the outcome of those PPA Declslons whlch were Based Upon the Eorecast Reflected their Interests, Though the strength of this Reflection Varled lexpands on o-perspective conclusion 17. Parties having stakes in the outcome of the WNP 1 and 3 decision tended to participate heavily in the public involvement process. Generally they fell into two groups: those with financial interests in the nuclear plants, whishing to see their completion, and those desiring to protect the environment and explore conservation alternatives as completely as possible. A review of their technical comments shows that their remarks tended to reflect their interests, though with varying degrees of strength. PNUCC members comments did not always $1 \mathrm{mply}$ 
technical modifications which would increase the forecast, but never suggested changes which were against their interests. Environmental protection groups more explicitly suggested technical changes which would either lower the forecast or encourage more ambitious reglonal conservation programs than BPA's forecast and resource analysis implied.

\section{Eenclusions from $T$ - and $P$-Perspective cross-Cues}

\section{The Fact that End-Use Models were "Intellectualiy} Rashlonable" at the Time of BPA's First Forecast Made Their Acceptance Easier (expands on $T$-perspective conclusion 2 ) The ORNL End-Use Demand Models ultimately selected for commercial and residential forecasting contained a number of technical features specifically geared to policy analysis. During public involvement, these features were generally cited as the models' technical points of strength. While these capabilities for the basis for their selection, it is also true that the models had a reputation for being "stateof-the-art" in terms of their overall theoretical approach. This fact was known by many upon entering public involvement and those unfamiliar with the models could percelve their "intellectual popularity" in the remarks and behavior of panelists at the workshops. Given this, it seems likely that at least part of the models acceptability stemmed from a "bandwagon effect" rather than detalled technical evaluation. 
2. The coanlt lve Dlssonance soringing from the Attemot to Reconcile soM and sou Reports was the consequence of the Technical Aporoaches Avallable at the Time (expands on P-perspective conclusion 15). The search for new forecasting tools by BPA staff grew out of a falled attempt to bulld up load projections to the levels of the sou forecast using a "paper-and-pencil" disaggregated approach. It was the limited tools avallable at the time, however, which prompted the ad hoc attempt to bulld load projections up from the bottom using avallable data and forecasts of economlc activity. Had other modeling tools been available, this labor-intensive approach might not have been considered and the conclusions drawn radically different.

3. The More "Politically open" climate of the Munro Administration was consistent with the concerns Bulit into the ORNL End-Use Models (expands on P-perspect ive conclusion 17. Sterling Munro assumed the office of Bonnevilie Rower Administrator under the Carter Administration when a national energy policy was the foremost concern of the President. Munro's background was political, and his central focus as Administrator was to reconcile the complex problems of reglonal energy politics, chlefly through the mechanism of the Regional Power Act. The ORNL End-Use Models, also a product of the Carter Administration, were explicitly constructed to address pollcy issue central to the energy politics of the time. Thus, the "political 
openness" under funro not only permltted the search for new forecasting tools to occur but made the capabilities of the ORNL models both acceptable and attractive.

\section{Model structures Helped to Define, More Globally, how} Individuals view the World, Define Problems, and Search for Solutions, A commonly used procedure in creative problem solving is to reframe the problem. viewing old lssues or concerns with a fresh eye, or from a new vantage point, often permits novel solutions. It is when a methodology or approach to a problem is automatically adopted that vision becomes limited. The models used by BPA were very flexible tools, but they set up a way of looking at the world (e.g. energy use in the commercial sector as square footage serviced by equipment of a particular efficiency using a specific fuel at certain level of intensity) which quickly became second nature to its users. In the long $r u n$, this can be seen to $11 \mathrm{mit}$ approaches. The question becomes how to use the avallable models to solve a problem for a reduced definition of the problem) rather than fust how to solve a problem.

cenclusion from 0 - and P-Perspective Cross-cues

1. The selection of Administrators was Based upon views of the Problems Facing the Region Held by the Federal Government (expands on p-perspective conclusion 12), Each Bonneville Power Administrator has assumed office facing a 
slightly (or greatly) different set of problems and bringing a somewhat different set of skills to bear. It is through pollcy setting for the agency that the Administrator exerts a unique influence on the management of power-generating resources in the region. The cholce of Administrator, however, is by political appointment, and most frequently follows a change of partisanship in the presidency. Whatever background skills the new Administrator brings to office, then, are deemed appropriate by the party then prevaling in natlonal government and are seen as consistent with their general (and sometimes specific) policy leanings.

2. By crosscutting Inines of command the Forecast Producthen Process "Selected For" DLfferent Types of Management skilis (expands on 0-perspective conclusion 15), One major school of organizational theory would insist that a large bureaucracy such as BPA must function as a well-structured hierarchy, with tasks and responsibilities falling within the unique domains of particular organizational subunits and authority following formal chains of command. In reality, this plcture of the organization is rarely fully supported by fact, though organlzations do vary greatly in terms of how closely task performance corresponds to organizational structure. BRA was in a transition period during the 1982 forecast production cycle. During such times, the ability to communicate laterally across involved Divisions and to develop a "big picture" of the overall technical priorities 
and requirements becomes of paramount importance. These circumstances thus "selected for" the skills possessed by the chlef developers of the forecasting tools, as prime qualifying factors for management positions.

\section{As with virtually all organizations. BPA's operating} Procedures Helped Shape Perceptions of the staff, Mind sets develop not only in response to the characteristics of the tools used to carry out a project, but also in response to the organizational procedures governing their use. Hence, the "approved way of dolng things" can easily become the only way of doling things consldered when confronting a problem. In the crystallizing operating procedures developed for forecast production can be seen emerging perceptual frames for seeking problem solutions.

\section{Conclustons from $T, O$ and $P$ : The Biq Picture}

The true strength of Multiple Perspectives Iles not in the useful two-dimensional descrlptions which it generates when perspectives are palred but in the union of technical, organizational, and personal perspectives. The "big pleture" encompasseg the three Individual paradigms of investigation and its manifold cross-cues. Because of the complexity of three-way interactions between perspectives, however, it is easier (and clearer) to sketch a coherent picture of the BPA forecasting process than to produce a set of numbered Items, as was done above. While BPA's forecast 
was state-of-the-art in the utility industry, and while it represented a major Improvement over 1 ts predecessors, its overall methodology left its users still vulnerable to the effects of unforeseen or surprise events (such as wPPSS or the oll crisis had surprised planners a decade earlier). The blg picture allows an insightful evaluation of the BPA forecast (through the question of risk and uncertainty), ldentlfles several areas needing development, and leads to some recommendations on how to evolve a forecasting apparatus in an organization environment such as BPA's. Forecasts become meanlngful as a part of a support system for decisions. To function successfully, a forwardlooking decision support system should contain three components. The first is a forecasting component, which permits decision makers (or their staff) to trace out the consequences of different actions or events. The second component is planning, which presents a set (or sets) of actions an organization should take to meet its objectives given certain anticipated conditions. The third component is a monitoring system, providing the feedback necessary for an organization to fudge the effectiveness of its decisions. The integrated use of these three mechanisms provides the means by which organizations address the risk and uncertainty surrounding decision making.

Although in common usage the terms "risk" and "uncertainty" are used interchangably an important, and too often 
overlooked, distinction is made betyeen the terms. in the simplest case, which contrasts with both conditions of risk and uncertainty, the outcome of a decision or the consequence of an event, once it occurs, is both unlque and Inevitable. This is decision making (or planning) under certalnty, and requires the simplest of gulding strategles. Under conditions of Lisk, the unique outcome of a decision or event is not known. The full set of possible outcomes, however, are known (or assumed to be known) along with the odds or probabilities of their occurrence. Games of chance (e.g. dice) exemplify conditions of risk. By contrast, under conditions of uncertainty not only is there no single unique outcome to be expected, but the odds associated with a serles of possible outcomes are not known (i.e. multiple paths, unknown probabliltles). Often under uncertainty an additional, and significant, condition also holds: it is not even possible to specify the full array of possible outcomes (Martino, 1978:340). In such an unenviable environment for planning, the spectre of a "surprlse" or "shock" future always lurks over those asslgned to deal with it.

It is in the addressing of uncertainty that the primary areas of concern 11 luminated by the three perspectives display the largest degree of overlap. From a strictly technical point of view, it is recognized that modeling techniques and strategies must be rigorously fitted to each of the critical almensions of the situation being modeled. 
Unfortunately, unless strictly technical criteria for problem definition are supplemented by broader concerns -e.g. those of the 0 - and P-perspectives -- many of the key dimensions go unrecognized. From an organizational perspective, principal actors do not want surprises which complicate their jobs, hurt their professional reputations, or jeopardize their continued access to people and resources. From a personal perspectlve, key decision makers want to avold the stigma assoclated with making conspicuously bad decisions. Thus, from all three perspectives, the choice of a strategy to address uncertainty is an important one. That such choices frequently prove inadequate is largely because the participants are unable to see the overall problem through the lenses of all of the three perspectives, but, rather, focus upon portions or fragments of the overall situation. From these more fragmented vantage points, the Imperative of addressing the full or requisite varlety of uncertainties seems less critical and a potentially dangerous imbalance of effort results. As such, the imperative Is often counterbalanced or offset by other, ultimately less significant, considerations le.g. Eamiliarity with methodology, expedience, image, etc.).

The use of point forecasts, characterlzed by a single trend or trajectory of change, in planning treats the environment as though it were characterized by certainty. Bssentlally the strategy is "one plan for the only possible 
Euture". Using such a strategy, decision making is rendered simple (often inappropriately so). Point forecast may be used without serlous feopardy when environmental stability is guaranteed over the lifetime of the plan, when the forecast and planning horizons are short, and/or when a large and significant portion of the determinants are under the direct control of planners or decision makers. Correctly used, range forecast are employed in risky (but not uncertain) environments. It is thus assumed that the set of forecasts either exhaustively addresses each possible outcome or future or that the forecast scenarlos bracket the entire range of these possibilities on the high and low ends. Furthermore, it is assumed that the behavior of the environment is sufficiently well known that discrete probabilities of occurrence can be meaningfully assigned to each of the alternatives by means other than subjective fudgment. Such a strategy is approprlate when the stochastic behavior of the environment has been thoroughly charted and/or when planners can exert influence to constrain (though not deterministically control) the full spectrum of elements limiting environmental variation. Under the conditions of uncertainty, the behavior of critical elements in the environment which the planner must confront is incompletely or imperfectly known. It is impossible for forecasters to assign odds or probabilities that reflect anything more than their subjective assessment 
of the degrees of their confldence in their models' performance. When they do, as Ascher and overholt (1983:267) have noted, they tend to overrate confidence levels consistently. Moreover, when the future is truly uncertain, it is also impossible to ascertain whether the complete array of critical factors potentially affecting the accuracy or usefulness of the forecast have been Identifled and addressed. Under these circumstances, however, it is essential that the possibility of surprise outcomes (however seemingly remote) not be ignored in the planning process, nor should core assumptions go unchallenged. Forecasting should, in this context, ideally resemble "gaming", where a wide array of different scenarlos or low probablilty/high impact events and changes in the very assumptions which are too often taken for granted are explored with the intent of giving planners and decision makers a "feel" for the sensitivity of future outcomes both to the assumptions in their models and to factors within and outside of their control. This will sensitize the users to disaster avoldance planning and to effective crisis management. An exploration of key "unlikely events" or "environmental shocks" should supplement any futures "recommended" as reference cases for planning and, correspondingly, should be incorporated into the actual planning process.

The Sum-Of-Utilities forecast worked successfully for so long because of the uncommon degree of reglonal stability 
during the period of hydrosystem development. Though load growth occasionally accelerated or decelerated (resulting in correspondingly uinor under- or overforecasts), the overall trend was sufficiently steady that a forecasting and planning assumption of (for all practical purposes) a certain future proved workable. By the mid-1970s, however, the impacts of the real, but previously ignored uncertainties surrounding electrlcity use (e.g. responsiveness to rate increases, construction delays and cost overruns, mandatory building standards for new commercial construction, etc.) began to be felt with severe consequences. PNUCC's development (via contract) of an econometric model to "cross-check" the sou Eindings was a step in the right direction, but only one step. The limited range of possibilities addressed in the assumptions underlying the model's operation virtually guaranteed that, within only a few years time, actual loads in the region would fall well below the predicted lower ninety percent confidence bound. The model was allowed to run mechanically, driven by economic and demographic varlables without any attempts to anticipate new policy developments in the region -- the future it produced looked no different qualitatively from the past. The single scenarlo developed by PNUCC was characterized by optimistically low electricity prices, and these prices were in large measure, responsible for the 
continued large increases in levels of regional power consumption.

The 1982 BPA forecast represented a substantial advance over the PNUCC forecasts, both in terms of the analytical sophistication (and capabilities) of the speciflc models used and in terms of the wider spectrum of futures considered. The base, high, and low cases represented distinct scenarios predicated upon different sets of economic and policy assumptions. As such, they in no sense represented statistical confidence intervals (such as those developed by the PNUCC Econometric Model) nor did the unfortunately misnamed base case represent a midine within the range (i.e. given the behavior of the economic drivers producing the high and low cases there was no reason that they should be evenly dispersed around the base). Probability assignments for actuals falling outside the range or between the cases were made subjectively, incorporating the multiple but not necessarliy explicit, considerations encompassed by staff judgment.

To reiterate several important points made in Chapter II, core assumptions reflect or embody one's beliefs about the "state of the world" and how it changes over time. Economic, technologlcal, political, soclal, and cultural factors all may effect future load growth, and how these factors are treated has a significant bearing upon the outcome of a forecast. Core assumptions may be built into 
models or govern their use. These assumptions may be selected after careful deliberation, but too often modelers are unaware of much of what they are assuming or Its signiflcance. In constructing its 1982 forecast, BPA provided detail on the assumptions underlying its forecast range which, though uncharacteristically great for regional power forecasting, still left many important assumptions unstated (or unrecognized) and many dimensions of uncertainty, therefore, unexplored. In Chapter II, a number of assumptlons regarding models and inputs were enumerated. Table XVI presents a sampling of core assumptions giving shape to BPA's 1982 forecast.

The environment surrounding energy planning, however, particularly over a twenty-year time horizon, is uncertain (in the technical sense of the term). Over the past two decades possiblilties which had seemed too remote to acknowledge or too "Improbable" to consider became actualities, stunning (and embarassing) the planners who had dismissed them. In the International petroleum markets of the 1960s, oll shocks resulting from Middle Eastern political instability were never dadt with explicitly, much to the later chagrin of the seven sisters and the American populace. More recently, within the Northwest power planning arena of the 1970s, construction delays and cost overruns were not considered in electricity pricing forecasts, since the magnitude and timing of such difficulties 
TABLE XVI

SELECTED CORE ASSUMPTIONS UNDERLYING BPA'S 1982 FORECAST

\section{T-Perspective}

- generating resources (or conservation) will be acquired on schedule and at cost (a particularly herolc assumption given experience with WPPSS!)

- there will be no long-lasting generating resource failures (e.g. no Three Mile Islands)

- Improvements in efficlency of end-use technologies will proceed incrementaliy (no breakthroughs or innovations)

\section{Q-Perspective}

- the world petroleum market will not experlence further "oil shocks"

- though economic activity may decline in the region (or nation) there will be no Depression

- large industries will remain in the region through the end of the forecast perlod (e.g. no wholesale outmigration of aluminum companies)

- no other wholesale suppliers of electricity (e.g. British Columbia Hydro) will compete with BPA for Nor thwest utility customers

- the provisions of the Regional Act will remain in effect in their current form through 2000

\section{R-Perspective}

- the 1988, 1992, and 1996 Presldents-elect will not Eundamentally alter national energy policy

- future BPA Administrators will not alter the basic agenda governing resource acquisitions, ratemaking, or utility sales agreements 
could not be specified. In both cases, the serlousness of the oversights were not anticlpated but recognized only in retrospect.

Based on these considerations, Inherent limitations of the basic forecasting methodology currently common throughout the electric utility industry, and used by both BPA and the Regional Counc1l, become evident. From the experience of the 1970's, the power planning community has learned that the effects of price and policy cannot be ignored and that planning for a single, narrow vision of the future is inadequate. The models chosen, their core assumptions, and the methodology guiding their use reflect a recognition both of uncertainty in the values which economic and price variables may assume and of their ultimate significance. The baseline, high, and low scenarios represent only different levels on a linear scale of economic activity and different levels of conservation program effectiveness. The major events which affected the energy industry in the 1970s as noted above were not smooth, quantitative shifts in levels of basic economic variables. They were sudden, unexpected developments -- outcomes unanticipated and uncertain in the sense defined above -- with strong, abrupt impacts which left both power planners and managers in something of a state of shock.

The use of multiple forecasts in planning, as increasingly recognized by BPA and the electric utility industry, 
Is a necessary condition for long-term success. It is not, however, in and of itself sufficient. In the long run, the only surprise-free future, to paraphrase the late Herman Kahn, wouid be one with no surprises. The accuracy of a forecast tends to be inversely correlated with its time horizon (Ascher and Overholt 1983:105). Thus, as the scope of planning lengthens, the need to explore and prepare for a broader array of distinct environmental and decision scenarios expands. Scenarios should embrace trends, events, forces, or impacts which would prove significant, whether or not they might currently be deemed likely.

Two basic strategies guide the use of diverse forecast scenarlos: optimizing (good risk) and disaster-avoiding (good hedge). Optimizing approaches are most approprlate and most effective in truly risky environments (i.e. those where the array of outcomes is known and assoclated probabilities at least closely estimated, if not known). As noted above, range approaches, when properly used, may prove sufflclent in rlsky environments. Several speclflc crlterla, however, must be met. First, and most important, the environment must be truly risky, not uncertain. Only under those conditions are the probabllity assignments needed to arrive at an "optimal" solution meaningful. second, there must exist some evidence that the boundarles of the range do Indeed encompass all, or most, slgniflcant outcomes. Thls can only be established through tests of, rather than as- 
sumptions of, the comprehensiyeness of the range. Finally. if the range is characterized by smooth boundarles one of two conditions must hold. Either period-to-period trend fluctuations must not be of significance (in terms of glanning responses) or another means must be avallable to deal with thege fluctuations. A smooth progressing serles of events and a wildly oscillating or fluctuating series of events may ultimately arrive at the same destination, but they require much different responses. If such fluctuations are possible, they must not be ignored.

The range approach to power forecasting, in effect, addresses uncertainty as though it were risk. In BPA's 1982 forecast a much wider bandwidth of economic, demographic, and pollcy conslderations was embodied in the three forecasts than was the case with their predecessors in the region, but none of the scenarios explores the impacts of those "extreme" possibilities which produce such serious consequences for those Ignoring them. The three cases filter out disruptive effects of possible political upheavals on the energy market for the world economy as a whole); they smooth the peaks and valleys of business cycle fluctuation over the long run; they assume timely and cost-effective resource completion in the determination of electricity prices; they ignore the possiblilty any technological improvements beyond efficiency increases in existing equipment (1.e. breakthrough technology is dismlssed or 
overlooked); and they do not explore the conseguences of out-migration of major industrles (especially the DSIs). Potentially, "surprises" in any of these uncertainty areas, if they occurred, could force actual power sales outside of the predicted range, or at least produce consplcuously uneven or discontinuous patterns of sales. In BPA's forecast, however, the factors deemed relevant for explicit consideration are treated as though they described the perimeters of a well-defined and well-known distribution of future load outcomes (or at least the perimeters of those outcomes deemed worth planning for). Probability assignments, though explicitly acknowledged to be subjective and judgmental, are often treated as though they could be meaningfully subjected to the same types of statistical manipulations or transformations as objective odds (e.g. expected value calculations). For all practical purposes, then, these forecast-producing strategles redefine the problems of uncertainty as problems of risk. The disaster-avolding strategy allows planners to "hedge their bets", and is most approprlately used in truly uncertain planning environments (either as a sole or supplementary strategy). This strategy centers on enabling unexpected events to be managed, rather than anticipated. As such, it endeavors to anticipate the effects of highimpact events, whether they are considered to be likely or not, and allow the advance preparation of workable responses 
or preanptive actior. The scenarios developed must be diverse, both quantitatively and qualitatively.

It is unlikely that, had BPA's current Eorecasting system (and the guiding strategy for its use) been in place in the early to mid-1970s, the over-bullding of the wPPS nuclear plants would have been avoided. Because the new demand models are responsive to changes in electricity price, load predictions certainly would have been lower than those of the sou forecasts and, correspondingly, the overbuilding of resources (and its impact on rates) would have been less severe. Given the economic climate of the mid-1970s, however, it is questionable that even low case inputs developed at that time would have predicted the full recessionary impact of the early $1980 \mathrm{~s}$ on the paciflc Northwest (the input projections used in the PNUCC Econometric Model were such that, as noted above, even the lower 90 percent confidence bound to forecasted loads exceeded early 1980 s actuals). Given the general unwillingness of Eorecasters and planners to speculate on the introduction of government standards for new construction, the load-dampenIng impacts of commercial bullding programs designed and Implemented during the Carter Administration would not have been anticlpated. Finally, given the optimistic assumptions on resource costs and completion, electricity price projections would have been unrealistically low. In short, a strategy of forecasting for a risky environment would have 
probably improved the situation in the region somewhat but would not have provided adequate insurance agalnst historlcal uncertainties and their consequences.

By contrast, a hedging strategy, if performed correctly and if coupled with approprlately flexible planning, could have minimized, if not avolded the wPPS problems. As with the oil Embargo, the precise timing and magnitude of thermal plant cost overruns for the wPPS profects could not be predicted, though given the frequency with which large-scale projects significantly overrun their estimated costs, the latter occurrence should not have been considered a now probability" event (see Peck and scherer, 1962: 20-23 for a discussion of predicted cost errors in military projects). Both events would undoubtedly have been percelved as possiblilties but might not have been included in any "best guess" projections. Had disaster avoldance also been part of the forecasting and planning agendas at the time, resource development strategies could have been developed which would accommodate both "surprise" and "business-asusual" futures. Dependence upon forelgn oll could have been lessened by fuller development of domestic resources and by expanding reserves. Greater efforts could have been made in the Northwest to "modularize" generating resources so that smaller "chunks" of load could have been brought on line as needed. Some overbullding would likely have occurred, given 
dominant perceptions at the time, but the effects could have been mitigated more easily.

knowing what needs to be done from a technical standpoint is helpful only when coupled with knowledge of how to do it. Multiple Perspectives offers the means to implementation by 1 lluminating relevant organizational and personal elements. Before examining how BPA's current methodology might be strengthened however, it is first essential to lliustrate the factors which have in effect bounded the search for effective forecasting strategies.

For BPA (and the reglonal power planning community) the development of the forecast methodology used in 1982 represented a step forward in terms of what kinds of uncertaintles could be addressed and required a large recruitment of organizational resources. Given the elaborateness of the models selected for review, the type of public involvement sollclted and the deadline for the WNP scheduling declsion, pursuing alternative methodological strategies became impractical. Much of this workload, however, was an artifact of the size and elaborateness of the models considered. simpler or smaller models would likely have permitted the time to consider and evaluate core assumptions, other perspectives, and surprise events and their Impacts, all essential steps needed to evolve a good disaster-avoidance strategy. The factors which are chiefly responsible for the 
selection of the forecast methodology are numerous and primarily non-technical.

Organizationally, many procedures are set up to use the results of optimizing strategies as inputs. When plans or decislons are based upon the use of expected values, probability distributions, or statistical confidence intervals, there is pressure (subtle and not-so-subtle) for forecasts to be designed accordingly (e.g. range plus probabllities). (This was particularly true at BPA under Johnson, given the data requirements of the financlal analysis process.) Interorganizationally, new but familiar strategies are more readily accepted than new unfamiliar ones. WPPSS stakeholders were represented by technical experts who, like most of BPA's staff, were most comfortable with econometric or engineering approaches to demand modeling, and optimizing methodologies. This appears to be generally true of the electric utility industry. Disciglinary depth is rarely counterbalanced by disciplinary breadth, so commonalities in training tend to focus considerations on a 1 imited number of approaches considered "legitimate" or "practical", those involving complex models. Since BPA was required to obtain such models "off-the-shelf" or through development under contract, basic model designs were prepackaged. Public review, in turn, focused upon a choice among predetermined options rather than either a cholce of options or a cholce of strategy for their use. Attention is thus focused almost 
exclusively upon second-order technical consldexations (details of models) and away from first-order technical considerations (choice of effective strategies for model or forecast use).

Were the utility industry to undertake actions to address uncertainty to the fullest extent possible, its approach to forecasting would need to embody features of the disaster-avoiding strategles described above. such strategies, in many respects, resemble the war games employed by the military to prepare its leaders for the fullest spectrum of possible strategic and tactical combat situations. This approach must be anchored upon a recognition that the future itself is uncertain (i.e. future events are not thoroughly determined by current circumstances and, hence, uncertainty is real, not merely a measure of imperfections or errors in models) and as such not predictable. Rather than only try to optimize decisions by guessing which scenarios are most likely and then planning just for those futures, this approach seeks to explore the widest array of possible situations, recognizing fully that none of them may actually occur as represented. (This requires a freedom from heavy dependence on speciflc models, since models not only determine how the world will be seen, but also limit which parts may be seen). In the process of playing the games, however, the decision makers develop ways of responding to each type of situation or uncertainty ldentifled, increasing 
the likelihood that nothing will occur which could catch them completely unprepared (Enzer, 1984).

For this sort of approach to be successfully implemented, a number of criteria must be met, both general and speciflc in nature. Multiple Perspectives provides crucial insights which facilitate the identification and use of these criteria. Most generally, the three major components of decision support -- forecasting, planning, and monitoring -- must work in coordinated fashion. The forecasting component must consider the factors that would have the most significant, rather than the most likely, effects upon the trend under consideration in order to narrow the organization's "window of vulnerability" as much as possible. Unless the forecasting component explores the consequences of a wide spectrum of alternatives, even creative and aggressive planning will remain somewhat superflclal, blind to its sensitivity to critical external factors. The planning component must be flexible enough to respond to unexpected developments or shifts in trends. These responses should be, to the extent possible, incremental and reversible and should be appropriately timed (e.g. the action plan should not overrespond to brlef or transient alterations of a long-term pattern). Without flexibility on the planning and decision-making end, forecasting an uncertain environment does little more than test the "nerve" of the decision maker who can see all the possibilities for 
disaster or success but do nothing other than choose a single plan of action and hope that none of the feared alternatives occur. Finally, the monitoring (or intelligence gathering) component is needed to ldentify which of the paths developed in the forecast is closest to the one actual events are following and to ascertain whether or not a change of path (requiring a change of plan) is taking place at any moment in the ongoing planning and decisionmaking process. If intelligence is not gathered on both the factors that affect the trends consldered by the forecasts and their outcomes, the ongoing process of making decisions which implement (or, where appropriate, modify) a plan is severely hampered. At worst, planners have no idea what is occurring and can only respond reactively when outcomes are obvious (such as the members of the Northwest power planning community did, only serlously reassessing load growth after it slowed dramatlcally over a four or five year period). At best, planners may know what is happening but, without some depth in the monitoring effort, w1ll not know how or why. With good Intelligence, problems of understanding may still arise but they are minimized to the extent possible. From the T-perspective, the only way to prepare for, and hopefully therefore avert disastrous surprises lor alternatively, capture golden opportunities) is to examine a wider array of alternative scenarlos for the future. The scenarlos, though primarliy almed at disaster avoldance, 
could be built around a Elexible optimizing strategy. In other words, though a central or baseline resource development strategy, which focused upon a "best guess" of the future which will occur, might still be at the core of the approach it would be supplemented by contingency plans, or preconceived responses to shocks or surprises. The forecast scenarios supporting these plans would explore high lmpact effects of different environments, different policies, and different decision making styles. The $0-$, and $P$-perspectives, however, reveal a number of currently existing obstacles to the implementation of this more ambitious technical approach which would need to be overcome.

Regionally the traditional power planning process, involving PNUCC and the sou forecast, malntained Inertia through the late 1970s. BPA's system, based on ranges, constituted a major development in itself and its architects, like most power forecasters (and decisionmakers), were (and continue to be) unfamillar with this proposed approach to dealing with uncertainty, and underestimate the usefulness (and in some cases advantages) of smaller, simpler models. The need to make decisions on resources such as WNP 1, 2, and 3 in a timely fashion often precludes further modification of the forecasting process supporting It (a particularly grave problem when large or elaborate models are used), while the need for a final resolution of the WNP problem, whlch entalls completion of some of the 
plants, a prleri limits the flexibility of resource development, at least until the plants in question are disposed of. Furthermore, Bonneville's forecasting system was put into place during the early years of the Reagan Administration. One of the cornerstones of Reagan's Adminlstration has been to fulfill a 1980 campalgn promise to "remove the fat from the Federal bureaucracy". The ensuing government-wide belt-tightening (at least within the civilian portion) has virtually precluded the acquisition of funds sufficient to scale up the long-term forecasting and planning process to include additional scenarios. The perception, however, is strongly wedded to the resource reguirements of large modeling systems. Multiple, simple models may be used for scenario development at a much lower cost. Finally, the 1982 forecast established a new precedent for resource planning. Organizationally, BPA underwent a major reorientation (reflected both structurally and functionally) in developing the 1982 forecast. Its Administrator also made decisions based on a set of numbers and a methdology. Particularly in its experimental stages, an expanded approach to forecasting and planning, even if ultimately more meaningful and beneficial, would likely add confusion to an already complicated process of public involvement and could possibly call into question decisions to which the region has already committed. While this would be appropriate if a blatant error in BPA's planning process was uncovered, it 
would be unnecessarlly destructive if the source of disagreement was the result of all-too-common numerical errors associated with unfamiliar methods.

As asserted earlier, the application of Multiple Perspectives not only results in a useful multifaceted definition of the problem but also provides the beginnings of a solution. From the T-perspective, the problem is one of the consequences of uncertainty: what the organization isn't prepared to handle can hurt it, possibly severely. Flexible planning must be supported by forecasting which examines both most signiflcant and most likely futures. This entalis exploring the impacts of numerous scenarios, some surprisefree, others containing surprise events. From the 0-perspective, it is imperative that organizational resources be used efficiently and appropriately and that outside resources be tapped effectively. To the extent possible, procedural changes should be kept to a minimum, costs kept down, and existing operations kept on schedule. The organizational expertise of Requirements, Rates, Rescurces, and Conservation groups would be drawn in to address issues most closely related to their respective missions. The role of the public and signiflcant interorganizational actors should be consldered: public Involvement might be full or limited. From the P-perspective, it becomes clear that any proposals for changing forecasting (or planning) procedures must be tallored to the personal styles and priorities of 
BPA's upper management and the prevaling view of priority concerns. While the abovedescribed hedging strategy for forecasting and planning would have provided benefits during the terms of office of the last three Administrators, it would have to have been "sold" differently. During Hodel's Administration the speciflc models used in 1982 had not been developed, but other econometric tools were available which could have been used for scenario analysis. Selling the methodology would have been most difficult at this time, given the apparent stability of load growth. The regional drought and Impacts of the 011 Embargo, however, could have been used as examples of "surprise events" which needed to be planned for. Under Munro, BPA's forecasting system began its "gestation period". A more rudimentary version of the proposed "scenario methodology" might have been promoted based upon its abilities to "pre-test" the implications of different Reglonal B1Il proposals to BPA and reglonal interest groups. Under Johnson, the importance of forecasting was recognized. Because some sort of baseline load projections were needed for resource acquisition decisions, the additional scenarios would probably best be received as supplementary -- extra insurance on the forecast range. Following is a description of how this might be carrled out. The range forecast, as it stands, could remain at the center of BPA's planning strategy as three key reference projections against which to measure resource requirements. 
This would allow the agency to expand its treatment of long-range load uncertainty without having to "reinvent the wheel". Essential to using the range as a point of departure is the recognition of the limitations of the optimizing strategy underlying the overall forecast methodology, the models used, and the assignment of subjective probabilities. The limitations of an optimizing strategy were discussed at length earlier, and will not be repeated. Suffice to say, users as well as producers of forecasts should be aware of them. In similar fashion, both staff and management should be aware of the weaknesses, as well as the strengths of complex models. Though complex models do often provide detailed outputs, or perform a large menu of options, their merits have been oversold in the utillty industry. studies have shown that methodological sophistication and complexity add little to forecast accuracy (Ascher and Overholt, 1983: 105), while often rendering models (and their products) more difficult to use or understand, particularly for executives or managers. In partlcular, the pitfalls of over-dependence upon national econometrlc models should be recognized. Particularly when the full spectrum of scenarious is confined to three or four "best guesses" in an optimizing strategy, accuracy becomes Important. These scenarlos, however, are ultimately driven by vislons of national economic futures which have conspicuously missed significant events, such as the onset of the 1981-82 recession (Greenwald, 1984:42-44). 
This is not to say that complex models should be discarded, only that they should be used carefully and that their sophistication should not be used as an argument for not considering or using other approaches. Finally, any assignment of probabiltles should be broken down into its constituent judgments so that its subjective nature is underscored and rendered explicit for all forecast users. As noted earlier, such subjective numerical assignments represent the modelers' degree of confidence in the performance of their models and the assumptions behind their use. BPA's assignment of probabilities, however, presents only the resultant probability values, leaving opaque what constellation of forecast assumptions and model performance assessments is embedded therein. Decomposing the value would entail listing, in detall, the assumptions defining the range and defining the resultant compound probabilities le.g. "It is assumed that even in the low case no economlc crashes occur, the government does not intervene, plants still come in on schedule and at cost, etc."). This exercise alone forces the forecasting stafe into taking a deeper look at their modeling procedures, alerts management to what the staff has and hasn't considered, and allows consumers of the forecast to substitute their own judgments for those of the BPA staff and reevaluate the end product and the decisions based upon them. Perhaps more importantly, however, the exercise defines a prime starting point for 
exploring potentially disruptive impacts of "unlikely occurrences", by substituting the assumptions opposite those included in the forecast, one by one, into the models and rerunning the forecast (e.g. "what if an economic crash occurs, or the government slaps new restrictions on energy use, or plant costs rise sharply due to construction delays, etc.?")

The construction of scenarios supplementing the range would be targeted at achieving two major purposes. First, the scenarlos, composed of constellations of plausible real world events, would be used to assess the credibility of the range boundaries and associated probablities. If many plauslble scenarlos produced values falling outside the hlgh or low, the probablities should be reconsidered. By contrast, if most scenarios fell within the range, this would constitute a fuller endorsement of its use as a planning tool. Second, the scenarios would begin to fill out a full fledged disaster-avoldance scenario, exploring 11 kely effects of high-impact events (such as oll embargoes, resource cost overruns, or technological breakthroughs) on loads (or elements of the regional economy). Though it is nearly impossible to predict when, and exactly how, such events would occur, it is possible to provide decision makers with a feel for their consequences and allow them to anticipate this response. What is important is that the scenarios portray the impacts of real world events or 
decisions, rather than simply magnitude adjustments of input varlables, on loads so that the forecasts are Ilnked to things which decision makers would find concrete. Moreover, the scenarios should examine numerous technical, organizational, and personal factors which could have slgnificant impacts on electricity futures. (One of the purposes of such an exercise is to determine which factors do or do not result in signiflcant impacts.) For example, technical factors considered might include uncertainties in assessments of oil reserves, breakthroughs in the development of alternative energy sources, or the widespread adoption of ultra-efficient energy using equipment. Organizationally, scenarios could explore the impacts on loads of a new oil crisis through economic boom and bust (1.e. Depression), competition from Canadian suppliers of hydroelectricity, amendment or repeal of the Regional Power Act, the wholesale departure of the aluminum industry from the Northwest, or changes in budget for BPA conservation programs. Finally, impacts springing from differences in personal management styles at both the national and regional levels could be explored. This would not necessarily entail guessing who might be elected President or appointed Administrator, only Identifying contrasting approaches to bureaucratic management and their consequences. The scenarios could be simulated exclusively on the existing modeling system or could 
be supplemented with alternative models (used for methodological comparisons) or "back of the envelope" calculations. The process of generating significant alternative scenarios yields much fruitful results when a varlety of diferent 0 - and P-perspectives can be tapped. Ascher and Overholt (1983) note two research findings that underscore the Importance of Incorporating a broad band of insights into forecasting procedures: first, that complex models perform better when guided by judgment than when left to operate mechanically without intervention (pp. 98-99); and second, that forecast accuracy and usefulness is largely determined by the validity of core assumptions prior to the choice of models or methods (p. 106). The real problem is determining what questions should be asked, rather than merely focusing upon how answers should be sought for questions whlch have already been posed. Ideally, the process of soliciting insights Into the core assumptions underlying the scenarlos-first order methodological considerations -- would extend outside the power plannning community. Business leaders, politiclans, lawyers, reporters, and "lay persons" in general all possess understandings of parts of the world which would benefit the forecast techniclan, but these inslghts are primarliy qualitative and not well suited to usual technical model reviews. Hence, requests for outside comments should seek open-ended responses on the questions of load futures, for not only from expert 
modelers like NERA or EVA, but also from experts on modeling (11ke Asher and overholt) and non-modelers as well. At a bare minimum, initial scenario development efforts should include non-technical types within the organization.

This supplemental exercise of examining the sensitivity of loads to alternative, and in some cases, radically different assumptions would provide BPA some Insurance against such devastating surprises as wPps without necessitating anything more than a minor procedural reorganization. To minimize stress on the organization, the exercise could be carried out at times outslde the forecast production cycle (if necessary), could be performed at varying levels of effort depending upon circumstances, and could be designed to be cumulative -- that is, rather than repeat the same scenarios or assumption sensitivity tests each year new contingencies could be investigated so that the body of simulations expands in number and scope from year to year. What would be critical to this process, irrespective of its deslgn, is that decision makers recognize that the range is a starting rather than a finishing point, for planning, that serious thought be given to contingency plans which would modify Bonneville's operations to respond to the requirements of the various scenarios, and that an intelilgence or monitoring system be devised to provide early alert both to changes in the planning climate and to outcomes of BPA actions. 
A full implementation plan would, of course, require greater detail than the decriptions above, but a more intense problem-focused use of Multiple Perspectives could be applied to assess the specific organizational resources to be tapped and to package communications to appeal to individuals in the upper management circle. Such a specific application, though following loglcally from this research, could be the basis of a dissertation in itself.

Table XVII which follows, summarizes the key conclusions produced using Multiple Perspectives, including both insights derived from the use of a single perspective in isolation and those derived from two or more of the perspectives taken together.

\section{CONCLUSIONS ABOUT MULTIPLE PERSPECTIVES: WHAT THE BPA} FORECAST SAYS

The Multiple Perspective Concept provided a number of Insights about BPA's flrst Independent forecast. The preceeding section detailed conclusions generated using the three perspectives both Individually and cross-cued with one another. The exercise of applying the MP Concept to the rather intricate set of processes which culminated in the production of BPA's 1982 forecast not only ylelded insights about the forecast, but, it also provided a second set of Insights about Multiple Perspectives, and their application to research situations. 
TABLE XVII

A SUMMARY OF KEY CONCLUSIONS FROM MULTIPLE PERSPECTIVES

Technical Perspective

1. BPA's modeling system was more complex than any previously used for regional electricity forecasting.

2. The use of a range of forecasts constluted a definite improvement over single trajectory point forecasts.

3. The DRI national economic model, in many ways the starting point for the forecast, remained largely a black box to its users.

4. Though detailed, BPA's forecasting system left the effects of feedbacks between electricity prices and other economic variables explored.

5. Although the forecast range was developed using a well-defined methodology, the probability assignments assoclated with that range were not.

\section{Organizational Perspective}

1. The actions of BPA's forecasting group can only be understood by observing the development of ad hoc procedures.

2. The ascendancy of forecasting and resource analysis at BPA were mirrored in changes in organizational structures and staffing levels.

3. The early 1980 s reorganlzation at BPA can best be viewed as an organizational problem-solving response to the Regional Act and to the growing WPPSS problem.

4. The two primary groups of stakeholders particlpating in public involvement were those with financial interests in WPPSS and those promoting conservation and environmental protection.

\section{Rersonal perspective}

1. Through thelr policies, each of the three most recent BPA Administrators defined how BPA would perceive and respond to the resource planning situation.

2. Administrator Peter Johnson's background in business influence both how he would approach the wPPSS decision, and how he would employ forecasting toward that end.

3. The leaders of Power Requirements forecasting effort orlginally searched for a new approach as the result of an abortive attempt, years earlier, to disaggregate the sou forecast. 
Combined Rerspectives

1. The organizational needs of Financlal Management, Power Resources, and Conservation groups strongly influenced the selection of models (end-use, with explicit conservation policy testing capabilities) and methodology (range forecast coupled with optimizing strategy).

2. Public involvement was used extensively during the forecast process, but, because it followed the selection of modeling alternatives, could, at best, address only second-order technlcal considerations.

3. A hedging strategy, grounded in a broad variety of load scenarlos, is needed to avold disasters such as WPPSS.

4. Lack of familiarity in the power planning community with hedging strategies and planning under uncertainty and a perceived environmental stability projected by recent forecasts are the strongest obstacles to changing the long-term forecasting process.

5. A good disaster-avoidance strategy can be developed without an increase in forecasting staff and budget, provided less time is spent on maintaining and operating elaborate models, and more spent on assumption clarification, consideration of surprises, and use of the 0 - and $P$-perspectives. 
Listed below are conclusions arrived at through the process of Investigation using Multiple Perspectives. These conclusions focus upon specific methodological strengths and weaknesses assoclated with application of the Multiple Perspective concept. They additionally present some new inslghts and recommendations on 1 ts use which were the result of this inquiry. Hopefully, these insights will facilitate the continuing development of this potent methodological tool.

\section{Qverall Methodological considerations}

In general, conclusions regarding the use of the Multiple Perspective concept fall into two distinct groups. Those lending themselves specifically to the use and application of one of the perspectives, and those more appropriate to the overall investigative strategy. Since the latter, in a certain respect, provide the context for the former they are presented first.

1. Each of the Individual Perspectives Should be Developed as completely as Possible. Though the emphasis of investigation is upon multiple perspectives, $\mathrm{T}-, 0-$, and $\mathrm{P}-\mathrm{per}-$ spectives each by themselves yield much useful information. Researchers employing the Multiple Perspective Concept should endeavor to develop insights from each of the individual perspectives as completely as possible. This not only provides more information, it more cleanly separates 
the viewpoints or paradigms characterizing each of the perspectives and makes the task of cross-cuing more straightforward, if not simpler.

\section{Researchers should strive for Investigatory Balance}

both Whth in and Between Rerspectlves, Even Though Results may prove Uneven. In this dissertation, an attempt was made to devote equal time and effort to exploring each of the perspectives. Moreover, within each perspective, an attempt was made to give significant areas or objects of exploration consistent and comparable treatment (e.g. all the models in BPA's forecasting system were diagrammed and their inputs listed, all of the organizations involved in public involvement were examined along certain key attributes such as mission, history of interaction with BPA, etc.). This seems to warrant general recommendation as a methodology, with checklists, tables, and morphologies the principal tools. It must be recognized, however, that results will very likely tend to be uneven. In this dissertation, the largest volume of relevant information came from the $T$-perspective investigation (due to the complexity of the modeling system). The 0-perspective, by contrast, seemed to yleld the largest yariety of elements (1.e. diverse organizational interests) influencing the forecast process. 
3. Care Should be Taken Not to Overcompensate for Techndcal Training by Undervaluing $T$ - Relative to 0 - and P-Perspectives. If it is true that no one protests a religion more strongly than one who has recently lost the falth, it is also true that few embrace a religion more zealously than new converts. For many trained predominantly in the investigatory paradigm of the $T$-perspective, $O$ and $P$ are an exciting source of enlightenment. It is thus tempting to neglect the T-perspective somewhat in favor of the challenge (and promise) of the organizational and personal perspectives. The T-perspective, however, should not be undervalued or otherwise given short shrift. In this dissertation, the numerous assumptions about the world built into the structures of the complex models used by BPA were among the most significant determinants of the forecast outcomes and constraints on the forecast process. While it 1s Imperative to get beyond the perceptual constraints of the technical perspective, it is equally important to respect this perspectives many strengths.

4. "Audit Trails" and Digraph Representations are Important Elements of "Validation" for Multiole Perspec= tives. Multiple Perspectives involves the use of several distinct paradigms of inquiry to examine a common process or object of study. While statistical validation criteria usually associated with the T-perspective are not appropriate to $O$ and $P$, it is nonetheless important that 
explorations proceeding along these other lines of inquiry be explicitly documented and reproducible (e.g. corporate and judicial decisions axe not validated, but the logic by which they were arrived at may often by reconstructed). Investigative reporters, lawyers, organizational analysts, and cultural anthropologists in the fleld are all required to provide evidence for their conclusions. An "audit trail" of documentation should accompany the results reported for each perspective and description should precede conclusions. At present a need exists for the development of validation procedures for insights derived from the application of multiple as opposed to individual perspectives. The digraph presented in the preceeding chapter constitute a useful procedure, but one whlch needs fuller development.

\section{Participant observation is a Useful Technique in}

organizational situations, but to be Applied Fruitfuliy its Strengths and reaknesses must be Recognized. Experimental research is useful when looking at a few varlables or phenomena in a different approach and multiple methodologies. To get a true plcture, interviews and records should be supplemented by direct involvement with land observation of) the processes under conslderation. As a BPA employee, the author of this dissertation was, de facto, a partlcipant observer in the forecast development process. The advantages of such an involvement are numerous and Include more complete and alrect access to relevant (and in 
some cases obscure) data, a broader Investigatory scope (due to a more realistic initial characterization of the research problem), and a more economical use of research time (since some relevant information will, almost literally, "fall into the Investigator's lap"). Disadvantages, which must be adjusted for, flow from potential conflicts of interests. Job pressures may influence reporting, forcing the "official" organizational interpretation into research findings, or the parochlal perceptions of one's organization (e.g. defensiveness or hostility to the critics of the forecast) and work may further taint what of necessity, is already imperfect objectivity. A useful way out of the latter dilemma is for the investigator to "role-play" with various 0-perspectives, seeing his or her own organization through others' eyes and acknowledging the legitimacy of these perspectives where approprlate.

\section{Speclfic Methodologlcal Conclustons}

Listed below are conclusions derived from this research on the application of a single perspective lor ways of distinguishing one perspective from another). To the extent possible conclusions pertaining to a particular perspective have been grouped together.

1. Then Attempting to Describe Complex Systems or Models from the T-Perspective, it is Useful to Move Back and Forth Between a Broad and a Narrow Focus, Modeling systems such 
as the one used by BPA are characterlzed by a great deal of internal complexity. To render this complexity understandable, it is useful to first assume a broad, comprehensive view of the system as a whole, but with little resolution or detail, and then "zoom in" on speclelc attributes of the component parts. In Chapter II, this procedure was followed and it served as a useful organizing princlple for research (hopefully rendering the resulting product more readable).

2. The Basic Concept of a system Defined as a collection of Elements and the Relations Between. Serves as a Guiding Principle for Completeness of T-Perspective Description. While moving from big picture to small picture provides the context for T-perspective description (and renders it comprehensible), another investigatory principle is needed to ensure descriptive completeness. In this study, the modeling system was treated as a system in the formal, rather than colloquial sense. Th1s meant ldentifylng all of the elements in the system (and in the process, establishing a boundary whlch at the same time determined what would be considered externalities) and mapping the specific Information or data flows (relations) between them. This required filling in gaps in the officlal documentation, but permitted a thorough input-output analysis which, in and of itself, yielded numerous insights. 
3. A Number of Technical Teols (such as Reachabulty Matrices, and Flow Diagrams) are Avallable which can be Generally Aoglied to T-Perspective Analysis, while a vast number of technical and statistical procedures exist which could be applied to technical problems, most are approprlate only to specific classes of problems. A few seem both generally applicable and generally useful. These techniques, such as the reachablilty matrix used in chapter II, provide the means toward the end of laying out an explicit technical system. Even when routinely or reflexively applied, these techniques are revealing (e.g. missing feedback loops, concatenated impacts).

4. An Organization's Own Records are a Useful starting Point for o-Perspective Investigation. As a public agency, BPA is requlred to keep, and make avallable, organizational records. Though many organizations do not face such requirements they generally do maintain a number of records which provide a useful starting polnt (but rarely a finishing polnt) for o-perspective research. Organizational charts, staffing records, and "official" histories, by themselves, can provide slgnificant insight into key organizational events. BPA additlonally keeps transcripts of many public hearings which become indespensable documents in reconstructing organizational history. 
5. When Seeking Exolanatory Factors for Ofganizational Decision-Making (or Decision-Suprorting) Processes, Consider Loci of Organizational Charge, Though organizations normally change slowly (and often only under duress) change usually reflects altered priorities and perceptions. Even when these do not directly influence the phenomena or processes being studied, they usually say something important about the general organizational climate. In this study, the relative growth of certain portions of BPA revealed a great deal about priorities and interorganizational politics (e.g. Conservation's growth from a section to an office).

6. Though an organization's operating Procedures in Many Ways Represent the Basle Unit of 0-Perspectlve Inoulry it 1s Essential to Remember that these Procedures are often In Elux. An organization's habits are embodied in its standard operating procedures. Organizations, however, are usually changing, sometimes (though not routinely) quite rapidly. Under these conditions, only some sops are useful determinants of behavior. One must look at ad hoc procedures being developed (somewhat experimentally) and watch their crystalization Into soPs. In the case of the 1982 forecast, most procedures were new and only in the infant stages of standardization. 
7. In the Interorganizational Arena. Financial Investments are Good Indicators of Interests and offlelal positions. Not everything an organization does is reduclble to profit maximization. This is particularly the case among regulated Industries such as electric utilities. Financlal investments, however, do rank very hlgh among organlzations' concerns and these investments will be protected as fully as possible. As such, they provide a key (though not the only key) for understanding the basis of an organization's behavior. Investments in the wPPSS plants were among the most signiflcant points of contention in BPA forecasting process.

8. A Great Deal Can Be Learned About Organizations by Looking Into Mismatches Between Structure and Function. Formal organlzational charts only reveal the "offlclal" structure of that organization -- the hierarchy of offices and authority. This is rarely sufficlent to describe organIzational behavior or process in any significant detail. Many organizational functions crosscut its structural divisions, as the production of BPA's forecast did, and are the subject of matrix management. These mismatches (not necessarily in the peforative sense) of structure and function constitute yet another key to 0 -perspective investigation. 
9. In Examining organlzations, Look Net only to the Dominant corporate culture but roward Different corporate Subcultures, Deal and Kennedy introduced the notion of corporate cultures to management 1iterature, and it is useful to determine which category of corporate culture an organization falls into. Organizations are not homogeneous in character particularly during perlods of change. Identifying different subcultures allows the investigator a deeper look into corporate dynamics, while at the same time highlighting areas of contrast in both missions and procedures. Thus, though BPA as a whole strongly resembled a traditional, hlerarchical government bureaucracy, units such as power Requirements displayed characteristics more like research "think tanks" with a premium on creative problem-solving, extensive group interaction, and technical generalism las opposed to specialization).

10. Hedla Accounts of Events can Be Good Roints of Departure for 0 - and $P$-Perspective Research. In many cases, clear starting points (or "leads") for 0 - and P-perspective research are difficult to locate. Issues of major significance to the public tend to make the attention of the mass media, and reviewing library archives of newspapers and periodicals can raise issues worth pursuing (in fact, many organizations such as BPA make use of clipping services which collect and consolidate relevant articles). Newspaper columns are revealing both in terms of the "newsworthy" 
items they identify (their manifest content) and the 1ssues or interests they represent (their latent content). Such written accounts, however, must be points of departure for investigation to be fortified, whenever possible, with other research, not prepackaged conclusions.

11. In separating $Q$-and P-Perspectives, It is Useful to Distinquish Persons from the Roles They Play or the offices They Hold, Because they both consider the actions of people, the 0 - and $P$-perspectlves are easlly blurred together. The essential difference is not, however, their subject matter but the way they approach it for their point of view). The 0 -perspective is concerned with the actions of groups of individuals or the codifications of those actions (i.e. operating procedures). The P-perspective, by contrast, focuses upon individual uniqueness or ldiosyncracy -- background, style, ir personal worldview. when looking at the actions of an individual, the question then becomes one of determining the extent to which those actions were the routine response of an offlce holder or behaviors only someone with a particular background could perform. When one delves into the explanatory factors accounting for the Individual's actions, one is in the arena of the P-perspective. 


\section{The Aporoach one Adopts to $P$-Perspect /ve Research} Depends Upon The Purpose of The Mult lole Perspective study, The Multiple Perspective Concept is a tool which may be applied to a varlety of complex decision areas having very different foci of interest. Technology assessments are prospective, looking towards possible impacts of proposed technological developments. By contrast, other studies, such as this one, are more retrospective in nature, attempting to explain (or account for) the chief determinants of complex processes or declsions which have already occurred. The P-perspective focuses upon unique actions or outlooks and depending upon the research application may be employed very differently. In retrospective studies, the researcher must try to determine which individuals did, in fact, influence an outcome "and attempt to illustrate how their unique outlooks served as determinants. In prospective studies, the question is on what sort of impacts might be expected from an action or technology, and a broader spectrum of viewpoints are sought from the types of individuals that might be affected. This more fully taps the explanatory power of the P-perspective but makes closure more difficult to achleve.

\section{Cross-cuing should seek to Map the paradiamatis}

Elements of One Perspective into Those of Another, Because the three perspectives are used in Multiple Perspectives studies to look at the same subject matter from different 
vantage points, it may become difficult to separate cross-cues from single perspective views. Earlier in this chapter, a basis for distinguishing cross-cues from conclusions flowing from one of the perspectives in isolation was descrlbed: cross-cues must explicitly show how the concerns, or paradigmatic elements, of one perspective influences or give shape to the elements of another. Thus, to expand upon the example given earlier, if one discusses the technical product of a group as an organizational output (i.e. describing only the organizational concerns, operating procedures, and chain of command underlying its production, without a description of its contents) one is working from the 0 -perspective. Conversely, if one focuses upon the contents, but not the organizational infrastructure behind its development, one is working from the $T$-perspective. If, however, one describes how specific organizational procedures and priorities affect speciflc technical cholces, one is cross-cuing.

\section{A Useful Tool for organizing and Describing Cross-Cues} in Retrospective studies is a simple Timeline. To be fully useful, cross-cuing should proceed by means of some methodology. Otherwise it is extremely difficult to even begin to feel that one has drawn out the significant conclusions in a study. At least for retrospective studies, a simple timeline (or perhaps three parallel timelines) constitutes a useful organizing principle, not unlike a checklist. The 
investigator may display the most significant elements of all three perspectives at once and conslder causal or interactive relationships between them. This, like the use of digraphs, often reveals connections previously unseen or not considered.

\section{Sross-cuing is an Extremely Useful Technigue to Get} Beyond Simplistic one-Dimensional Pictures (or Arquments). Each of the three perspectives filters and transforms the world through a different set of lenses and interpretive structures. Like one dimensional pictures of threedimensional objects, such interpretive filters "flatten out" certain determinative factors or fill explanatory gaps to produce a coherent gestalt of sorts. While the Multiple Perspective Concept neither guarantees truth nor produces an exhaustive description of reality, it does reveal features of the world which would otherwise be obscured. Crosscuing can signlficantly unblas the findings of a single perspective. For instance, looking at the BPA forecast exclusively from the 0 -perspective tends to build the picture of a "turf battle", with speclal organizational interests being the "true" determinants of forecast outcomes. When one couples $\mathrm{T}$ - and P-research to this tentative conclusion one discovers a more complex process of "negotiation through substantive technical products", where the validity and substantive quality of forecast methods and conclusions exert a determinative (though not fully 
determinative) influence upon decisions and technical

comments align sometimes weakly or strongly with organizational interests. This depth of Insight provides the basis for constructive planning where simple adversarial confrontation might otherwise prevall.

As this study has shown, the use of Multiple Perspectives opens up dimensions of insight into complex decision areas which would otherwlse remain opaque. In particular, the exercise of cross-cuing can significantly deepen the volume of useful knowledge about the object of research. Like many useful tools, the Multiple Perspective Concept will evolve or develop only as it is applied to many different situations, where its potentials can be expanded and its currently weak or limited aspects limitations improved upon. The subject of this dissertation, BPA's first independent forecast, provided a case study in which a varlety of organizations, with almost as varled interests, interacted largely through technical products to arrive at a significant planning decision. As such, it provided an excellent case study for the application of Multiple Perspectives. The exercise uncovered a wide array of factors influencing the forecast outcome which more traditional approaches would have overlooked. Additionally, it suggested a methodology or rationale for cross-cuing which could be more generally applied to Multiple Perspective studies. 
A number of issues surrounding the use of the MP Concept still remain to be explored. Most immediately recognizable are the need to develop firmer distinctions between 0 - and $P$-perspectives in investigative contexts, the need to formalize methodologies for exploring the P-perspective, and the need to realize the promise held by digraphs as a technique of validation. These will undoubtedly be developed in future studies, strengthening further our abilities to bridge analysis and action.

\section{CONCLUDING THOUGHTS}

From the discussion in this chapter, it can be seen that Multiple Perspectives provides a useful and potent tool for understanding the many facets of complex decision-making processes. The usefulness of the MP Concept, however, extends beyond the sphere of essentially academic concerns and into the realm of the more pragmatic day-to-day conslderations of organizations. This study provides a number of insights about power forecasting which are of significance to both Bonnevilie and the electric utility Industry in general, and it is approprlate to conclude this dissertation by summarily relterating the findings most important to BPA.

On the most superficlal level of its application, Multiple Perspectives serves a descriptive function. By defining the fundamental characteristics of the three 
paradigms of inguiry, the MP Concept directs attention toward the technlcal, organlzational, and personal dimensions of decision areas in a more thorough and systematic fashion. The detailed descriptions of forecasting models (and the linkages between them), organizational interests, and effects of different Administrators' policies presented in Chapters II, III, and IV of this dissertation consolidate most of the information about the development of BPA's 1982 forecast. Having such a centralized source of information, in and of itself, is valuable to organizations like BPA in that it lessens the likelihood of decislons belng made based upon fragmented or limited perceptions of ongoing organizational processes.

More significantly, Multiple Perspectives can be used to provide deeper and more penetrating insights into the dynamics underlying decision processes, and, further, suggest directions for improving or strengthening these processes. The cross-cuing and digraph analysis exercises carried out in Chapter $v$ revealed the major forces which shaped the forecast and, at the same time, uncovered limitations or "blind spots" in the process. Like many utilities developing long-range plans in the early 1980s, BPA sought to avold the technical mistakes which had led to overforecasting in the 1970s. Its forecasting system contained detailed end-use models which had been developed specifically for conservation policy testing purposes. Its 
forecasting methodology reflected an increased recognition of load uncertainty and substituted a range of forecasts for the single point forecasts which had earlier been used for regional power planning. Its public involvement process allowed a peer review by other members of the utility industry and various interest groups. This process helped the agency define and better meet its planning objectives, and the interactions between key participants in this process, and the effects of their interactions, are illuminated using a digraph analysis of Multiple Perspectives.

As organization's objectives, however, are not necessarily identical to its needs, and it is here that Multiple Perspectives provides its most valuable insights. The environment whlch the utility industry finds ltself in is potentialiy very volatile. Load growth is ultimately sensitive to a number of diverse factors -- political, technological, economic, and social -- which power producers need to account for in their planning. Range forecasts look at a wider spectrum of possibilities than point forecasts, but st11l represent a form of "best guess", one which examines quantitatively, but not qualitatively, different states of key varlables. While ranges may be useful to develop a core strategy for resource development, unless they are supplemented by a hedging strategy whlch ldentifles and explores the consequences of high impact/low probability events, they leave their users vulnerable to potentlally 
devastating surprises. In an uncertain environment, disaster avoldance should take precedence over optimization.

The findings of this Multiple Perspectives case study of BPA's first forecast suggest a number of changes in the forecasting and resource planning strategy commoniy used in the electric utility industry.

- Given the potential for volatility of the factors influencing load growth, resource plans should maximize near-term flexiblilty and responsiveness. This entails employing a core strategy which emphasizes the use of modular resources which can be developed (or rescheduled) quickly and preparing a supplemental hedging strategy in which responses to high impact events (irrespective of their assumed Iikelihood) are consldered in advance of their occurrence. The objective is to plan for many options, not to predict which surprises will occur.

- In order to generate the diverse scenarlos needed to prepare an adequate hedging strategy, models (or techniques) should be used which are simpler, faster, and less dataintensive than the large end-use tools widely employed in the utility industry. These large models should be used only when the highly disaggregated products of their operation are truly needed.

- In scenario development, full use should be made of the diverse 0 - and P-perspectives which can be tapped, both in-house and through a differently structured public in- 
volvement process. Internally, Multiple Perspectives may be used to improve the mix and balance of training possessed by the staff and to determine what types of skills will be needed in the future. In terms of public involvement, the MP Concept may be used to encourage a thoughtful exchange of diverse ideas and to avoid reducing technical dialog to the confrontation of political interests. Lawyers, business leaders, politicians, retired military leaders, and reporters all have insights into gualitative factors which could have sizeable impacts on load growth. These insights should be brought to bear at the front end of the forecast development process to ensure the exploration of an array of core assumptions (e.g. war in the Persian gulf, solar photovoltaic breakthroughs, nuclear plant meltdowns, an economic Depression, etc.) broad enough for disaster avoidance. - Lastly, throughout the planning process, there should be a continuous movement back and forth between broad and narrow considerations to ensure not only that the process is provlding correct answers but also posing the correct questions. Once a preliminary research or planning strategy is arrived at, it is all too easy to expend more and more effort perfecting or elaborating already complicated models or procedures instead of determining whether the correct Issues have been identified and addressed correctly. The utility community is now generally unfamlilar with the Multiple Perspective Concept (the exception being the 
Electric Dower Research Institute's study prepared by Ilnstone, 1986). Adopting and using it will necessitate a change in perceptions and horizons. Though this is not always a comfortable process, the rewards it offers in dealing with major uncertainties far outwelgh the small costs.

POSTSCRIPT 1987

Nearly five years have passed since BPA completed its 1982 forecast, and it is instructive to review what has happened in the years following that ploneer effort. In retrospect, Peter Johnson's decision to delay completion of the two of the WPPSS plants appears to have been correct. Power sales in the region since 1982 have proven even lower than BPA's forecast predicted and had Johnson succumbed to pressure to continue construction on WNP 1 and 3 , financing the projects would have proven untenable (bond ratings for the WPPSS plants declined even with full attention focused upon a single project).

Within BPA, ad hoc procedures became routinized as the basic protocol for forecast development was repeated on an annual basis. As noted in the conclusions of this dissertation, the unresolved problems identified during the forecast review process effectively defined the research agenda for the organizational units involved in forecast reduction. By 1983, BPA had developed a midterm forecasting 
model tallored to ratemaking and a flve-year time horlzon. The model was simple in structure, developed as a regression on employment and temperature variables, and well suited to representing the affects of cyclical business activity. By 1984, the long-term forecast modeling system had been substantially overnauled, though its basic methodological underpinnlings remained unchanged. A Regional Economic Model (REM) was developed for BPA under contract by wharton Associates. The REM displayed two strengths over the economic and demographic methods it replaced. First, it modeled interactive relationships between various elements of the regional economy formerly not considered (though, significantly, it still remained unlinked with the price and demand components of the modeling system). Second, because the model was housed on BPA's computer system, and its computer code rewritten from FORTRAN to SAS by BPA staff, the model was much less of a black box than the DRI model had been. Though not fully transparent (i.e. it still required some national economic projections as inputs), its operations could be understood and evaluated. New end-use models were also developed under contract for the residential and commerclal sectors. Simllar in structure to those used in 1982, the new models were developed from regional, rather than national, data, provided fuller descriptions of energy-using technologies (though still sidestepping 
breakthrough and innovation), and possessed augmented conservation pollcy testing capabilities.

At the same time, the uses to which the long-range forecasting system was put expanded and diversified. Scenarlos were run to test the consequences of different rate proposals, resource schedules, and DSI relocation decisions. The outputs of the sector-specific models were used to drive conservation supply curves. These curves, like generating resource supply curves, calculate how much conservation can be expected to be obtained at different levels of program expenditures.

More recently, however, an awareness of many of the limitations of the large models being used for forecasting has emerged. Although the disaggregated structure of the end-use models is needed for estimating conservation programs (e.g. in the internally diverse commercial sector, consumption patterns and conservation potentlal differs significantly from one building type to another), it creates a number of problems. Speciflcally, operating the large modeling system is expensive, its detall is difficult to support by data, and slow turnaround severely limits the number of scenarios, or sensitivity runs, which can be conducted. In an attempt to remedy this situation, several departments within BPA have acguired models or computerized procedures which substitute for the large forecasting tools. To assess the impacts of proposed programs, the office of 
Conservation acquired a systems dynamics model, CPAM (Conservation Program Assessment Model), which simulates the key features of the entire modeling system (i.e. demands, prices, and resources) more quickly. The Decision Analys is Model (DAM) was developed for resource planning. EssentialIy a Monte Carlo simulator, DAM begins with the growth rates of the high, medium, and low forecasts and runs a series of "games" in which load growth rates are randomly altered on a year-to-year basis. To an extent, this procedure addresses the previously unacknowledged problem of uneven patterns of change in load growth (i.e. trajectories are no longer smooth or linear), though it does not identify Eactors providing the impetus for change, nor have the erratic load growth paths it generates been reviewed or assessed by decision makers. Finally, a number of PC-based spreadsheet programs have been developed to perform speciflc types of sensitivity runs (e.g. effects of bullding standards or oil price changes).

The perception of long-range load futures characterized by low rates of growth, though controversial in 1982, has become firmly entrenched in the minds of power planners (perhaps too flrmly entrenched). Part of the reason for this entrenchment has been the forecasts produced by the Regional Council. Using a modeling system only marginally different from BPA's, slightly different assumptions, and four, rather than three, scenarlos, the Council produced a 
range of forecasted loads which, not surprisingly, closely approxlmated BPA's. Th1s agreement between agencles, at best a quality control check on a particular forecasting methodology, has been interpreted by many as a convincing validation of a particular view of the future, and much planning proceeds under this interpretation.

Thus, while a number of improvements have taken place In the state-of-the-art of reglonal power forecasting since 1982, some fundamental weaknesses still remain. Though the ranges used for resource planning are wide, their plausibility has never been tested using scenarlos representing a wide array of distinct environmental conditions. Resource planning has frequently proceeed using the forecast's subjective probabilities to compute expected values or measures of distribution suited to "hard" numbers. Efforts to improve the process of assigning probabilities have, to date focused upon developing quantitative methods for aggregating and combining the subjectively derived values rather than examining the assumptions underlying them. Perhaps most importantly, aslde from a conceptual exercise performed by an Uncertainty Work Group (of which this author was a member), no serious consideration has been given to disaster-avoldance planning. Many of the core assumptions underlying BPA's annual long-term forecast have evaded explicit recognition, as have the consequences of alternative assumptions on load profections. Still needed are a 
spectrum of diverse scenarios incorporating gualitative Inslghts, while challenging key assumptlons, on the forecasting side. To date, BPA has done sensitivity analyses on select issue areas (e.g. DSI incentive rates, plant delays, etc.) but has not made an organized or systematic effort to look at high pact events.

Among planners and decision makers in the power planning community, the perception of low demand growth now prevalls. Decreasing electricity sales in the early 1980s, Low BPA and Reglonal Council forecasts, and selected studies on the effects of rate hikes and DSI outmigration have been percelved as convincing arguments that most risk to be faced is downside risk (i.e. loads will, if anything, fall lower than forecasted, making it more difficult to sell available power and reduce the regional surplus). Risk on the upside (higher loads than expected) is generally thought to be adequately covered by as-yet-unfinished thermal resources (e.g. WNP 1 and 3), planned during a time of apparent impending shortages. As a result, BPA, faced with difficulties in making its U.S. Treasury repayments, has deemphasized further long-range forecasting and resource planning efforts. Instead, it has renewed its focus on marketing almed to decrease the current surplus and embraced the newer concept of demand side management which seeks to reduce future load uncertainties by securing firm power contracts with its customers. This reorientation towards 
near-term considerations is reflected in a reorganization which BPA is undertaking at the time of this writing which, almost ironically, recombines the forecasting, conservation, and resource functions which were separated and expanded prior to the 1982 forecast.

Although this strategy may work for BPA, in the long run it contains a weakness which could prove dangerous. Like someone who foregoes insurance coverage, BPA could either find itself fortunate and operating without mishap or suddenly find itself confronting large changes in demand for which it is unprepared. When BPA, and the Council, moved away from point forecasts and towards range forecasts, they took reglonal power planning a step in the right direction and explored areas of uncertalnty previously lgnored. Unless additional steps are taken (perhaps in a slightly different direction), however, power planners will miss the opportunity to ensure the region's preparedness for potentially disastrous occurrences and develop flexible responses to the important challenges which likely await the utility industry. 
BI BLIOGRAPHY

Ackoff, Russell L., 1978. The Art of Problem Solving Accompanied by Ackoff's Fables, Wiley Interscience.

Allison, G., 1971. Essence of Decision: Explaining the Cuban Missile Crisis, Little Brown and Co., Boston, MA.

Andersen, D.F., 1977. Mathematical Models and Decision Making in Bureaucracies: A case storv Told from Three Points of View, MIT: Ph.D. Dissertation.

Ascher, w., 1978. Forecasting: An Appraisal for Policy= Makers and Planners, John Hopkins University Press, Princeton, NJ.

Ascher, W., and W. Overholt, 1983. Strategic Planning and Forecasting: Political Risk and Economic Opportunity, Wiley Interscience, New York.

Berlinsk1, D., 1976. On systems Analys is: An Essay Concerning the Iimitations of some Mathematical Models in the Social, Political and Blological sciences, MIT Press, Cambridge, MA.

Bonneville Power Administration (BPA), 1981a. Technical Review of the Oak Ridge National Laboratory Engineering Economic Model of Residential Energy Use, Report No. DOE/BP-85. Division of Power Requirements, Energy Modeling and Analysis Branch, Portland, OR.

BPA, 1981b. Technical Review of the Pacific Northwest utilities conference committee sconometric Model, Report No. DOE/BP-84. Division of Power Requirements Branch of Energy Modeling and Analysis, Portland, OR.

BPA, 1981c. Technical Review of the Oak Ridge National Laboratory Commerclal Energy Use Model, Report No. DOE/BP-83. Division of Power Requirements Energy Modeling and Analys is Branch, Portland, OR. 
E2A, 1981d. Update and Re-estimation of the Northwest Energy Polley Profect Energy Demand Forecasting Model, Applied Economics Associates Inc., Report to Bonnevilie Power Administration, Report No. DOE/BP-81. Division of Power Requirements, Branch of Energy Modeling and Analysis, Portland, OR.

BPA, 1982a. Bonneville Power Administration Forecasts of Electricity Consumption, 1980-2000, Report No. DOE/BP-127. Division of Power Requiremenis, Portland, OR.

BPA, 1982b. Bonneville Power Administration Forecast of Electricity Consumption: Appendix I: Economicl Demographic Projections, Inputs to BPA Energy Forecasting Models, Report No. DOE/BP-114. Division of Requirements, Economic studies section, Portland, OR.

BPA, 1982c. Bonneville Power Administration Forecasts of Electrlcity consumption: Appendix II: Technical Documentation of Final BPA Energy Forecasting Models, Division of Power Reguirements, Energy Modeling and Analysis Branch, Portland, OR.

BPA, 1982d. Analysis of Regional Resource Alternatives, Division of Power Resources, Portland, OR.

Deal, T.E. and Kennedy, A.A., 1982. Corporate Cultures: The Rites and Rituals of corporate life, Addison Wesley, USA.

Emery, F.E. and Trist, E.I., 1975. Towards a Soclal Ecology: Contextual Appreciations of the Future in the Present, Plenum Publishing Corp., New York.

Enzer, S., Sept., 1984. "Anticipating the Unpredictable," Technological Forecasting and Social Change, Vol. 26, No. 2 .

Ernst and Ernst, July, 1976. Incentives for Electric utilities to Overforecast, Report to the Bonneville Power Administration, U.S. Department of Interior.

Godet, M., June, 1983. "Reducing the Blunders in Forecasting," Futures, Vol. 15, No. 3, 181-192.

Gordon, Geoffrey, 1978. System Simulation, Prentice-Hall, Inc., Englewood Cliffs, NJ. 
Greenwala, J., August 27, 1984. "The Forecasters Flunk: Poor Predictions Give Once Prestigious Pundits a Dismal Reputation," Time, 42-44.

Hoos, I.R., 1972. Systems Analysis in Public Policy A Critique, University of California Press, Berkeley, CA.

Keen, H., January, 1987. "Economists and Their Forecasts: Have the Projections Been That Bad?" Business

Economics, Vol. 22, No. 1, 37-40.

Labys, Walter C., July, 1982. "Measuring the Validity and Performance of Energy Models," Energy Economics, 159-168.

Instone, Harold A., 1981. The Multiple Perspective Concept with Applications to Technology Assessment and other Decision Areas, Futures Research Institute, Portland state University, Portland, OR.

Linstone, Harold A., 1984. Multiple Perspectives for Decilion Making: Bridging the Gap Between Analysis and Action, Elsevier Science Publishing Co., Inc., New York.

Ilnstone, Harold A., 1986. Multiple Rerspectives: Bridaing the Gap Between Analys is and Action, Report No. EA-4669, Electric Power Research Institute, Palo Alto, $\mathrm{CA}$

McLennan, Janet, October 7, 1981. Memorandum "Summary of Management Perspectives on BPA's Role, Image, and Aspirations."

Martino, Joseph P., 1978. Technological Forecasting for Declsionmaking, Amerlcan Elsevier Publishing Co., New York.

Marshal1, George E., September, 1978. Electrical Energy in the Pacific Northwest, U.S. Army Corps of Engineers, seattle, WA.

M1dttun, A. and T. Baumgartner, June, 1986. "Negotlating Energy Futures: The Politics of Energy Forecasting," Energy Poldcy, Vol. 17, No. 3, 219-241. 
Norwood, G., 1931. Solumbla River Power for the people: A History of Polleles of the Bonneville Power Administration, U.S. Government Printing office, DOE BP-7.

Peck, M.J. and Scherer, F.M., 1962. The Weapons Acquisition Process, Harvard Univ. Press, Cambridge, MA

Richert-Boe, P., July 13-19, 1982. "Peter Johnson: The BPA's New Power Player," Willamette Week, Portland, OR.

Springer, V., 1976. Power and the Pacific Northwest: A History of the Bonneville Power Administration, U.S. Government Printing office.

U.S. Department of Energy, January 11-12, 1982. Official Report of the Proceedings of Public Review Workshop, BPA Energy Model Assessments, Bill's Recording Service, Portland, OR.

U.S. Department of Energy, December 9, 1981. Official Report of the Proceedings of Bonneville Power Administration's Public Review Workshop of Economic and Demographic Variables, Bill's Recording Service (Court Reporters), Portland, OR.

Wack, P., 1985. "Scenarios: Shooting the Rapids." Harvard Business Review, Vol. 63 , No. $\underline{6}, 139-150$.

Wack, P., 1985. "Scenar1os: Uncharted Waters Ahead." Harvard Business Review, Vol. 63, No. $\underline{5}$, 73-89.

Wildaysky, Aaron and Ellen Tenenbaum. 1981. The Politics of Mistrust: Estimating American 0 il and Gas Resources, Sage Publications, Beverly Hills, CA. 